\title{
AVALIAÇÃO DAS DOENÇAS CHIADORAS RECORRENTES DA INFÂNCIA COMO FATOR DE RISCO PARA PNEUMONIA
}

Tese de Doutorado

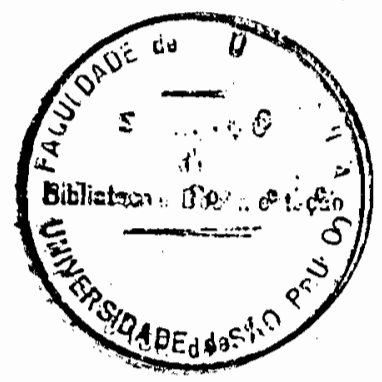

Candidato: Júlio Cesar Rodrigues Pereira

Orientador: Prof. Dr. Gilberto Ribeiro Arantes 


\section{AGRADECIMENTOS}

Mais do que expressar gratidão, devo registrar que este estudo só foi possivel graças a algumas pessoas que se entusiasmaram com a idéia e solidariamente aderiram ao trabalho:

- Maria Mercedes Loureiro Escuder, minha esposa mas também colega dedicada e competente que supervisionou as atividades de campo e de organização de bases de dados e ainda colaborou com sugestões e críticas cada passo deste trabalho desde sua concepção até sua redação final;

- João Paulo B. Lotufo, pneumologista pediatra, e na sua pessoa todo o Departamento de Pediatria do Hospital Universitário da USP que acolheu o projeto de pesquisa e ofereceu-lhe campo para a coleta de dados. Mais um débito, entre outros precedentes, de minha vida acadêmica a esta amizade;

- Adriana Miele e Sandra Elisabeth Vieira, pediatras do HU-USP que, por designação do Departamento de Pediatria, se encarregaram da exaustiva tarefa de coleta de dados, selecionando pacientes, examinando-os e entrevistando seus responsáveis e, arduamente, enfrentando o desafio de identificar controles sob o rigor metodológico do estudo.

Embora sem ter tido envolvimento direto, José Enio Duarte Sevilha precisa ter seu nome aqui registrado. Tendo me oferecido oportunidade profissional que solicitava dedicação intensiva à produção acadêmica, favoreceu expressivamente meu crescimento intelectual, com resultados entre os quais não posso deixar de inscrever o presente trabalho.

Da mesma forma, o Prof. Paulo Saldiva da FMUSP, que me ofereceu um apoio decisivo durante a fase de concepçāo deste estudo, deve ser especialmente agradecido. Especialmente porque se trata de uma figura impar no cenário acadêmico, aliando ao brilho de sua inteligência e sabedoria qualidades de modéstia e generosidade incomuns.

Ao contrário de sua expressa recomendação, registro aqui meus agradecimentos ao Prof. Gilberto R. Arantes, meu orientador. As qualidades que caracterizam sua pessoa e sua vida profissional são valores que cultivo como 0 símbolo de uma ética que exclui a adulação e onde ser assertivo é um compromisso de transparência e honestidade. Assim, à revelia de sua vontade, expresso meu reconhecimento nesta página dedicada a minha manifestação pessoal. Com esta postura devo estar a emulá-lo. 


\section{DEDICATÓRIA}

"Ma come si fa a guardare qualcosa lasciando da parte l'io?"

O signor Palomar, de Italo Calvino, exercitando a abstração de si mesmo para observar o mundo.

Porque não quero ignorar meu eu, em primeiro lugar dedico meu trabalho àqueles com quem divido minha intimidade e sem cuja interação minha vida resultaria desprovida do ânimo e da paixão que a alimentam. Victor, meu filho, prolongamento do meu próprio ser que me proporciona essa alegria misteriosa da paternidade. Mercedes, minha esposa, do irmão espanhol dita Viva, acabou Biba por transcrição de pronúncia mas conservou do original a condição de portadora de vida. Vida que assopra em mim a cada dia no amor que cultivamos.

"Pai nosso, filho de Crono, ... a mim pungeme o coração a sorte do judicioso Odisseu, o desditoso, que ... há tanto tempo vem penando"

Atenas a Zeus, na Odisséia, de Homero, Canto I.

Dedico ainda este trabalho a Wilson e seu pai. Durante anos, sempre acompanhado do pai de facies constrita pela dor engolida de assistir impotente 0 sofrimento do filho, Wilson me visitou regularmente em madrugadas angustiadas de Pronto Socorro. Nossos encontros logo se tornaram silenciosos porque também depressa se esgotaram as perguntas e respostas sobre aquela asma. Privado de tratamento regular, Wilson havia chegado à pré-puberdade quando o vi pela última vez e então a doença já tinha deformado seu tórax e o rosto de seu pai. Reverencio aqui todos os "Wilsons" e seus pais cuja odisséia espera um Homero para contar e uma Atenas para proteger. 


\section{RESUMO}

Comentando-se algumas evidências da literatura e da análise de dados secundários de morbidade e mortalidade, estabelece-se a hipótese de que as doenças chiadoras recorrentes da infância possam constituir-se em fator de risco para o desenvolvimento de infeç̧ões pulmonares.

Um estudo caso-controle é desenvolvido para testar esta hipótese reunindo 51 casos de pneumonia pareados por sexo e idade a 51 controles sadios e 51 controles doentes não respiratórios. A amostra é colhida entre pacientes do Hospital Universitário da USP sendo condição de entrada para os casos um diagnóstico de pneumonia adquirida na comunidade e livre de tratamento anterior. Os controles são selecionados dentro da mesma clientela entre pacientes com outro diagnóstico e crianças sadias usuárias dos mesmos serviços, identificadas entre acompanhantes de pacientes. Casos e controles são submetidos a idêntica investigação quanto a presença de doença (pneumonia) e de exposição ao fator de risco investigado (doença chiadora recorrente) através de anamnese e exame físico padronizados, realizados independentemente por dois observadores distintos. Ambos os observadores são pediatras designados pelo Departamento de Pediatria do Hospital para esta tarefa e recebem orientação e supervisão para uma observação padronizada. Os dados assim recolhidos são processados em análises estatisticas uni e multivariadas para explorar diferenças entre casos e controles.

A amostra estudada resulta constituida por crianças de idade média de 2 anos (com variação entre um mês e sete anos), entre as quais $47 \%$ são meninos. $O$ diagnóstico de pneumonia é validado através da aplicação de análise discriminante multivariada das informações relativas a sinais clínicos, encontrando-se uma compatibilidade entre a conclusão clínica e estes sinais da ordem de pelo menos $75 \%$. O diagnóstico de exposição a doença chiadora é validado pela presença de história compativel segundo premissas pré-estabelecidas nos métodos do estudo (diagnóstico de asma e pelo menos um episódio de dispnéia nos últimos 12 meses ou históna de chiado recorrente que melhora com medicação e pelo menos dois episódios nos últimos 12 meses) em 40 dos 41 expostos identificados. O questionário de identificação da exposição tem a repitibilidade medida através de sua reaplicação pelo mesmo observador a uma amostra de $20 \%$ do total de crianças examinadas. Encontrase um nivel geral de concordância entre a primeira e segunda aplicação do questionário de $76,7 \%$ e um indice Kappa de 0,65. 
A associação entre pneumonia e doença chiadora recorrente é analisada através de regressão logistica com controle para todas as variáveis que em análise univariada mostram frequência estatisticamente significante entre casos e controles. Encontra-se que o risco de pneumonia entre crianças expostas a doença chiadora é 7 vezes maior do que entre crianças não expostas, controladas a renda familiar e a situação de aglomeração no quarto de dormir, também identificadas como fatores de risco para pneumonia ("odds ratio" de 5,6 e 2,4 para rendas baixa e média comparadas com renda alta e "odds ratio" de 1,5 para cada pessoa a mais no quarto de dormir). Calcula-se que para a comunidade hospitalar estudada a doença chiadora recorrente represente um risco atribuivel para pneumonia entre $33 \%$ e $51 \%$, conforme a aplicação de diferentes técnicas de cálculo.

Conclui-se que as doenças chiadoras recorrentes da infância constituem-se em importante fator de risco para pneumonia e que seu controle, através da inclusão de assistência sistemática a pacientes com este diagnóstico nos programas de Saúde Pública para o controle de doenças respiratórias da infância, pode ter importante impacto sobre a incidência de pneumonias. 


\section{ABSTRACT}

Taking into account some evidences from the literature and from analysis of available data, a hyphothesis that childhood wheezing diseases are related to pneunomia is established.

A case-control study is designed to test this hypothesis taking 51 cases of pneumonia matched by sex and age to 51 healthy and 51 non-respiratory controls. The sample is drawn from patients of the "Hospital Universitário da USP". Entry condition for cases is to bear a community acquired pneumonia free of previous treatment and for controls is to be custommer of the same health services. Cases and controls are equally investigated with regards to the presence of pneumonia and history of wheezing diseases, investigation being conducted by two independent observers. Both are paediatricians selected by the Hospital Paediatric Department and are dully trained and supervised as to assure a standardized observation. Data are processed in oneway and multivariate statistical analyses to explore diferences between cases and controls.

The sample studied comprises children aged 2 years in average (range between one month and seven years) and male subjects account for $47 \%$ of the total. The diagnosis of pneumonia is validated through multivariate discriminant analysis which shows that clinical opinion is compatible to clinical signs in at least $75 \%$ of the cases. The clinical conclusion of presence of wheezing disease is found compatible to previously defined criteria in 40 out of 41 patients. Repeatability of such information is assessed by re-aplication of the questionnaire for wheezing disease investigation to a sample of $20 \%$ of the total number of children, which is carried out by the same observer of the first interview. An overall agreement of $76.7 \%$ and a Kappa of 0.65 is found.

Association between pneumonia and wheezing disease is analysed through logistic regression controlling the effects of all variables which have shown statistically significant differences between cases and controls. It is found that children who bear a wheezing disease have a risk to pneumonia which is 7 times greater than those who do not, allowing for socioeconomic status and bedroom crowding, both also risk fators: odds ratio of 5.6 and 2.4 for low and medium family income as opposed to high income and odds ratio of 1.5 for each increase of one person in bedroom. Derived from different techniques, an attributable risk for wheezing disease ranging from $33 \%$ to $51 \%$ is calculated. 
It is concluded that wheezing diseases of childhood are an important risk factor to pneumonia and that its control, by means of regular medical assistance of patients being included among the items of current public health programmes, should result in an important effect over the frequency of pneumonia. 


\section{ÍNDICE}

página

\section{I - INTRODUÇÃO} $-1$

I.1 - AS DOENÇAS RESPIRATÓRIAS NA INFÂNCIA E SUAS ESTRATÉGIAS DE CONTROLE____ 2

1.2 - EPIDEMIOLOGIA DAS DOENÇAS RESPIRATÓRIAS NA INFĀNCIA

I.3 - OBJETIVOS DO PRESENTE ESTUDO ___ 35

II - MATERIAL E MÉTODOS - 36

11.1 - AMOSTRA ESTUDADA — 37

II.2 - DESCRIÇÃO DAS VARIÁVEIS ESTUDADAS E MÉTODOS DE ANÁLISE — 41

III. RESULTADOS - 46

III.1 - CARACTERIZAÇĀO DA AMOSTRA ESTUDADA - 47

III.2 - CARACTERIZAÇĀO SOCIAL E ECONÓMICA DE CASOS E CONTROLES 50

III.3 - CARACTERIZAÇĀO DE VARIÁVEIS DE INFORMAÇÃO COMPLEMENTAR_-_ 57

III.3.1 - Situação atual de saúde - 57

III.3.2 - Antecedentes pessoais-_ 60

III.3.3 - Antecedentes familiares 65

III.3.4 - Fatores ambientais- 67

III.4 - INVESTIGAÇÃO DO DIAGNÓSTICO DE PNEUMONIA:
Caracterização da presença de doença-- 68

III.5 - INVESTIIGAÇÃO DO DIAGNÓSTICO DE DOENÇA CHIADORA RECORRENTE:
Caracterização da presença do fator de exposiçăo _-_ 76

III.6 - INVESTIGAÇĀO DA RELAÇĀO ENTRE DOENÇA CHIADORA RECORRENTE E
PNEUMONIA-- 86

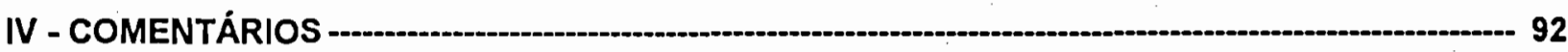

IV.1 - SOBRE A EPIDEMIOLOGIA_______ 93

IV.2 - SOBRE A ASMA E AS DOENÇAS CHIADORAS DA INFÂNCIA 100

IV.3 - SOBRE O PRESENTE ESTUDO 109

IV.3.1 - Dos métodos e da identificação de casos e controles- 109

IV.3.2 - Dos resultados___ 122

IV.3.3 - Das conclusões e inferências _-____- 126

V - CONCLUSÕES -..-1..- 132

VI - COMENTÁRIOS FINAIS - 135

BIBLIOGRAFIA - 139

ANEXO I - Protocolos de coleta de dados e roteiros de padronização do preenchimento

ANEXO II - Relação de pacientes que compuseram a amostra estudada 


\section{ÍNDICE DAS TABELAS}

TABELA 1- COEFICIENTES DE MORTALIDADE GERAL, POR ASMA E POR PNEUMONIA PARA MENORES DE 10 ANOS NO EST. DE SÃO PAULO E RESPECTIVOS VALORES EM DISTÂNCIAS PADRONIZADAS DA MÉDIA (ZSCORE) - 1980 A 1993

TABELAII- COEFICIENTES DE MORTALIDADE PROPORCIONAL POR MIL ÓBITOS PARA PNEUMONIA E ASMA EM MENORES DE 12 ANOS NO EST. DE SÄO PAULO - 1980 A 1993

TABELA III - CRUZAMENTO DE CAUSAS DE ÓBITOS: PRESENCA E AUSÉNCIA DE PNEUMONIA E ASMA ENTRE MÚLTIPLAS CAUSAS - 1985 A 1993

TABELAIV - AFERIÇÃO DO PAREAMENTO ENTRE CASOS E CONTROLES: IDADE MÉDIA E ERRO PADRÃO SEGUNDO O SEXO E A CLASSIFICAÇÃO

TABELA V - DISTRIBUIÇÃO DE GÊNERO E RAÇA SEGUNDO A CLASSIFICAÇĀO DO PACIENTE 48

TABELA VI - DIAGNÓSTICOS REALIZADOS PARA OS CONTROLES NÃO RESPIRATÓRIOS 49

TABELA VII - CONDIÇÓES DE MORADIA SEGUNDO A CLASSIFICAÇÃO DO PACIENTE 50

TABELA VIII - COMPOSIÇÃO DA FAMILIA SEGUNDO A CLASSIFICAÇÃO DO PACIENTE 52

TABELA IX - OPÇÕES POR SERVIÇOS DE SAÚDE SEGUNDO A CLASSIFICAÇĀO DO PACIENTE 54

TABELAX - UTILIZAÇÃo DE SERVIÇOS DE SAÚdE SEGUNDO A CLASSIFICAÇÃo dO PACIENTE 56

TABELAXI - DOENÇAS INDEPENDENTES DE QUEIXA ATUAL IDENTIFICADAS EM CASOS E CONTROLES

TABELA XII - CLASSIFICAÇÃO NUTRICIONAL DE CASOS E CONTROLES 59

TABELA XIII - ANTECEDENTES CLINICOS SEGUNDO A CLASSIFICAÇÃO DO PACIENTE60

TABELA XIV - HISTÓRIA FAMILIAR DE DOENÇAS RELACIONADAS AO FATOR DE EXPOSIÇÃO SEGUNDO A CLASSIFICAÇÃO DO PACIENTE

TABELAXV - CARACTERISTICAS DO MEIO AMBIENTE SEGUNDO A CLASSIFICAÇÃO DO PACIENTE 
TABELAXVI - HISTÓRIA CLINICA DOS PACIENTES SEGUNDO SUA CLASSIFICAÇÃO: HISTÓRIA PREGRESSA DA QUEIXA ATUAL

TABELA XVII - HISTÓRIA CLINICA DOS PACIENTES SEGUNDO SUA CLASSIFICAÇÃO: EXAME FISICO

TABELA XVIII - CARACTERIZAÇÃO DO DIAGNÓSTICO DE PNEUMONIA: EXAME RADIOLÓGICO, HIPÓTESE ETIOLÓGICA E CONDUTA ADOTADA

TABELAXIX - CARACTERIZAÇÃO DO DIAGNÓSTICO DE EXPOSIÇÃO 76

TABELA XX - AVALIAÇÃO DE REPITIBILIDADE DAS INFORMAÇŐES RELATIVAS À EXPOSIÇÃO AO FATOR DE RISCO INVESTIGADO 83

TABELA XXI - CRUZAMENTO SIMPLES DE VARIÁVEIS:PRESENÇA E AUSÊNCIA DE PNEUMONIA E DOENÇA CHIADORA $-86$ 


\section{ÍNDICE DOS GRÁFICOS}

GRAFICO 1- ÓBITOS EM MENORES DE 10 ANOS COM PRESENÇA DE DOENÇA página RESPIRATÓRIA NO ESTADO DE SÃO PAULO, SEGUNDO A FAIXA ETÁRIA - 1980 A 1993 8

GRAFICO II -

DEMANDA AMBULATORIAL POR IDADE DEVIDA A DOENÇA RESPIRATÓRIA EM CRIANÇAS - ESTADO DE SÃO PAULO: 1992 9

GRÁFICO III - DEMANDA HOSPITALAR POR IDADE DEVIDA A DOENÇA RESPIRATÓRIA EM CRIANÇAS - CIDADE DE SÃO PAULO: OUTUBRO/1992 A OUTUBRO/1993 9

GRÁFICO IV - SAZONALIDADE DAS DOENÇAS RESPIRATÓRIAS EM CRIANÇAS: DEMANDA AMBULATORIAL - ESTADO DE SÃO PAULO, 1989/90 10

GRAFICO V - SAZONALIDADE DAS DOENÇAS RESPIRATÓRIAS EM CRIANÇAS: DEMANDA AMBULATORIAL - ESTADO DE SÃO PAULO, 1992

GRAFICO VI - SAZONALIDADE DAS DOENÇAS RESPIRATÓRIAS EM CRIANÇAS: DEMANDA AMBULATORIAL POR DIAGNÓSTICO - ESTADO DE SÃO PAULO, 1993/94 12

GRÁFICO VII- SAZONALIDADE DAS DOENÇAS RESPIRATÓRIAS EM CRIANÇAS: DEMANDA HOSPITALAR POR DIAGNÓSTICO - CIDADE DE SÃO PAULO, 1992/93 13

GRAFICO VIII - CURVAS DE MORTALIDADE GERAL, POR ASMA E POR PNEUMONIA EM MENORES DE 10 ANOS NO ESTADO DE SÃO PAULO - 1980 A 1993 16

GRAFICO IX - MORTALIDADE PROPORCIONAL POR PNEUMONIA EM MENORES DE 12 ANOS NO EST. DE SÃO PAULO - 1980 A 1993

GRAFICO X -

MORTALIDADE PROPORCIONAL POR ASMA EM MENORES DE 12 ANOS NO EST. DE SÃO PAULO - 1980 A 1993 19

GRAFICOXI- REGRESSÃO LINEAR ENTRE AS FREQUENNCIAS ANUAIS DE ASMA E PNEUMONIA COMO CAUSA DE ÓBITO EM MENORES NO EST. DE SÃO PAULO 1980 A 1993

GRAFICO XII - CURVAS DE DISTRIBUIÇÃO DAS MEDIDAS DE SITUAÇÃO NUTRICIONAL EM CASOS E CONTROLES 58

GRAFICO XIII - COMPARAÇÃO DA SITUAÇÃO NUTRICIONAL DE CASOS E CONTROLES, MEDIDA EM DESVIOS PADRONIZADOS DA MEDIANA DE POPULAÇÃO PADRÃO (NCHS) 59

GRÁFICO XIV - C CURVAS DE DISTRIBUIÇÃO DE FREQUÉNCIA DAS MÉDIAS DE RESPOSTAS À INVESTIGAÇÃO DE EXPOSIÇÃO NAS PRIMEIRA E SEGUNDA ENTREVISTAS 85 


\section{ÍNDICE DOS QUADROS}

QUADRO 1 -

"OUTPUT" DO PACOTE ESTATISTICO SPSS-PC PARA REGRESSÃO LOGISTICA

página DE DOENÇA RESPIRATÓRIA COM VÁRIOS POLUENTES ATMOSFÉRICOS INTERNAÇÃO HOSPITALAR DE MENORES DE 12 ANOS NA CIDADE DE SÃO PAULO, 1992/1993

QUADRO II - RESULTADO DA ANÁLISE DISCRIMINANTE MULTIVARIADA PARA AFERIÇÃO DA CAPACIDADE DOS SINAIS CLINICOS EM DISTINGUIR CASOS E CONTROLES 75

QUADRO III - RESULTADOS DE REGRESSÃO LOGISTICA: MODELO COM TODAS AS VARIÁVEIS E SEQÜENNCIA DE PASSOS DE EXCLUSÅO DE VARIÁVEIS AQUÉM DA TOLERÁNCIA ESTATISTICA

QUADRO IV - $\quad$ RESULTADOS DE REGRESSÅO LOGISTICA: MODELO FINAL COM AVALIAÇÂO DE CONSISTENCIA 
I - INTRODUÇÃO 


\section{I.1 - AS DOENÇAS RESPIRATÓRIAS NA INFÂNCIA E SUAS ESTRATÉGIAS DE CONTROLE}

As doenças respiratórias ganharam reconhecimento formal como problema de saúde pủblica à partir da aprovação pela $29^{a}$ Assembléia Mundial de Saúde (1976) de uma recomendação para inclusão de uma secção tratando de infecções respiratórias agudas (IRA) no Sexto Programa Geral de Trabalho da Organização Mundial da Saúde (OMS), iniciado em janeiro de 1978. Neste ano, Bulla e Hitze ${ }^{1}$ publicaram um artigo de revisão que se tornou clássico mostrando uma situação alarmante principalmente no que interessava os paises menos desenvolvidos: enquanto a taxa de mortalidade por IRA em países desenvolvidos era da ordem de 60/100mil habitantes, nos paises pobres chegava a superar 1000/100mil habitantes para faixa etária de menores de um ano. Nestes paises as IRA correspondiam a $40-60 \%$ dos óbitos de menores de 5 anos e a pneumonia era a principal causa de óbito por IRA, correspondendo a $75,5 \%$ do total.

Em 1979, a Assembléia Mundial da Saúde aprovou a Resolução WHA32.33 com recomendações específicas para o estabelecimento de programas nacionais de controle e definição de métodos efetivos de prevenção e tratamento das IRA. Em junho de 1981, o $20^{\circ}$ Encontro do Comitê Consultivo da Organização Panamericana da Saúde (OPS) para Pesquisa Médica encomendou estudos sobre a matéria a um subcomitè organizado para tal fim. Como resultado, em 1983, é editado na forma de livro ${ }^{2}$ o documento RD/21/3 da OPS, intitulado Acute respiratory infections in children.

$\mathrm{Na}$ introdução deste documento pode-se identificar a expectativa de que o controle das doenças respiratórias da infância viesse a seguir o mesmo caminho do controle das diarréias, registrando: "The analogy of diarrheal diseases and oral rehydratation is apt. It is now accepted that most acute diarrhea is secretory in origin. ... The basic physiologic mechanism which have been discovered have direct research in antidiarrheal agents towards agents which stimulate the normal absorptive processes

1. Bulla A, Hitze KL. Acute respiratory infections: a review. Bull World Health Org 1978; 56(3): 481-98.

2. Unit of Research Promotion and Coordination, Division of Human Resources and Research. Acute respiratory infections in children. Washington: Pan American Health Organization, 1983. 
and counterbalance or inhibit secretion. The oral glucose-electrolyte solutions ... now constitute the mainstay of effective intervention therapy in diarrheal diseases". Desde então, a despeito de inegáveis esforços de investigação no campo, nada se identificou de mecanismo fisiopatológico comum que nas doenças respiratórias pudesse ser o denominador comum que se transformasse em sustentáculo de um programa de intervenção para redução da morbi-mortalidade por IRA.

Este mesmo documento, numa ampla revisão de literatura, demonstra que as doenças respiratórias são uma causa de morbidade comum na infância e que crianças de qualquer país tendem a apresentar de 6 a 10 episódios de doença por ano e que, à parte as infecções do trato respiratório alto, são a bronquite (sic) e a pneumonia os diagnósticos mais frequentes. Em relação à pneumonia são apresentados dados que sugerem uma frequência mais elevada em países e regiōes mais pobres, levando a uma conclusão de que, embora as crianças em geral estejam igualmente expostas às doenças respiratórias, em situação socioeconômica adversa estas doenças tendem a incluir casos mais graves e mais letais.

Propos-se um programa de controle para as IRA ${ }^{3}$ que seria baseado em 3 ações: imunização, educação sanitária e tratamento de casos. Esta última, por ser mais especifica para as IRA em contraste com as duas primeiras de escopo mais amplo, ganha maior atenção e se baseia principalmente na garantia de acesso a antibioticoterapia a pacientes selecionados através de técnicas simplificadas de identificação de gravidade. Experiências anteriores já haviam mostrado a possibilidade de sucesso de uma abordagem como esta ${ }^{4}$, mas há que ser critico quanto a seu mérito intrinseco já que a ação comunitária envolvida em sua implantação por si só traz impactos ao nivel de saúde da população. Newell ${ }^{5}$, em 1975, numa extensa análise de diferentes experiências em todo o mundo, concluiu que a organização de serviços de saúde, qualquer que fosse sua natureza ou motivação técnica, politica ou ideológica, poderia ter impacto sobre a saúde de uma população. Na mesma obra, Behrhorst ${ }^{6}$ relata uma experiência comunitária em Chimaltenango, Guatemala, que para implementar a assistência à saúde de uma comunidade de indios cakchiqueles (sic) acabou envolvendo iniciativas no campo da educação e agricultura cujos reflexos na

3. Douglas RM, Kumar $V$, Miller DL et al.. A programme for controlling acute respiratory infections in children: Memorandum from a WHO Meeting. Bull World Health Org 1984; 62(1): 47-58.

4. Smith D. Patterns of ARI morbldity/mortality and health services utilization in the Azaro Vailey, Papua New Guinea, 198081. Proc 18th Ann Symp Med Soc Papua New Guinea, Port Morsby, 1982.

5. Newell KW. La salud por el pueblo. Ginebra: Organizacion Mundial de la Salud, 1975: 211-23.

6. Behrhorst C. El proyecto de desarrollo de Chimaltenango (Guatemala). In: Newell KW. Op. cit. (referência 5): 33-57. 
vida local explicariam melhor do que qualquer programa de saúde específico o eventual progresso do estado sanitário daquela população.

Em agosto de 1985, a OMS promoveu uma oficina de trabalho internacional na Universidade de Adelaide, em Sidney, Austrália, para discutir o problema das IRA e as estratégias para seu controle. Três técnicos da Unidade de Tuberculose e Infecções Respiratórias apresentaram um trabalho ${ }^{7}$ onde identificaram como principais fatores de risco para infecção respiratória o baixo peso ao nascer, a desnutrição e a poluição do ar a nivel doméstico (indoor air pollution). Como tais fatores excedem o âmbito e a especificidade das IRA, os autores dão ênfase ao perfil etiológico das IRA graves,

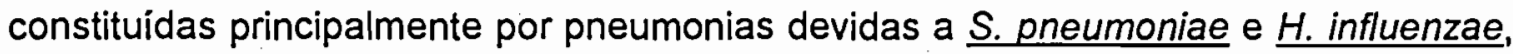
para sugerir uma estratégia de controle centrada principalmente no tratamento de casos clínicos.

A importância que neste contexto assume a antibioticoterapia gera controvérsias principalmente porque especialistas da área lembram que a maioria das IRA é de etiologia viral. Antonio Pio, Chefe da Unidade de Tuberculose e Infecções Respiratórias da OMS, em artigo publicado em $1986^{8}$, procura esclarecer a racionalidade do programa proposto enfatizando que é a infecção bacteriana a principal responsável pela alta mortalidade por IRA que se registra principalmente nos paises em desenvolvimento. Revendo a literatura mostra que nestes paises até $63 \%$ de aspirados de punção pulmonar identificam bactérias e que as pneumonias virais devem ter uma participação da ordem de $23 \%$, sem que se possa excluir a superinfecção. Além de lembrar que a imunização (coqueluche, sarampo, difteria e tuberculose) e a educação sanitária (conhecimentos para a identificação da gravidade de uma IRA, atenção à vacinação da criança, proteção da criança contra poluição por frio/ tabaco/gases/ fumaças, importância do pré-natal e do aleitamento materno) são também pontos importantes do programa de controle das IRA, recomenda que 0 tratamento de casos de IRA contemple uma estrutura de serviços com niveis de referência, um treinamento adequado dos trabalhadores da saúde na padronização de atividades e ainda um sistema de vigilância para monitorar qualidade e efetividade do trabalho.

7. Pio AJ, Leowski J, Ten Dam HG. The magnitude of the problem of acute respiratory infections. Proceedings of an International Workshop on Acute Respiratory Infections in Children. Sydney: University of Adelaide, 1985: 3-16.

8. Pio A. Acute respiratory infections in children in developing countries: an international point of view. Ped Infec Dis 1986, 5(2): 179-83. 
Ainda em 1986, Jerzy Leowski ${ }^{9}$, também da Unidade de Tuberculose e Infecções Respiratórias da OMS, publica um artigo revendo dados secundários de diferentes paises que atualizam e ratificam as informaçōes anteriormente produzidas por Bulla \& Hitze. Ele descreve que no mundo morrem anualmente 15 milhões de crianças menores de 5 anos, 4 milhões das quais por doenças respiratórias. Entre estes óbitos $65 \%$ são crianças menores de um ano e $60 \%$ ocorrem em países menos desenvolvidos, com taxa de mortalidade infantil maior do que 100/mil nascidos vivos. Entre os diagnósticos de óbito por IRA de menores de um ano destacam-se: pneumonias com $37 \%$, infecçōes do trato respiratório superior com 3,5\%, bronquite aguda e bronquiolite com $3,2 \%$. Na faixa etária de 1 a 5 anos, pneumonia comparece com $34 \%$, sarampo com $6,2 \%$, infecções do trato respiratório superior $5,2 \%$, bronquite aguda e bronquiolite com 2,8\%. Faz também comparações entre países mostrando que no Peru a mortalidade é cerca de 37 a 43 vezes maior do que no Canadá e que nas Filipinas chega a ser até 73 vezes maior do que na Austrália. Identifica como fatores de risco o produto nacional bruto do pais (coeficiente de correlação de ",89), 0 local de moradia onde zonas rurais apresentam incidencia $40 \%$ mais elevada, e educação materna onde analfabetismo implica em risco 2 ou 4 vezes maior do que uma educação elementar ou de nivel secundário, respectivamente.

Embora já então, nos diagnósticos de bronquite aguda e bronquiolite, se identificasse doenças chiadoras no perfil das doenças respiratórias da infância, foi apenas na versão de $1990^{10}$ que o tratamento de broncoespasmo foi incluido no programa oficial de controle das IRA. Mesmo assim, o programa limita-se a incluir normas para tratamento da crise broncoespástica não fazendo referència ao acompanhamento de doenças chiadoras. Como sugere o próprio nome do programa, a intervenção se restringe aos episódios agudos de infecção, oferecendo-se um tratamento limitado a estes episódios. Mesmo o nivel de referência do programa não é visto como instância de elucidação diagnóstica e tratamento de doenças de base, mas somente como um nivel de maior recurso tecnológico para uma intervenção mais intensiva nos casos mais graves. As doenças chiadoras, a asma brônquica, não sãc consideradas problemas para enfoque prioritário.

O Estado de São Paulo, através de sua Secretaria de Saúde, registrou a única iniciativa de saúde pública diversa das normas emanadas da Organização Mundial de

\footnotetext{
9 . Leowskl J. Mortality from ARI in children under 5 years of age: global estimates. Rapp Trimest Statist Sanit Mon 1986; 39 138-44.

10. World Health Organization. Programme for the control of acute respiratory infections. Programme Report WHO/ARI/90.7 Geneva: WHO, 1990.
} 
Saúde. Em 1988, três técnicos desta Secretaria ${ }^{11}$, registrando que a cada 2 mil crianças atendidas pelos serviços primários de saúde entre 800 e 1000 apresentavam doença respiratória e que destas pelo menos 40 requeriam tratamento hospitalar, descreveram um modelo hierarquizado de serviços com três niveis de assistência: primário, caracterizado como um consultório médico simples; secundário, constituido por ambulatório para acompanhamentos de curto prazo e unidade de internação para observação de pacientes também por curto prazo; terciário composto por um ambulatório de especialidade e uma enfermaria para tratamento hospitalar. A cada nivel de assistência estabelecia-se uma dotação tecnológica especifica tanto em termos de recursos humanos quanto de apoio diagnóstico e terapeutico.

Este programa de São Paulo foi avaliado em trabalho ${ }^{12}$ publicado em 1992 que reviu 18.255 casos atendidos pelo programa. Demostrou uma alta efetividade, expressa como capacidade de redução no número de internações por pneumonia e medida em 52,41\% (intervalo de confiança de $95 \%$ entre $44,57 \%$ e 59,57\%). Registrou também alto índice de eficiência, avaliada como a razão entre casos tratados com sucesso e total de casos atendidos: 99,46\%. No entanto, constatou-se uma eficácia, definida como proporção de facilidades do programa de fato implantadas, muito aquém do desejável: $86 \%$ para o nivel terciário, $57 \%$ para o nivel secundário, $100 \%$ para o nivel primário, $30 \%$ para organização do sistema de referência e $0 \%$ para implantação de comissōes coordenadoras locais, prescritas pelo programa. Atribuiu-se esta baixa eficácia à falta de determinação para implantação do programa por parte dos tomadores de decisão dentro do sistema de saúde, registrando-se que apenas $44 \%$ das regiōes de saúde haviam implantado o programa e que entre estas o compromisso havia se restringido principalmente a garantir acesso às facilidades existentes, consultórios médicos e hospitais.

Este trabalho identificou ainda que as doenças chiadoras, asma incluida mas excluidas as bronquites virais agudas, só eram precedidas em frequência na demanda por serviços pelas infecções respiratórias altas e, mais ainda, que estabeleciam estreita relação com a pneumonia, terceira causa de demanda, pois pacientes com diagnóstico de doença chiadora apresentavam pneumonia como doença associada com uma frequência 4,98 (intervalo de confiança de 95\% entre 3,49 e 7,10) vezes maior do que pacientes atendidos por outras causas.

11. Pereira JCR, Miranda Ribeiro TV, Pripas S. Newsletter from Brazil. J Trop Ped 1988; 34: 199-200.

12. Pereira JCR, Stuginski LA, Miranda Ribeiro TV. Assessment of a strategy for the control of respiratory diseases in children. Rev Saúde públ, S.Paulo, 1992; 26(6): 414-23. 
A asma brônquica tem sido preterida de atenção entre os problemas respiratórios das crianças. Talvez este fato seja o corolário de uma antiga subestimação de sua gravidade por parte dos médicos, pois como registra Siegel ${ }^{13}$, em artigo sobre a história da asma, Laennec dizia que a asma conferia ao portador uma perspectiva de vida longa, Trousseau afirmava que "asthma n'est pas fatale" e William Osler sentenciava que "the asthmatic pants into old age".

\section{I.2 - EPIDEMIOLOGIA DAS DOENÇAS RESPIRATÓRIAS NA INFÂNCIA}

Um seminário internacional ${ }^{14}$ promovido pela OMS em dezembro de 1991 , em Washington, reuniu informações atualizadas sobre a epidemiologia da pneumonia. Nos paises pobres, ela é responsável por 27 a $43 \%$ dos óbitos de crianças, corresponde a $30-35 \%$ das internações hospitalares, é causada principalmente por $\underline{S}$. pneumoniae, $\underline{H}$. influenzae e $S$. aureus. $O$ baixo peso ao nascer, a desnutrição, a deficiência de vitamina $A$, o sarampo e a ausência de aleitamento materno são fatores de risco que duplicam as chances de pneumonia ou óbito por pneumonia. Aglomeração, como número elevado de pessoas por habitação, é também fator de risco sendo que crianças que vivem em casas com 3 ou mais menores de 5 anos apresentam um frequência de óbitos por pneumonia duas vezes maior do que crianças vivendo em melhores condições. Crianças filhas de pais ambos fumantes têm $50 \%$ mais episódios de internação hospitalar do que crianças filhas de um único genitor fumante. Crianças que dispendem mais de 4 horas por dia ao lado do fogão doméstico tem duas vezes mais pneumonia do que aquelas cuja mesma exposição é inferior a uma hora.

No Estado de São Paulo, revendo-se 432381 óbitos de menores de 10 anos ocorridos no periodo de 1980 a 1993, encontrou-se que as doenças respiratórias (CID 460 a 519, e CID 011 - Tuberculose, Nona Revisão) tiveram participação em 23,56\% dos casos, $81,11 \%$ das vezes com o diagnóstico de pneumonia. Estudando-se as 90258 internações de crianças registradas pelo Sistema Único de Saúde na capital do Estado durante o periodo de 15/10/92 a 15/10/93, encontrou-se que as doenças respiratórias corresponderam a $27,42 \%$ das admissões hospitalares. Tanto no perfil da mortalidade quanto da morbidade, os menores de 5 anos constituem-se na faixa etária

13. Siegel SC. History of asthma deaths from antiquity. J Allergy Clin Immunol 1987; 80(3Pt2): 458-62.

14. Anonimous. Childhood pneumonia: strategies to meet the challenge. London: AHRTAG, 1992. 
mais importante. Os gráficos I, II e III mostram a distribuição dos casos por idade entre óbitos, atendimentos ambulatoriais e internações hospitalares

GRÁFICO I- ÓBITOS EM MENORES DE 10 ANOS COM PRESENÇA DE DOENÇA RESPIRATÓRIA NO ESTADO DE SÃO PAULO, SEGUNDO A FAIXA ETÁRIA 1980 A 1993

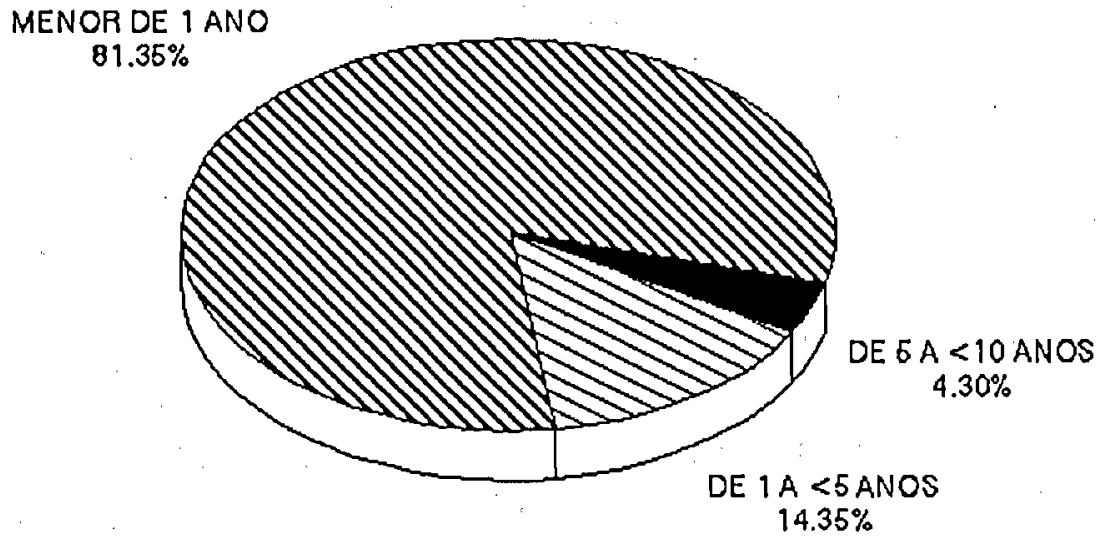

Fonte: SEADE

101.889 obltos resplratorios em $\mathbf{4 3 2 . 3 8 1}$

reglstros 
GRÁFICO II - DEMANDA AMBULATORIAL POR IDADE DEVIDA A DOENÇA RESPIRATORIA EM CRIANCCAS - ESTADO DE SÄO PAULO: 1992

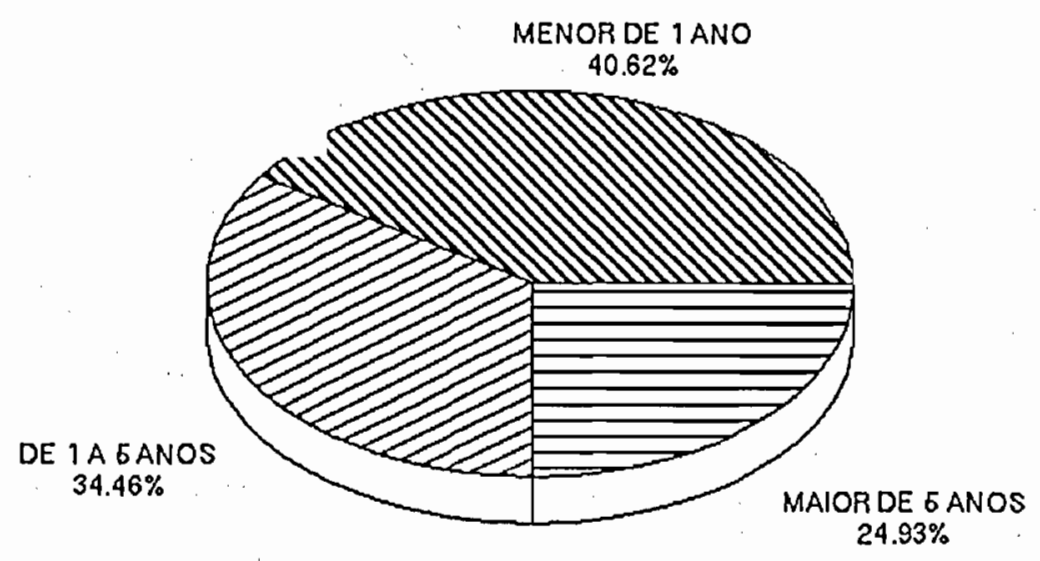

Fonte: ComDRI/Sec. Saude do Est. S.Paulo 76.128 casos registrados

GRÁFICO III - DEMANDA HOSPITALAR POR IDADE DEVIDA A DOENÇA RESPIRATÓRIA EM CRIANÇAS - CIDADE DE SÃO PAULO: OUTUBRO/1992 A OUTUBRO/1993

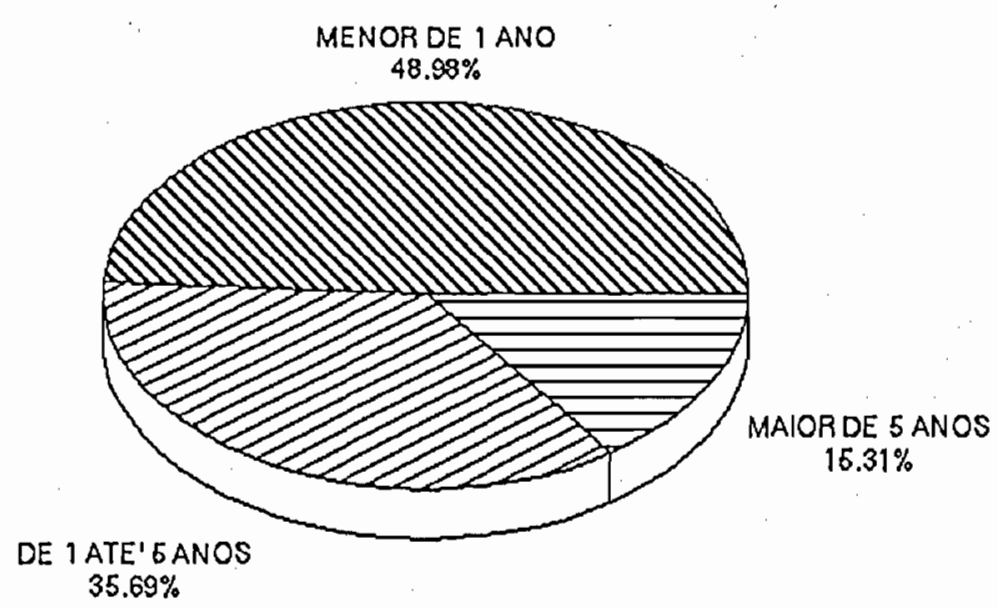

Fonte: Cis/Sec. de Saude Est. Sa O Paulo 24.763 casos om 90.256 Interna coos 
Informações referentes ao atendimento ambulatorial de doenças respiratórias em crianças disponiveis na Secretaria de Saúde do Estado para os anos de 1989/90 e 1992 sugerem uma sazonalidade na ocorrência destas doenças ao longo do ano. Os gráficos IV e $\mathrm{V}$ mostram o aumento de incidência no periodo de inverno. Em ambos, como nos que se sucederão, os registros são descatados por pontos e uma linha imaginária é apresentada como a curva alisada que melhor se ajustaria a estes registros. Tal curva é gerada automaticamente pelo pacote gráfico utilizado (Harvard Graphics) e tenta minimizar as distâncias entre os registros de forma a sugerir tendências.

GRÁFICO IV - SAZONALIDADE DAS DOENÇAS RESPIRATÓRIAS EM CRIANÇAS: DEMANDA AMBULATORIAL - ESTADO DE SÄO PAULO, 1989/90

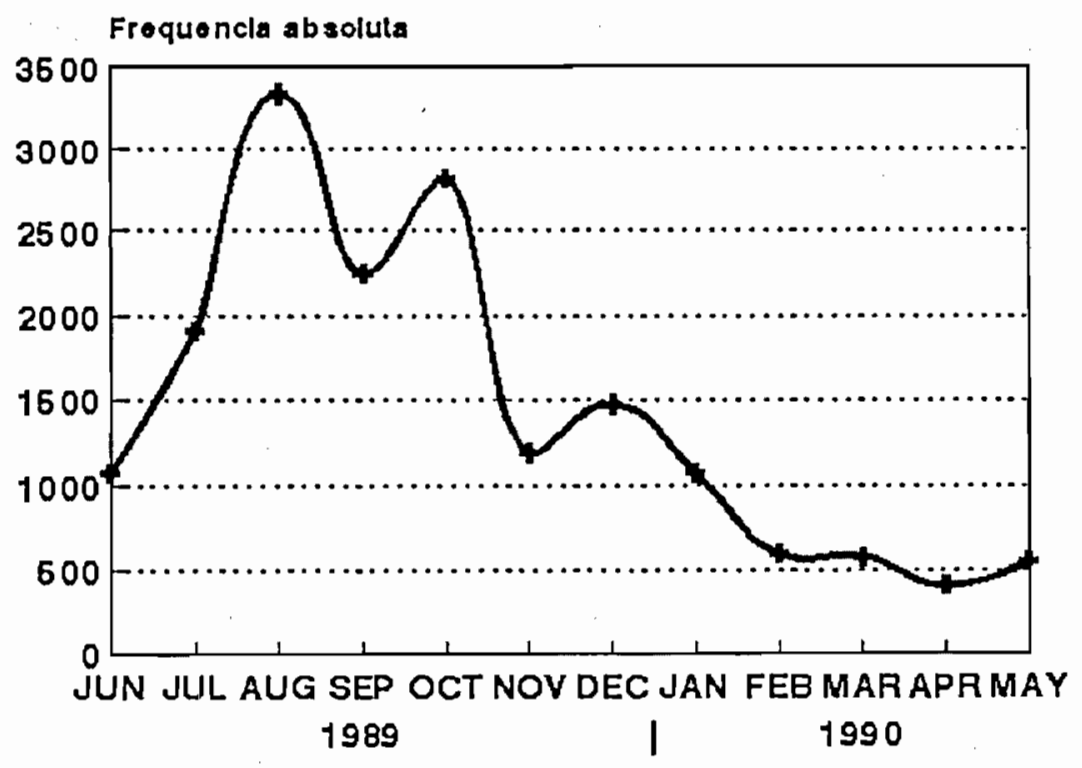

Fonto: Soc. Saudo Est. Sao Paulo-ComDRI 17.254 ob servacoes 
GRÁFICO V - SAZONALIDADE DAS DOENÇAS RESPIRATÓRIAS EM CRIANÇAS: DEMANDA AMBULATORIAL - ESTADO DE SÄO PAULO, 1992

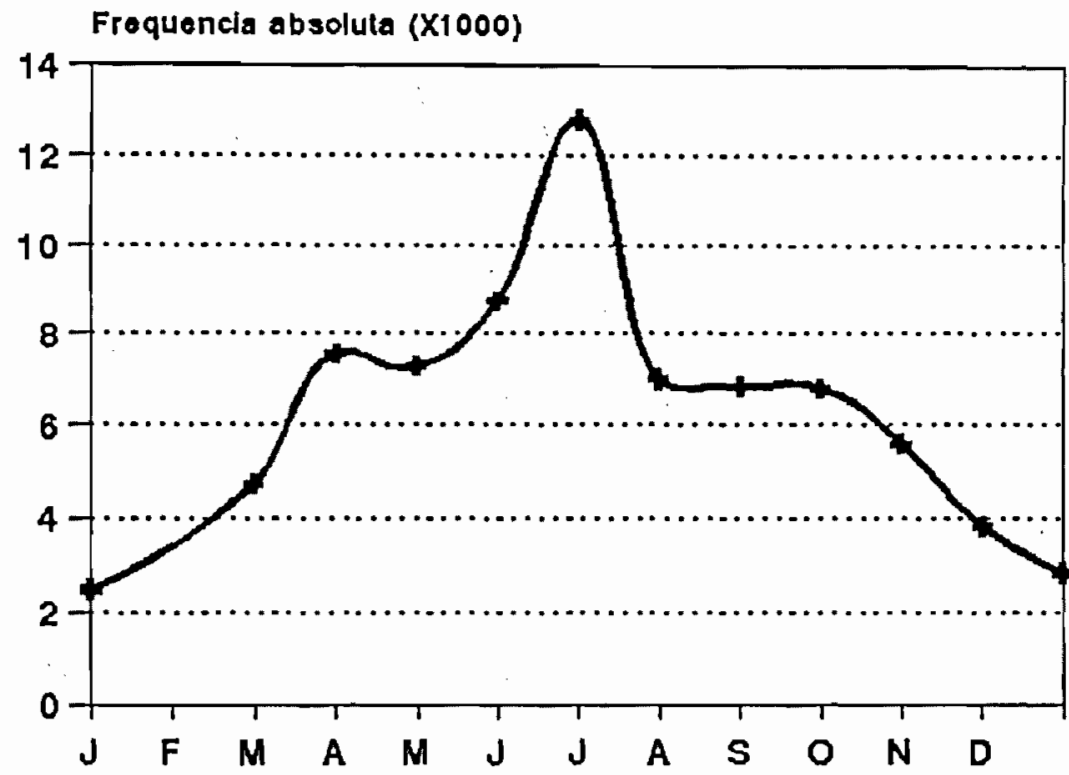

Fonte: Sec. Saude Est. Sa o Paulo-ComDRI 76.128 observacoes

Dados relativos ao atendimento ambulatorial no periodo 1993-94 (gráfico VI) permitem conhecer-se que 0 aumento de incidência no inverno, que é novamente registrado, deve-se principalmente ao aumento da frequência relativa de infecções agudas das vias aéreas superiores, embora também aumentem sua participação proporcional as bronquites/ bronquiolites e a pneumonia. 
GRÁFICO VI - SAZONALIDADE DAS DOENÇAS RESPIRATÓRIAS EM CRIANÇAS: DEMANDA AMBULATORIAL POR DIAGNÓSTICO - ESTADO DE SÃO PAULO, 1993/94

Froquoncla absoluta (X1000)

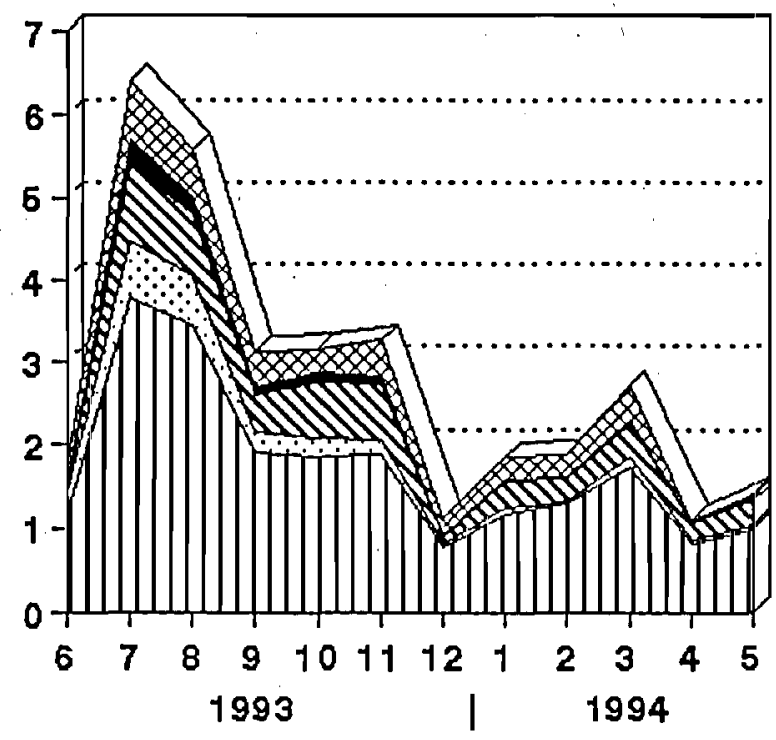

Fonte: Sec. Saude Est. Sao Paulo-ComDRI

A sazonalidade das doenças respiratórias da infância é também registrada nas internações hospitalares, como mostra 0 gráfico VII onde, apesar de um aumento de frequência ser registrado isoladamente em novembro/92, distinguem-se os meses de inverno com números mais elevados de registros. Contribuem para 0 acréscimo de internações no periodo de inverno principalmente a pneumonia e as bronquites/ bronquiolites, que aumentam sua participação proporcional. 
GRÁFICO VII - SAZONALIDADE DAS DOENÇAS RESPIRATÓRIAS EM CRIANÇAS: DEMANDA HOSPITALAR POR DIAGNÓSTICO - CIDADE DE SĀO PAULO, 1992/93

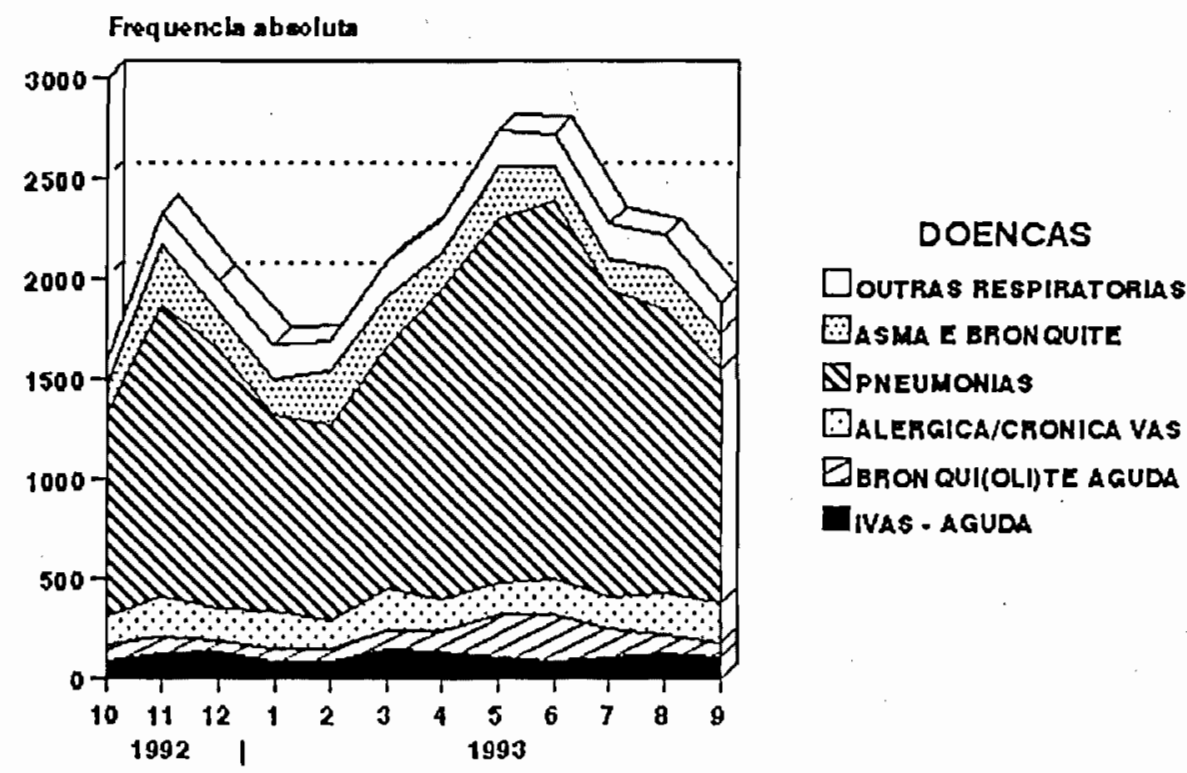

Fonte: Sec. Saude Eat. Sao Paulo, CIS 26.646 observacoos

Arias et al. ${ }^{15}$, numa publicação da Organização Panamericana da Saúde de 1992, reviram as tendências de mortalidade em diferentes paises do mundo. Demonstraram que, enquanto nos Estados Unidos e Canadá, principalmente à partir dos anos setenta, o coeficiente de mortalidade por pneumonia decresce com uma aceleração maior do que decresce o coeficiente de mortalidade geral, nos países menos desenvolvidos, embora se registre igualmente tendências de decréscimo, as curvas para mortalidade geral e por pneumonia têm inclinações semelhantes. Isto leva ao entendimento de que, enquanto nos paises desenvolvidos alguma ação promove uma redução especifica da mortalidade por pneumonia, nos paises mais pobres o decréscimo de óbitos por pneumonia apenas segue uma tendēncia geral de redução da mortalidade, que de resto é universal como característica do progressivo desenvolvimento das sociedades.

15. Arias SJ, Benguigul $Y$, Bossio JC. Infecciones respiratorias agudas en las Américas: magnitud, tendencia y avances en el control. Washington: OPS, Série PALTEX, 1992. 
Revendo-se os dados disponiveis para o Estado de São Paulo para asma (CID 490 "Bronquite não especificada como aguda ou crônica", 491 "Bronquite crônica", 493 "Asma", 496 "Obstrução crônica das vias respiratórias") e pneumonia ( CID 480 "Viral", 481 "Pneumococcica", 482 "Outras bactérias", 483 "Outro microorganismo especificado", 484 "Como complicação de outra patologia", 485 "Broncopneumonia", 486 "Microorganismo não especificado"), encontra-se um perfil de pais não desenvolvido com a tendência de decréscimo de mortalidade por pneumonia pouco diferindo da tendência de redução geral das taxas de mortalidade. O gráfico VIII dá representação às informaçōes da Tabela I abaixo, onde são apresentados os coeficientes de mortalidade geral, por asma e por pneumonia para menores de 10 anos. O número de óbitos por asma e pneumonia considera a presença destes diagnósticos quer como causa básica ou causa associada: a partir de 1985 os registros de óbitos reunem multiplas causas. Anota-se ai também a medida dos coeficientes transformados em diferenças padronizadas da média (zscores), artificio que permite trazer todos os coeficientes para uma mesma escala e possibilita sua representação gráfica num mesmo intervalo de valores. Os coeficientes geral, por pneumonia e por asma parecem ajustar-se a distribuiçōes normais tanto pelo teste de KolmogorovSmirnov $^{16}$ (valores de $p$ para ajuste a curva normal resultaram em $0,742,0,972 \mathrm{e}$ 0,940 , respectivamente) quanto pelo teste de projeção gráfica dos valores originais com os respectivos valores padronizados de sua posição hierárquica nas leituras realizadas $^{17}$, no qual resultam em projeçōes muito próximas de uma reta (valores de $r$ de Pearson de 0,966, 0,977 e 0,974, respectivamente).

16. Siegel S, Castellan Jr NJ. Nonparametric statisties for the behavioral sciences. New York: McGraw-Hill; 1988: $144-51$. 17 . Armitage P, Berry G. Slatistical methods in medical research. London: Blackwell Scientific Publications; $1987: 368,416-7$. 
TABELAI - COEFICIENTES DE MORTALIDADE GERAL, POR ASMA E POR PNEUMONIA PARA MENORES DE 10 ANOS NO EST. DE SÃO PAULO E RESPECTIVOS VALORES EM DISTÂNCIAS PADRONIZADAS DA MÉDIA (ZSCORE) - 1980 A 1993 - MÚLTIPLAS CAUSAS A PARTIR DE' 1985

\begin{tabular}{|c|c|c|c|c|c|c|c|}
\hline \multirow[t]{2}{*}{ ANO } & \multirow{2}{*}{$\begin{array}{r}\text { POPULA } \\
\text { ÇÃO }\end{array}$} & \multirow{2}{*}{$\begin{array}{c}\text { SBITOS } \\
\text { TOTAL }\end{array}$} & \multirow{2}{*}{$\begin{array}{r}\text { OBITOS } \\
\text { PNEUMO } \\
\text { NIA }\end{array}$} & \multirow{2}{*}{$\begin{array}{c}\text { DEITOS } \\
\text { ASMA }\end{array}$} & \multicolumn{3}{|c|}{ COEFICIENTES POR 100MIL HAB. } \\
\hline & & & & & GERAL & $\begin{array}{c}\text { PNEUMO } \\
\text { NIA }\end{array}$ & ASMA \\
\hline \multirow[t]{2}{*}{80} & 5889491 & 42465 & 7351 & 184 & 721,03 & 124,82 & 3,12 \\
\hline & ZSCORE - - > & & & & $(1,55)$ & $(1,21)$ & $(, 73)$ \\
\hline \multirow[t]{2}{*}{81} & 5937259 & 42274 & 7560 & 172 & 712,01 & 127,33 & 2,90 \\
\hline & ZSCORE ---> & & & & $(1,49)$ & $(1,32)$ & $(, 35)$ \\
\hline \multirow[t]{2}{*}{82} & 5983899 & 41899 & 7950 & 194 & 700,20 & 132,86 & 3,24 \\
\hline & ZSCORE ---> & & & & $(1,40)$ & $(1,55)$ & $(, 94)$ \\
\hline \multirow{2}{*}{$\begin{array}{r}83 \\
2\end{array}$} & 6079390 & 35165 & 5845 & 158 & 578,43 & 96,14 & 2,60 \\
\hline & $S C O R E--->$ & & & & $(, 54)$ & $(, 01)$ & $(-, 17)$ \\
\hline \multirow[t]{2}{*}{84} & 6031363 & 36140 & 5551 & 169 & 599,20 & 92,04 & 2,80 \\
\hline & ZSCORE - - > & & & & $(, 69)$ & $(-, 15)$ & $(, 17)$ \\
\hline \multirow[t]{2}{*}{85} & 6127897 & 29353 & 6637 & 191 & 479,01 & 108,31 & 3,12 \\
\hline & $2 S C O R E-->$ & & & & $(-, 16)$ & $(, 52)$ & $(, 73)$ \\
\hline \multirow[t]{2}{*}{86} & 6176876 & 29685 & 6877 & 176 & 480,58 & 111,33 & 2,85 \\
\hline & ZSCORE - - & & & & $(-, 15)$ & $(, 65)$ & $(, 26)$ \\
\hline \multirow[t]{2}{*}{87} & 6226356 & 27415 & 5630 & 146 & 440,31 & 90,42 & 2,34 \\
\hline & $Z S C O R E--->$ & $>$ & & & $(-, 43)$ & $(-, 22)$ & $(-, 62)$ \\
\hline \multirow[t]{2}{*}{88} & 6276341 & 28020 & 5849 & 218 & 446,44 & 93,19 & 3,47 \\
\hline & ZSCORE ---> & & & & $(-, 39)$ & $(-, 11)$ & $(1,35)$ \\
\hline \multirow[t]{2}{*}{89} & 6326796 & 25802 & 5150 & 157 & 407,82 & 81,40 & 2,48 \\
\hline & ZSCORE - - & & & & $(-, 67)$ & $(-, 60)$ & $(-, 38)$ \\
\hline \multirow[t]{2}{*}{90} & 6377831 & 31141 & 6313 & 215 & 488,27 & 98,98 & 3,37 \\
\hline & ZSCORE ---> & & & & $(-, 09)$ & $(, 13)$ & $(1,17)$ \\
\hline \multirow[t]{2}{*}{91} & 6428443 & 21204 & 3901 & 113 & 329,85 & 60,68 & 1,76 \\
\hline & ZSCORE ---> & & & & $(-1,22)$ & $(-1,47)$ & $(-1,64)$ \\
\hline \multirow[t]{2}{*}{92} & 6478362 & 20765 & 4082 & 125 & 320,53 & 63,01 & 1,93 \\
\hline & $Z S C O R E-->$ & & & & $(-1,29)$ & $(-1,37)$ & $(-1,34)$ \\
\hline \multirow[t]{2}{*}{93} & 6458041 & 21053 & 3956 & 116 & 326,00 & 61,26 & 1,80 \\
\hline & ZSCORE - - > & & & & $(-1,25)$ & $(-1,45)$ & $(-1,57)$ \\
\hline
\end{tabular}


GRÁFICO VIII - CURVAS DE MORTALIDADE GERAL, POR ASMA E POR PNEUMONIA EM MENORES DE 10 ANOS NO ESTADO DE SÄO PAULO - 1980 A 1993

DISTANCIAS PADR ONIZADAS DA MEDIA

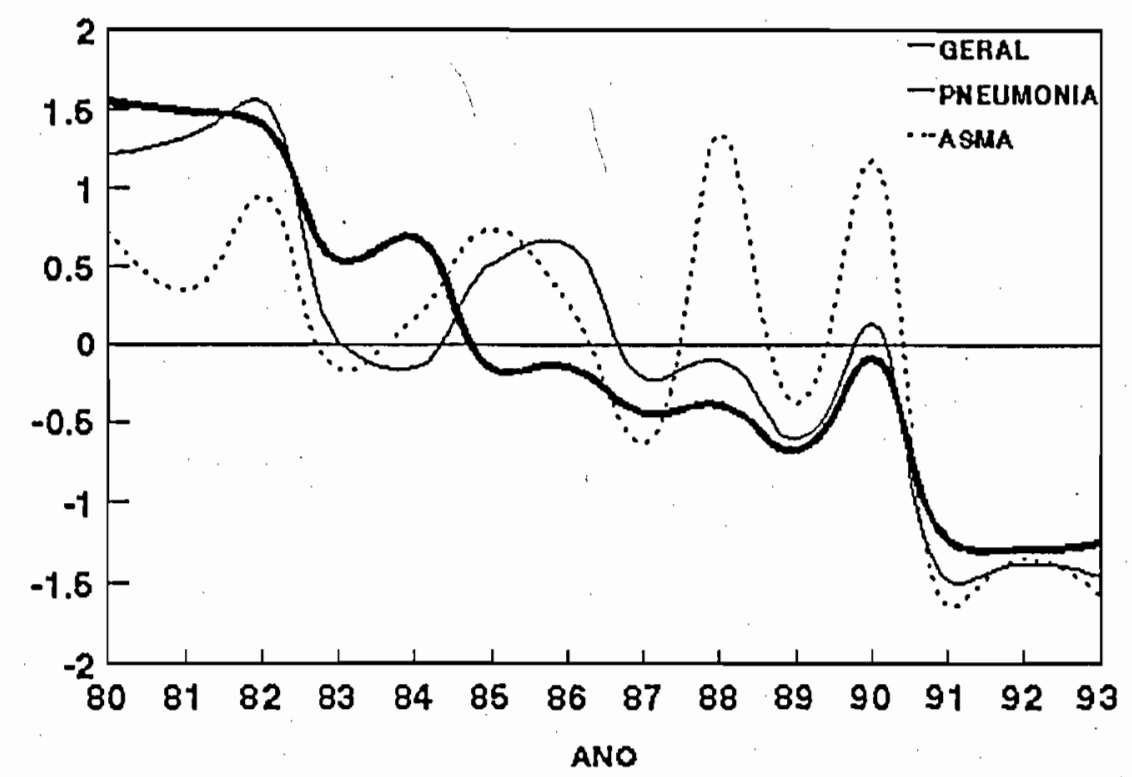

Fonte: SEADE

A mortalidade por causa específica analisada por coeficientes que tomam a população como denominadọr não é, no entanto, suficiente para exploração de tendências de doenças. De fato, uma revisão de tendência de mortalidade por asma na França publicada por Cooreman et al. ${ }^{18}$ em 1992, restringindo-se a esta abordagem acabou por menosprezar a mortalidade por asma na faixa etária de 5 a 35 anos para enfatizar exageradamente a faixa de 65 anos e mais. Charpin ${ }^{19}$, um autor clássico do campo, argüiu a análise mostrando que observados os coeficientes de mortalidade proporcional, onde o denominador é o total de óbitos registrados, os óbitos por asma em pessoas de 5 a 35 anos tinham tido um aumento de $84 \%$ no período de 1968 a 1984 , enquanto que entre os maiores de 65 anos a participação da asma tinha tido uma redução de $3,3 \%$. Para proceder a uma análise de participação proporcional de pneumonia e asma entre os óbitos registrados no Estado de São Paulo, conseguiu-se uma ampliação da base de dados original usada para os coeficientes de população,

18. Cooreman J, Segala C, Henry C, Neukirch F. Mortalité rapportée à l'asthme: tendances pour la France de 1970 à 1987. Rev Mal Resp 1992; 9:495-501.

19. Charpin D, Vervloet D. 2000 morts par asthme en France chaque année: qui sont-ils? Rev Mal Resp 1993; 10: $277-8$. 
estendo-se a informação dos registros de óbito até a idade de 12 anos, exclusive, faixa etária habitualmente reconhecida como área da Pediatria. A Tabela II mostra as informações obtidas, onde se observa que os coeficientes de mortalidade proporcional de pneumonia e asma em 1993 são, respectivamente, 8,5\% e 28,0\% maiores que os registrados em 1980. Novamente, os diagnósticos de asma e pneumonia foram considerados quer como causa básica ou associada.

TABELA II - COEFICIENTES DE MORTALIDADE PROPORCIONAL POR MIL OBITOS PARA PNEUMONIA E ASMA EM MENORES DE 12 ANOS NO EST. DE SÄO PAULO - 1980 A 1993 - MÚLTIPLAS CAUSA A PARTIR DE 1985

\begin{tabular}{lrrrrr}
\hline ANO & $\begin{array}{r}\text { TOTALDE } \\
\text { OBITOS }\end{array}$ & $\begin{array}{r}\text { OBITOS } \\
\text { PNEUMONIA }\end{array}$ & $\begin{array}{r}\text { MORT. PROP. } \\
\text { PNEUMONIA }\end{array}$ & $\begin{array}{r}\text { OBITOS } \\
\text { ASMA }\end{array}$ & $\begin{array}{r}\text { MORT. PROP. } \\
\text { ASMA }\end{array}$ \\
\hline 80 & 42944 & 7386 & 171,99 & 188 & 4,38 \\
81 & 42704 & 7581 & 177,52 & 173 & 4,05 \\
82 & 42348 & 7966 & 188,11 & 196 & 4,63 \\
83 & 35588 & 5581 & 156,82 & 171 & 4,80 \\
84 & 36579 & 5874 & 160,58 & 159 & 4,35 \\
85 & 29834 & 6696 & 224,44 & 194 & 6,50 \\
86 & 30170 & 6938 & 229,96 & 180 & 5,97 \\
87 & 27881 & 5690 & 204,08 & 150 & 5,38 \\
88 & 28505 & 5910 & 207,33 & 222 & 7,79 \\
89 & 26331 & 5216 & 198,09 & 165 & 6,27 \\
90 & 31732 & 6377 & 200,96 & 220 & 6,93 \\
91 & 21678 & 3955 & 182,44 & 118 & 5,44 \\
92 & 21231 & 4141 & 195,04 & 132 & 6,22 \\
93 & 21555 & 4022 & 186,59 & 121 & 5,61 \\
\hline
\end{tabular}

Fonte: SEADE

A análise da mortalidade proporcional por causa especifica não permite conclusōes definitivas sobre as tendências de óbito porque depende do comportamento das outras causas componentes da mortalidade geral. No entanto, numa abstração teórica que fixe para fins de análise a influência dos outros componentes pode-se explorar um suposto comportamento de causas especificas. $O$ gráfico IX mostra a curva de distribuição e a linha de regressão da mortalidade proporcional por pneumonia, entendida como óbito com participação de pneumonia como causa direta ou agravante. Há uma tendência aparente de crescimento anual da ordem de 1,65 casos de pneumonia por cada mil óbitos, mas este coeficiente de regressão da reta não alcança significância estatística $(p=, 2613)$. 
GRÁFICO IX - MORTALIDADE PROPORCIONAL POR PNEUMONIA EM MENORES DE 12 ANOS NO EST. DE SÄO PAULO - 1980 A 1993

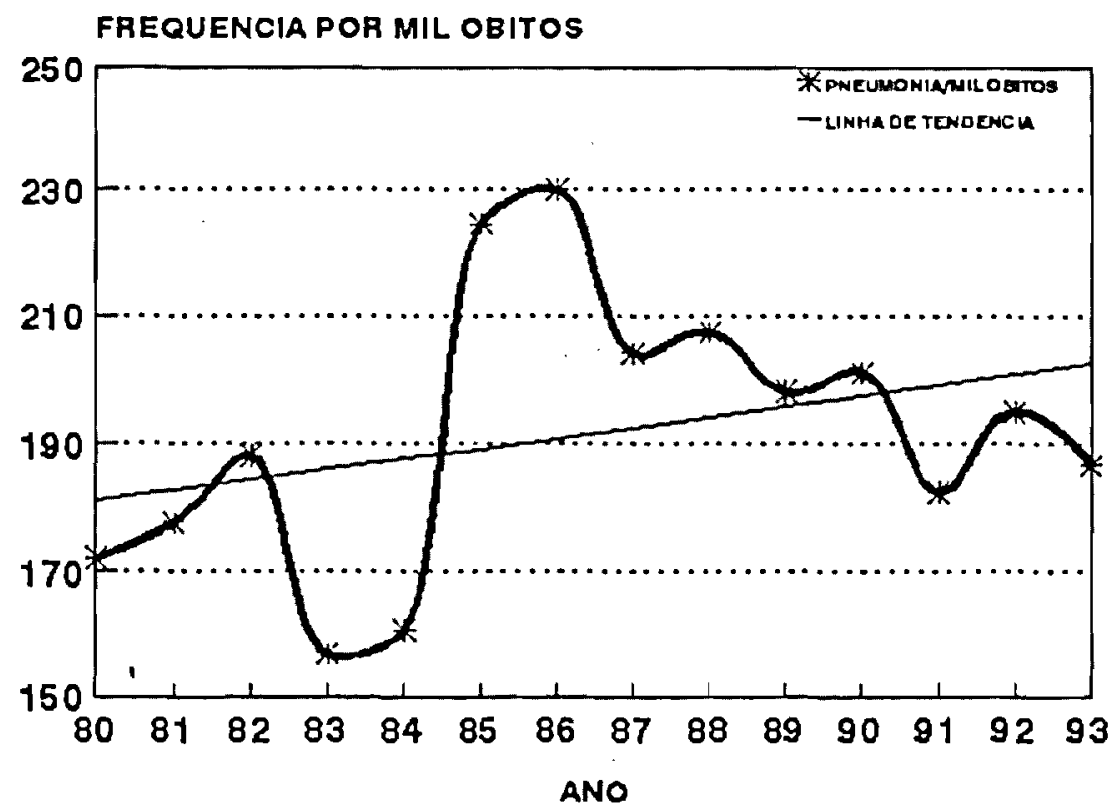

Fonte: SEADE

439.080 obltos roglstrados entre 1980.93

Aplicando-se a mesma análise aos óbitos com registro de participação de asma entre as causas, encontrou-se uma tendència de crescimento estatisticamente significante $(p=, 0152)$ que é da ordem de 0,16 casos de asma por cada mil óbitos a cada ano (gráfico X). Como os óbitos desta faixa etária somam atualmente algo mais que duas dezenas de milhares a cada ano, poder-se-ia esperar que a cada ano houvesse um aumento de cerca de 3 óbitos por asma no total de óbitos registrados, ou seja, se se puder supor fixas as contribuiçōes individuais dos diferentes componentes da mortalidade geral, tal seria o aumento esperado. Como já comentou Speizer ${ }^{20}$, embora se registre tendências de aumento de óbitos com participação da asma, como eles são ainda poucos em nủmeros absolutos, sua ocorrēncia segue muitas vezes desapercebida pelos médicos, muitos dos quais passarão toda sua vida profissional sem testemunhar um caso sequer de óbito com esta causa. 
GRÁFICO $X$ - MORTALIDADE PROPORCIONAL POR ASMA EM MENORES DE 12 ANOS NO EST. DE SÃO PAULO - 1980 A 1993

FREQUENCIA POR MIL OBITOS

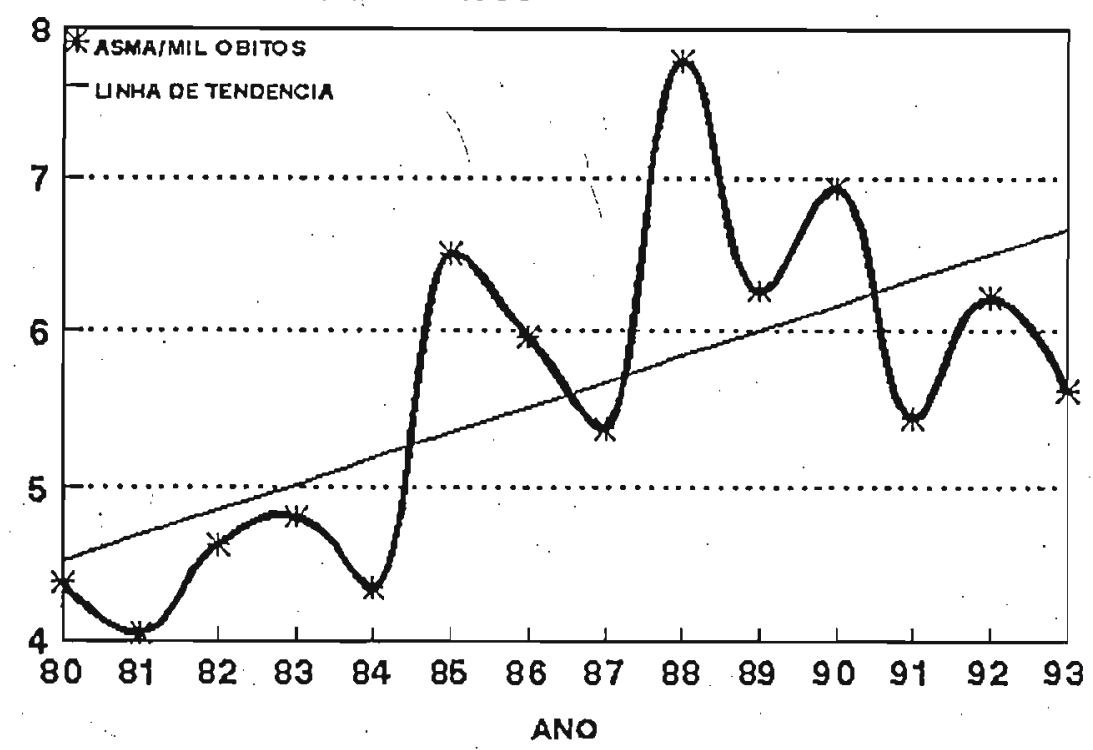

Fonto: SEADE

439.080 obltoo roglatrados ontro 1980.93

Embora qualquer alarme da identificação desta tendência de crescimento proporcional da asma entre os óbitos seja minimizado tanto por sua expressão em números absolutos quanto pelo fato de que seu crescimento proporcional possa ser devido a decréscimo de outras causas, pode-se proseguir na exploração dos dados considerando-se as relações que a asma possa estabelecer com outros diagnósticos para contribuir com o óbito. Neste sentido é de todo pertinente investigar sua possivel associação com a pneumonia, cujas cifras de mortalidade certamente não são despreziveis pois se trata da segunda causa entre menores de um ano e primeira causa entre crianças de um a cinco anos. $\mathrm{O}$ gráfico $\mathrm{XI}$ mostra o cruzamento das mortalidades proporcionais por asma e pneumonia a cada ano, que regredidos a uma reta resultam num coeficiente de correlação de $r=, 695(p=, 005)$. O coeficiente $\cdot$ de regressão é de 13,67 , sugerindo que, se o padrão de mortalidade fosse fixo, a cada aumento de um caso de asma em cada mil óbitos poderia corresponder um aumento de quase 14 casos de pneumonia em cada mil óbitos. Como o aumento anual de asma seria de apenas 0,16 mortes por mil, sua contribuição para um aumento anual de pneumonia resultaria em 2,18 novos óbitos de pneumonia por ano a cada mil óbitos registrados. Em outras palavras, os 3 novos casos de óbito com asma que se 
calcularia para cada ano poderiam ser acompanhados de cerca de 41 novos óbitos de pneumonia.

GRÁFICO XI - REGRESSÃO LINEAR' ENTRE AS FREQUÊNCIAS ANUAIS DE ASMA E PNEUMONIA COMO CAUSA DE ÓBITO EM MENORES NO EST. DE SÃO PAULO - 1980 A 1993

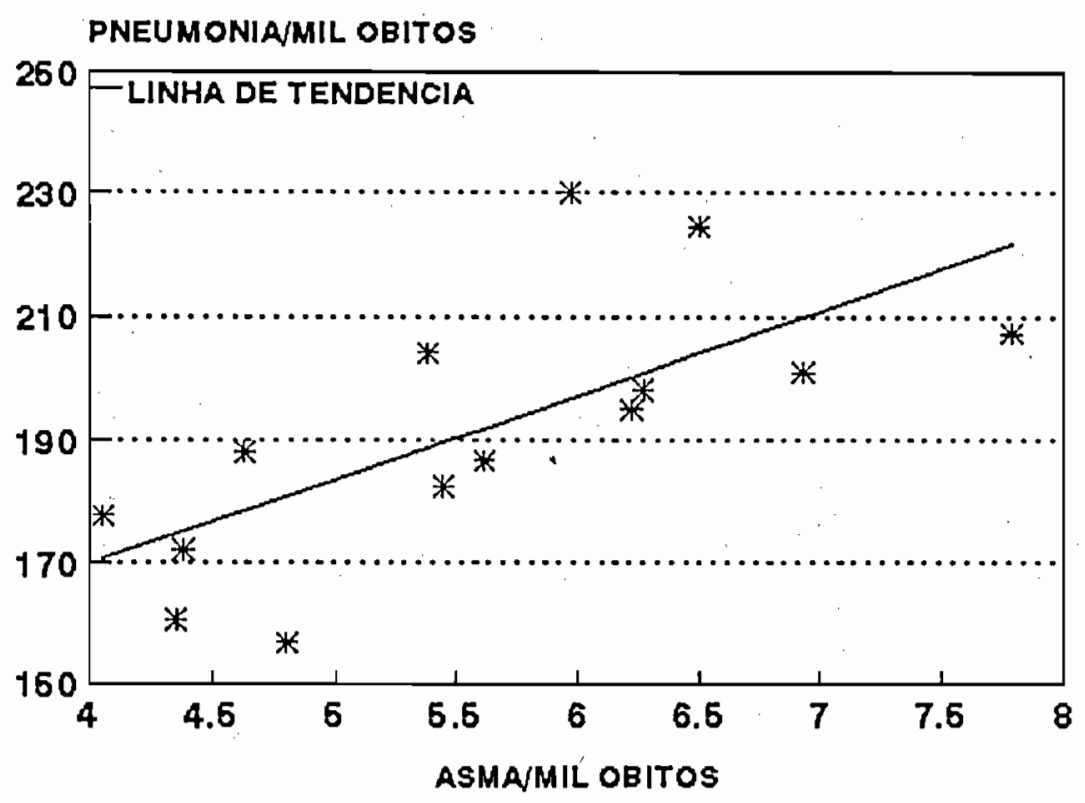

Fonte: SEADE

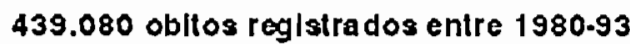

Abandonando a abstração que a análise de mortalidade proporcional impõe, considerou-se uma forma alternativa de explorar esta associação entre asma e pneumonia tendo-se em conta que para os anos de $1985 \mathrm{em}$ diante dispöe-se do registro de causas múltiplas de óbitos. Construiu-se a Tabela III de contingência abaixo considerando-se a presença destes diagnósticos quer como causa básica ou como causa associada ao óbito, de forma a permitir quantificar sua associação através do cálculo do odds ratio. O valor calculado é de 2,86 (intervalo de confiança de $95 \%$ entre 2,58 e 3,17 ) que sugere que a chance de pneumonia é quase três vezes maior entre óbitos com asma do que entre óbitos sem asma. $O$ cálculo de risco relativo poderia ser cogitado por se tratar de todo um universo completo de eventos de morte e resultaria em 2,07, no entanto, dado o uso deste indicador como risco para individuos e não para óbitos, seu enunciado poderia falsamente sugerir risco para população e como medida de associação preferiu-se o odds ratio. A conclusão que o odds ratio sugere é que 
para a população, dado o risco de óbito, o risco de presença de pneumonia entre as causas de morte é quase 3 vezes maior para os óbitos que registram asma como diagnóstico básico ou associado.

Se se proceder ao cálculo do risco atribuivel como mais uma alternativa de explorar-se a associação, obtém-se uma figura modesta de $0,84 \%$, dado que asma comparece nos óbitos com baixa frequência. Este risco atribuivel sugere que se 0 diagnóstico de asma estivesse ausente entre as causas de óbito, o resultado seria a redução de um óbito por pneumonia a cada 119 registrados ou, como hoje se registra em torno de 4 mil óbitos de pneumonia por ano, ter-se-ia uma redução de 33 óbitos de pneumonia por ano. A interpretação desta medida sofre a restrição de que não se refere ao risco atribuível para a presença de asma na população cujo controle poderia resultar em redução de pneumonia, mas que dada a probabilidade de óbito se entre estes a asma fosse eliminada ter-se-ia uma redução de $0,84 \%$ de óbitos com pneumonia.

TABELA III - CRUZAMENTO DE CAUSAS DE ÓBITOS: PRESENÇA E AUSÊNCIA DE PNEUMONIA E ASMA ENTRE MÚLTIPLAS CAUSAS - 1985 A 1993

\begin{tabular}{rrrrr}
\hline PNEUMONIA & $-\rightarrow$ & AUSENTE & PRESENTE & TOTAL \\
\hline \multirow{2}{*}{ ASMA } & AUSENTE & 189104 & 48311 & 237415 \\
PRESENTE & 868 & 634 & 1502 \\
\hline \multicolumn{2}{c}{ TOTAL } & 189972 & 48945 & 238917 \\
\hline$X^{2}$ (Yates $)=436,57(p=, 00)$ & &
\end{tabular}

Embora a análise da mortalidade proporcional por causa específica não permita conclusões definitivas pela premissa de desconsiderar o comportamento de outros componentes da mortalidade geral, é digna de nota a convergência de resultados. A abordagem de correlação de frequēncias anuais de mortalidade proporcional sugere que, se o padrão de mortalidade proporcional fosse fixo, a interrupção do crescimento da asma poderia resultar na redução de 41 novos óbitos com pneumonia a cada ano. A abordagem que examina associação de eventos entre causas múltiplas de óbitos sugere que se o efeito da asma sobre a pneumonia puder ser detido pode-se esperar uma redução de cerca de 33 óbitos com pneumonia a cada ano. As duas abordagens 
convergem para figuras semelhantes reforçando a idéia de que um controle efetivo da asma possa contribuir para uma progressiva redução dos óbitos com diagnóstico de preumonia.

Mas se a asma pode ser um fator contribuinte para os óbitos respiratórios em crianças, certamente ela não é causa isolada mas um componente a mais numa complexa rede de causalidade. De fato, embora não se disponha de dados para todo o Estado, sabe-se que na regiāo metropolitana da capital a poluição atmosférica exerce importante influência na ocorrência de óbitos por doença respiratöria em criança. Saldiva et al. $^{21}$, em publicação recente, mostraram que a elevação de óxidos de nitrogênio (NOx) eleva a probabilidade de óbito por doença respiratória em crianças menores de 5 anos em cerca de $30 \%$ (odds ratio de 1,3, intervalo de confiança de 95\% entre 1,17 e 1,43). Com a colaboração do Prof. Saldiva, com vistas a informar o presente estudo reviu-se as internações de crianças do periodo 1992-93 em confrontação com os indices médios diários de poluição registrados na cidade de São Paulo. As 90.256 internaçōes registradas no periodo foram classificadas como respiratórias (25.545 diagnósticos pertencentes ao capitulo VIII da Classificação Internacional de Doenças, Nona Revisão) e não-respiratórias (64.711) e para cada registro de internação ajuntou-se informações de medidas de poluição para a data de admissão do paciente. A probabilidade de admissão por doença respiratória contrastada com a admissão por outras doenças segundo os registros de poluentes atmosféricos e fatores climáticos do mesmo dia foi então analisada por regressão logística tomando como variável dependente a binomial presença ou ausência de doença respiratória. Obteve-se os resultados apresentados no Quadro I.

21. Saldiva PHN, Lichtenfels AJFC, Paiva PSO et al.. Association between air pollution and mortality due to respiratory diseases in children in Sáo Paulo, Brazil: a preliminary report. Environ Res 1994; 65: 218-25. 
QUADRO 1- "OUTPUT" DO PACOTE ESTATISTICO SPSS-PC PARA REGRESSÃO LOGÍSTICA DE DOENÇA RESPIRATÓRIA COM VÁRIOS POLUENTES ATMOSFÉRICOS - INTERNAČ̃O HOSPITALAR DE MENORES DE 12 ANOS NA CIDADE DE SÃO PAULO, $1992 / 93$

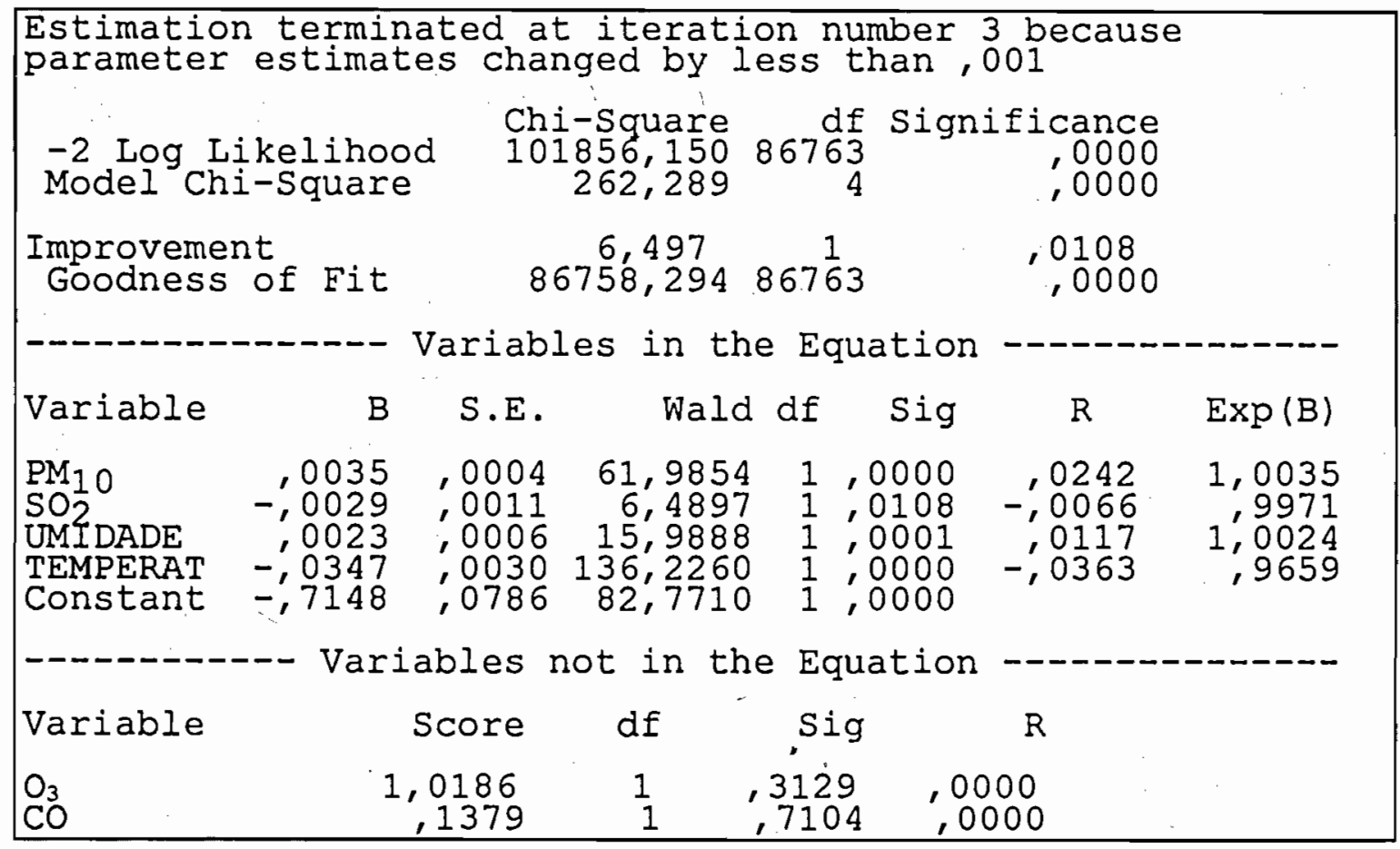

O modelo logistico apresentou um ajuste estatistico muito pobre (Goodness-offit $\operatorname{com} p=, 000$ ) para os dados analisados, mas os resultados não deixam de sugerir que a poluição atmosférica deva, à exemplo de sua ação sobre a mortalidade, influenciar a frequência de admissão hospitalar por doença respiratória em crianças. $O$ papel do NOx não pode ser analisado por indisponibilidade de registros para o periodo e tanto ozônio quanto monóxido de carbono não demonstraram niveis adequados de correlação com a admissão hospitalar para serem aceitos no modelo. Das variáveis aceitas para a equação logística entende-se que elevação tanto de particulados menores de 10 micra $\left(P M_{10}\right)$ quanto de umidade associam-se com elevação do número de internações por doença respiratória. O contrário aconteceria com temperatura e $\mathrm{SO}_{2}$, cuja diminuição é que se associaria com elevação de internações respiratórias. Esta conclusão paradoxal sobre $\mathrm{O}^{\mathrm{SO}_{2}}$ se explica pela sua alta colinearidade com o $\mathrm{PM}_{10}(r=-, 71607, p=, 010)$, que por sua vez apresenta-se como o mais importante poluente a influir nas doenças respiratórias.

O odds ratio medido para o $\mathrm{PM}_{10}$ pode parecer inexpressivo $(1,0035)$, mas há que se lembrar que este seria o risco devido ao aumento de apenas um micrograma de 
$\mathrm{PM}_{10}$ por metro cúbico de ar, que é a sua unidade de medida. Se a variação habitual de $\mathrm{PM}_{10}$ pode ser representada pelo desvio padrão de sua distribuição de frequências, ela é da ordem de 38,82 , o que aplicado como coeficiente na equação de regressão resulta num odds ratio de 1,14. Isto leva a conclusão de que elevações de $\mathrm{PM}_{10} \mathrm{em}$ niveis habitualmente registrados na cidade resultam num aumento de probabilidade de internação de crianças por doenças respiratórias que é da ordem de $14 \%$. O mesmo raciocinio aplicado às outras variáveis resultam em probabilidades da ordem de $13,8 \%$ para diminuição de temperatura (desvio padrão de 3,74 ) e de $2,3 \%$ para aumentos de umidade (desvio padrão de 10,26). Registre-se ainda que tais efeitos pressupõem controle simultâneo das outras variáveis, ou seja são efeitos exclusivos, e que variaçōes simultâneas dos poluentes resultam em efeito multiplicativo sobre o risco de admissão hospitalar de criança por doença respiratória.

Wandalsen $^{22}$, estudando a demanda pediátrica de ambulatório e hospital por asma em Santo André, registrou tendências de crescimento de morbidade e também concluiu que o poluente atmosférico que provavelmente mais contribuiria para o fenômeno seria o $\mathrm{PM}_{10}$. Também de forma análoga aos resultados da análise aqui apresentada, encontrou associação negativa com niveis de $\mathrm{SO}_{2}$ e temperatura e positiva com umidade.

Wardlaw $^{23}$, em artigo de revisão, confirma que embora a exposição experimental ao $\mathrm{SO}_{2}$ provoque broncoconstrição, vários estudos epidemiológicos falham em encontrar associação entre asma e niveis de $\mathrm{SO}_{2}$, provavelmente porque os niveis atmosféricos (média de 17,10 microgramas $/ \mathrm{m}^{3}$ ou $0,005 \mathrm{ppm}$ em nosso estudo) raramente alcançam os niveis usados em laboratório $(0,25$ a 0,60 ppm). Abbey et al. ${ }^{24}$ estudando uma população de 3914 adventistas, cujos rigorosos hábitos de higiene pessoal excluem exposição a outros poluentes que não atmosféricos, para um periodo de 10 anos, encontraram que material particulado e ozónio associavam-se a exacerbação de sintomas respiratórios, mas que $\mathrm{SO}_{2}$ não demonstrava qualquer relação estatistica significativa. No entanto, enquanto a média anual de horas com registro acima de niveis criticos havia sido de 394,6 para particulado e 337,0 para ozônio, para $\mathrm{SO}_{2}$ esta média era de apenas 42,9 .

22. Wandalsen NF. Aspectos epidemiológicos das crises de asma brônquica na populaçåo infantil do municlpio de Santo André, no perlodo de 1975 a 1984. Escola Paulista de Medicina: Tese de Mestrado, 1988.

23. Wardlaw AJ. The role of air pollution in asthma. Clin Experim Allergy 1993; 23: 81-96.

24. Abbey DE, Petersen F, Mills PK, Beeson WL. Long-term ambient concentrations of total suspended particulates, ozone, and sulfur dioxide and respiralory symploms in a nonsmoking population. Arch Environ Health 1993; 48(1); 33-46. 
Embora a poluição ambiental constitua-se em fator de risco para doenças respiratórias de uma forma geral, a asma é particularmente susceptivel a estes fatores irritantes da mucosa respiratória. Rossi et al. ${ }^{25}$ estudando a demanda de pacientes adultos de um hospital universitário na Finlândia pelo periodo de uma ano, encontraram que a exposição ao $\mathrm{NO}_{2}$ era mais importante que a exposição ao pólen ou que a diminuições de temperatura no desencadeamento de crises asmáticas graves. Schmitzberger et al. ${ }^{26}$ estudaram 1626 escolares no periodo de janeiro a abril de 1989 numa região alpina da Europa e encontraram que, controladas as exposiçōes a fumaça de cigarro e variações de idade, sexo, altura e condição socioeconômica, elevaçōes de $\mathrm{SO}_{2}, \mathrm{NO}_{2}$ e $\mathrm{O}_{3}$ associavam-se a reduçōes de fluxo aéreo nas vias respiratórias. Demonstraram também que tabagismo materno associava-se tanto a maior frequência de diagnóstico de asma quanto a reduçāo de funçōes respiratórias.

A nivel do microambiente doméstico, umidade e tabagismo parecem ser os maiores fatores de risco para asma. Brunekreef ${ }^{27}$, que estudou 1051 crianças de idade entre 6 e 12 anos, encontrou que a umidade na forma apenas de manchas de paredes implicavam em risco para tosse e chiado (odds ratio $=1,57$ e 1,52, respectivamente) e que se a umidade envolvesse crescimento de mofo, além de maior risco para tosse e chiado, aparecia também um risco para asma propriamente dita (odds ratio de 1,53). Andrae et al. ${ }^{28}$ estudaram 5301 crianças com idade entre 6 meses e 16 anos em diferentes regiões da Suécia e encontraram que umidade na casa somada a pais fumantes resultavam num risco 2,8 vezes maior para hiperreatividade brônquica e 2,5 vezes maior para presença de asma. Encontraram ainda que viver próximo a fábrica de papel representava um risco de 1,3, mostrando que a poluição atmosférica poderia agravar um eventual risco por poluição doméstica. Chilmonczyk et al. ${ }^{29}$, nos Estados Unidos, estudaram 209 crianças com idade entre 8 meses e 13 anos dosando a presença de cotinina, um metabólito do tabaco inalado, na urina e demonstraram um relação tipo dose-resposta com niveis de cotinina aumentando conforme $o$ aumento de exposição dado pelo número de fumantes na

25. Rossi OVJ, Kinnula VL, Tienari J, Huhti E. Association of severe asthma attacks with weather, pollen, and air pollutants. Thorax 1993; 48: 2448 .

26. Schmitzberger R, Rhomberg K, Buchele $H$ et al.. Effects of air pollution on the respiratory tract of children. Pediatr Pulmonol 1993; 15: 68-74.

27. Brunekreef B. Associations between questionnaire reports of home dampness and childhood respiratory symptoms. Science Total Environ 1992; 127: 79-89.

28. Andrae S, Axelson O, Bjorkstén B, Fredriksson M, Kjellman N-I M. Symptons of bronchial hyperreactivity and asthma in relation to environmental factors. Arch Dis Child 1988, 63: 473-8.

29. Chilmonczyk BA, Salmun LM, Megathlin KN et al.. Association between exposure to environmental tobbaco smoke and exacerbations of asthma in children. N Eng! J Med 1993; 328: 1665-9. 
família e com um concorrente aumento de frequência tanto de função pulmonar diminuida quanto de exacerbações de asma pré-existente.

Fatores ambientais e alérgicos também interagem entre si na causação da asma. Harving et al. $^{30}$ estudaram 96 familias de pacientes asmáticos ou portadores de dermatite atópica e encontraram que a umidade da casa e a falta de ventilação associavam-se a um aumento de concentração da população de ácaros, correspondendo a uma maior exposição a alérgenos. Mais ainda, os efeitos ambientais sozinhos não explicam a incidência de asma pois, conforme sugerem estudos com gêmeos ${ }^{31}$, a hereditariedade pode ser fator explicativo para 60 a $70 \%$ dos casos de febre do feno e asma. Esta herança genética parece ser complexa e envolver diferentes genes autossômicos pois Levitt ${ }^{32}$, em experimentos com ratos de linhagem genética conhecida, demonstrou que a susceptibilidade a diferentes neurotransmissores (acetil-colina, 5-hidroxitriptamina, substância $P$ ) tem diferentes modos de transmissão e condicionam diferentes perfis fenotípicos.

Tem sido um desafio para os especialistas explicar a variabilidade de prevalência de asma em diferentes regiões do mundo. Em Tristão da Cunha ${ }^{33}$, uma pequena îlha no meio do Oceano Atlântico, a asma pode chegar a afetar uma em cada três pessoas, enquanto que entre esquimós e alguns indios americanos ${ }^{34}$, bem como em populações das montanhas da Papua New Guinea ${ }^{35}$, é doença rara. Embora se possa pensar em fatores ambientais para explicar que populações indigenas, poupadas da poluição atmosférica caracteristica das sociedades industriais, tenham baixa frequência da doença, tal explicação conflita com a situação de Tristão da Cunha, mais sugestiva de uma sociedade estável com alguma característica genética interna. No entanto, é inegável que populações de baixa incidência de asma quando expostas a um ambiente diferente podem vir a apresentar elevação na frequência da doença. Waite et al. ${ }^{36}$ estudaram crianças da llha de Tolekau que em 1966 foram transferidas para a Nova Zelândia por força de um furacão que devastou a região. Em

30. Harving $H$, Korsgaard J, Dahl R. House-dust mites and associated environmental conditions in Danish homes. Allergy 1993; 48: 106-109.

31. Duffy DL, Martin NG, Battistutta D, Hopper JL, Mathews JD. Genetics of asthma and hay fever in Australian twins. Am Rev Respir Dis 1990; 142: 1351-8.

32. Levitt RC. Understanding blological variability in susceptibility to respiratory disease. Pharmacogenetics $1991 ; 1: 947$.

33. Mantle J, Pepys J. Asthma among Tristan da Cunha islanders. Clin Allergy 1974; 4: 161-5.

34. Henxheimer H, Schaefer O. Asthma in Canadian eskimos. New Engl J Med 1974; 291: 1419-24.

35. Anderson RH. The epidemiological and allergic features of asthma in the New Guinea Highlands. Clin Allergy 1974; 4: 171-6.

36. Waite DA, Eyles EF, Tonkin SL, O'Donnell TV. Asthma prevalence in Tokelaun children in two environments. Clin Allergy 1980; 10: 71-5. 
1980, as crianças que haviam retornado à ilha apresentavam asma com uma frequência de $11 \%$ enquanto que aquelas que haviam permanecido na Nova Zelândia apresentavam a doença com frequència de $25,3 \%$.

Não só fatores genéticos e ambientais têm uma interação complexa na determinação da doença, como fatores socioeconômicos podem constituir-se em variáveis de confusão. Embora tais fatores não pareçam exercer influência própria sobre a doença, como demonstrou Pilling ${ }^{37}$ numa vasta revisão de literatura e como concluíram McNichol et al. ${ }^{38}$ após acompanharem crianças asmáticas e controles em Melbourne, na Austrália, por sete anos, eles talvez condicionem diferentes oportunidades de acesso a serviços médicos e de educação para reconhecimento e tratamento adequado da doença. De fato, Wood et al. ${ }^{39}$ estudando 78 crianças asmáticas de origem hispânica no Texas, encontraram que aquelas que tinham pior evolução da doença (maior número de dias com sintomas, maior número da faltas à escola, maior número de internações hospitalares, maior redução das funções respiratónias) eram também as que não só eram mais expostas a poluição na forma de pais tabagistas como também pertenciam às familias que menor compreensão tinham da doença e que menos aderiam ao tratamento correto. Halfon et al. ${ }^{40}$ reviram os dados do inquérito nacional promovido pela autoridades americanas em 1988 (amostra de 47485 familias) e concluiram que as crianças mais pobres e mais jovens (menos de 6 anos) apresentavam asma com major frequência e que também realizam menos consultas médicas de rotina para registrarem um número maior de internaçōes hospitalares e de atendimentos de urgência por asma. Tal informação sugere uma assistência médica descontinua com diminuição de oportunidades de tratamento adequado para as camadas socioeconômicas menos privilegiadas. Littlejohns e MacDonald ${ }^{41}$, que reviram dados semelhantes de inquérito nacional no Reino Unido para adultos maiores de 16 anos, também concluiram que as classes menos privilegiadas socioeconomicamente apresentavam morbidade por asma mais elevada e aventaram a hipótese de privação de oportunidades de tratamento como explicação.

37. Pilling D. The child with asthma: social, emotional, educational adjustment. An annoted bibliography. Slough: NFER Publishing Company Ltd, 1975.

38. McNichol KN, Williams HE, Allan J, McAndrew I. Spectrum of asthma in children. III, psychological and social components. Br Med J 1973; 4: 16-20.

39. Wood PR, Hidalgo HA, Prihoda TJ, Kromer ME. Hispanic children with asthma: morbidity. Pediatrics 1993; 91(1): $62-9$.

40. Halfon N, Newacheck PW. Childhood asthma and poverty: differential impacts an utilization of health services. Pediatrics 1993; 91(1): 56-61.

41. Littlejohns P, MacDonald LD. The relationship between severe asthma and social class. Respir Med 1993; 87: $139-43$. 
O risco elevado de óbito por asma para negros jovens (menos de 35 anos) nos Estados Unidos, que vem sendo registrado nos últimos anos por diferentes estudos $^{42}, 43$ realizados naquele pais, parece ser acompanhado por uma igual elevação de risco na prevalência da doença ${ }^{44}$ e de risco para internação hospitalar ${ }^{45}$ entre os portadores de doença. Um editorial da revista oficial da Associação Médica Americana ${ }^{46}$, revendo as informações neste campo, sugere que o problema não tenha natureza étnica mas sim social, já que os negros compareceriam com maior número nas classes sociais menos assistidas e assim, não por condicionante social de doença mas por restrição social de acesso a assistência médica adequada, acabariam por se apresentar como raça mais afetada pelo incremento de mortalidade e morbidade por asma que se registra naquele pais. Um estudo de Denson-Lino et al. ${ }^{47}$ sugere que aos pais de familias mais pobres não falta capacidade de entendimento adequado de normas de tratamento porque quando tais normas não envolvem despesas (remoção de brinquedos de pelúcia, remoção de móveis/ utensilios depositários de mofo, umidade e pó) estes pais tendem a ter um desempenho igual ou melhor ao de pais de classes socioeconômicas mais elevadas. As dificuldades se radicam na capacidade de efetuar despesas como comprar invólucros plásticos para colchões, substituir travesseiros, instalar filtro de ar ou ar condicionado, ou seja, são de natureza econômica.

O aumento de morbidade e mortalidade por asma que vinha sendo registrado em diferentes paises como Reino Unido ${ }^{48}$, Nova Zelândia ${ }^{49}$, Estados Unidos ${ }^{50}$, França $^{51}$ e Canadá ${ }^{52}$, já apontava sistematicamente a faixa etária entre 5 e 35 anos

42. Welss Kb, Wagener DK. Changing patterns of asthma mortality: Identifying target populations at high risk. JAMA. 1990; 264: 1683-1687.

43. Kaplan KM. Epidemiology of deaths from astma in Pennsylvania, 1978-87. Public Health Reports 1993; $108(1)$ : 66-9.

44. Weitzman $M$, Gortmaker SL, Sobol AM, Perrin JM. Recent trends in the prevalence and severity of childhood asthma. JAMA 1992: 268: 2673-7.

45. Gerstman BB, Bosco LA, Tomita DK. Trends in the prevalence of asthma hospitalization in the 5 to 14-year-old Michigan Medicaid population, 1980 to 1986. J Allergy Clin Immunol 1993; 91: 838-43.

46. Editorial. Asthma deaths: a social or medical problem? JAMA 1993: 269(15); 19945.

47. Denson-Lino JM, Willies-Jacobo JW, Rosas A, O'Connor RD, Wilson NW. Effect of economic status on the use of house dust mite avoidance measures in asthmatic children. Ann Allergy 1993; 71(2): 130-2.

48. Burney PGJ. Asthma mortality in England and Wales - evidence for a further increase. Lancet 1986; II: $323-6$.

49. Jackson RT, Beaglehole R, Rea HH, Sutherland DC. Mortality from asthma: a new epidemic in New Zealand. Br Med J 1982; 285: $771-4$.

50. Sly RM. Increases in deaths from asthma. Am Allergy 1984; 53: $20-5$.

51. Bousquet T, Hatton F, Godard P. Michel FB. Asthma mortality in France. J Allergy Clin Immunol 1987; 80(3Pt2): 389-94.

52. Mao $Y$, Semenciw $R$, Morrison $H$, MacWilliam $L$, Davies $J$, Wigle $D$. Increased rates of illness and deaths from asthma in Canada. Can Med Assoc J 1987; 137(7): 620-4. 
como a mais afetada. Estudos mais recentes têm demonstrado que dentro desta faixa etárias, as crianças podem ser as mais seriamente atingidas. Vollmer et al. ${ }^{53}$, estudando uma população atualmente em cerca de 370 mil pessoas para o periodo de 1967 a 1987, encontraram que os menores de 5 anos eram os que mais contribuiam para a elevação de internações hospitalares por asma, sendo que os meninos eram mais afetados que as meninas. Manfreda et al. ${ }^{54}$, num estudo que interessou 1,1 milhões de pessoas, encontraram um aumento na prevalência de asma diagnosticada por médico e identificaram a faixa etária de 5 a 14 anos como a mais afetada. Ambos os estudos não puderam demonstrar que mudanças de diagnóstico de bronquite aguda para asma pudessem justificar tal aumento de morbidade, conclusão que tampouco conseguiu demonstrar a tentativa de Whallett e Ayres ${ }^{55}$ no campo da mortalidade por asma no Reino Unido. Kun et al. ${ }^{56}$, que na Austrália estudaram admissões de um hospital para menores de 14 anos entre 1979 e 1989, encontraram que a razão de atendimentos por asma no total de atendimentos hospitalares havia subido de 0,017 para 0,072 e que mudanças de diagnóstico não poderiam explicar este aumento que talvez se devesse a aumento de severidade da doença.

Wilkins e $\mathrm{MaO}^{57}$ analisando dados de internação hospitalar para todo o Canadá no periodo de 1980 a 1988, identificaram esta predominância de aumento de morbidade para menores de 15 anos apenas em algumas regiōes (particularmente na Prince Edward (s/and) e apontaram que razão entre os sexos masculino/feminino havia sido de 1,5:1 nesta faixa etária, com um inversão para 1:2 na faixa de 15 a 34 anos. Distribuição de morbidade por sexo semelhante foi encontrada por Skobeloff et al. ${ }^{58}$ revendo 33269 internações de 67 hospitais da Pensilvania para o periodo de 1986 a 1989. Na faixa etária até 10 anos encontraram o dobro da frequência de internação para o sexo masculino, na faixa 11 a 20 anos ambos sexos tinham frequências equivalentes e na faixa de 10 a 50 anos as mulheres tinham frequência três vezes maiores do que os homens.

53. Vollmer WM, Buist AS, Osbrone ML. Twenty year trends in hospital discharges for asthma among members of a health maintenance organization. J Clin Epidemiol 1992; 45(9): 999-1006.

54. Manfreda J, Becker AB, Wang P-Z, Roos LL, Anthonisen NR. Trends in physician-diagnosed asthma prevalence in Manitoba between 1980 and 1990. Chest 1993; 103(1): 151-57.

55. Whallett EJ, Ayres JG. Labelling shift from acute bronchitis may be contributing to the recent rise in asthma mortality in the 5-34 age group. Respir Med 1993; 87: 183-6.

56. Kun HY, Oates RK, Mellis CM. Hospital admissions and altendances for asthma - a true increase? Med J Aust 1993; 159: 312-3.

57. Mao $Y$, Wilkins $K$. Trends in rates of admission to hospital an death from asthma among children and young adults in Canada during the 1980s. Can Med Assoc J 1993; 148(2): 185-90.

58. Skobeloff EM, Spivey WH, St.Clair SS, Scholfstall JM. The influence of age and sex on asthma admissions. JAMA 1992; 268(24): 3437-40. 
Neville et al. $^{59}$ realizaram um inquérito nacional no Reino Unido nos anos de 1991 e 1992 e encontraram que a faixa etária de 0 a 9 anos concentrava os atendimentos de asma, além de apresentarem maior proporção de casos referidos para tratamento hospitalar. Ayres et al. $^{60}$, numa critica a este trabalho não só reafirmaram estas informaçōes como também ofereceram um detalhe a mais, que dentro desta faixa etária seriam as crianças entre 0 e 4 anos as mais afetadas, com uma frequência de episódios de ataques de asma por semana por cada 100 mil pessoas da ordem de 193,6. As faixas etárias seguintes, a saber 5 a 14 anos, 15 a 44 anos, 45 a 64 anos e mais de 65 anos, teriam frequências de $115,1,40,3,35,1$ e 36,1, respectivamente.

Desta forma, finalmente, volta-se a reafirmar a importância dos menores de 5 anos na epidemiologia das doenças respiratórias. Não só são estas crianças as mais afetadas pelas infecções respiratórias agudas, como aparentemente são elas também as que maior desafio representam para o controle da asma brônquica. Esta condição aparentemente contribui com seus indices indesejavelmente elevados de mortalidade, quer diretamente com uma tendència de aumento proporcional progressivo, quer indiretamente associando-se a infecções respiratórias. Independentemente de qualquer risco de óbito, há que se lembrar com Ryan, que prescrevia banhos gelados para o tratamento da asma, o desespero causado pela própria doença ${ }^{61}$ :

"Among the various chronic complaints to which the human frame is liable, very few can be considered of a more formidable nature than a confirmed asthma. The idea of its being an incurable disorder, its threatening instant of suffocation at every attack, are circunstances altogether so alarming to a patient, as must necessarily weaken and depress a mind endowed with the utmost fortitude and resignation. Any remedy the that could be found capacle of administering permanent relief, to a person in such an afflicting situation, must be looked upon as of the utmost importance to mankind".

Neste perfil epidemiológico das doenças respiratórias na infância onde se destacam asma e pneumonia, há que se anotar que a literatura registra evidências de

59. Neville RG, Clark RC, Hoskins G, Smith B. National asthma attack audit 1991-2. Br Med J 1993; 306: 559-62.

60. Ayres J, Tunnicliffe W, Miles J. Rate of asthmatic attacks [Letter]. Br Med J 1993; 306: 1069.

61. Ryan M. Observations on the history and cure of asthma, in which the property of using the cold bath in that disorder is fully consldered. London: C.A.J. \& J. Robinson, 1793: V. 
relações senão entre estas doenças pelo menos entre seus fenômenos subjacentes, a disfunção bronquica e a infecção.

É fato conhecido que a infecção viral predispõe à hiperreatividade brônquica. $O$ clássico trabalho publicado em 1976 por Empey et al. ${ }^{62}$ documentou a resposta exagerada da árvore brônquica de indivíduos normais com infecções leves do trato respiratório alto a estímulos com soluções de histamina e ácido cítrico e sugeriu que esta hiperreatividade fosse devida a lesões do epitélio que levariam a uma maior exposição dos receptores de irritação. Esta hipótese foi levantada porque no estudo encontrou-se que a inalação de atropina teria efeito protetor sobre a resposta brônquica, sugerindo que reflexos vagais estivessem envolvidos. Mas a fisiopatologia do fenômeno é ainda controvertida, como sugere revisão oferecida por Sterk ${ }^{63}$, que lembra um possivel papel de neuropeptideos periféricos cuja degradação poderia ser retardada por alterações metabólicas induzidas pelo vírus, bem como uma possivel participação de mediadores quimicos liberados pelos processos imunológicos e inflamatórios que acompanham a infecção, ou ainda mesmo a possivel alteração funcional direta dos receptores beta-adrenérgicos por ação do vírus. Estudos recentes $^{64}$ têm sugerido ainda que 0 interferon alfa, cuja produção é rapidamente induzida por vírus, seja responsável pela liberação de histamina, que por sua vez conduziria à broncoconstrição.

Vários estudos sugerem que infecções virais, particularmente por Virus Sincicial Respiratório (RSV), predisponham ao desenvolvimento de asma ${ }^{65}, 66,67,68,69$. Um recente estudo caso-controle realizado em Nottingham ${ }^{70}$, encontrou que crianças expostas a bronquiolite têm um risco aumentado em 2,8 vezes para apresentar doença

62. Empey DW, Laitinen LA, Jacobs L, Gold WM, Nadel JA. Mechanisms of bronchial hyperreactivity in normal subjects after upper respiratory tract infection. Am Rev Respir Dis 1976; 113: 131-9.

63 . Sterk PJ. Virus-induced airway hyperresponsiveness in man. Eur Respir J 1993; 6:894-902.

64. Krasnowska M, Malolepszy J, Liebhart E, Inglot AD. Inhaled natural human interferon alpha induces bronchoespastic reactions in asthmatics. Archivum Immunologiae Therapiae Experimentalis 1992; 40:75-78.

65. Wittig HJ, Cranford NJ, Glaser J. The relationship between bronchiolitis and childhood asthma: a follow-up study of 100 cases of broncholitis in infancy. J Allergy 1959; 30:19-23.

66. Scislicki A, Rudnik J, Gawel J, Pryjma J. The risk of bronchial asthma in children with a history of obstructive bronchitis in the first two years of life. Arch Immunol Ther Exp 1978; 26:723-9.

67. Pullan CR, Hey EN. Wheezing, asthma and pulmonary dysfunction 10 years after infection with respiratory syncitial virus in infancy. Br Med J 1982; 284:1665-9.

68. Mok JYQ, Simpson H. Outcome for acute bronchitis, bronchiolitis and pneumonia in infancy. Arch Dis Child 1984; 59:3069.

69. Sly PD, Hibbert ME. Childhood asthma following hospitalization with acute viral bronchiolitis in infancy. Pediatr Pulmonol 1989; 7: 153-8.

70. Murray M, Webb MSC, O'Callaghan C, Swarbrick AS, Milner AD. Respiratory status and allergy after bronchiolitis. Arch Dis Child 1992; 67: 482-7. 
chiadora, controladas variáveis de confusão como pais tabagistas, aleitamento materno, história familiar e pessoal de atopia, tamanho da familia e classe social. Além do RSV, infecções por outros virus ${ }^{71}, 7^{72}$ e a coqueluche ${ }^{73}$ são apontadas como prováveis responsáveis pelo desenvolvimento da asma. As infeç̧ões virais também exacerbam uma asma pré-existente ${ }^{74}$, efeito que também podem ter as infecçōes bacterianas ${ }^{75}, 76,77$, provavelmente devido a liberação de mediadores por processos tanto imunológicos quanto inespecíficos.

No entanto, a investigação da relação entre doenças chiadoras e infecções respiratórias tem negligenciado os possíveis efeitos das primeiras sobre as últimas. Num editorial da revista "Clinical Allergy", Clough e Dow ${ }^{78}$ lembram a questão do sentido da associação asma / infecção mencionando que " ...(a) hypothesis is that asthmatics may be more at risk of developing respiratory infections" mas, no entanto, năo exploram $\circ$ assunto e restringem-se a mencionar a literatura que tem olhado a associação pelo outro lado: infecção respiratória possivelmente levando a asma. Simpson e Mok $^{79}$, numa revisão sobre as relaçōes entre asma e infecção, afirmam que, no que interessa a asma infantil, os estudos disponiveis "do not clarify whether reactivity is the determinant of outcome in RS virus lower respiratory infection or whether it occurs as a sequel to infection".

Embora não tomado como objeto central de investigação, este possivel efeito da doença chiadora sobre a infeç̧ão respiratória já foi muitas vezes negado em análises marginais de estudos com outras preocupações. Trigg et al. ${ }^{80}$ examinaram

71. Minor TE, Dick EC, Baker JW, Oullette JJ, Cohen M, Reed CE. Rhinovirus and influenza type A infections as preciptants of asthma. Am Rev Respir Dis 1976; 113: 149-53.

72. Curwitz $D$, Mindorff $C$. Levison $H$. Increased incidence of bronchial reactivity in children with a history of bronchitis. $J$ Paediatr 1981; 98: 551-5.

73. Johnston DA, Bland JM, Ingram D, Anderson HR, Warner JO. Effect of whooping cough in infancy, a subsequent lung function and bronchial reactivity. Am Rev Respir Dis 1986; 134: 270-5.

74. Pattemore PK, Johnston SL, Bardin PG. Viruses as precipitants of asthma symptoms. I. Epidemiology. Clin Exp Allergy 1992; 22: 325-36.

75. Norn S, Stahl Skov $P$, Jensen C, Jarlov JO, Espersen F. Histamine release induced by bacteria. A new mechanism in asthma? Agents Actions 1987; 20(1/2):29-34.

76. Berend N, Peters MJ, Armour CL. Effect of inhaled formyl-methionyl-leucyl-phenyllalanine on airway function. Thorax 1987; 42:36-40.

77 . Hutchinson AA, Hinson JM, Brigham KL, Snapper JR. Effect of endotoxin on airway responsiveness to aerosol histamine In sheep. J Appl Physiol: Respirat Environ Exercise Physiol 1983; 54: 1463-8.

78. Clough JB, Dow L. Epidemiological approach to bronchial responsiveness. [Editorial]. Clin Allergy 1987; 17: 265-9.

79. Simpson H, Mok JYQ. Outcome of respiratory disease in childhood. In; Milner AD, Martin RJ [Editors]. Neonatal and Pediatric Respiratory Medicine. London: Butterworths, 1985.

80. Trigg CJ, Bennett JB, Tooley M, D'Souza MF, Davies RJ. Do patients with bronchial hyperreactivity attend more frequently with respiratory complaints in general practice? Proceedings of the British Thoracic Society Winter Meeting, London 89/12/87: Abstract S4, pg. 9. 
retrospectivamente 5 anos de registros de prontuários de pacientes de uma clínica dividindo-os em 3 grupos de resposta brônquica à histamina $\left(\mathrm{PC}_{20}<=2 \mathrm{mg} / \mathrm{ml}, 2\right.$ $\mathrm{mg} / \mathrm{ml}<\mathrm{PC}_{20}<32 \mathrm{mg} / \mathrm{ml}$ e $\mathrm{PC}_{20}>=32 \mathrm{mg} / \mathrm{ml}$ ) e não encontraram qualquer diferença na frequência de sintomas respiratórios. No grupo australiano da Profa. Woolcock, um estudo $^{81}$ concluiu que não haveria relação entre a hiperreatividade brônquica e infecções recentes do trato respiratório superior. Mesmo em se tratando de bronquite aguda, existe uma resistência em se admitir a possibilidade de uma infecção bacteriana como complicação, o que deu margem a Phelan et $a^{82}$, do respeitável grupo de Perth liderado pelo Prof. Landau, escreverem "the frequency of secondary bacterial infection (em bronquite aguda) is undocumented but probably very rare in children living in good social circunstances".

Para se tomar adequadamente em consideração estas informaçōes da literatura, há que se lembrar a distinção entre a hiperreatividade brônquica e a asma, bem como atentar para o fato que o perfil epidemiológico da doença deve variar segundo a situação geográfica, social e econômica, como sugere a declaração de Phelan et al. acima ao mencionar "good social circunstances". No que interessa a hiperreatividade brônquica, $\mathrm{Curry}^{83}$, considerado pioneiro nos estudos deste campo, já apontava para o fato de que ela não seria capaz de distinguir asmáticos de indivíduos normais. Modernamente, Stanescu e Frans ${ }^{84}$ estudando adultos encontraram que a hiperreatividade não seria uma caracteristica constante da asma, Britton e Tattersfield $^{85}$ concluiram que a hiperreatividade não é nem sensivel nem especifica para a identificação de asma, conclusão semelhante a que chegaram Spiropoulos et al. $^{86}$.

Asma e hiperreatividade são entidades distintas, uma de natureza clínica e outra laboratorial, e embora a investigação experimental de asma recorra com frequência à hiperreatividade como um indicador da doença há que se ter presente a distinção entre as duas, principalmente no campo da epidemiologia. Tão independente

81. Peat JK, Britton WJ, Salome CM, Woolcock AJ. Bronchial hyperresponsiviness in two populations of Australian schoolchildren. II. Relative importance of associated factors. Clin Allergy 1987; 17:283-90.

82. Phelan PD, Landau LI, Olinsky A. Respiratory illness in children. Oxford: Balckwell Scientific Publications, 1990. Pg. 63.

83. Curry JJ. Comparative action of acetyl-beta-methyl-choline and histamine on the respiratory tract in normal, patients with hay fever, and subjects with bronchial asthma. J Clin Invest 1947; 26:43-8.

84. Stanescu DC, Frans A. Bronchial asthma without increased airway reactivity. Eur J Respir Dis 1982; 63:5-12.

85. Britton J, Tattersfield A. Does measurement of bronchial hyperresponsiveness help in clinical diagnosis of asthma? Eur $J$ Respir Dis 1986; 68:233-8.

86. Splropoulos $\mathrm{K}$, Stevens J, Eigen $\mathrm{H}$, Spiropoulos A. Specificity and sensitivity of methacholine challenge test in children with normal and hyperreactive airways. Acta Paediatr Scand 1986; 75(5): 737-43. 
parece ser a hiperreatividade brônquica da asma que em Southamptom (Reino Unido)

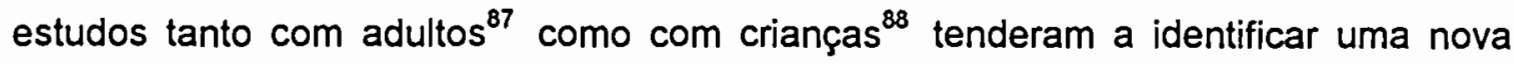
entidade clínica que, composta de sintomas respiratórios e hiperreatividade brônquica, seria distinta da asma como ela é clinicamente reconhecida, embora respondendo a tratamento semelhante. Sears et al. ${ }^{89}$, na Nova Zelândia, no acompanhamento de uma coorte de 800 crianças desde o nascimento, encontraram que aos nove anos $13 \%$ das crianças assintomáticas tinham resposta positiva à inalação de metacolina e que $35 \%$ das crianças asmáticas tinham teste negativo. Salome et al. ${ }^{90}$, que na Austrália encontraram que $6,7 \%$ de crianças hiperreativas não tinham sintomas respiratórios e que $5,6 \%$ dos asmáticos não tinham hiperreatividade, sugerem que a hiperreatividade deva ser usada como um indicador de severidade da asma. Na Inglaterra, Lee et al. ${ }^{91}$, num estudo tipo corte transversal de população de escolares, encontraram alta correlação entre resposta brônquica à histamina e severidade da asma medida em número médio de ataques de dispnéia, e Pereira et $\mathrm{al}^{92}$, num estudo caso-controle, encontraram que a resposta brônquica ao exercicio era um bom preditor da severidade de asma em crianças, medida como variação de PEFR (peak expiratory flow rate). Estas conclusões lembram a impressão empirica que Tiffeneau ${ }^{93}$, também um pioneiro na investigação da hiperreatividade brônquica, registrava jả em 1958:

"La sensibilité pulmonaire aux mediateurs (acetylcholine, histamine) s'accroit au contraire au fur et à mesure que l'asthme s'accentue: elle est souvent mille fois plus grande dans l'asthme ancient dit inveteré que dans un asthme debutant".

A hiperreatividade não deve, portanto, ser tomada como equivalente de asma mas como indicador de sua severidade. Por isso, o presente trabalho entende que

87. Mortagy AK, Howell JBL, Waters WE. Respiratory symptoms and bronchial reactivity: identification of a syndrome and its relation to asthma. B Med J 1986; 293: 525-9.

88. Clifford RD, Howell JB, Radford $M$, Holgate ST. Associations between respiratory symptoms, bronchial rsponse to methacholine, and atopy in two age groups of schoolchildren. Arch Dis Child 1989; 64(8): 1133-9.

89: Sears MR, Jones DT. Holdaway MA et al..Prevalence of bronchial reactivity to inhaled methacholine in New Zealand children. Thorax 1986; 41: 283-9.

90. Salome CM, Peat JK, Britton WJ, Woolcock AJ. Bronchial hyperresponsiveness in 2 populations of australian children. I. Relation to respiratory symptoms and diagnosed asthma. Clin Aliergy 1987; 17: 271-81.

91. Lee DA, Winslow NR, Speight ANP, Hey EN. Prevalence and spectrum of asthma in childhood. Br Med J 1983; 286: 1256-B.

92. Pereira JCR, Carswell F. Hughes AO. Assessment and prediction of asthma and its severity in the pediatric community. Rev Saúde públ, S. Paulo, 1990; 24(6): 437-44.

93. Tiffeneau R. Hypersensibilité cholinergico-histaminique pulmonaire de l'asthmatique. Acta Allerg 1958; 12(Suppl 5): 187 221. 
tanto as evidências de que infecções virais predisponham a asma quanto as evidências de que hiperreatividade não predisponha a infecção não esgotam as relações entre asma, ou doenças chiadoras, e infecção.

\section{I.3 - OBJETIVOS DO PRESENTE ESTUDO}

Nas considerações anteriores desta introdução destacam-se evidências de que a asma, ou as doenças chiadoras da infância, têm inequivoca importância entre as doenças respiratórias deste grupo etário e que estas doenças podem estar associadas a infecções pulmonares. O objetivo do presente estudo é avaliar se e quanto alteraçöes funcionais da árvore brônquica que caracterizam as doenças broncoespásticas da infância podem constituir-se em fator predisponente ao desenvolvimento de infecções pulmonares. A doença chiadora recorrente e a pneumonia são tomadas como entidades clínicas através das quais busca-se conhecer uma possivel associação entre os dois fenômenos.

Para esta avaliação, o presente estudo estabelece como hipótese a ser testada que as crianças que apresentam doença chiadora, se comparàdas a crianças livres desta doença, têm um maior risco de desenvolver pneumonia. Tem ainda como objetivo verificar se outras variáveis podem também constituir-se em fatores de risco cuja presença possa afetar a relação entre os dois fenômenos que se pretende estudar. Não promove, no entanto, uma busca exaustiva destas variáveis definindo que para a coleta de informações serão considerados itens que tenham importância já anteriormente definida na literatura e que para análise seräo considerados itens cuja distribuição na amostra estudada sugira influência sobre o aparecimento de pneumonia ou sobre a relação entre pneumonia e doença chiadora.

A hipótese será testada numa amostra de um ambiente específico do qual deverá ser representativa e para o qual as conclusões do estudo possam ser aplicadas. As inferências sobre as relações dos fenômenos serão aplicáveis para o ambiente estudado e conjecturadas para o universo além deste ambiente.

Para atender a estes objetivos concebeu-se um estudo caso-controle a ser aplicado num hospital comunitário, na forma cuja descrição se segue. 
II - MATERIAL E MÉTODOS 
O presente estudo contemplou o desenho epidemiológico observacional casocontrole, onde a doença observada é a pneumonia e o fator investigado é a exposição anterior a doença chiadora recorrente. É premissa deste estudo que tanto o diagnóstico de doença quanto de exposição pertence ao campo da clínica e por isso vale-se do juizo de pediatras para a identificação dos dois eventos. As informações clinicas que subsidiam esta tomada de decisão são registradas para todos os indivíduos entrando no estudo e são usadas para avaliação de consistência e propriedade do diagnóstico clínico mas, no entanto, os fenômenos são analisados na forma como são identificados por decisão clínica.

Caracterizando doentes e não doentes com informações complementares sobre outras condições potencialmente intervenientes quer na situação de doença ou de exposição, o estudo avalia também os possiveis efeitos de outras variáveis sobre a doença, bem como pondera, quando aplicável, tais efeitos sobre a relação entre doença e exposição.

\section{II.1 - AMOSTRA ESTUDADA}

Estudou-se uma amostra da clientela de pediatria do Hospital Universitário da Faculdade de Medicina da Universidade de São Paulo. Após um teste piloto realizado entre 8 e 21 de dezembro de 1993, o projeto foi submetido ao Departamento de Pediatria do Hospital, que o aprovou em fevereiro de 1994 indicando duas médicas pediatras de seus quadros para realizarem a coleta de dados: a uma foi atribuída a tarefa de investigar a presença de doença (pneumonia) e a outra a tarefa de identificar a exposição anterior ao fator investigado (doença chiadora recorrente). Ambas receberam orientações para preenchimento do instrumento de coleta de dados com uma cópia do projeto de pesquisa e um manual de padronização de coleta de dados (cópias em anexo). Seu trabalho foi acompanhado através de reuniões semanais com uma supervisora de campo e o investigador do projeto.

A despeito de sua condição de hospital escola, este hospital é um hospital geral comunitário atendendo uma população adstrita a sua área geográfica, zona oeste da capital, e a comunidade universitária. É referência da rede pública de serviços de saúde da área, a cujos casos dá atendimento integral sem distinção quer por gravidade ou interesse acadêmico. Entendeu-se que tais premissas fossem 
importantes para o estudo de forma a excluir qualquer possível vicio de seleção de pacientes para entrada na investigação. Baltazar ${ }^{94}$ lembra que uma premissa básica de estudos caso-controle é que a possibilidade de resultar exposto ao fator investigado seja a mesma para casos e controles. Espera-se que uma amostra retirada de serviços regionalizados como os do Hospital Universitário demonstre uma uniformidade demográfica, socioeconômica e de oportunidades de acesso a assistência médica que garantam esta premissa.

O tamanho da amostra foi calculado aplicando-se as fórmulas propostas por Schlesselman ${ }^{95}$, e também recomendadas por Lemeshow ${ }^{96}$. Para o cálculo do número de pares discordantes necessários a um estudo caso-controle observa-se a seguinte fórmula:

$$
m=\frac{\left[z_{a} / 2+z_{b} R Q(P(1-P)]^{2}\right.}{(P-1 / 2)^{2}}
$$

onde

$$
P=O R /(1+O R)
$$

entendendo-se que:

$$
\begin{aligned}
& m=\text { número de pares discordantes } \\
& z_{a}=z \text { de alfa } \\
& z_{b}=z \text { de beta } \\
& R Q=\text { raiz quadrada } \\
& O R=\text { Odds ratio esperado ou suposto }
\end{aligned}
$$

O número total de pares é derivado da fórmula:

$$
M=\frac{m}{\left(p_{0} q_{1}+p_{1} q_{0}\right)}
$$

94. Baltazar JC. El potencial del método de casos y controles para las evaluaciones epidemiológicas rápidas. Boletln de la Oficina Sanitaria Panamericana 1994; $117(1): 4452$.

95. Schlesseiman JJ. Case-control studies. Design, conduct, analysis. New York: Oxford University Press, $1982: 161$.

96. Lemeshow S. Adequacy of sample size in health studies. New York: John Wiley \& Sons, 1990. Apud: Baltazar JC, Op. cit. (referencia 94): 47. 
onde

$$
\mathrm{p}_{1}=\frac{\mathrm{p}_{0} \mathrm{OR}}{1+\mathrm{p}_{0}(\mathrm{OR}-1)}
$$

entendendo-se que:

$\mathrm{M}=$ número total de pares

$p_{0}=$ proporção de expostos entre controles, que pode ser assumida por uma frequência conhecida para a população

$p_{1}=$ proporção de expostos entre casos

Quando mais de um grupo controle for considerado corrige-se o valor de " $\mathrm{M}$ " através da seguinte fórmula:

$$
n=\frac{(C+1) M}{2 C}
$$

onde

$$
\begin{aligned}
& n=\text { número corrigido para } \circ \text { total de pares } \\
& C=\text { número de grupos controle considerados }
\end{aligned}
$$

Estabelecendo-se um nivel de significância de $0,05\left(z_{a}=1,96\right)$ e um poder de $0,90\left(z_{b}=1,28\right)$, recorreu-se a informações de um estudo realizado no Estado de São Paulo ${ }^{97}$, onde encontrou-se que as doenças chiadoras representavam $26,87 \%$ da demanda (bronquite $15,68 \%$ e asma 11,19\%) e que dois cálculos de odds ratio para associação entre asma e pneumonia sugeriam as figuras de 3 e 4,98, respectivamente para demanda ambulatorial e registro de óbitos por múltiplas causas. Como estimativas para o estudo pode-se então arbitrar um odds ratio de 4 e uma frequência de doença chiadora entre controles da ordem de $15 \%$. À vista da recomendaçăo de se trabalhar com dois ou mais grupos controle ${ }^{98}$, o presente estudo se propos a estudar casos de pneumonia pareados a controles doentes por doença não respiratória e a controles sadios. Com esta estratégia pretendeu-se criar um conjunto de controles para comparação com casos que, formado por dois grupos de extrações distintas, tivesse

97 . Pereira JCR, Stuginsky LA, Miranda Ribeiro TV. Op. cit.(referência 12).

98. Ahlbom A, Norell S. Introduction to modern epidemiology. Chestnut Hill,MA: Epidemiology Resources Inc, 1990: 53. 
oportunidade de registrar a frequencia de exposição dentro de um espectro mais largo de categorização de controles. Procedendo-se aos cálculos para um estudo com 2 grupos controles conclui-se por uma amostra com 43 casos e respectivos controles (m $=25, M=57, n=43$ ).

Tomando em consideração as evidências de unanimidade na literatura quanto a considerável variação na frequência de asma em crianças de acordo com o sexo e a idade 99,100 , casos e controles foram pareados segundo estas variáveis. No pareamento, embora que com tolerância, buscou-se que a diferença de idade não fosse maior que 6 meses entre caso e controle para as crianças maiores de 2 anos, e que 3 meses entre de menores de 2 anos.

Os casos de pneumonia e os casos de outro diagnóstico foram identificados no pronto atendimento que se constitui porta de entrada do hospital, enquanto que os casos de crianças sadias foram buscados entre acompanhantes de pacientes. Foi condição de entrada no estudo que os casos fossem de pneumonia virgem de tratamento anterior e adquirida na comunidade. Todo diagnóstico de pneumonia teve comprovação radiológica. Foram candidatos a entrada no estudo todos os casos que preencheram estas condições após 0 inicio da coleta de dados em 14/03/94, que apresentaram-se ao hospital no periodo diurno e cujos pais ou acompanhantes responsáveis concordaram em responder à entrevista. Sempre que identificado um caso, o paciente seguinte de outro diagnóstico ou acompanhante sadio era recrutado para controle com consentimento dos pais ou responsáveis.

Responderam às entrevistas os acompanhantes das crianças, cujos vínculos de parentesco foram estabelecidos no questionário.

99. Dodge RR, Burrows B. The prevalence and incidence of asthma and asthma-like symptoms in a general population sample. Am Rev. Respir Dis 1980; 122:567-75.

100. Park ES, Golding J, Carswell F, Stewart-Brown S. Preschool wheezing and prognosis at 10. Arch Dis Child 1986; 61:642-6. 


\section{II.2 - DESCRIÇÃO DAS VARIÁVEIS ESTUDADAS E MÉTODOS DE ANÁLISE}

As informações sobre casos e controles foram registradas através da aplicação de dois protocolos de coleta de dados, cujas cópias são anexadas ao fim deste trabalho. A aplicação de cada questionário foi feita de forma independente pelas médicas designadas pelo Departamento de Pediatria do Hospital, a uma cabendo a investigação da presença de doença (pneumonia) e a outra a investigação de história de exposição (doença chiadora recorrente). As informações coletadas serviram tanto à análise do objeto de estudo quanto à aferição da consistência das conclusões clinicas. Cada uma das médicas, à luz das informações colhidas para o preenchimento do protocolo de sua responsabilidade e de sua própria anamnese e exame clínico, concluia sobre a presença de doença ou de exposição. Todas as informações coletadas foram objeto de análise univariada para identificar diferenças entre casos e controles. Variáveis categóricas foram comparadas pelo teste de Kruskal-Wallis ${ }^{101}$ e variáveis contínuas por análise de variância ${ }^{102}$ (ANOVA).

O diagnóstico de pneumonia, para além das impressões clínicas, foi ainda convalidado por exame radiológico em todos os casos. A ausência de imagem radiológica não exclui a presença de pneumonia, mas sua presença pode confirmar a hipótese diagnóstica e indicar a gravidade da infecção ${ }^{103}$. Além da conclusão do médico examinador, foram anotados dados de sintomas e sinais colhidos em anamnese e exame clínico de todos os pacientes estudados, independentemente de sua condição de caso ou controle (veja em anexo). Para validar a conclusão do clínico, além da análise univariada de cada dado coletado para casos e controles, procedeu-se a uma análise discriminante multivariada ${ }^{104}$ utilizando-se os sinais clínicos. Não se considerou a inclusão de sintomas à vista das informações de literatura que, pelo menos para asmáticos, sugerem que os pacientes tenham uma avaliação pobre de seus sintomas respiratórios ${ }^{105}$, o que é mais consistente ainda entre os pacientes mais graves $^{106}$. Considerou-se os seguintes sinais:

101. Siegel S, Castellan Jr NJ. Op. cit. (referência 16): 206-16.

102. Armitage P, Berry G. Op. cit. (referéncla.17): 186-93.

103. Hasse M, Berdal BP. Straume B et al.. Pneumonia - a clinical or radiographic diagnosis? Scand J Infect Dis 1992; 64755.

104. Hair JF Jr, Anderson RE, Tatham RL. Multivariate data analysis. New York: Macmillan Publishing Co., $1987: 73-114$.

105. Kendrick AH, Higgs CMB, Whitfield MJ, Laszlo G. Accuracy of perception of severity of asthma: patients treated in general practice. Br Med J 1993; 307: 422-4

106. Strunk RC, Mrazek DA, Fuhramann GSW, LaBrecque JF. Physiologic and psychological characteristics associated with death due to asthma in childhodd. JAMA 195; 254: 1193-8. 
AUSCULTA: variável categórica ordinal somando a eventual presença de estertores subcrepitantes, crepitantes e sopro brônquico;

RAIO X: variável categórica ordinal somando a eventual presença de condensação lobar ou segmentar, condensação intersticial ou alveolar, pneumatocele, atelectasia, derrame, hiperinsuflação e pneumotórax;

TEMPERATURA MEDIDA: como variável contínua;

FREQUÊNCIA RESPIRATÓRIA: como variável continua;

FREQUÊNCIA CARDÍACA: como variável continua;

TOXEMIA: como variável categórica ordinal com valores entre 0 e 4 (ausente a quatro cruzes);

DISPNÉIA: como variável categórica ordinal com valores entre 0 e 4 (ausente a quatro cruzes).

Para derivação das funções discriminantes utilizou-se uma amostra aleatória de $60 \%$ dos registros (analysis sample) e para validá-las os $40 \%$ de registros remanecentes (hold-out sample).

O diagnóstico de doença chiadora recorrente foi arbitrado pela médica examinadora, mas anotou-se informações que pudessem auxiliar a aferição desta conclusão, na forma de um questionário que, aplicado aos informantes tanto de casos como de controles na forma de uma anamnese dirigida, recolheu informações clínicas sugestivas da alteração funcional que deve caracterizar a doença chiadora recorrente (veja em anexo). Estabeleceu-se para fins de aferição posterior do diagnóstico médico, que seria adequado considerar expostos a doença chiadora recorrente todas as crianças que ou tivessem história de diagnóstico médico anterior de asma e pelo menos um episódio de chiado com dispnéia responsivo a medicação nos últimos 12 meses ou que tivessem história de chiado recorrente acompanhado de dispnéia que melhore com medicação e que tenha registrado pelo menos 2 episódios nos últimos 12 meses.

Julgou-se também pertinente ter medida a repitibilidade das informações coletadas por questionário. Estabeleceu-se que pelo menos $20 \%$ dos questionários deveriam ser repetidos numa amostra aleatória. Os informantes foram convocados para repetição da entrevista através de visitas domiciliares e receberam subsidio financeiro para ressarcir despesas de transporte. A nova entrevista foi realizada pelo mesmo observador, a médica encarregada da investigação de exposição, com o mesmo informante. 
A repitibilidade das informações foi avaliada através do cálculo das frequências de concordância observada e esperada, do indice de concordância Kappa ${ }^{107}$ e dos coeficientes de correlação de Pearson ${ }^{103}$ e Spearman ${ }^{109}$. Para aferir o nivel geral de concordância todas as variáveis foram reduzidas ... mesma unidade de medida como diferenças padronizadas da média e foram agrupadas numa única variável representando a média de todas as medidas. Esta variável teve suas medidas comparadas para a primeira e segunda entrevista da mesma forma que cada variável original individualmente: concordância observada e esperada, Kappa e coeficientes de correlação.

Além das duas principais variáveis correspondendo ao diagnóstico de doença e exposição, o estudo tomou ainda em consideração variáveis de informação complementar que pudessem ser importantes na caracterização da homogeneidade $/$ heterogeneidade de casos e controles bem como que pudessem representar fator de confusão na análise da relação entre doença e exposição.

Casos e controles foram caracterizados quanto a situação socioeconômica através de diferentes informações sobre as condições de moradia, composição da familia, nivel educacional, nivel salarial e acesso a serviços de saúde. Interessa conhecer a homogeneidade de casos e controles em relação a estas variáveis e eventualmente, na presença de heterogeneidade, controlar seus possiveis efeitos sobre a relação doença / exposição investigada.

Como variáveis com possivel interferência na relação entre doença e exposição, anotou-se os antecedentes pessoais relativos a doenças atópicas ou com possivel relação com atopia (eczema, rinite alérgica, laringite estridulosa, laringotraqueobronquite, sinusite, otite), doenças respiratórias que podem causar danos funcionais de longo prazo (sarampo, coqueluche, tuberculose, bronquiolite) e ocorrência de pneumonias anteriores. Cada uma destas condições corresponderam a duas variáveis distintas, uma binomial assinalando a presença ou não de história positiva e outra registrando o número de episódios nos últimos 12 meses. Com relação a história anterior de pneumonia, anotou-se o número de pneumonias anteriores, a idade em que ocorreram e as condiçōes de tratamento (ambulatorial ou hospitalar). Anotou-se também antecedentes familiares de asma e atopia em parentes de primeiro grau.

107. Siegel S, Castellan Jr NJ. Op. cit. (referência 16): 284-91

108. Woodward M, Francis LMA. Statistics for health management and research. London: Edward Arnold 1988; 196-203 109. Siegel S, Castellan Jr NJ. Op. cit. (referência 16): 235-244. 
Ainda como variáveis de informação complementar foram consideradas informaçōes relativas ao meio ambiente a que estivessem expostos os pacientes, uma vez que poluição ambiental pode sabidamente afetar tanto a doença estudada (pneumonia) quanto o fator de exposição investigado (doença chiadora) ${ }^{110}, 111,112$. Registrou-se o número de pessoas dormindo no quarto que a criança, o número de tabagistas na familia, o uso de fogões com combustiveis que exalam gases ou fumaça, a eventual falta de insolação do quarto da criança, a presença de umidade na casa e a eventual proximidade da casa com fábrica que libere gases, odores ou fumaça. Todas estas variáveis foram anotadas como binomiais (sim ou não) e a informação colhida através de exaustiva exploração de cada item de forma a garantir perfeito entendimento, a exemplo da coleta de informações clínicas onde o resultado da informação não é uma simples resposta a pergunta.

Para avaliar os efeitos da exposição a doença chiadora recorrente sobre a presença de pneumonia com controle para todas as possiveis variáveis de confusão, optou-se pela análise por regressão logística, na forma que é largamente descrita por Schlesselman ${ }^{113}$ em seu livro dedicado aos estudos caso-controle. A comparação entre casos e controles foi feita contrastando-se os primeiros aos dois grupos controles reunidos em um único. Com esta estratégia procurou-se oferecer ao grupo controle um largo espectro para observação da ocorrência de exposição e outros fatores que pudessem vir a ser identificados como relevantes à relação estudada. Além do fator de exposição, doença chiadora recorrente, foram consideradas para o modelo logístico todas as variáveis de informação complementar que na análise univariada apresentaram diferenças significativas entre casos e controles. As variáveis relativas a atopia e asma como antecedente pessoal ou familiar e aquelas relativas a poluição ambiental foram de antemão consideradas para análise. A equação matemática do modelo logístico tem a seguinte fórmula:

$$
\operatorname{Lg} O R=B_{0}+B_{1} X_{1}+B_{2} X_{2}+\ldots+B_{n} X_{n}
$$

110. Ware JH, Dockery DW, Spiro A et al.. Passive smoking, gas cooking and respiratory health of children living in six cities. Am Rev Respir Dis 1984; 129: 366-74.

111. Burchfiel CM, Higgins MW, Keller JB et al..Passive smoking in childhood: respiratatory conditions and pulmonary function In Tecunseh, Michigan. Am Rev Respir Dis 1986; 133: 966-73.

112. Willers S, Svenonius E, Skarping G. Passive smoking and childhood asthma: urinary cotinine levels in children with asthma and In referents. Allergy 1991; 46: 330-4.

113. Schlesselman JJ. Multivariate analysis. In: Schlesselman JJ, Op. cit. (referéncia 95): 227-90 
onde:

Lg OR - é o logaritmo natural do "odds ratio", ou o logit da probabilidade de doença;

$B_{0}$ - é uma constante

$B_{1} . . B_{n}$ - são os coeficientes de regressão

$X_{1} . . X_{n}$ - são as variáveis independentes (exposição e outras)

Como se pode entender da fórmula acima, o crescimento de uma variável entrando na equação representa acréscimo geométrico de risco e a presença de mais de uma variável no modelo resulta em efeito multiplicativo para o risco final. Para cada variável, obtém-se não só seu coeficiente de regressão mas também seu erro padrão, de forma que se pode medir não apenas o "odds ratio", mas também seu intervalo de confiança.

Enquanto o "odds ratio" mede a associação entre duas variáveis, um outro indice, o risco atribuivel ${ }^{114}, 115$, mede a diferença de frequência entre expostos e não expostos sugerindo o impacto que teria o controle da exposição sobre a frequência da doença. $\dot{E}$ premissa para sua interpretação que a amostra estudada seja representativa da população a que se refira, ou seja que a frequência de exposição entre casos e controles seja semelhante a sua frequência entre portadores e não portadores da doença estudada na população. No presente estudo o risco atribuivel será calculado como forma de máxima exploração da relação pesquisada entre pneumonia e doença chiadora, mas sua interpretação terá os limites da população de referência do estudo, ou seja a população de pacientes do Hospital Universitário. 114. Almeida Fo. N, Rouquayrol MZ. Introduçăo à epidemiologia moderna. Rio de Janeiro: COOPMED Editora, 1992: $106-$
109.

115. Armitage P, Berry G. Op. cit. (referência 17): 469-72. 
III. RESULTADOS 


\section{III.1 - CARACTERIZAÇÃO DA AMOSTRA ESTUDADA}

No periodo entre 14/03/94 e 02/08/94 foram examinadas 153 crianças com idades entre um mês e sete anos (idade média de 2 anos): 51 casos de pneumonia, 51 controles portadores de doença não respiratória e 51 controles sadios. O pareamento por sexo foi perfeito e o pareamento por idade registrou, para a faixa etária de menores de 2 anos, uma diferença máxima de 4,27 meses (média de 2,00) entre casos e controles não respiratórios e de 4,53 meses (média de 1,87) entre casos e controles sadios. Para a faixa etária de maiores de 2 anos a diferença máxima de idade entre casos e controles não respiratórios foi de 7,93 meses (média de 3,89 ) e entre casos e controles sadios de 10,83 meses (média de 3,85 ). Entre os controles menores de 2 anos 75\% tiveram uma diferença de idade inferior a 3 meses e entre os controles maiores de 2 anos $80 \%$ tiveram tal diferença inferior a 6 meses. Não houve diferença de idade estatisticamente significante entre os grupos (ao nivel de $p<, 05)$, como sugere a Tabela IV.

TABELA IV - AFERIÇÃO DO PAREAMENTO ENTRE CASOS E CONTROLES: DADE MÉDIA E ERRO PADRÃO SEGUNDO O SEXO E A CLASSIFICAÇÃO

\begin{tabular}{|c|c|c|c|c|}
\hline \multirow[t]{3}{*}{ CLASSIFICAÇĀO } & \multicolumn{4}{|c|}{ SEXO DO PACIENTE } \\
\hline & \multicolumn{2}{|c|}{ MASCULINO } & \multicolumn{2}{|c|}{ FEMININO } \\
\hline & Média & Erro Padrão & Média & Erro Padrão \\
\hline CASO $\ldots \ldots \ldots \ldots \ldots$ & 18,09 & 3,47 & 28,12 & 3,73 \\
\hline CONTROLE NĀO PN........ & 18,42 & 3,40 & 28,90 & 3,85 \\
\hline CONTROLE SADIO......... & 17,99 & 3,54 & 27,63 & 3,75 \\
\hline TOTAL............... & 18,16 & 1,98 & 28,22 & 2,15 \\
\hline
\end{tabular}

As informações sobre os pacientes foram obtidas através da mãe (86,90\% dos pacientes), do pai $(7,20 \%)$, de avó $(2,60 \%)$, de tia $(2,60 \%)$ ou de irmã $(0,70 \%$, um único paciente). Na amostra estudada houve predomínio discreto de meninas e 
expressivo da raça branca, como mostra a Tabela V. Entre casos e controles as diferenças de raça analisadas por teste não paramétrico de análise de variância (Kruskal-Wallis) não revelou expressão estatística significante ao nivel de $5 \%\left(X^{2}=\right.$ $2,27, p=, 32)$.

$\begin{array}{ll}\text { TABELA V - } & \text { DISTRIBUIÇĀO DE GẼNERO } \\ \text { CLASSIFICAÇĀO DO PACIENTE }\end{array} \quad$ RAÇA SEGUNDO A

\begin{tabular}{|c|c|c|c|c|}
\hline \multirow[t]{2}{*}{ VARIAVEIS : } & \multicolumn{3}{|c|}{ CLASSIFICAÇĀO } & \multirow{2}{*}{ TOTAL } \\
\hline & CASO & $\begin{array}{l}\text { CONTROLE } \\
\text { NÄO PN }\end{array}$ & $\begin{array}{c}\text { CONTROLE } \\
\text { SADIO }\end{array}$ & \\
\hline
\end{tabular}

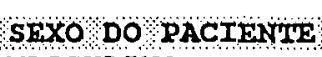

MASCULINO

Frequência absoluta..

Frequencia relativa..

24

24

47,18

24

47,18

72

FEMININO

Frequência absoluta..

27

Frequência relativa..

52,98

27

27

81

TOTAI

Frequência absoluta..

51

51

51

153

RAÇA DO PACIENTE

BRANCO

Frequência absoluta..

Frequência relativa..

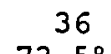

73,58

42

36

114

NEGRO

$\begin{array}{ccccc}\text { Frequência absoluta.. } & 3 & 2 & 7 & 12 \\ \text { Frequência relativa.. } & 6,18 & 4,08 & 13,78 & 8,08\end{array}$

AMARELO

Frequência absoluta..

6,18

4,08

8,08

Frequência relativa..

0

0

2
3,98

2,38

MULATO

Frequência absoluta.:

10
20,48

$12, \stackrel{6}{08}$

11,8

22

Frequência relativa..

12,08

$\begin{array}{cc}2 & 1 \\ 48 & 2,08\end{array}$

0

14,78

SEM INFORMAÇÃO

Frequência absoluta..

Frequência relativa..

, 08

2,3

TOTAL

Frequência absoluta. .

51

51

51

153

- Frequếncia relativa calculada sobre casos válidos *

Entre os controles não respiratórios, a doença mais frequente foi a diarréia, como mostra a Tabela VI. 
TABELA VI - DIAGNÓSTICOS REALIZADOS PARA OS CONTROLES NĀO RESPIRATÓRIOS

\begin{tabular}{|c|c|c|}
\hline DIAGNÓSTICO & absoluta & Frequência relativa \\
\hline DIARREIA $\ldots \ldots \ldots \ldots \ldots \ldots \ldots \ldots \ldots \ldots \ldots \ldots \ldots$ & 27 & 52,948 \\
\hline ACIDENTES \& TRAUMATISMOS $\ldots \ldots \ldots$ & 5 & 9,808 \\
\hline OTITE (sem IVAS associada) ...... & 2 & 3,928 \\
\hline MENINGITE $\ldots \ldots \ldots \ldots \ldots \ldots \ldots$ & 2 & 3,928 \\
\hline ARTROPATIA $\ldots \ldots \ldots \ldots \ldots \ldots$ & 2 & 3,928 \\
\hline ABCESSO DENTARIO $\ldots \ldots \ldots \ldots \ldots$ & 1. & 1,968 \\
\hline ABDOME AGUDO $\ldots \ldots \ldots \ldots \ldots \ldots$ & 1 & 1,968 \\
\hline ADENITE $\ldots \ldots \ldots \ldots \ldots \ldots \ldots$ & 1 & 1,968 \\
\hline ANEMIA+ICTERICIA $\ldots \ldots \ldots \ldots \ldots$ & 1 & 1,968 \\
\hline CRISE CONVULSIVA ........... & 1 & 1,968 \\
\hline FEBRE A ESCLARECER $\ldots \ldots \ldots \ldots$ & 1 & 1,968 \\
\hline HIPERTENSÃO + HI PERALDOSTERONISMO. & 1 & 1,968 \\
\hline HIPERTROFIA DE AMIGDALA ........ & 1 & 1,968 \\
\hline ICC + CARDIOPATIA A ESCLARECER $\ldots$ & 1 & 1,968 \\
\hline PAROTIDITE $\ldots \ldots \ldots \ldots \ldots \ldots \ldots$ & 1 & 1,968 \\
\hline PETÉQUIAS $\ldots \ldots \ldots \ldots \ldots \ldots \ldots$ & 1 & 1,968 \\
\hline PURPURA $\ldots \ldots \ldots \ldots \ldots \ldots \ldots$ & 1 & 1,968 \\
\hline vôMITos $\ldots \ldots \ldots \ldots \ldots \ldots \ldots \ldots$ & 1 & 1,968 \\
\hline TOTAL & 51 & 100,008 \\
\hline
\end{tabular}




\section{III.2 - CARACTERIZAÇÃO SOCIAL E ECONÔMICA DE CASOS E CONTROLES}

A Tabela VIl oferece descrição das condições de habitação das crianças estudadas. São significantes as diferenças na composição da moradia (individual ou coletiva $-X^{2}=7,13, p=, 02$ ) e na localização do banheiro (não tem, dentro de casa ou fora de casa $-X^{2}=13,79 p=, 00$ ), sendo que para ambas as variáveis controles sadios distinguem-se de casos e controles não respiratórios que, no entanto, não diferem entre si. TABELA VII - CONDIÇÕES DE MORADIA SEGUNDO A CLASSIFICAÇÃO DO
PACIENTE

\begin{tabular}{|c|c|c|c|c|}
\hline \multirow[t]{2}{*}{ VARIAVEIS: } & \multicolumn{3}{|c|}{ CLASSIFICAÇÃO } & \multirow[t]{2}{*}{ TOTAL } \\
\hline & CASO & $\begin{array}{l}\text { CONTROLE } \\
\text { NAO PN }\end{array}$ & $\begin{array}{l}\text { CONTROIE } \\
\text { SADIO }\end{array}$ & \\
\hline \multirow{2}{*}{\multicolumn{5}{|c|}{$\begin{array}{l}\text { COMPOSIÇÃO MORADIA } \\
\text { SO A FAMIIIA }\end{array}$}} \\
\hline & & & & \\
\hline $\begin{array}{l}\text { Frequência absoluta.. } \\
\text { Frequência relativa.. }\end{array}$ & $\begin{array}{c}43 \\
84,38\end{array}$ & $\begin{array}{r}42 \\
82,48\end{array}$ & $\begin{array}{l}50 \\
98,08\end{array}$ & $\begin{array}{c}135 \\
88,28\end{array}$ \\
\hline \multicolumn{5}{|l|}{ COLETIVA } \\
\hline $\begin{array}{l}\text { Frequência absoluta.. } \\
\text { Frequência relativa.. }\end{array}$ & $\begin{array}{c}8 \\
15,78\end{array}$ & $\begin{array}{c}9 \\
17,68\end{array}$ & 2,08 & $\begin{array}{c}18 \\
11,88\end{array}$ \\
\hline \multicolumn{5}{|l|}{ II PO NORADIA } \\
\hline \multicolumn{5}{|l|}{ PROPRIA } \\
\hline $\begin{array}{l}\text { Frequência absoluta.. } \\
\text { Frequência relativa.. }\end{array}$ & $\begin{array}{c}27 \\
52,98\end{array}$ & $\begin{array}{r}24 \\
47,18\end{array}$ & $\begin{array}{c}29 \\
56,98\end{array}$ & $\begin{array}{c}80 \\
52,38\end{array}$ \\
\hline \multicolumn{5}{|l|}{ ALUGADA } \\
\hline $\begin{array}{l}\text { Frequência absoluta. } \\
\text { Frequencia relativa.. }\end{array}$ & $\begin{array}{c}10 \\
19,68\end{array}$ & $\begin{array}{c}13 \\
25,58\end{array}$ & $\begin{array}{c}13 \\
25,58\end{array}$ & $\begin{array}{c}36 \\
23,58\end{array}$ \\
\hline \multicolumn{5}{|l|}{ CEDIDA } \\
\hline $\begin{array}{l}\text { Frequência absoluta.. } \\
\text { Frequência relativa.. }\end{array}$ & 27,58 & $\begin{array}{c}14 \\
27,58\end{array}$ & $\begin{array}{c}9 \\
17,68\end{array}$ & $\begin{array}{c}37 \\
24,28\end{array}$ \\
\hline \multicolumn{5}{|l|}{ TIPO DE CONS TRUCCAO } \\
\hline \multicolumn{5}{|l|}{ ALVENARIA } \\
\hline $\begin{array}{l}\text { Frequência absoluta.. } \\
\text { Frequência relativa.. }\end{array}$ & $\begin{array}{c}38 \\
74,58\end{array}$ & $\begin{array}{c}40 \\
80,08\end{array}$ & $\begin{array}{c}46 \\
90,28\end{array}$ & $\begin{array}{l}124 \\
81,68\end{array}$ \\
\hline \multicolumn{5}{|l|}{ MADEIRA } \\
\hline $\begin{array}{l}\text { Frequência absoluta.. } \\
\text { Frequência relativa.. }\end{array}$ & $\begin{array}{c}13 \\
25,58\end{array}$ & $\begin{array}{c}8 \\
16,08\end{array}$ & $\begin{array}{c}5 \\
9,88\end{array}$ & $\begin{array}{c}26 \\
17,18\end{array}$ \\
\hline $\begin{array}{l}\text { TIJOLO E MADEIRA } \\
\text { Frequência absoluta.. } \\
\text { Frequência relativa.. }\end{array}$ & $\begin{array}{l}0 \\
, 08\end{array}$ & $\begin{array}{c}2 \\
4,08\end{array}$ & $\begin{array}{l}0 \\
, 08\end{array}$ & $\begin{array}{c}2 \\
1,38\end{array}$ \\
\hline $\begin{array}{l}\text { SEM INFORMAÇÃo } \\
\text { Frequência absoluta.. } \\
\text { Frequencia relativa.. }\end{array}$ & $\begin{array}{l}0 \\
, 08\end{array}$ & $\begin{array}{c}1 \\
2,08\end{array}$ & $\begin{array}{l}0 \\
.08\end{array}$ & $\begin{array}{l}1 \\
, 78\end{array}$ \\
\hline
\end{tabular}


Conlĩnuação

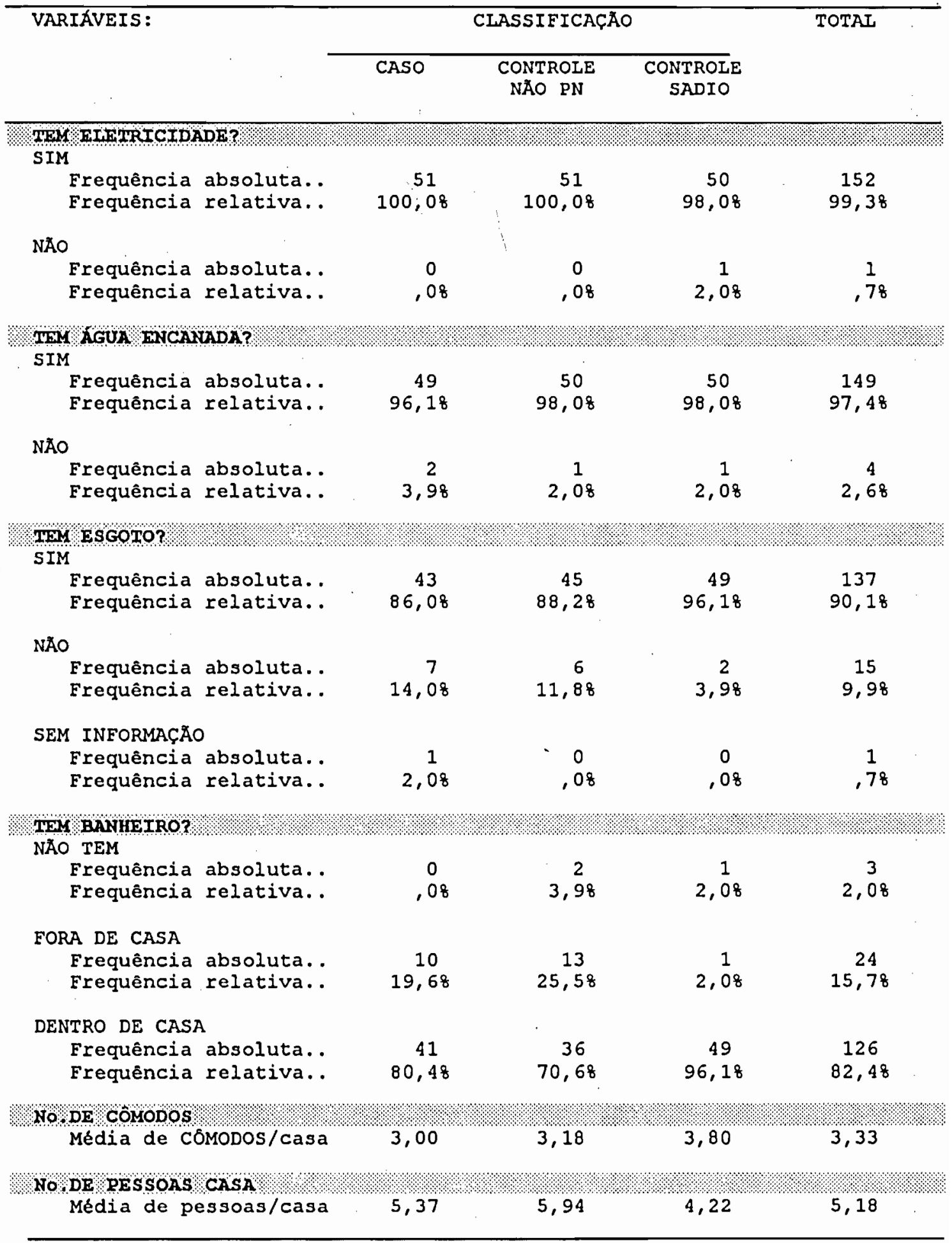

* Frequéncla relativa calculada sobre casos válidos * 
A Tabela VIII descreve a composição das familias. Em relação às faixas etárias das pessoas das familias, os controles diferem entre si para pessoas maiores de 5 anos (faixa de $>5$ a 15 anos, $F=2,21, p=, 11$; faixa de adultos, $F=2,27, p=$ ,10), mas não têm diferença significante em relação aos casos quando tomados individualmente. Há diferença significante tambẻm em relação à renda familiar ( $F=$ $12,93, p=, 00$ ); onde os controles sadios distinguem-se tanto de casos quanto de controles não respiratórios, os quais, no entanto, não diferem entre si. O nivel de escolaridade de pai e mãe também difere significativamente entre casos e controles $\left(X^{2}=31,60, p=, 00\right.$ e $X^{2}=31,18, p=, 00$, respectivamente), sendo responsáveis pela diferença os controles sadios que mostram uma posição melhor em relação aos casos e controles năo respiratórios os quais, no entanto, não diferem entre si.

\section{TABELA VIII - COMPOSIÇÃO DA FAMÍLIA SEGUNDO A CLASSIFICAÇÃO DO PACIENTE}

\begin{tabular}{|c|c|c|c|c|}
\hline \multirow[t]{2}{*}{ VARIAVEIS: } & \multicolumn{3}{|c|}{ CLASSIFICAÇAO } & \multirow[t]{2}{*}{ TOTAL } \\
\hline & CASO & $\begin{array}{l}\text { CONTROLE } \\
\text { NÄO PN }\end{array}$ & $\begin{array}{l}\text { CONTROIE } \\
\text { SADIO }\end{array}$ & \\
\hline \multicolumn{5}{|l|}{$\begin{array}{l}\text { FATXA ETARTA DAS PESSOAS } \\
\text { CRIANCCAS ATE I } 5 \text { ANOS }\end{array}$} \\
\hline 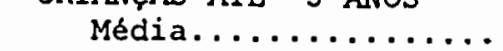 & 1,67 & 1,59 & 1,51 & 1,59 \\
\hline Erro padrão......... &, 11 &, 10 & .09 & $\begin{array}{r}1,09 \\
.06\end{array}$ \\
\hline \multicolumn{5}{|l|}{ CRIANÇAS >5 ATE ' 15 ANOS } \\
\hline Média............... &, 71 &, 80 & 47 & 66 \\
\hline Erro padrå......... &, 11 &, 12 & 11 &, 07 \\
\hline \multicolumn{5}{|l|}{ ADULTOS } \\
\hline Média............ & 2,22 & 2,61 & 2,12 & 2,31 \\
\hline Erro padrão......... &, 16 &, 23 &, 10 & .10 \\
\hline \multicolumn{5}{|l|}{ Mo pEs SOAS O MRABALHAM } \\
\hline Média............. & 1,41 & 1,61 & 1,63 & 1,55 \\
\hline Erro padrå......... & .12 & .16 &, 10 &, 07 \\
\hline \multicolumn{4}{|c|}{ 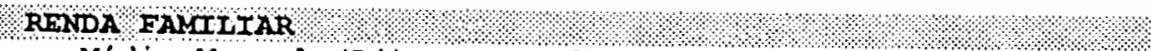 } & ঋঝ \\
\hline Média Mensal (Rs).... & 269,15 & 341,52 & 952,40 & 543,01 \\
\hline Erro padrão.......... & 42,43 & 46,73 & 158,43 & 68,16 \\
\hline \multirow{2}{*}{\multicolumn{5}{|c|}{$\begin{array}{l}\text { EDUCAGÄO DO DAT } \\
\text { ANALFABETO }\end{array}$}} \\
\hline & & & & \\
\hline \multirow{2}{*}{$\begin{array}{l}\text { Frequência absoluta.. } \\
\text { Frequência relativa.. }\end{array}$} & 10 & 6 & 1 & 17 \\
\hline & 21,78 & 13,38 & 2,18 & 12,28 \\
\hline \multicolumn{5}{|l|}{ 10.GRAU INCOMPLETO } \\
\hline Frequência absoluta.. & 26 & 26 & 13 & 65 \\
\hline Frequência relativa.. & 56,58 & 57,88 & 27,18 & 46,88 \\
\hline \multicolumn{5}{|l|}{ 10.GRAU COMPLETO } \\
\hline $\begin{array}{l}\text { Frequência absoluta.. } \\
\text { Frequência relativa }\end{array}$ & $\begin{array}{l}3 \\
58\end{array}$ & $\begin{array}{l}5 \\
10\end{array}$ & $\frac{18}{9}$ & 17 \\
\hline & & & & \\
\hline
\end{tabular}


Continuaçào

\begin{tabular}{|c|c|c|c|c|}
\hline \multirow[t]{2}{*}{ VARIAVEIS: } & \multicolumn{3}{|c|}{ CLASSIFICAÇĀO } & \multirow[t]{2}{*}{ TOTAL } \\
\hline & CASO & $\begin{array}{l}\text { CONTROLE } \\
\text { NÃO PN }\end{array}$ & $\begin{array}{l}\text { CONTROLE } \\
\text { SADIO }\end{array}$ & \\
\hline \multicolumn{5}{|l|}{ EPDOCAÇATO DO PAT } \\
\hline \multicolumn{5}{|l|}{ 20.GRAU INCOMPLETO } \\
\hline $\begin{array}{l}\text { Frequência absoluta.. } \\
\text { Frequência relativa.. }\end{array}$ & $\begin{array}{c}3 \\
6,58\end{array}$ & $\begin{array}{c}2 \\
4,48\end{array}$ & $\begin{array}{c}2 \\
4,28\end{array}$ & $\begin{array}{c}7 \\
5,08\end{array}$ \\
\hline \multicolumn{5}{|l|}{ 20.GRAU COMPLETO } \\
\hline $\begin{array}{l}\text { Frequência absoluta.. } \\
\text { Frequência relativa.. }\end{array}$ & $\begin{array}{c}2 \\
4,38\end{array}$ & $\begin{array}{c}4 \\
8,98\end{array}$ & $\begin{array}{c}9 \\
18,88\end{array}$ & $\begin{array}{c}15 \\
10,88\end{array}$ \\
\hline \multicolumn{5}{|l|}{ SUPERIOR INCOMPLETO } \\
\hline $\begin{array}{l}\text { Frequencia absoluta.. } \\
\text { Frequência relativa.. }\end{array}$ & 2,28 & 2,28 & $\begin{array}{c}4 \\
8,38\end{array}$ & $\begin{array}{c}6 \\
4,38\end{array}$ \\
\hline \multicolumn{5}{|l|}{ SUPERIOR COMPLETO } \\
\hline $\begin{array}{l}\text { Frequência absoluta.. } \\
\text { Frequência relativa.. }\end{array}$ & 2,28 & 2,28 & $\begin{array}{c}10 \\
20,88\end{array}$ & $\begin{array}{l}12 \\
8,68\end{array}$ \\
\hline \multicolumn{5}{|l|}{ SEM INEORMAÇĀO } \\
\hline $\begin{array}{l}\text { Frequência absoluta.. } \\
\text { Frequência relativa.. }\end{array}$ & $\begin{array}{c}5 \\
10,98\end{array}$ & 13,38 & $\begin{array}{c}3 \\
6,38\end{array}$ & 10,18 \\
\hline \multirow{2}{*}{\multicolumn{5}{|c|}{ অ BDUCACAO DA WAE $/ \%$ \% }} \\
\hline \multicolumn{3}{|c|}{ ANALFABETO } & & \\
\hline $\begin{array}{l}\text { Frequência absoluta.. } \\
\text { Frequência relativa.. }\end{array}$ & 23,58 & $\begin{array}{c}7 \\
14,08\end{array}$ & $\begin{array}{c}3 \\
5,98\end{array}$ & $\begin{array}{c}22 \\
14,58\end{array}$ \\
\hline \multicolumn{5}{|l|}{ 10.GRAU INCOMPLETO } \\
\hline $\begin{array}{l}\text { Frequência absoluta.. } \\
\text { Frequência relativa.. }\end{array}$ & $\begin{array}{c}29 \\
56,98\end{array}$ & $\begin{array}{c}28 \\
56,08\end{array}$ & $\begin{array}{c}13 \\
25,58\end{array}$ & $\begin{array}{c}70 \\
46,18\end{array}$ \\
\hline \multicolumn{5}{|l|}{ 10.GRAU COMPLETO } \\
\hline $\begin{array}{l}\text { Frequência absoluta.. } \\
\text { Frequência relativa.. }\end{array}$ & $\begin{array}{c}2 \\
3,98\end{array}$ & $\begin{array}{c}7 \\
14,08\end{array}$ & $\begin{array}{c}7 \\
13,78\end{array}$ & $\begin{array}{c}16 \\
10,58\end{array}$ \\
\hline \multicolumn{5}{|l|}{ 20.GRAU INCOMPLETO } \\
\hline $\begin{array}{l}\text { Frequência absoluta.. } \\
\text { Frequência relativa.. }\end{array}$ & $\begin{array}{c}2 \\
3,98\end{array}$ & $\begin{array}{c}3 \\
6,08\end{array}$ & $\begin{array}{c}5 \\
9,88\end{array}$ & $\begin{array}{c}10 \\
6,68\end{array}$ \\
\hline \multicolumn{5}{|l|}{ 20.GRAU COMPLETO } \\
\hline $\begin{array}{l}\text { Frequencia absoluta.. } \\
\text { Frequência relativa.. }\end{array}$ & $\begin{array}{c}5 \\
9,88\end{array}$ & $\begin{array}{c}3 \\
6,08\end{array}$ & $\begin{array}{c}6 \\
11,88\end{array}$ & $\begin{array}{l}14 \\
9,28\end{array}$ \\
\hline \multicolumn{5}{|l|}{ SUPERIOR INCOMPLETO } \\
\hline $\begin{array}{l}\text { Frequencia absoluta.. } \\
\text { Frequência relativa.. }\end{array}$ & $\begin{array}{l}0 \\
, 08\end{array}$ & $\begin{array}{c}1 \\
2,08\end{array}$ & $\begin{array}{c}4 \\
7,88\end{array}$ & $\begin{array}{c}5 \\
3,38\end{array}$ \\
\hline \multicolumn{5}{|l|}{ SUPERIOR COMPLETO } \\
\hline $\begin{array}{l}\text { Frequência absoluta.. } \\
\text { Frequência relativa.. }\end{array}$ & $\begin{array}{c}1 \\
2,08\end{array}$ & $\begin{array}{c}1 \\
2,08\end{array}$ & $\begin{array}{c}13 \\
25,58\end{array}$ & $\begin{array}{c}15 \\
9,98\end{array}$ \\
\hline $\begin{array}{l}\text { SEM INFORMAÇÃo } \\
\text { Frequência absoluta.. } \\
\text { Frequência relativa.. }\end{array}$ & $\begin{array}{c}0 \\
, 08\end{array}$ & $\begin{array}{c}1 \\
2,08\end{array}$ & $\begin{array}{c}0 \\
.08\end{array}$ & $\begin{array}{l}1 \\
.78\end{array}$ \\
\hline
\end{tabular}

* Frequêncla relativa calculada sobre casos válidos * 
As Tabelas IX e $X$ mostram o padrão de utilização de serviços de saúde por casos e controles. A igualdade de oportunidades de acesso fica demonstrada na semelhança de comportamentos de busca de serviços médicos, não se registrando diferenças estatisticamente significantes nas escolhas de primeira, segunda e terceira opçōes $\left(X^{2}=3,78, p=, 15 ; X^{2}=3,19, p=, 20 ; X^{2}=3,42, p=, 18\right.$, respectivamente). No entanto, pode-se notar que os controles sadios, de forma compativel com as diferenças de renda familiar observadas, tendem a utilizar menos o Hospital Universitário e mais os serviços privados (Tabela X).

TABELAIX - OPÇÕES POR SERVIÇOS DE SAÚDE SEGUNDO A CLASSIFICAÇÃO DO PACIENTE

\begin{tabular}{|c|c|c|c|c|}
\hline \multirow{2}{*}{ VARIAVEIS: } & \multicolumn{3}{|c|}{ CLASSIFICAÇĀO } & \multirow{2}{*}{ TOTAL } \\
\hline & CASO & $\begin{array}{c}\text { CONTROLE } \\
\text { NAOO PN }\end{array}$ & $\begin{array}{c}\text { CONTROLE } \\
\text { SADIO }\end{array}$ & \\
\hline \multicolumn{5}{|l|}{ 1a OPCÃO ATD MÉDICO } \\
\hline $\begin{array}{l}\text { HOSPITAL UNIVERSITARIO } \\
\text { Frequência absoluta.. } \\
\text { Frequência relativa.. }\end{array}$ & $\begin{array}{c}21 \\
41,28\end{array}$ & $\begin{array}{c}27 \\
52,98\end{array}$ & $\begin{array}{c}23 \\
45,18\end{array}$ & $\begin{array}{c}71 \\
46,48\end{array}$ \\
\hline $\begin{array}{l}\text { REDE PUBL/CONVENIADA SUS } \\
\text { Frequência absoluta.. } \\
\text { Frequência relativa.. }\end{array}$ & $\begin{array}{c}28 \\
54,98\end{array}$ & $\begin{array}{c}24 \\
47,18\end{array}$ & $\begin{array}{c}16 \\
31,48\end{array}$ & $\begin{array}{c}68 \\
44,48\end{array}$ \\
\hline $\begin{array}{c}\text { CONVENIO PROPRIO/EMPRESA } \\
\text { Frequência absoluta.. } \\
\text { Frequência relativa.. }\end{array}$ & $\begin{array}{c}2 \\
3,98\end{array}$ & $\begin{array}{l}0 \\
, 08\end{array}$ & $\begin{array}{c}7 \\
13,78\end{array}$ & $\begin{array}{c}9 \\
5,98\end{array}$ \\
\hline $\begin{array}{l}\text { SERVIÇO PRIVADO } \\
\text { Frequência absoluta.. } \\
\text { Frequência relativa.. }\end{array}$ & $\begin{array}{l}0 \\
, 08\end{array}$ & $\begin{array}{l}0 \\
, 08\end{array}$ & $\begin{array}{c}5 \\
9,88\end{array}$ & $\begin{array}{c}5 \\
3,38\end{array}$ \\
\hline
\end{tabular}


Continuaçao

\begin{tabular}{|c|c|c|c|c|}
\hline \multirow[t]{2}{*}{ VARIAVEIS: } & \multicolumn{3}{|c|}{ CIASSIFICAÇÃO } & \multirow[t]{2}{*}{ TOTAL } \\
\hline & CASO & $\begin{array}{l}\text { CONTROLE } \\
\text { NÄO PN }\end{array}$ & $\begin{array}{l}\text { CONTROLE } \\
\text { SADIO }\end{array}$ & \\
\hline \multicolumn{5}{|l|}{2 a OPCAO ATD YÉDICO $/$} \\
\hline \multicolumn{5}{|l|}{ HOSPITAI UNIVERSITARIO } \\
\hline $\begin{array}{l}\text { Frequência absoluta.. } \\
\text { Frequência relativa.. }\end{array}$ & $\begin{array}{c}18 \\
36,78\end{array}$ & $\begin{array}{c}11 \\
22,08\end{array}$ & $\begin{array}{c}14 \\
28,08\end{array}$ & $\begin{array}{c}43 \\
28,98\end{array}$ \\
\hline \multicolumn{5}{|l|}{ REDE PUBL/CONVENIADA SUS } \\
\hline $\begin{array}{l}\text { Frequencia absoluta.. } \\
\text { Frequencia relativa.. }\end{array}$ & $\begin{array}{c}28 \\
57,18\end{array}$ & $\begin{array}{c}39 \\
78,08\end{array}$ & $\begin{array}{c}26 \\
52,08\end{array}$ & $\begin{array}{c}93 \\
62,48\end{array}$ \\
\hline \multicolumn{5}{|l|}{ CONVENIO PROPRIO/EMPRESA } \\
\hline $\begin{array}{l}\text { Frequencia absoluta.. } \\
\text { Frequência relativa.. }\end{array}$ & $\begin{array}{c}2 \\
4,18\end{array}$ & $\begin{array}{l}0 \\
, 08\end{array}$ & $\begin{array}{c}7 \\
14,08\end{array}$ & $\begin{array}{c}9 \\
6,08\end{array}$ \\
\hline \multicolumn{5}{|l|}{ SERVIÇO PRIVADO } \\
\hline Frequência absoluta.. & 1 & 0 & 3 & 4 \\
\hline Frequência relativa.. & 2,08 &, 08 & 6,08 & 2,78 \\
\hline \multicolumn{5}{|l|}{ SEM INFORMAÇÃO } \\
\hline $\begin{array}{l}\text { Frequência absoluta.. } \\
\text { Frequẹncia relativa.. }\end{array}$ & $\begin{array}{c}2 \\
4,18\end{array}$ & $\begin{array}{c}1 \\
2,08\end{array}$ & $\begin{array}{c}1 \\
2,08\end{array}$ & $\begin{array}{c}4 \\
2,78\end{array}$ \\
\hline \multicolumn{5}{|l|}{ 3 a OPCHO ATD MEDICO } \\
\hline \multicolumn{5}{|l|}{ HOSPITAL UNIVERSITARIO } \\
\hline $\begin{array}{l}\text { Frequência absoluta.. } \\
\text { Frequência relativa.. }\end{array}$ & $\begin{array}{c}16 \\
42,18\end{array}$ & $\begin{array}{c}16 \\
44,48\end{array}$ & $\begin{array}{c}8 \\
26,78\end{array}$ & $\begin{array}{c}40 \\
38,58\end{array}$ \\
\hline \multicolumn{5}{|l|}{ REDE PUBL/CONVENIADA SUS } \\
\hline $\begin{array}{l}\text { Frequência absoluta.. } \\
\text { Frequencia relativa.. }\end{array}$ & $\begin{array}{c}21 \\
55,38\end{array}$ & $\begin{array}{c}15 \\
41,78\end{array}$ & $\begin{array}{c}17 \\
56,78\end{array}$ & $\begin{array}{c}53 \\
51,08\end{array}$ \\
\hline \multicolumn{5}{|l|}{ CONVENIO PROPRIO/EMPRESA } \\
\hline Frequencia absoluta.. & 0 & 4 & 2 & 6 \\
\hline Frequência relativa.. &, 08 & 11,18 & 6,78 & 5,88 \\
\hline \multicolumn{5}{|l|}{ SERVIÇO PRIVADO } \\
\hline Frequência absoluta.. & 1 & 1 & 2 & 4 \\
\hline Frequência relativa.. & 2,68 & 2,88 & 6,78 & 3,88 \\
\hline \multicolumn{5}{|l|}{ OUTROS } \\
\hline $\begin{array}{l}\text { Frequência absoluta.. } \\
\text { Frequência relativa.. }\end{array}$ & 0 & 0 & $3, \frac{1}{38}$ & 1 \\
\hline \multicolumn{5}{|l|}{ SEM INFORMAÇR̃O } \\
\hline $\begin{array}{l}\text { Frequencia absoluta. } \\
\text { Frequencia relativa. }\end{array}$ & $\begin{array}{c}13 \\
34,28\end{array}$ & $\begin{array}{c}15 \\
41,78\end{array}$ & $\begin{array}{c}21 \\
70,08\end{array}$ & $\begin{array}{c}49 \\
47,18\end{array}$ \\
\hline
\end{tabular}

* Erequêncla relativa calculada sobre casos válidos * 
TABELAX - UTILIZAÇÃO DE SERVIÇOS DE SAÜDE SEGUNDO A CLASSIFICAÇÃO DO PACIENTE

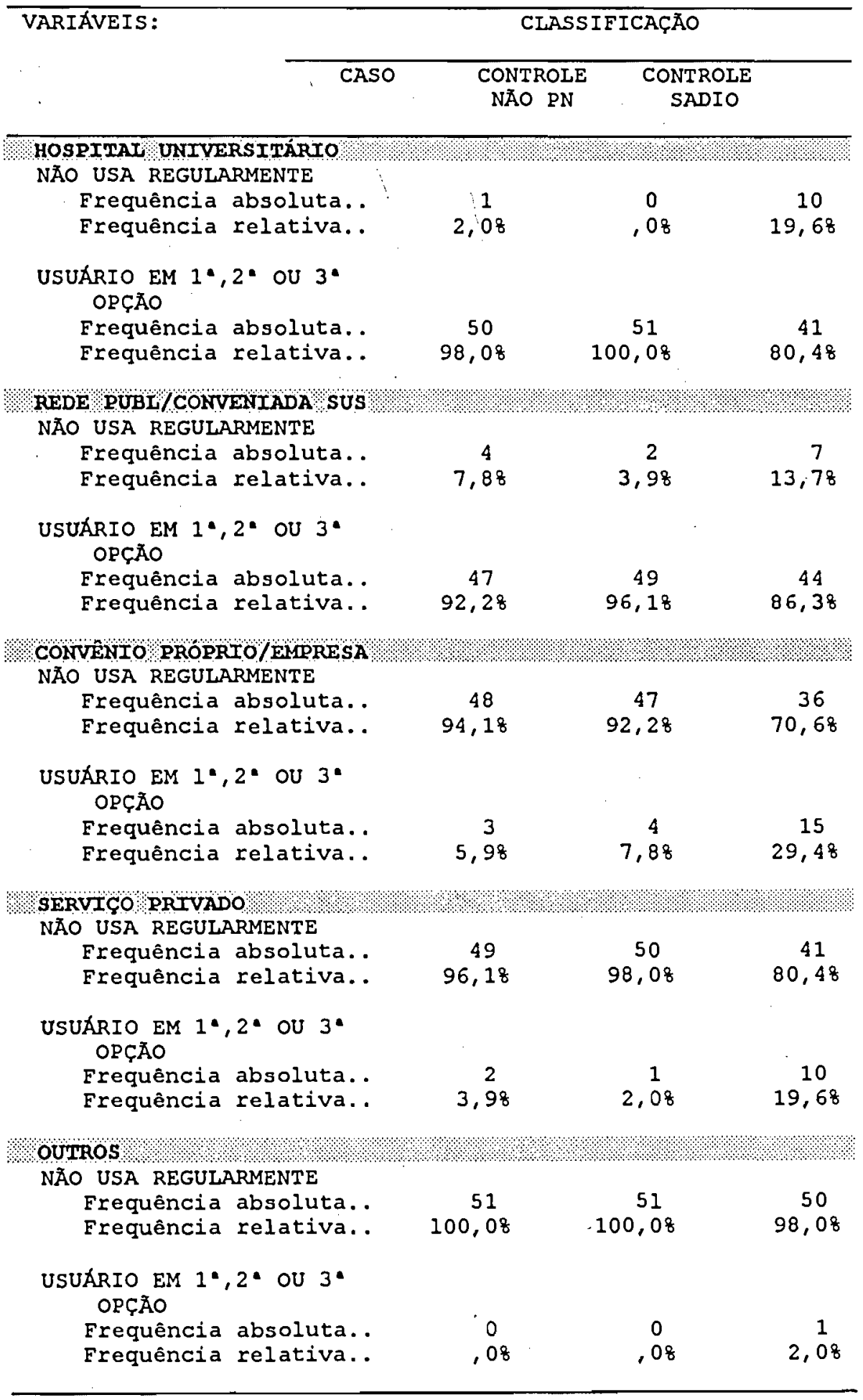




\section{III.3.1 - CARACTERIZAÇÃO DE VARIÁVEIS DE INFORMAÇÃO COMPLEMENTAR: Situação atual de saúde}

Indagados os informantes sobre a presença de doenças crônicas ou em tratamento, 35 pacientes (15 casos, 14 controles não respiratónios, 6 controles sadios) foram identificados como portadores de alguma doença, em tratamento ou não. A Tabela XI relaciona os diagnósticos e respectivos tratamentos: controles sadios têm uma frequência menor de doenças associadas e casos e controles não respiratórios, embora não apresentem diferença de frequência de doença, diferem quanto ao tipo de doença havendo uma concentração de referências a bronquite e chiados entre os casos.

TABELAXI - DOENÇAS INDEPENDENTES DE QUEIXA ATUAL IDENTIFICADAS EM CASOS E CONTROLES

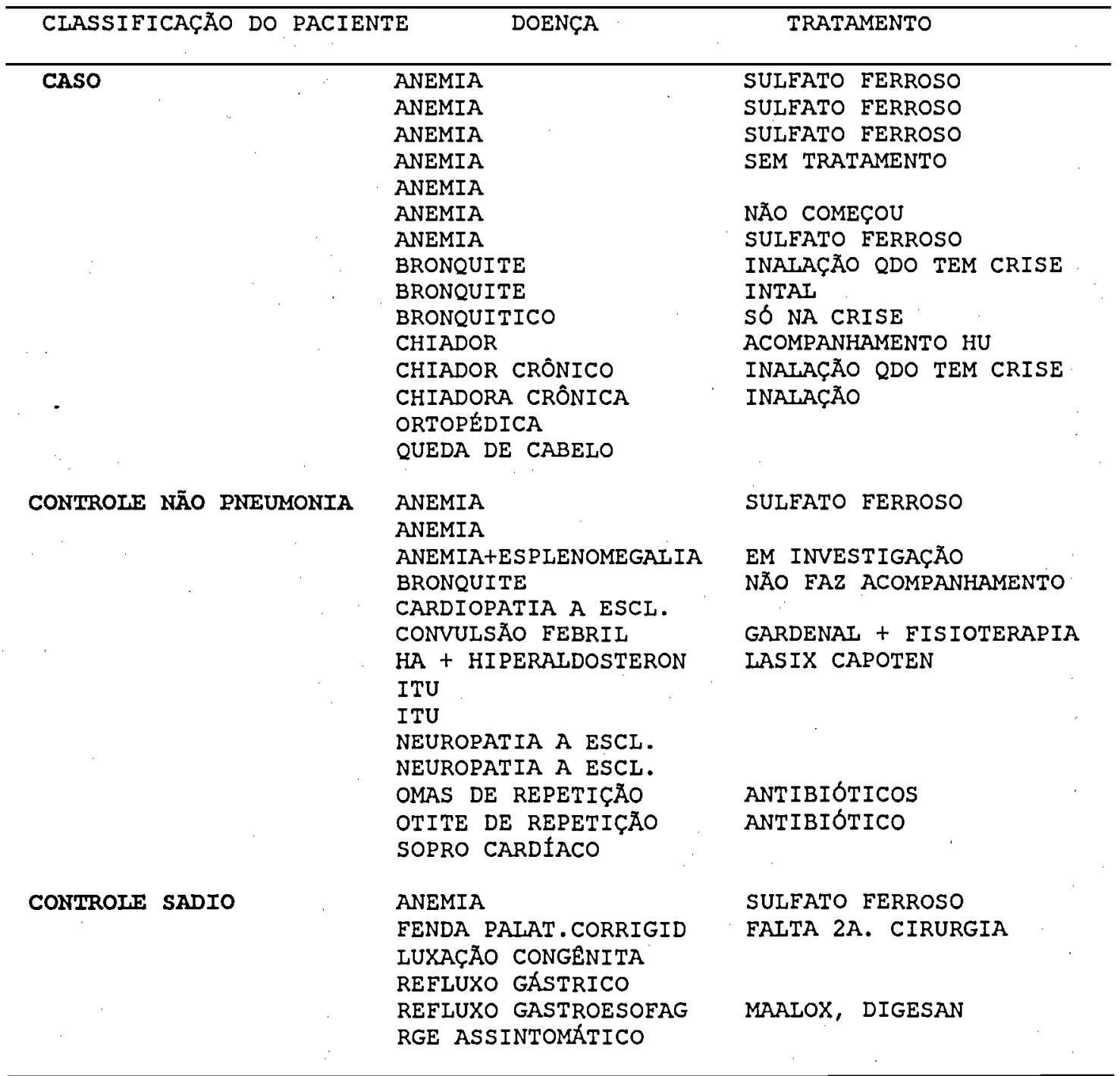


A situação nutricional das crianças examinadas está representada no Gráfico XII, através de curvas de distribuição da relação peso/altura, medida em distâncias padronizadas da mediana de população de referência (amostra do National Center for Health Statistics (NCHS), conforme recomendação $O M S^{116}$ ). Observa-se que enquanto casos e controles sadios têm curvas quase que sobrepostas, controles não respiratórios tem uma curva algo deslocada para a esquerda, sugerindo uma situação nutricional menos favorável.

\section{GRÁFICO XII - CURVAS DE DISTRIBUIÇĀO DAS MEDIDAS DE SITUAÇĀO NUTRICIONAL EM CASOS E CONTROLES}

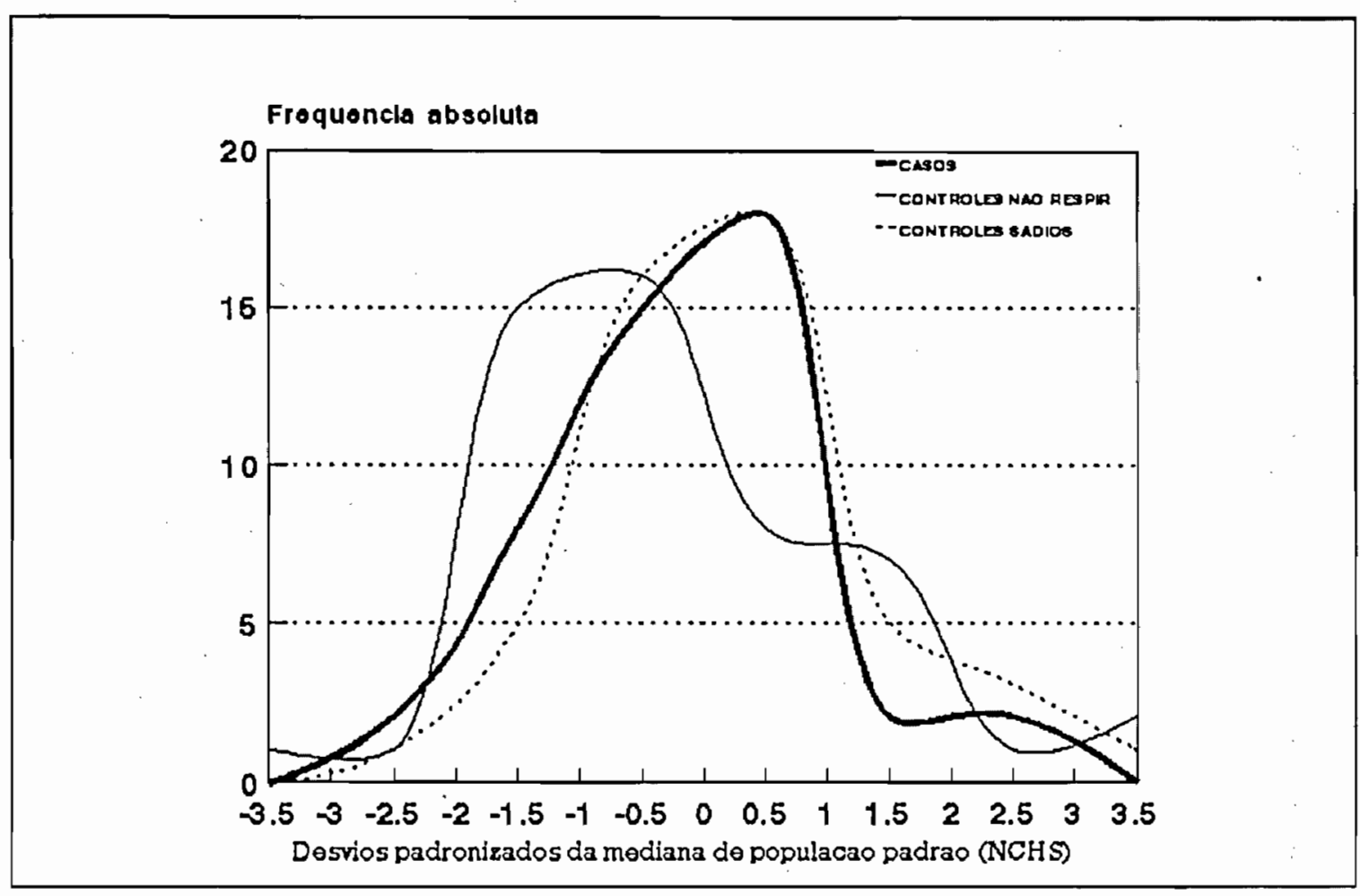

No entanto, como mostra o Gráfico XIII, embora cada grupo tenha uma média distinta da medida de situação nutricional, os intervalos de confiança se sobrepōem apontando que não há diferenças estatisticamente significantes. $O$ fato de que entre os 51 controles não respiratórios 27 (53\%) sejam casos de diarréia pode ajudar a explicar uma presença maior de desnutrição aguda neste grupo.

116. Organización Mundial de la Salud. Medición del cambio del estado nutricional. Ginebra: OMS, 1983. 
GRÁFICO XIII - COMPARAÇÃO DA SITUAÇÃO NUTRICIONAL DE CASOS E CONTROLES, MEDIDA EM DESVIOS PADRONIZADOS DA MEDIANA DE POPULAÇÄO PADRĀO (NCHS)

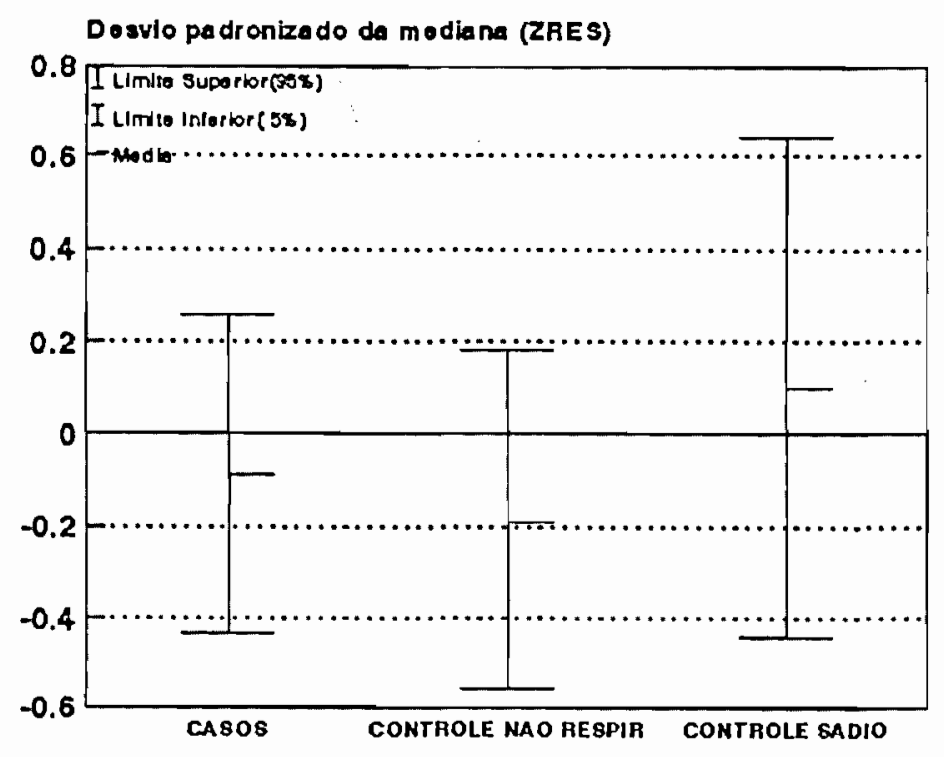

A Tabela XII mostra a classificaçăo de casos e controles segundo o estado nutricional. Além da frequência absoluta lê-se também os resíduos padronizados (ZRES) que permitem identificar uma maior concentração de desnutridos entre os controles não respiratórios $(1,7$ desvios padrão além do esperado, muito próximo do ponto de corte de 1,96, correspondente ao percentil 95 da distribuição de probabilidades). O teste do Qui Quadrado resulta num valor de " $p$ " discretamente superior a 0,05 , que se tomado como ponto de corte de significância estatistica permite que ainda se mantenha a hipótese nula de distribuição ao acaso das frequências ou, em outras palavras, que se admita que a situação nutricional de casos e controles não seja diferente.

TABELA XII - CLASSIFICAÇĀO NUTRICIONAL DE CASOS E CONTROLES

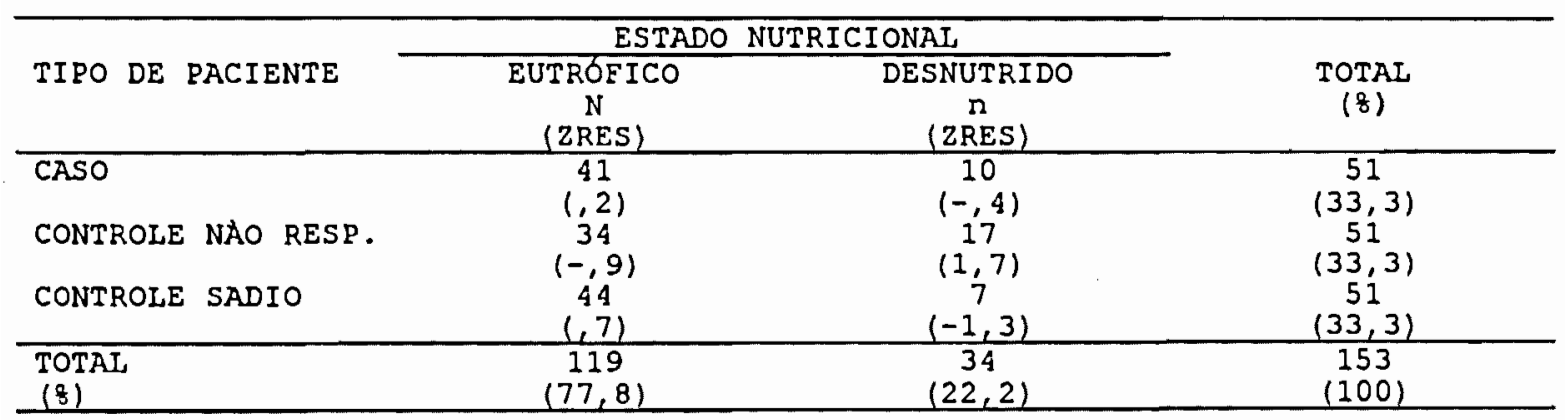

$x^{2}=5,97(p=, 05042)$ 


\section{III.3.2 - CARACTERIZAÇÃO DE VARIÁVEIS DE INFORMAÇÃO COMPLEMENTAR: Antecedentes pessoais}

A investigação da história pregressa dos pacientes forneceu as informações registradas na Tabela XIII. A história de laringotraqueobronquite é significativamente maior em casos $\left(X^{2}=12,43, p=, 00\right)$, mas entre todos os pacientes com história positiva não há diferença no número de episódios registrados nos últimos 12 meses. Nenhuma outra variável registrou diferença com expressão estatística entre casos e controles.

TABELA XIII - ANTECEDENTES CLÍNICOS SEGUNDO A CLASSIFICAÇÃO DO PACIENTE

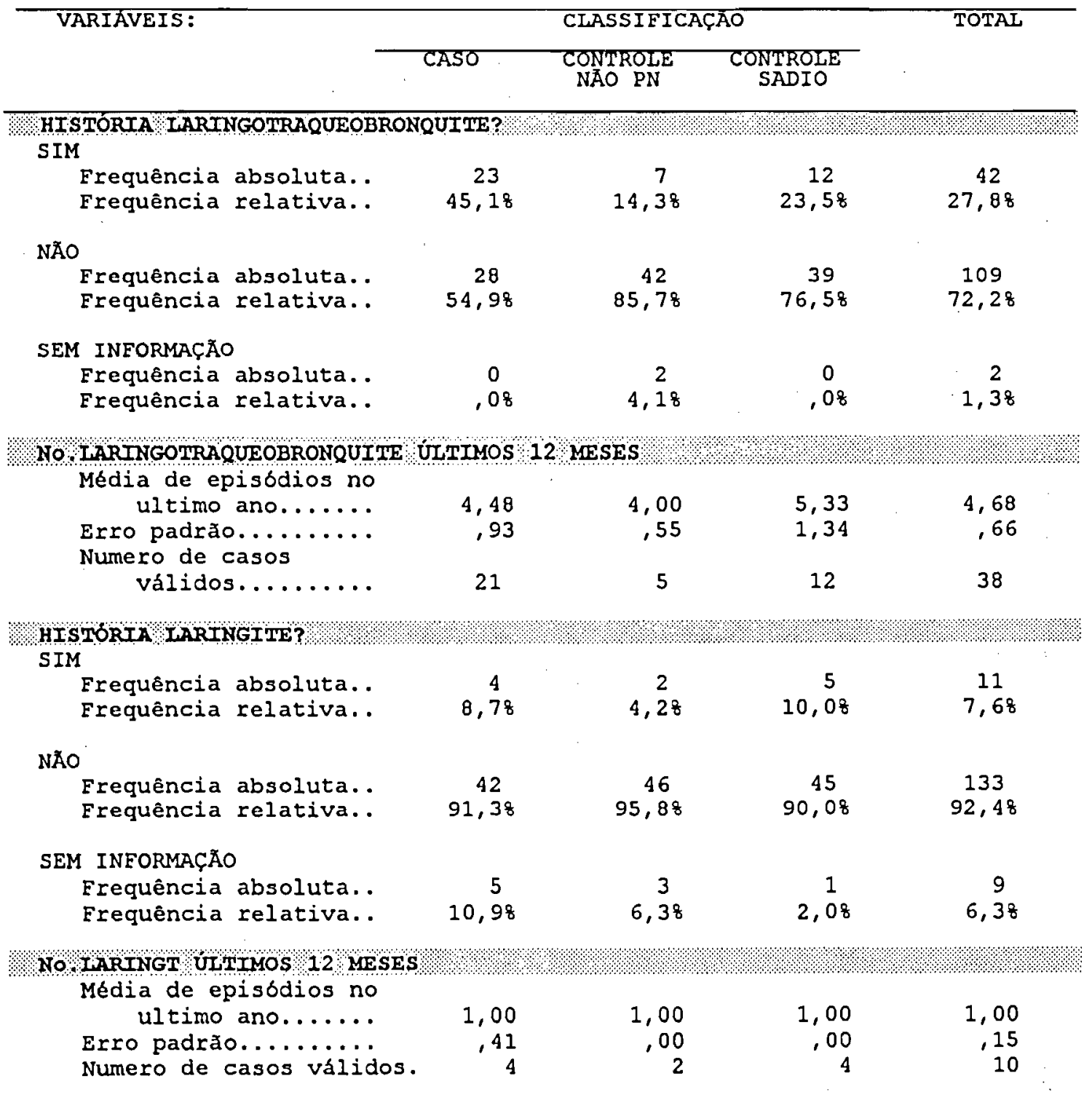




\section{Continuaçăo}

\begin{tabular}{|c|c|c|c|c|}
\hline \multirow[t]{2}{*}{ VARIAVEIS: } & \multicolumn{3}{|c|}{ CLASSIFICACAOO } & \multirow[t]{2}{*}{ TOTAL } \\
\hline & CASO & $\begin{array}{l}\text { CONTROLE } \\
\text { NÄO PN }\end{array}$ & $\begin{array}{l}\text { CONTROLE } \\
\text { SADIO }\end{array}$ & \\
\hline \multicolumn{5}{|l|}{ HISTÓRTA ECZEMA? } \\
\hline \multicolumn{5}{|l|}{ SIM } \\
\hline $\begin{array}{l}\text { Erequência absoluta.. } \\
\text { Erequência relativa.. }\end{array}$ & $\begin{array}{c}6 \\
12,28\end{array}$ & $\begin{array}{c}5 \\
10,48\end{array}$ & $\begin{array}{l}5 \\
9,88\end{array}$ & $\begin{array}{c}16 \\
10,88\end{array}$ \\
\hline \multicolumn{5}{|l|}{ NÃO } \\
\hline $\begin{array}{l}\text { Erequência absoluta.. } \\
\text { Erequência relativa.. }\end{array}$ & $\begin{array}{c}43 \\
87,88\end{array}$ & $\begin{array}{c}43 \\
89,68\end{array}$ & $\begin{array}{c}46 \\
90,28\end{array}$ & $\begin{array}{c}132 \\
89,28\end{array}$ \\
\hline SEM INFORMAÇÃO & & 一 & & \\
\hline $\begin{array}{l}\text { Frequência absoluta.. } \\
\text { Frequência relativa.. }\end{array}$ & $\begin{array}{c}2 \\
4,18\end{array}$ & $\begin{array}{c}3 \\
6,38\end{array}$ & $\begin{array}{l}0 \\
.08\end{array}$ & $\begin{array}{c}5 \\
3,48\end{array}$ \\
\hline
\end{tabular}

To. ECZEMA ÚTTMOS 12 MESES

Média de episódios no

Numero de casos ultimo ano.......

Erro padrao.........

2,20

, 73

válidos........

5

4,18

6,38

.08

3,48

HISTORIA RHMITE?

SIM

Frequencia absoluta.

Erequência relativa.

7

2,33

, 67

3
1,00

.00

1,91

, 39

11

3

NÄO

Frequência absoluta. .

Frequência relativa..

42

85,78

87,88

90,08

130

87,88

SEM INFORMAÇĀO

Frequência absoluta. .

2

Frequência relativa..

4,18

2

4,18

1

2,08

5

3,48

No. RTNITE ULTIMOS 12 MESES

Média de episódios no

ultimo ano......

Erro padrão.........

NSAPL

PERENE

NSAPL

PERENE

Numero de casos

NSAPL

NSAPL

NSAPI

NSAPL

válidos........

0

1

0

1

HISTOORIA STWUSIME?

SIM

Frequência absoluta..

3

Frequência relativa..

5,98

0

2

5

Nม̃०

Frequência absoluta..

$48 \quad 51$

Frequência relativa..

94,18

100,08

48

96,08

147

SEM INFORMAÇĀO

Frequência absoluta. .

Frequência relativa..

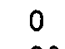

.08

0
.08

2,08

1

96,78

18

2,28

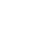


Continuaçăo

VARIÁVEIS :

CLASSIFICAÇĀO

TOTAL

\begin{tabular}{ccc}
\hline CASO & CONTROLE & CONTROIE \\
& NÄO PN & SADIO
\end{tabular}

WO SINUSITE UUTIMOS 12 MESES

Média de episodios no

ultimo ano.......

Erro padrão..........

1,00

, 00

Numero de casos

válidos........

NSAPL
NSAPL
0

0

$$
\begin{aligned}
& 50,00 \\
& 50,00
\end{aligned}
$$$$
2
$$

20,60

19,85

5

HISTOKTAROTITE?

SIM

Frequência absoluta. .

22

Frequência relativa..

43,18

20

40,08

18

60

36,08

39,78

NĀO

Frequência absoluta. .

29

Frequência relativa..

56,98

30

60,08

32

91

SEM INFORMAÇAOO

Frequência absoluta. .

0

Frequencia relativa..

, 08

2,08

64,08

60,38

NO OTITES UTTIMOS 12 NESES

Média de episódios no

Numero de casos ultimo ano.......

Erro padrăo..........

2,37

1,01

válidos........
19
2,78

1,04

18
1

2

1,38

HTSTORTA SARAMPO? SIM

Frequência absoluta.

Frequência relativa. .

$\begin{array}{cccc}1 & 1 & 1 & 3 \\ 08 & 2,08 & 2,08 & 2,08\end{array}$

NÃo

Frequência absoluta.. 49

Frequência relativa. .

$98,0 \%$

49

98,08

49

147

SEM INEORMAÇA

Frequência absoluta.

$2, \frac{1}{08}$

2,08

98,08

2,53

, 50

Frequencia relativa..

2,08

SARANPO HA QTOS MESES?

Tempo médio decorrido

Erro padrão.........

Numero de casos

$\begin{array}{llll}18,00 & 28,00 & 29,00 & 25,00 \\ \text { NSAPL } & \text { NSAPL } & \text { NSAPL } & 3,51\end{array}$

válidos.........

1

1

1

3

HISTORTA COQUELUCHE?

NÄO

Frequência absoluta.

51

51

50

100,08

50
100,08

151

Frequência relativa..

SEM INFORMAÇĀO

Frequência absoluta..

Frequência relativa..

0

1

2,08

2,08

2

$\begin{array}{llll}, 08 & 2,08 & 2,08 & 1,38\end{array}$




\begin{tabular}{|c|c|c|c|c|}
\hline \multirow[t]{2}{*}{ VARIXVEIS: } & \multicolumn{3}{|c|}{ CIASSIFICAÇĀO } & \multirow[t]{2}{*}{ TOTAL } \\
\hline & CASO & $\begin{array}{l}\text { CONTROLE } \\
\text { NAO PN }\end{array}$ & $\begin{array}{l}\text { CONTROLE } \\
\text { SADIO }\end{array}$ & \\
\hline $\begin{array}{l}\text { HISTÓRTA IBC } \\
\text { NÄO }\end{array}$ & ? & & & \\
\hline $\begin{array}{l}\text { Frequência absoluta.. } \\
\text { Frequência relativa.. }\end{array}$ & $\begin{array}{c}50 \\
100,0 \%\end{array}$ & $\begin{array}{c}51 \\
100,08\end{array}$ & $\begin{array}{c}51 \\
100,08\end{array}$ & $\begin{array}{c}152 \\
100,08\end{array}$ \\
\hline $\begin{array}{l}\text { SEM INFORMAÇÃo } \\
\text { Frequência absoluta.. } \\
\text { Frequência relativa.. }\end{array}$ & 2,08 & $\begin{array}{l}0 \\
.08\end{array}$ & $\begin{array}{l}0 \\
.08\end{array}$ & $\begin{array}{l}1 \\
, 78\end{array}$ \\
\hline
\end{tabular}

HISIORTA BRONQUIOLITE?

SIM

$\begin{array}{lcccc}\text { Frequência absoluta.. } & 3 & 3 & 7 & 13 \\ \text { Frequència relativa.. } & 7,38 & 6,48 & 14,08 & 9,48\end{array}$

NĀo

Frequência absoluta.. $\quad 38 \quad 34 \quad 43 \quad 44$

Frequência relativa.. $\quad 92,78 \quad 93,68 \quad 96,08 \quad 98$

SEM INFORMAÇĀO

$\begin{array}{lcccc}\text { Frequência absoluta.. } & 10 & 4 & 1 & 15 \\ \text { Frequência relativa.. } & 24,48 & 8,58 & 2,08 & 10,98\end{array}$

BRONQLT HA QTOS MESES?

Tempo médio decorrido

Erro padrão...........

Numero de casos

válidos...........

7,67

22,67

1,86

12,68

12,43

8,01

13,69

3

3

7

HISTORTA PNEUMONLA?

SIM

Frequência absoluta. .

Frequência relativa..

19

37,38

16

$31,4 \%$

14

28,08

49

NÅo

Frequência absoluta.

32

35

36

72,08

103

Frequência relativa..

62,78

$68,6 \%$

$67,8 \%$

SEM INEORMAÇÃO

Frequência absoluta..

0

0

$\begin{array}{llll}08 & 08 & 2,08 & , 78\end{array}$

2,08

1

No PN TRATADAS EM CASA

1

Frequência absoluta..

Frequência relativa. .

6

9

10

25

31,68

56,38

71,48

51,08

2

Frequência absoluta. .

Frequência relativa..

15,88

1
38

2

6

3
Erequência absoluta..
2
0
0
2
Frequência relativa..
10,58
, 08
, $0 \%$
4,18 
Continuaçăo

\begin{tabular}{|c|c|c|c|c|}
\hline VARIAVEIS: & & CLASSIFI & & TOTAL \\
\hline . & CASO & $\begin{array}{c}\text { CONTROLE } \\
\text { NÃO PN }\end{array}$ & $\begin{array}{c}\text { CONTROLE } \\
\text { SADIO }\end{array}$ & \\
\hline
\end{tabular}

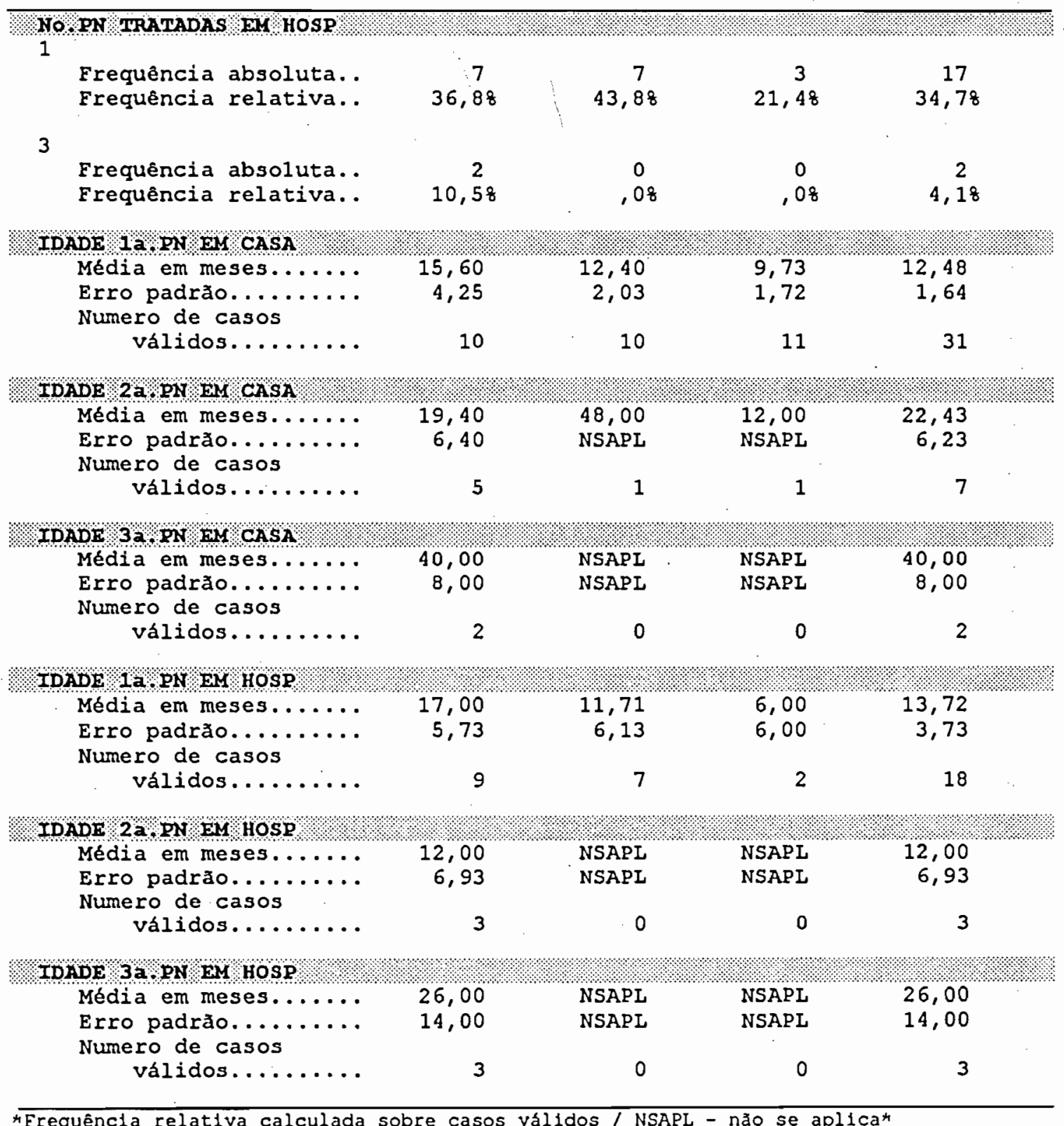

* Frequênc1a relatıva calculada sobre casos válidos / NSAPL - nåo se aplica» 


\section{III.3.3 - CARACTERIZAÇÃO DE VARIÁVEIS DE INFORMAÇÃO COMPLEMENTAR: Antecedentes familiares}

Examinou-se antecedentes familiares relativos à presença de atopia e asma na familia que se relacionam com o fator de exposição investigado (doença chiadora recorrente), não se tendo encontrado qualquer diferença significante entre os grupos de casos e controles. As informaçōes são apresentadas na Tabela XIV.

TABELA XIV - HISTÓRIA FAMILIAR DE DOENÇAS RELACIONADAS AO FATOR DE EXPOSIÇÃO SEGUNDO A CLASSIFICAÇÃO DO PACIENTE

\begin{tabular}{|c|c|c|c|}
\hline \multirow{2}{*}{ ANTECEDENTE FAMILIAR } & CLASSIFICAC & & TOTAL \\
\hline & $\begin{array}{c}\text { CONTROLE } \\
\text { NĀO PN }\end{array}$ & $\begin{array}{c}\text { CONTROLE } \\
\text { SADIO }\end{array}$ & \\
\hline
\end{tabular}

PATATOPICOP

SIM

Frequência absoluta. .

9

Frequência relativa..

NĀO

Frequência absoluta..

Frequência relativa..

SEM INFORMAÇÃO

Frequencia absoluta. .

Frequência relativa..
18,88

39

81,38

6,3
10
20,88

20,08

29

19,98

MÄ ATÖPICA?

SIM

Frequência absoluta..

Frequência relativa..

18

35,38

NĀO

Frequência absoluta. .

Frequência relativa..

SEM INFORMAÇAO

Frequência absoluta.

Frequência relativa..

IRMAO AROPICO? S IM

Frequência absoluta..

Frequencia relativa..

NĀO

Frequência absoluta.. 33

Frequência relativa.. $\quad 78,68$

SEM INFORMAÇÃO

Frequência absoluta.

Frequência relativa..

33

64,78

0

, 08

9

21,48

16

41,08

29

59,28

4. 2

2,08

12

35,38

37

32,28

91

60,78

58,08

3

2,08
117

80,18

7

4,88

2,08

\%.

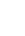


Continuaçåo

\begin{tabular}{|c|c|c|c|c|}
\hline \multirow{2}{*}{ ANTECEDENTE FAMILIAR } & \multicolumn{3}{|c|}{ CIASSIFICAÇĀO } & \multirow[t]{2}{*}{ TOTAL } \\
\hline & CASO & $\begin{array}{l}\text { CONTROLE } \\
\text { NÄO PN }\end{array}$ & $\begin{array}{l}\text { CONTROLE } \\
\text { SADIO }\end{array}$ & \\
\hline \multicolumn{5}{|l|}{ RAT ASMATICO? } \\
\hline SIM & . & & & \\
\hline $\begin{array}{l}\text { Frequência absoluta.. } \\
\text { Frequência relativa.. }\end{array}$ & $\begin{array}{c}4 \\
8 ; 08\end{array}$ & $\begin{array}{c}4 \\
8,28\end{array}$ & $\begin{array}{c}1 \\
2,08\end{array}$ & $\begin{array}{c}9 \\
6,08\end{array}$ \\
\hline \multicolumn{5}{|l|}{ NÃO } \\
\hline $\begin{array}{l}\text { Frequência absoluta.. } \\
\text { Frequência relativa.. }\end{array}$ & $\begin{array}{c}46 \\
92,08\end{array}$ & $\begin{array}{c}45 \\
91,88\end{array}$ & $\begin{array}{c}49 \\
98,08\end{array}$ & $\begin{array}{l}140 \\
94,08\end{array}$ \\
\hline $\begin{array}{l}\text { SEM INFORMAÇÃo } \\
\text { Frequência absoluta.. } \\
\text { Frequência relativa.. }\end{array}$ & $2, \frac{1}{08}$ & $\begin{array}{c}2 \\
4,18\end{array}$ & 2,08 & 2,78 \\
\hline \multicolumn{5}{|l|}{ WMAE ASMÁTICA? $/ /$} \\
\hline \multicolumn{5}{|l|}{ SIM } \\
\hline $\begin{array}{l}\text { Frequência absoluta.. } \\
\text { Frequência relativa.. }\end{array}$ & 9.88 & 4,18 & $\begin{array}{c}3 \\
6,08\end{array}$ & $\begin{array}{c}10 \\
6,78\end{array}$ \\
\hline \multicolumn{5}{|l|}{ NÃo } \\
\hline $\begin{array}{l}\text { Frequência absoluta.. } \\
\text { Frequência relativa.. }\end{array}$ & $\begin{array}{c}46 \\
90,28\end{array}$ & $\begin{array}{c}47 \\
95,98\end{array}$ & $\begin{array}{c}47 \\
94,08\end{array}$ & $\begin{array}{c}140 \\
93,38\end{array}$ \\
\hline $\begin{array}{l}\text { SEM INFORMAÇÃo } \\
\text { Frequência absoluta.. } \\
\text { Frequência relativa.. }\end{array}$ & $\begin{array}{l}0 \\
.08\end{array}$ & $\begin{array}{c}2 \\
4,18\end{array}$ & $\begin{array}{c}1 \\
2,08\end{array}$ & $\begin{array}{c}3 \\
2,08\end{array}$ \\
\hline \multicolumn{5}{|l|}{ IRMAO A SMATICO? } \\
\hline $\begin{array}{l}\text { SIM } \\
\text { Frequência absoluta.. } \\
\text { Frequência relativa.. }\end{array}$ & $\begin{array}{l}4 \\
9,58\end{array}$ & $\begin{array}{c}7 \\
17,98\end{array}$ & 11,88 & $\begin{array}{c}15 \\
13,08\end{array}$ \\
\hline $\begin{array}{l}\text { NÃo } \\
\text { Frequência absoluta.. } \\
\text { Frequência relativa.. }\end{array}$ & $\begin{array}{c}38 \\
90,58\end{array}$ & $\begin{array}{c}32 \\
82,18\end{array}$ & $\begin{array}{c}30 \\
88,28\end{array}$ & $\begin{array}{c}100 \\
87,08\end{array}$ \\
\hline $\begin{array}{l}\text { SEM INFORMAÇĀo } \\
\text { Frequência absoluta.. } \\
\text { Frequência relativa.. }\end{array}$ & $\begin{array}{c}9 \\
21,48\end{array}$ & $\begin{array}{c}12 \\
30,88\end{array}$ & $\begin{array}{c}17 \\
50,08\end{array}$ & $\begin{array}{c}38 \\
33,08\end{array}$ \\
\hline
\end{tabular}

ॠ Erequéncla relativa calculada sobre casos válidos 


\section{III.3.4 - CARACTERIZAÇÃO DE VARIÁVEIS DE INFORMAÇÃO COMPLEMENTAR: Fatores ambientais}

Investigou-se as condições ambientais a que estão expostos os pacientes indagando-se sobre a presença de fatores que se supōem possam influenciar tanto a presença de doença quanto do fator de exposição investigado. A Tabela XV mostra os resultados, onde se destacaram com diferenças estatisticamente significantes o número de pessoas dormindo no quarto da criança e o número de fumantes na casa. Em relação à primeira variável, os controles sadios tem um número significativamente menor de pessoas no quarto da criança quando comparado tanto com casos como com controles não respiratórios, embora estes não difiram entre si. Em relação ao número de fumantes, o grupo de casos não difere significativamente nem de controles sadios nem de controles não respiratórios, mas estes dois grupos têm diferença significante entre si. $\begin{array}{ll}\text { TABELA XV - } & \text { CARACTERISTICAS DO MEIO AMBIENTE SEGUNDO A } \\ \text { CLASSIFICAÇÃO DO PACIENTE } & \end{array}$

\begin{tabular}{|c|c|c|c|}
\hline \multirow{2}{*}{ VARIÁVEIS: } & CLASSIFICAC & & TOTAL \\
\hline & $\begin{array}{l}\text { CONTROLE } \\
\text { NAO PN }\end{array}$ & $\begin{array}{c}\text { CONTROLE } \\
\text { SADIO }\end{array}$ & \\
\hline
\end{tabular}

\begin{tabular}{|c|c|c|c|c|}
\hline \multicolumn{5}{|c|}{ A CASA TEM FOGĀO LENHHA/CARVÃO/QUEROSENE? } \\
\hline & & & & \\
\hline $\begin{array}{l}\text { Frequência absoluta.. } \\
\text { Frequência relativa.. }\end{array}$ & 2,08 & $\begin{array}{l}0 \\
.08\end{array}$ & $\begin{array}{l}0 \\
, 08\end{array}$ & $\begin{array}{l}1 \\
, 78\end{array}$ \\
\hline \multicolumn{5}{|l|}{ NÃO } \\
\hline $\begin{array}{l}\text { Frequência absoluta.. } \\
\text { Frequência relativa.. }\end{array}$ & $\begin{array}{c}50 \\
98,08\end{array}$ & $\begin{array}{c}51 \\
100,08\end{array}$ & $\begin{array}{c}51 \\
100,08\end{array}$ & $\begin{array}{c}152 \\
99,38\end{array}$ \\
\hline \multirow{2}{*}{\multicolumn{5}{|c|}{ FALTA INSOLAÇÃO NO QUARTO DA CRIANÇA? }} \\
\hline & & & & \\
\hline $\begin{array}{l}\text { Erequencia absoluta.. } \\
\text { Frequência relativa.. }\end{array}$ & $\begin{array}{c}12 \\
24,08\end{array}$ & $\begin{array}{c}14 \\
27,58\end{array}$ & $\begin{array}{c}14 \\
27,58\end{array}$ & $\begin{array}{c}40 \\
26,38\end{array}$ \\
\hline \multicolumn{5}{|l|}{ NÃO } \\
\hline $\begin{array}{l}\text { Frequência absoluta.. } \\
\text { Frequência relativa.. }\end{array}$ & $\begin{array}{c}38 \\
76,08\end{array}$ & $\begin{array}{c}37 \\
72,58\end{array}$ & $\begin{array}{c}37 \\
72,58\end{array}$ & $\begin{array}{c}112 \\
73,78\end{array}$ \\
\hline $\begin{array}{l}\text { SEM INFORMAÇÃo } \\
\text { Frequência absoluta.. } \\
\text { Frequência relativa.. }\end{array}$ & $\begin{array}{c}1 \\
2,08\end{array}$ & $\begin{array}{l}0 \\
.08\end{array}$ & $\begin{array}{l}0 \\
, 08\end{array}$ & $\begin{array}{l}1 \\
.78\end{array}$ \\
\hline
\end{tabular}


Continuaçåo

VARIÁVEIS:

CLASSIFICAÇÃO

TOTAL

$\begin{array}{ccc}\text { CASO } & \text { CONTROLE } & \text { CONTROIE } \\ \text { NÄO PN } & \text { SADIO }\end{array}$

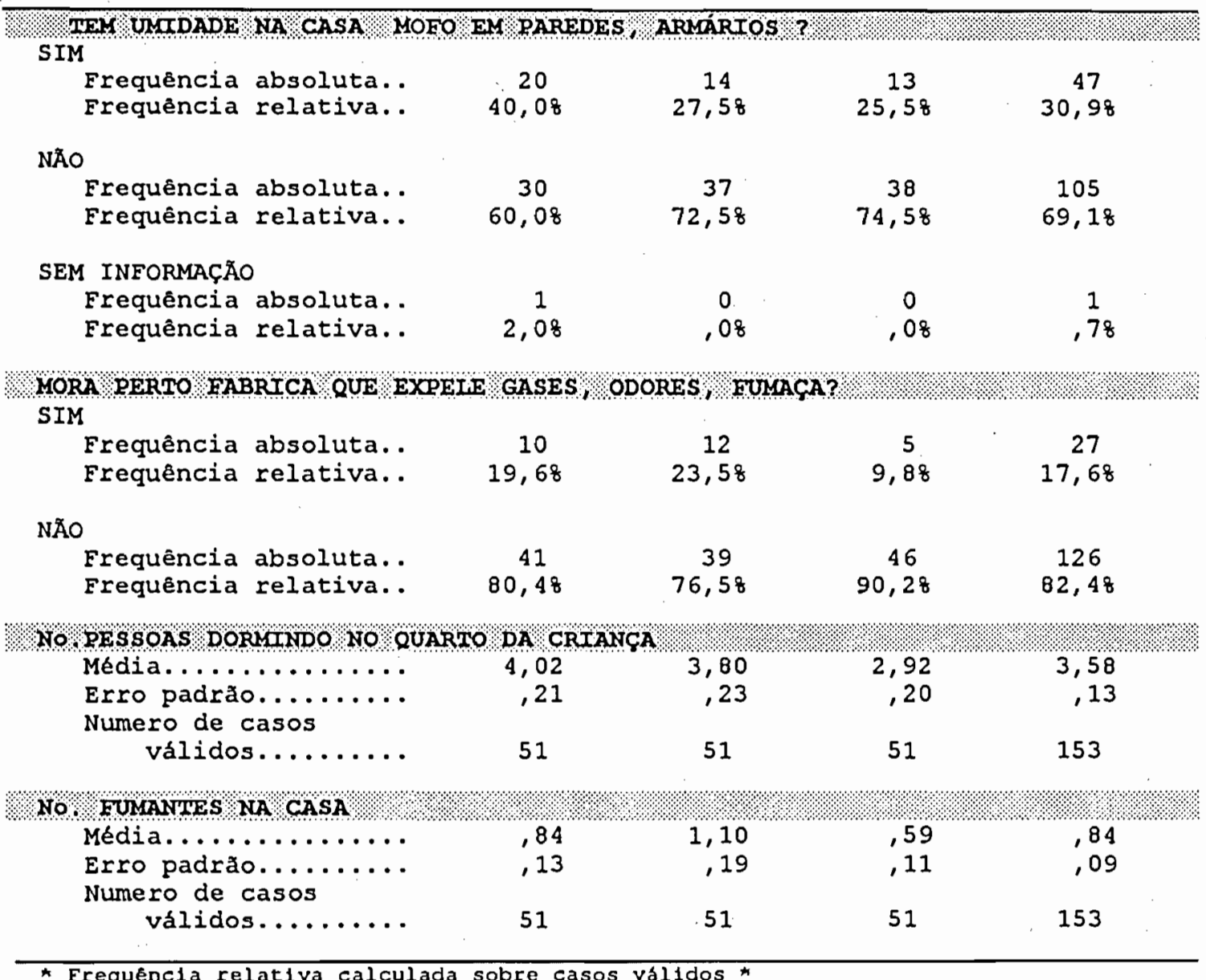

* Erequéncia relativa calculada sobre casos valldos *

\section{III.4 - INVESTIGAÇÃO DO DIAGNÓSTICO DE PNEUMONIA: Caracterização da presença de doença}

À exceção do exame radiológico que se reservou aos pacientes com hipótese clinica de pneumonia, todas as crianças foram igualmente examinadas para investigar-se a presença de pneumonia ou qualquer outra doença. A Tabela XVI apresenta as respostas obtidas no inquérito de história pregressa da queixa atual, aplicado mesmo aos controles sadios que não apresentavam qualquer queixa. A análise de variância não paramétrica (Kruskall-Wallis) apontou diferenças entre os grupos em todas as questões examinadas. No entanto, comparando-se os grupos 
dois a dois, encontrou-se que casos e controles não respiratórios não diferem quanto a história de dor abdominal, vômitos e anorexia e que controles sadios e controles não respiratórios não diferem quanto a história de dispnéia e dor torácica.

TABELAXVI - HISTÓRIA CLÍNICA DOS PACIENTES SEGUNDO SUA CLASSIFICAÇÃO: HISTÓRIA PREGRESSA DA QUEIXA ATUAL

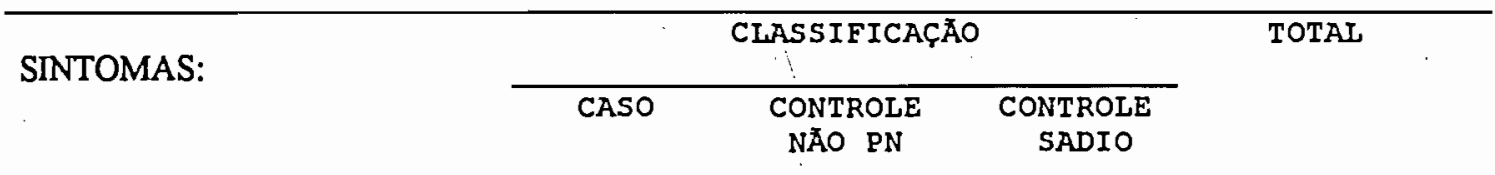

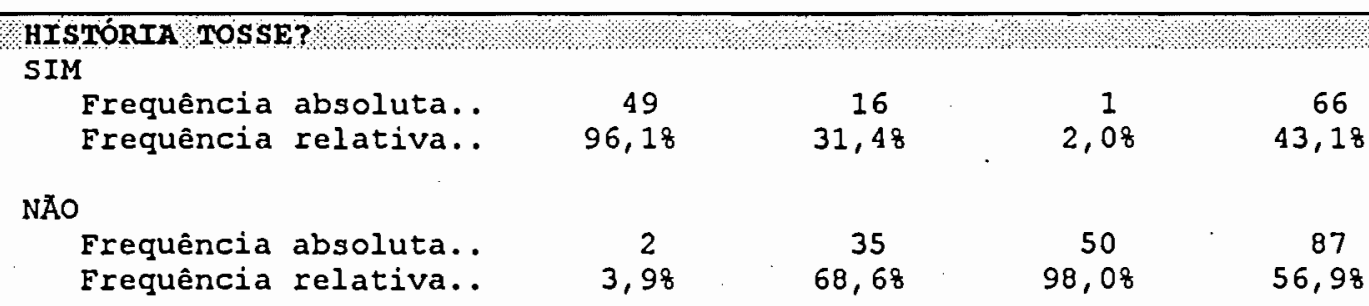

HISTORIA DISPNEIA?

SIM

Frequência absoluta..

42

Frequência relativa.. 82,48

3

5,98

0

, 08

45

29,48

NĀo

$\begin{array}{lcccc}\text { Frequência absoluta.. } & 9 & 48 & 51 & 108 \\ \text { Frequência relativa.. } & 17,68 & 94,18 & 100,08 & 70,68\end{array}$

HISTORTA FEBRE?

SIM

Frequência absoluta..

47

92,28

35

$68,6 \%$

0

82

Frequência relativa..

4

7,88

16

31,48

51

100,08

71

46,48

HIST DOR TÓRAX?

SIM

Frequência absoluta..

Frequência relativa..

8
27,68

2,58

0
, 08

7,58

NÄO

Frequência absoluta..

Frequência relativa..

21

72,48

39

97,58

51

100,08

111

SEM INFORMAÇAO

Frequência absoluta..

Frequência relativa..

22

75,98

11

27,58

0

33

, 08

27,58 
Continuacao

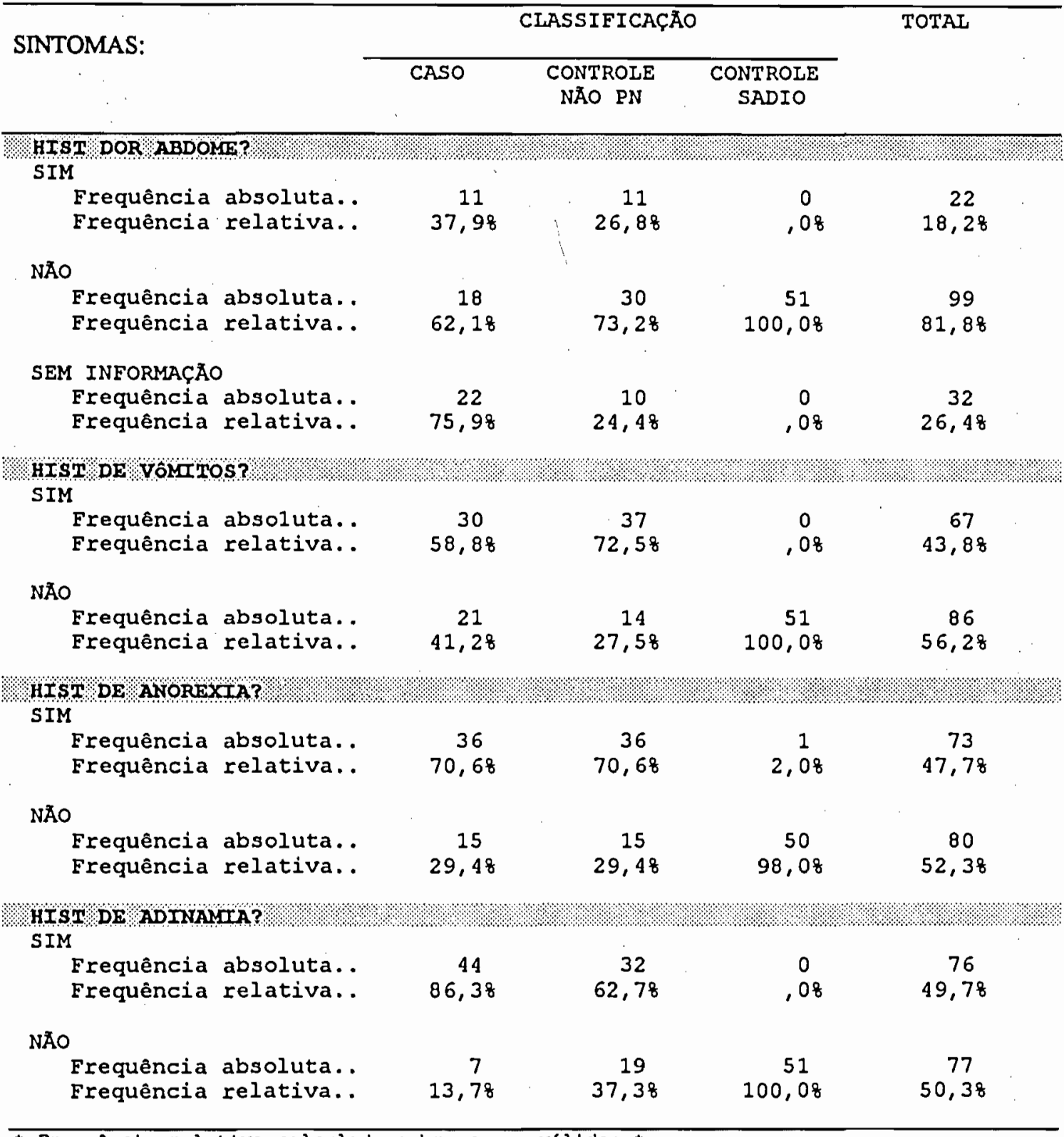

* Erequêncla relativa calculada sobre casos válldos *

$\mathrm{Na}$ tabela XVII abaixo registram-se as informações referentes ao exame físico dos pacientes. Todos os grupos mostraram valores totalmente independentes para temperatura, frequência cardiaca, frequência respiratória. Grau de dispnéia, de toxemia e todos os sinais de ausculta não foram diferentes entre controles não respiratórios e controles sadios, mas foram significativamente diferentes em relação a estes e os casos. 
TABELAXVII - HISTÓRIA CLINICA DOS PACIENTES SEGUNDO SUA CLASSIFICAÇÄO: EXAME FÍSICO

\begin{tabular}{|c|c|c|c|c|}
\hline \multirow{2}{*}{ SINAIS: } & \multicolumn{3}{|c|}{ CLASSIFICAÇĀO } & \multirow[t]{2}{*}{ TOTAI } \\
\hline & CASO & $\begin{array}{l}\text { CONTROLE } \\
\text { NAO PN }\end{array}$ & $\begin{array}{l}\text { CONTROLE } \\
\text { SADIO }\end{array}$ & \\
\hline \multicolumn{5}{|l|}{ TEMOPERATURA MEDIDA } \\
\hline $\begin{array}{l}\text { Média.............. } \\
\text { Erro padrăo....... } \\
\text { Numero de casos }\end{array}$ & $\begin{array}{r}37,53 \\
, 12\end{array}$ & $\begin{array}{r}36,95 \\
, 11\end{array}$ & $\begin{array}{r}36,55 \\
, 03\end{array}$ & $\begin{array}{r}37,00 \\
.06\end{array}$ \\
\hline válidos......... & 48 & 51 & 51 & 150 \\
\hline \multicolumn{5}{|l|}{ EREQUÉNCIA CARDIACA } \\
\hline $\begin{array}{l}\text { Média } \ldots \ldots \ldots \ldots \\
\text { Erro padrăo........... } \\
\text { Numero de casos }\end{array}$ & $\begin{array}{r}134,06 \\
2,45\end{array}$ & $\begin{array}{r}121,69 \\
2,69\end{array}$ & $\begin{array}{r}109,76 \\
2,60\end{array}$ & $\begin{array}{r}121,84 \\
1,68\end{array}$ \\
\hline válidos.......... & 51 & 51 & 51 & 153 \\
\hline \multicolumn{5}{|l|}{ AREQUENCIA RESPIRATÓRIA } \\
\hline 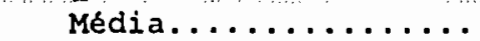 & 47,73 & 31,04 & 24,52 & 34,49 \\
\hline $\begin{array}{l}\text { Erro padrão.......... } \\
\text { Numero de casos }\end{array}$ & 1,63 & 1,52 & 1,37 & 1,18 \\
\hline válidos......... & 51 & 51 & 50 & 152 \\
\hline \multicolumn{5}{|l|}{$\begin{array}{l}\text { GRAU DE DISPNEIA } \\
\text { AUSENTE }\end{array}$} \\
\hline $\begin{array}{l}\text { Frequência absoluta.. } \\
\text { Frequência relativa.. }\end{array}$ & $\begin{array}{c}5 \\
9,88\end{array}$ & $\begin{array}{c}48 \\
94,18\end{array}$ & $\begin{array}{c}51 \\
100,08\end{array}$ & $\begin{array}{c}104 \\
68,08\end{array}$ \\
\hline $\begin{array}{l}\text { Frequência absoluta.. } \\
\text { Frequência relativa.. }\end{array}$ & $\begin{array}{c}22 \\
43,18\end{array}$ & $\begin{array}{c}3 \\
5,98\end{array}$ & .08 & $\begin{array}{c}25 \\
16,38\end{array}$ \\
\hline \multicolumn{5}{|l|}{++} \\
\hline $\begin{array}{l}\text { Frequência absoluta.. } \\
\text { Frequência relativa.. }\end{array}$ & $\begin{array}{c}19 \\
37,38\end{array}$ & $\begin{array}{l}0 \\
, 08\end{array}$ & .08 & $\begin{array}{c}19 \\
12,48\end{array}$ \\
\hline \multicolumn{5}{|l|}{+++} \\
\hline $\begin{array}{l}\text { Frequência absoluta.. } \\
\text { Frequência relativa.. }\end{array}$ & $\begin{array}{c}4 \\
7,88\end{array}$ & $\begin{array}{l}0 \\
.08\end{array}$ & 0 & $\begin{array}{c}4 \\
2,68\end{array}$ \\
\hline $\begin{array}{l}++++ \\
\text { Frequência absoluta.. } \\
\text { Frequência relativa.. }\end{array}$ & $2 ; 08$ & $\begin{array}{l}0 \\
.08\end{array}$ & $\begin{array}{l}0 \\
.08\end{array}$ & $\frac{1}{78}$ \\
\hline \multicolumn{5}{|l|}{ GRAU DE CIANOSE } \\
\hline $\begin{array}{l}\text { AUSENTE } \\
\text { Frequência absoluta.. } \\
\text { Frequência relativa.. }\end{array}$ & $\begin{array}{c}51 \\
100,08\end{array}$ & $\begin{array}{c}51 \\
100,08\end{array}$ & $\begin{array}{c}51 \\
100,08\end{array}$ & $\begin{array}{c}153 \\
100,08\end{array}$ \\
\hline
\end{tabular}


Continuaçăo

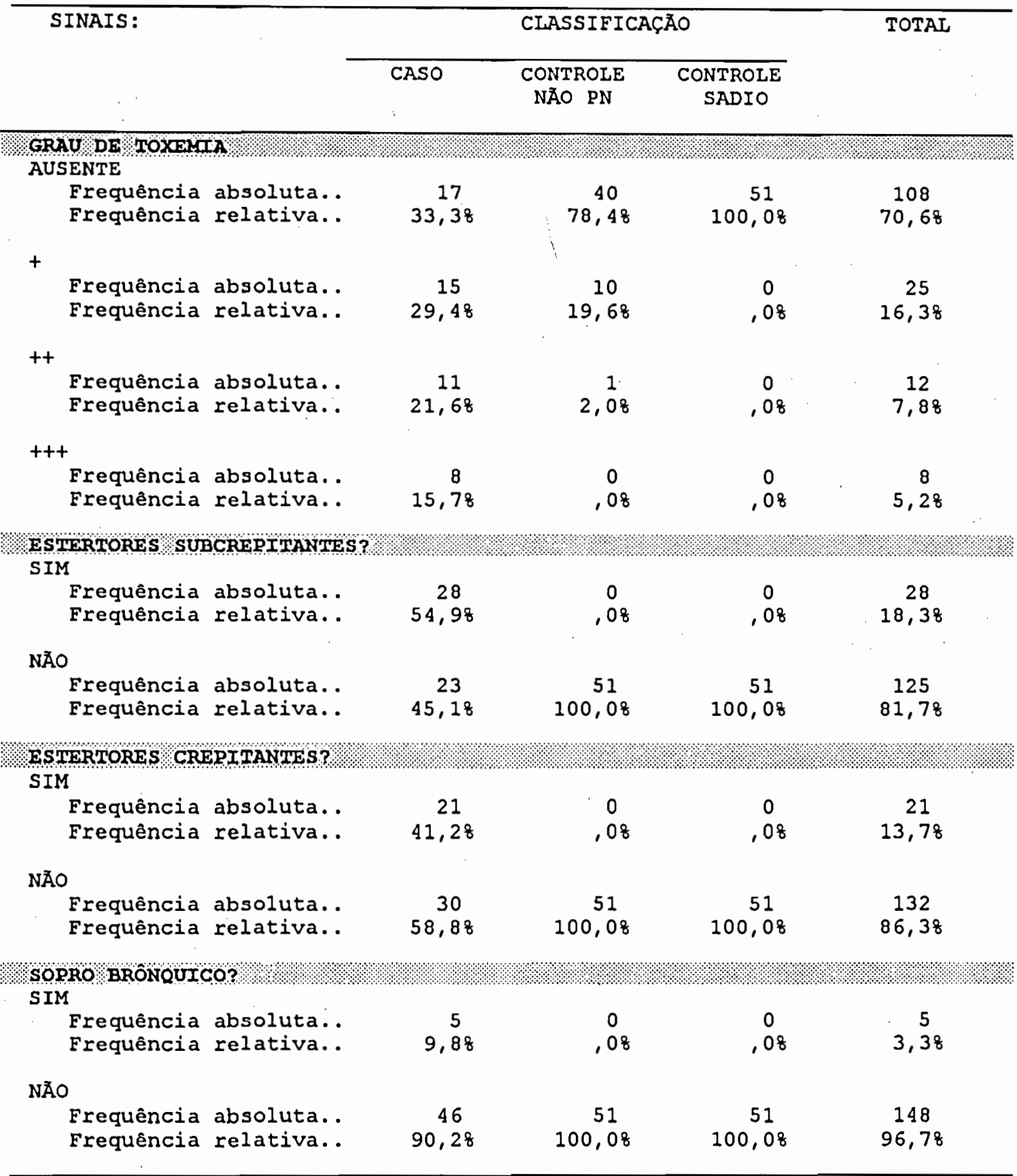

* Erequencla relativa calculada sobre casos vál1dos *

Todos os diagnósticos de pneumonia foram confirmados com exame radiológico. A Tabela XVIII descreve os achados radiológicos, a conclusão diagnóstica e a conduta adotada. Embora todos os casos fossem de pneumonia adquirida na comunidade, a maioria (78\%) consistiu de casos requerendo tratamento hospitalar. 
TABELA XVIII - CARACTERIZAÇÃO DO DIAGNÓSTICO DE PNEUMONIA: EXAME RADIOLÓGICO, HIPÓTESE ETIOLÓGICA E CONDUTA ADOTADA

\begin{tabular}{|c|c|c|}
\hline \multirow[t]{2}{*}{ SINAIS: } & \multicolumn{2}{|c|}{ FREQUENCIAS } \\
\hline & $\begin{array}{l}\text { Frequencia } \\
\text { absoluta }\end{array}$ & $\begin{array}{l}\text { Frequência } \\
\text { relativa }\end{array}$ \\
\hline \multicolumn{3}{|c|}{ 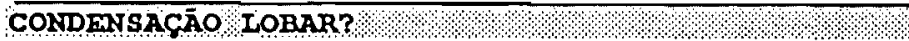 } \\
\hline $\operatorname{sIM} \ldots \ldots \ldots \ldots \ldots \ldots \ldots$ & 15 & 29,48 \\
\hline NAO $\ldots \ldots \ldots \ldots \ldots \ldots \ldots$ & 36 & 70,68 \\
\hline \multicolumn{3}{|l|}{ CONDENSAGAO TNTERSTICIAL? } \\
\hline $\operatorname{sIM} \ldots \ldots \ldots \ldots \ldots \ldots$ & 41 & 80,48 \\
\hline 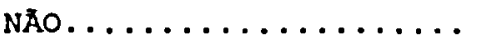 & 10 & 19,68 \\
\hline \multicolumn{3}{|c|}{ PNEUMATOCELE? } \\
\hline NẢO............ & 51 & 100,08 \\
\hline \multicolumn{3}{|l|}{ ATELECTASTA? } \\
\hline $\operatorname{sIM} \ldots \ldots \ldots \ldots \ldots \ldots$ & 3 & 5,98 \\
\hline NAO . . . . . . . . . & 48 & 94,18 \\
\hline \multicolumn{3}{|l|}{ DERRAME? } \\
\hline $\operatorname{siM} \ldots \ldots \ldots \ldots \ldots \ldots \ldots$ & 8 & 15,78 \\
\hline NAO................. & 43 & 84,38 \\
\hline \multicolumn{3}{|l|}{ HIPERUNSUFTAÇAOO? } \\
\hline sIM.............. & 1 & 2,08 \\
\hline NÃO............... & 50 & 98,08 \\
\hline \multicolumn{3}{|l|}{ PNEUMOTORAX? } \\
\hline NAO $\ldots \ldots \ldots \ldots \ldots \ldots \ldots$ & 51 & 100,08 \\
\hline \multicolumn{3}{|c|}{ ETIOLOGIA SUPOSTA DA PNEUMONIA } \\
\hline BACTERIANA. . . . . . & 51 & 100,08 \\
\hline \multicolumn{3}{|l|}{ CONDUTA ADOTADA: } \\
\hline TRATA/O AMBULATORIAL.... & 7 & 13,78 \\
\hline TRATA/O HOSPITALAR. . . . . & 40 & 78,48 \\
\hline ALTA............ & 4 & 7,88 \\
\hline
\end{tabular}

Tomando-se em conta que sintomas relatados por pacientes não tem a ob etividade das informações dos sinais colhidos pelo médico, com vistas a testar-se a capacidade dos sinais observados corretamente distinguir casos e controles, procedeu-se a uma análise discriminante multivariada tomando os sinais clínicos como variáveis independentes e a classificaçằ do paciente como variável dependente. O Quadro II mostra a saida resultante do processamento destes dados pelo pacote estatístico SPSS-PC/+. Numa seleçäo aleatória uma amostra (analysis sample) de 91 registros (27 casos, 33 controles não respiratórios, 31 controles sadios) foi usada para análise e outros 58 foram separados para teste de resultados 
(hold out sample). Quatro registros foram desprezados por falta de informação em alguma variável. Observando-se as médias das funções derivadas da análise, podese entender que a função 1 separa principalmente casos de controles e que a função 2 completa a discriminação entre controles não respiratórios e sadios. Na primeira função destacam-se pela ordem as imagens radiológicas, a dispnéia e a ausculta, enquanto que na função 2 destacam-se frequência cardiaca, frequência respiratória e temperatura. Ambas as funções mostraram consistência estatística $(p<, 05$ para Wilk's Lambda) e todas as variáveis foram aceitas no modelo com alta significancia estatística $(p<=, 01)$. A representação gráfica do cruzamento das duas funções na identificação de casos e controles (mapa temitorial) mostra que as variáveis consideradas (sinais clínicos) separam perfeitamente os três grupos de pacientes. A comparação entre situação real e predita pelo modelo discriminante mostra concordância de $79 \%$ na amostra de análise e de $75 \%$ na amostra de teste de resultados, sugerindo uma conclusão de que a aplicação das variáveis estudadas (sinais clínicos) deva, em tal proporção, conduzir a uma correta identificação de crianças com pneumonia (estudo casos no presente), crianças doentes mas afetadas por outras doenças (controles não respiratórios no presente estudo) e crianças sadias (controles sadios). 
QUADRO II- RESULTADO DA ANÁLISE DISCRIMINANTE MULTIVARIADA PARA AFERIÇÃO DA CAPACIDADE DOS SINAIS CLÍNICOS EM DISTINGUIR CASOS E CONTROLES

\begin{tabular}{|c|c|c|c|c|c|}
\hline \multicolumn{3}{|c|}{$\begin{array}{l}\text { Rotated correlations between } \\
\text { discriminating variables and } \\
\text { canonical discriminant functions }\end{array}$} & \multicolumn{3}{|c|}{$\begin{array}{c}\text { Canonical Discriminant Function } \\
\text { evaluated at Group Means } \\
\text { (Group Centroids) }\end{array}$} \\
\hline & FUNC 1 & FUNC 2 & & & \\
\hline \begin{tabular}{|l} 
RX \\
DISPNÉIA
\end{tabular} & $\begin{array}{l}.70546 * \\
52277^{\star}\end{array}$ &,- 03887 & Group & FUNC 1 & FUNC $\quad 2$ \\
\hline AUSCULTA & $43719 *$ & $\begin{array}{r}10587 \\
-\quad 02409\end{array}$ & $\frac{1}{2}$ & $\begin{array}{r}4,48614 \\
-1,86030\end{array}$ & $\begin{array}{l}1,76416 \\
-\quad 15821\end{array}$ \\
\hline FC &,- 09430 & , $61619 *$ & 3 & $-1,92696$ & $-1,36811$ \\
\hline FR & .06682 & $.61202^{\star}$ & & & \\
\hline TEMP &,- 00864 & $.48628 *$ & & & \\
\hline TOXEMIA & .06333 & $38846^{\star}$ & & & \\
\hline
\end{tabular}

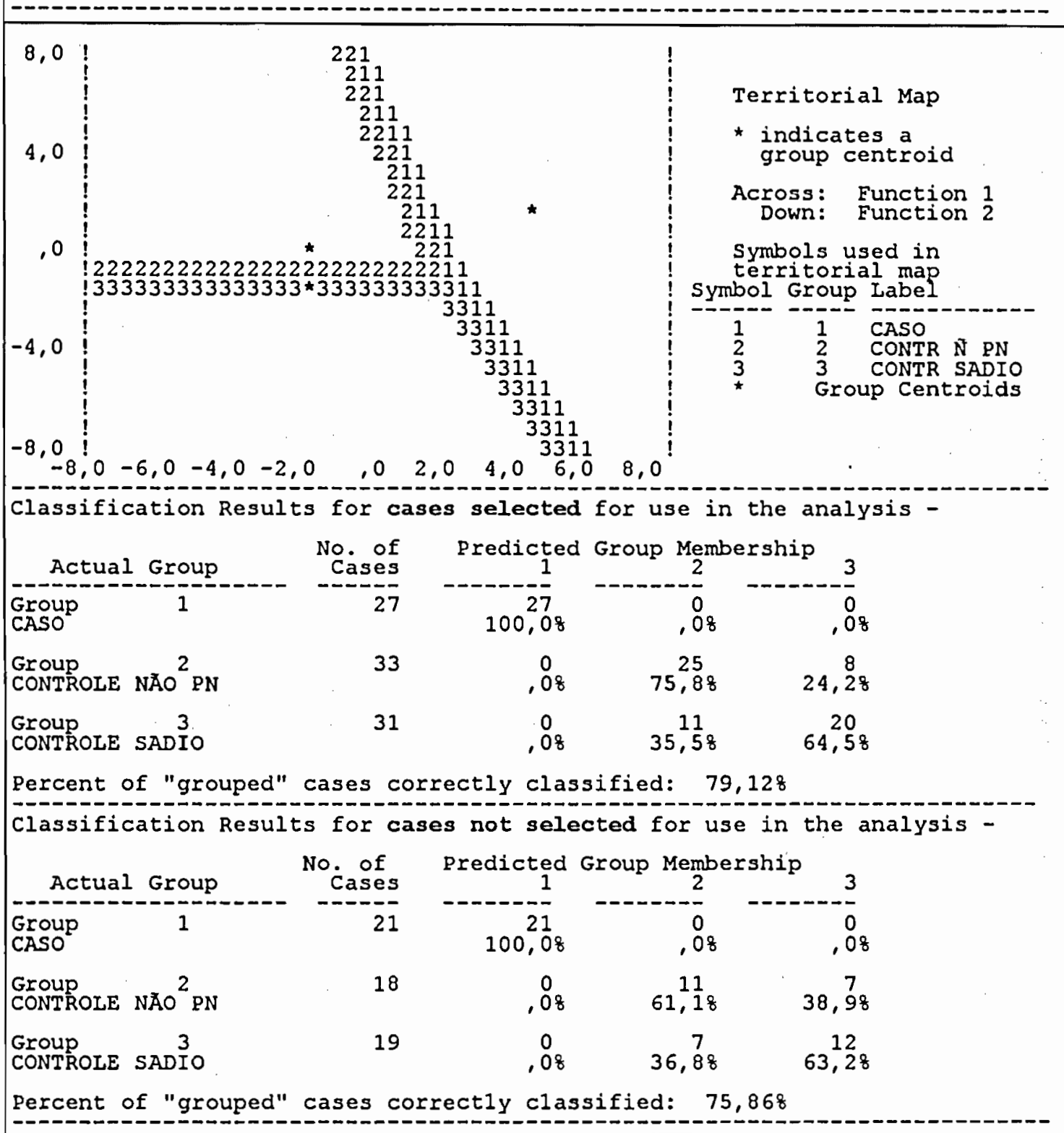




\section{III.5 - INVESTIGAÇÃO DO DIAGNÓSTICO DE DOENÇA CHIADORA RECORRENTE: Caracterização da presença do fator de exposição}

A aplicação do questionário de investigação da exposição a doença chiadora recorrente resultou nas informações que seguem descritas na Tabela XIX. As perguntas em que houve diferença entre casos e controles com significância estatística $\left(p<, 05\right.$ para $X^{2}$ medido através do teste de Kruskal-Wallis) foram história anterior de diagnóstico de asma e história anterior de chiado no peito. No entanto. analisando-se os grupos dois a dois encontra-se que, para as duas perguntas, os controles sadios, que apresentam frequências intermediárias, não diferem (ao nível de $p<=, 05)$ nem de casos nem de controles não respiratórios, embora estes difiram entre si.

$\mathrm{Na}$ conclusão do médico, a frequência de portadores de chiado crônico é significativamente mais elevada entre os casos, que diferem dos controles não respiratórios e dos controles sadios, enquanto estes últimos podem ser considerados iguais. Dos 41 pacientes diagnosticados como portadores de doença chiadora recorrente, à exceção de um, todos tinham história compativel com as premissas préfixadas pelo estudo: história de asma diagnosticada por médico com pelo menos um episódio de dispnéia nos últimos 12 meses ou história de chiado com dispnéia que melhora com broncodilatador e pelo menos 2 episódios registrados nos últimos 12 meses. A exceção foi um controle sadio com história de 7 episódios de chiado com dispnéia nos últimos 12 meses sem referência a uso de broncodilatador, embora com referência a susceptibilidade a mudanças de temperatura.

TABELA XIX - CARACTERIZAÇÃO DO DIAGNÓSTICO DE EXPOSIÇÃO

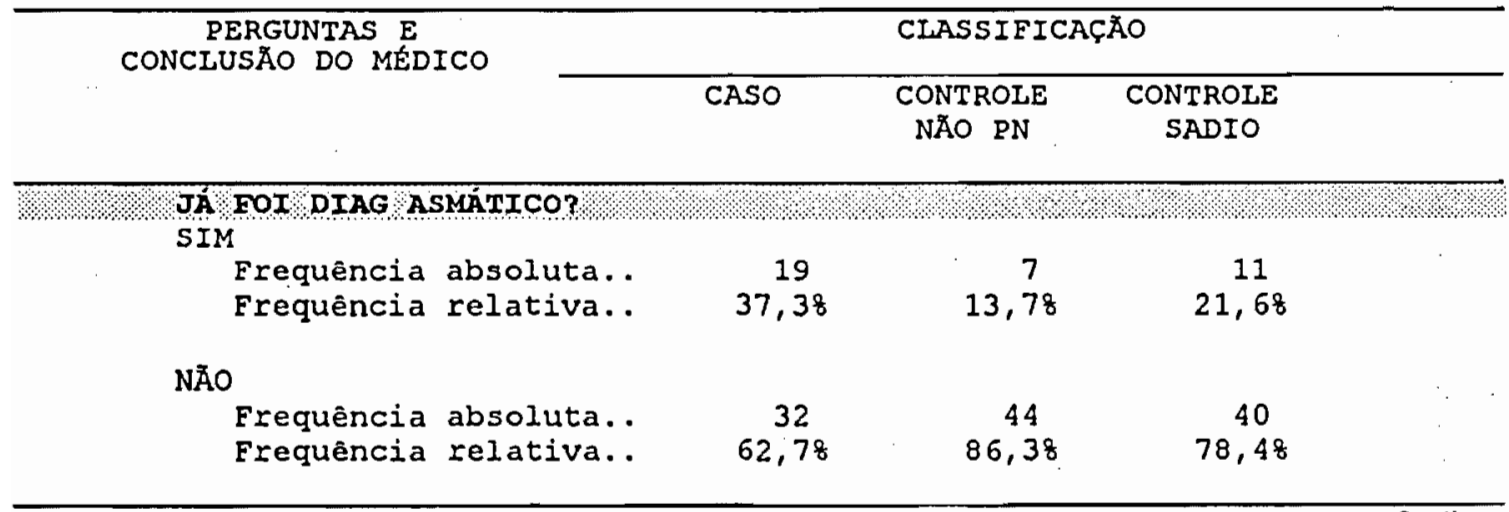


Continuaçato

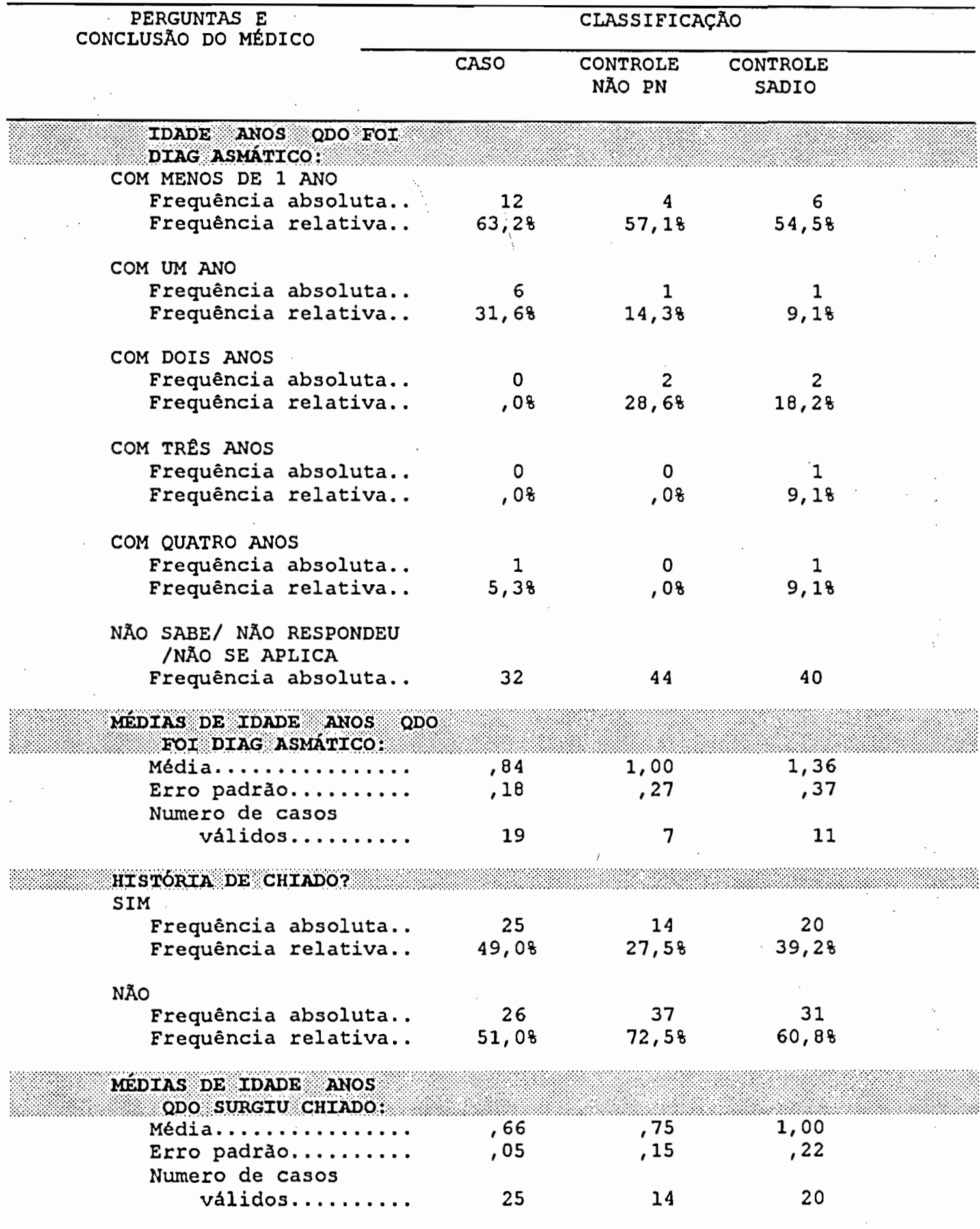


Continuaçáo

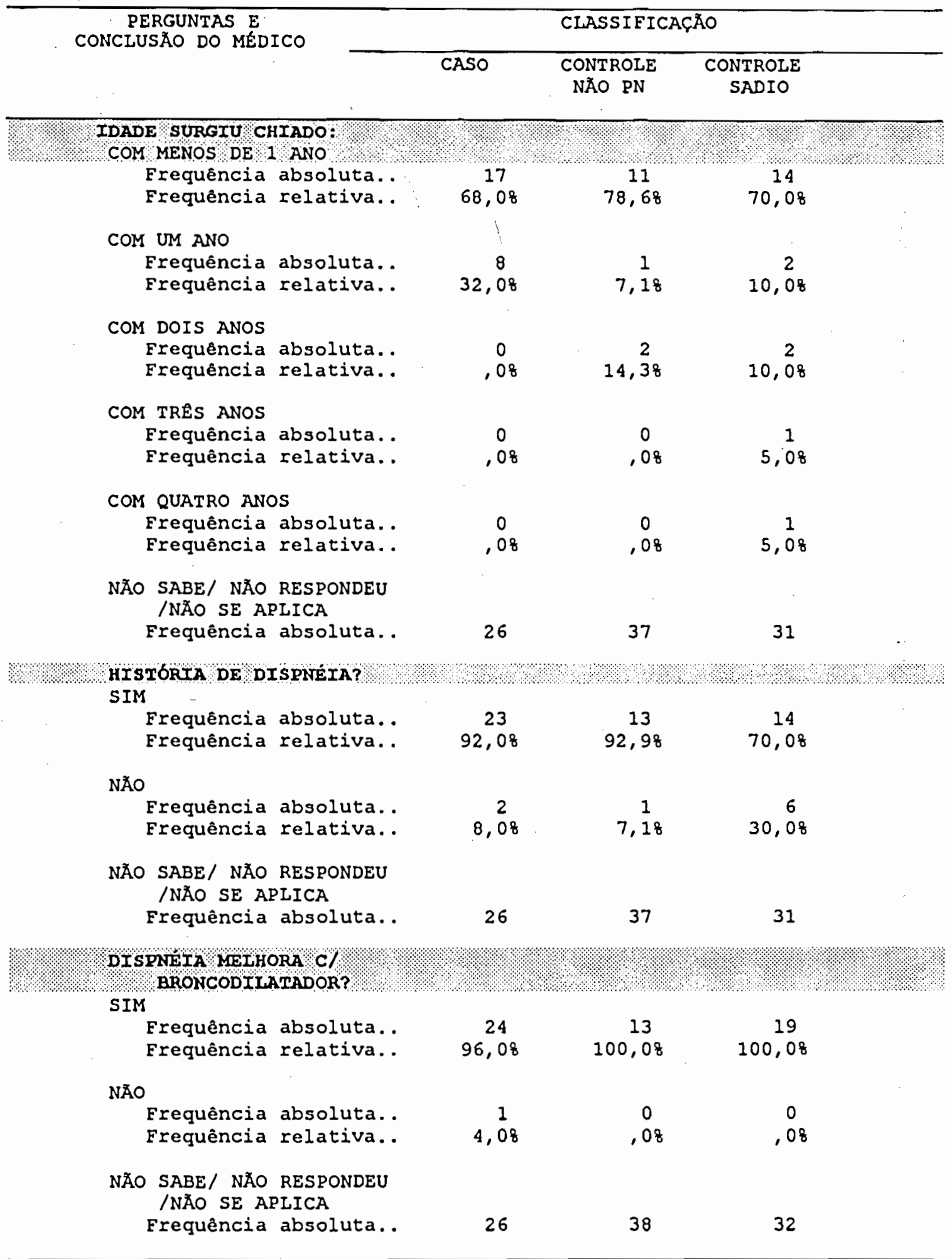


Continuaçăo

\begin{tabular}{|c|c|c|c|c|}
\hline \multirow{2}{*}{$\begin{array}{c}\text { PERGUNTAS E } \\
\text { CONCLUSÃO DO MEDICO }\end{array}$} & \multicolumn{4}{|c|}{ CLASSIFICAÇĀO } \\
\hline & CASO & $\begin{array}{l}\text { CONTROLE } \\
\text { NAO PN }\end{array}$ & $\begin{array}{l}\text { CONTROLE } \\
\text { SADIO }\end{array}$ & \\
\hline \multicolumn{5}{|c|}{$\begin{array}{l}\text { CHIADO ACOMPANHA EPISÓDIOS INFEC RESPIRATÓRTA? } \\
\text { SIM }\end{array}$} \\
\hline $\begin{array}{l}\text { Frequência absoluta.. } \\
\text { Frequência relativa.. }\end{array}$ & 96,08 & $\begin{array}{c}14 \\
100,08\end{array}$ & $\begin{array}{c}18 \\
90,08\end{array}$ & \\
\hline \multicolumn{5}{|l|}{ NÅO } \\
\hline $\begin{array}{l}\text { Frequência absoluta.. } \\
\text { Frequência relativa.. }\end{array}$ & $\begin{array}{l}1 \\
4,08\end{array}$ & $\begin{array}{l}0 \\
.08\end{array}$ & $\begin{array}{c}2 \\
10,08\end{array}$ & \\
\hline \multicolumn{5}{|l|}{$\begin{array}{l}\text { NÅO SABE/ NÃO RESPONDEU } \\
\text { /NÃO SE APLICA }\end{array}$} \\
\hline \multicolumn{5}{|c|}{$\begin{array}{l}\text { CHYADO APARECE FORA DE EPISÓDIOS DE INEEC RESPIRAT? } \\
\text { SIM }\end{array}$} \\
\hline $\begin{array}{l}\text { Frequência absoluta.. } \\
\text { Frequência relativa.. }\end{array}$ & 29,28 & 21,48 & 27,8 & \\
\hline \multicolumn{5}{|l|}{ NĀO } \\
\hline $\begin{array}{l}\text { Frequência absoluta.. } \\
\text { Frequência relativa.. }\end{array}$ & $\begin{array}{c}17 \\
70,88\end{array}$ & $\begin{array}{c}11 \\
78,68\end{array}$ & 72,28 & \\
\hline $\begin{array}{l}\text { NAO SABE/ NÃO RESPONDEU } \\
\text { /NÅO SE APLICA }\end{array}$ & & & & $\cdot$ \\
\hline Frequência absoluta.. & 27 & 37 & 33 & \\
\hline
\end{tabular}

FATORES DESENCADEANIES

RESERIADOS DESENCADEAM CHIADO? SIM

Frequência absoluta.. 24

Frequência relativa.. 96,08

14

100,08

18

NÃo

Frequência absoluta..

4,08

0

90,08

Frequencia relativa..

.08

2

NÅO SABE/ NÃO RESPONDEU

/NÃO SE APLICA

Frequência absoluta..

26

37

31

YUDANÇA TEMP DA CHIADO? SIM

Frequência absoluta..

22
88,08

50,08

$50, \frac{9}{08}$

NÃO

Frequência absoluta..

Frequencia relativa..

$12, \frac{3}{08}$

50,08

9

NÅO SABE/ NAO RESPONDEU

/NAOO SE APLICA

Erequência absoluta.. 
Continuaça

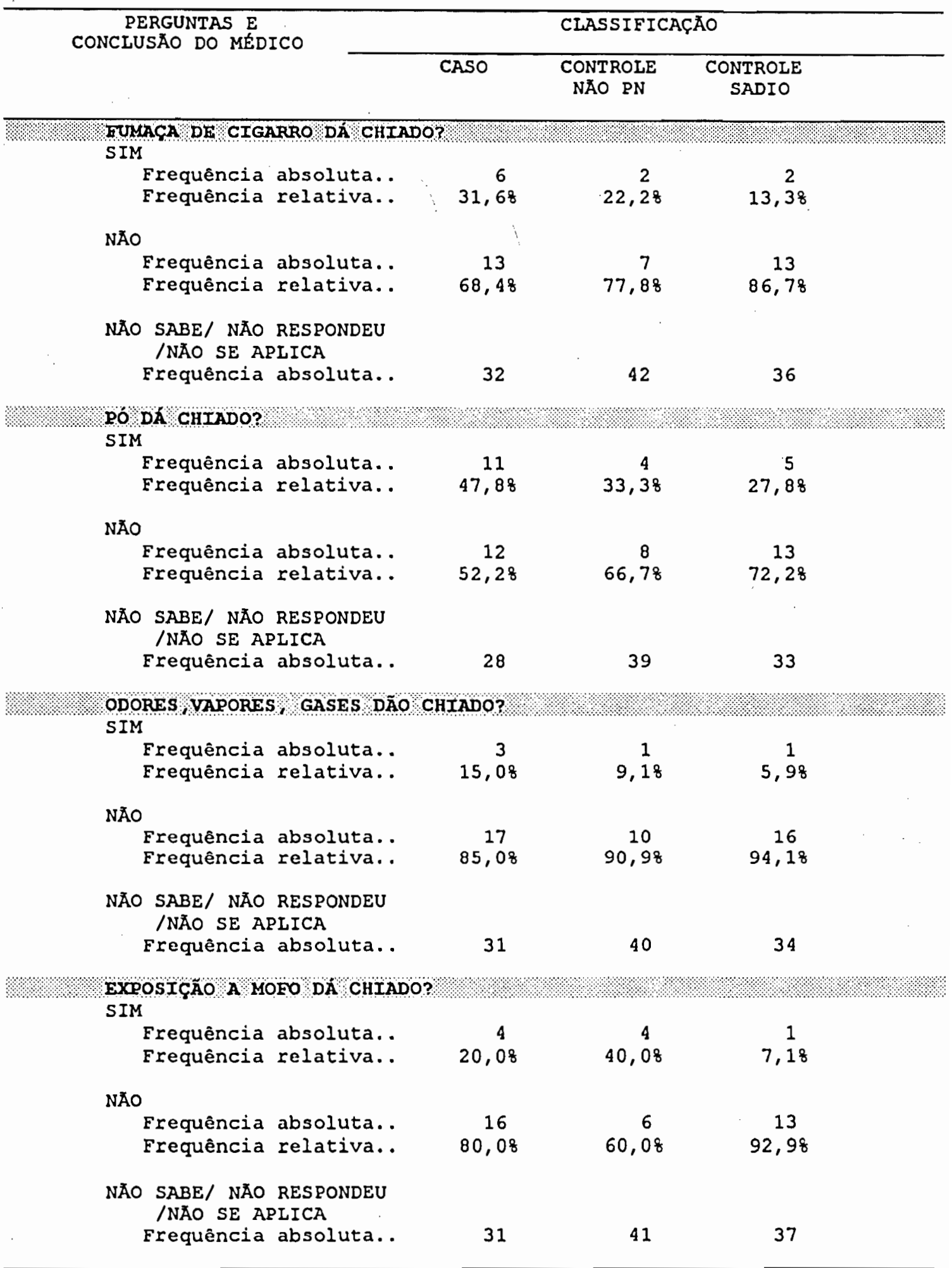


Continuaçăo

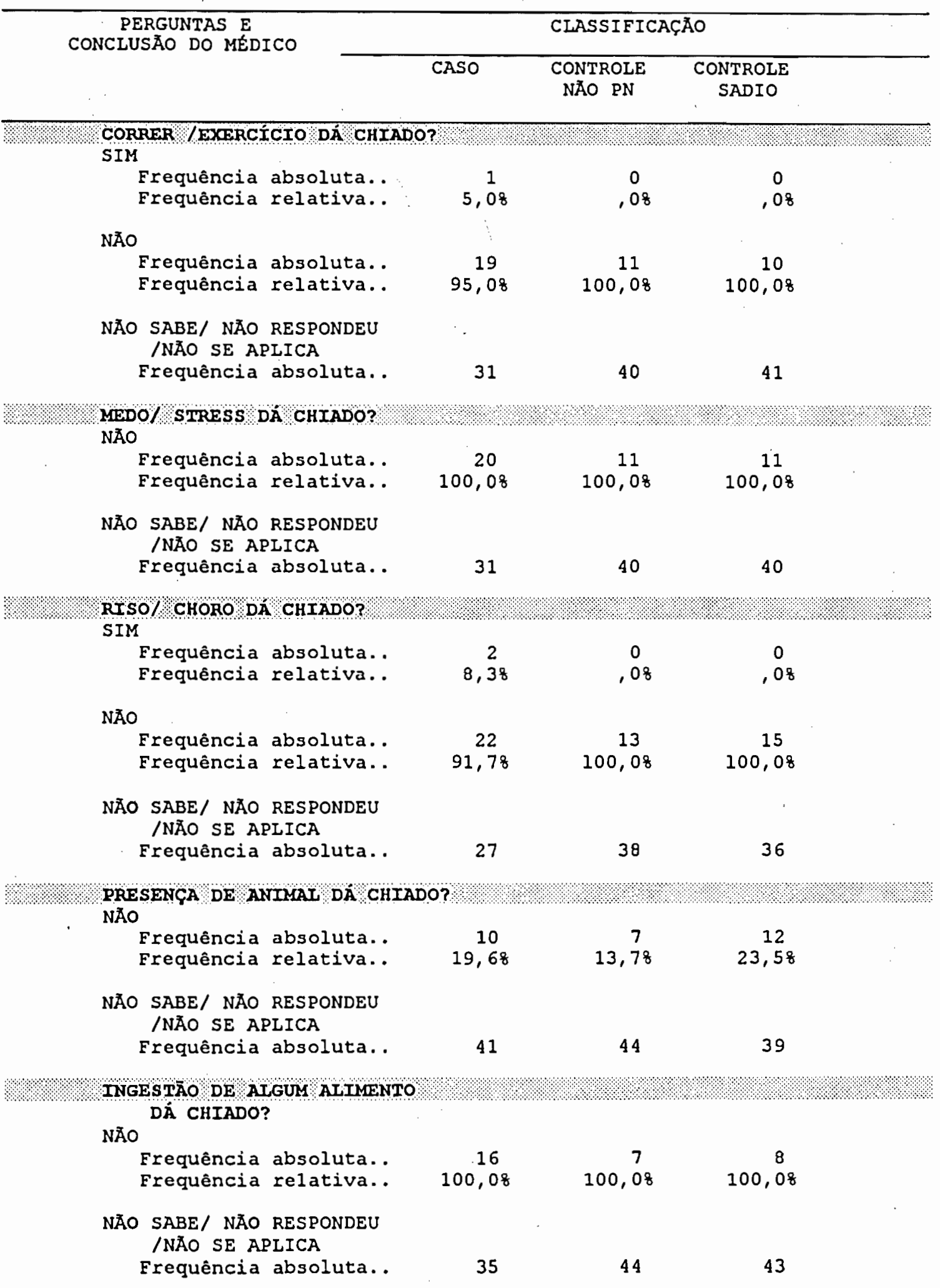


Continuagáa

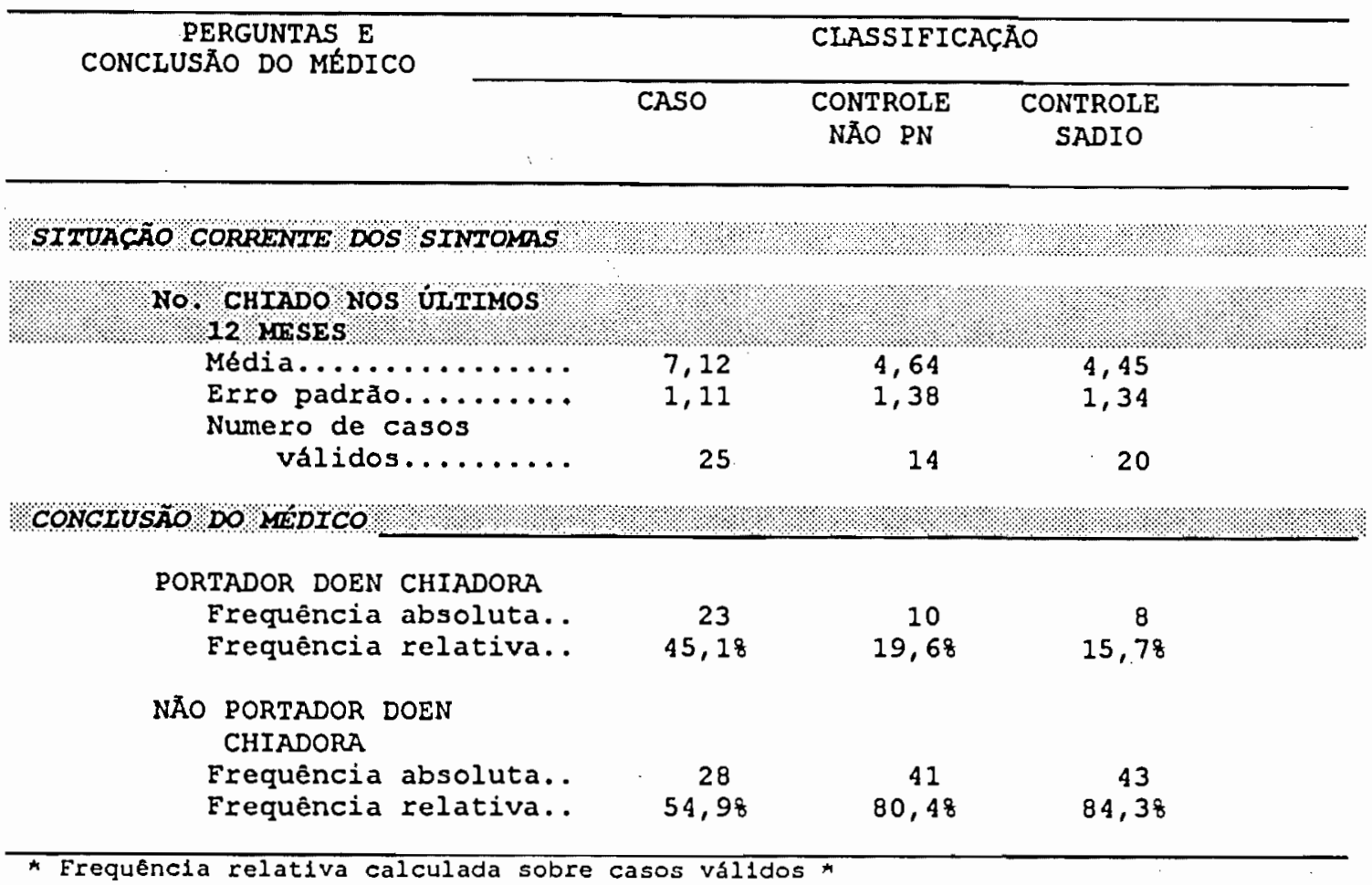

Com vistas a avaliar a confiabilidade das informaçōes coletadas pelo questionário de investigação da exposiçăo, procurou-se medir sua repitibilidade. Foram entrevistados 30 pacientes após um sorteio aleatório de 62 . Os 32 restantes não puderam ser localizados quer por endereço inconsistente ou por à não residirem no endereço declarado. A inconsistência de endereço foi particularmente expressiva em favelas onde os números das residências não obedeciam a qualquer ordem e os pacientes só podiam ser localizados quando a família era conhecida na comunidade. Todos os pacientes contatados aceitaram submeter-se a nova entrevista mas, no entanto, 2 não compareceram e foram substituidos para garantir-se 30 registros de repitibilidade, cerca de $20 \%$ do total de crianças estudadas.

Dos pacientes re-entrevistados 12 eram casos (40\%), 13 eram controles não respiratórios (43\%) e 5 eram controle sadios (17\%). O tempo decorrido entre a primeira e a segunda entrevista foi em média de 45 dias, 23 no minimo e 78 no máximo. A Tabela XX mostra os resultados das comparações entre as entrevistas: 
TABELAXX: AVALIAÇĀO DE REPITIBILIDADE DAS INFORMAÇŐES RELATIVAS À EXPOSIÇÃO AO FATOR DE RISCO INVESTIGADO

\begin{tabular}{|c|c|c|c|c|}
\hline \multirow[t]{2}{*}{ Perguntas do questionário } & \multirow{2}{*}{$\begin{array}{c}\text { concor } \\
\text { dancia } \\
\text { medida } \\
\text { (esperada) }\end{array}$} & \multirow{2}{*}{\multicolumn{3}{|c|}{ 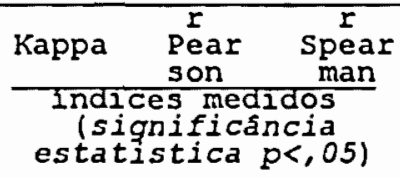 }} \\
\hline & & & & \\
\hline $\begin{array}{l}\text { A criança já foi anteriormente } \\
\text { diagnosticada como asmática? }\end{array}$ & $\begin{array}{l}90,0 \\
(70,0)\end{array}$ & $\begin{array}{l}.66 \\
(S)\end{array}$ & $\begin{array}{l}.67 \\
(S)\end{array}$ & $\begin{array}{l}67 \\
(S)\end{array}$ \\
\hline $\begin{array}{l}\text { Com que idade este diagnostico } \\
\text { foi feito pela primeira vez? }\end{array}$ & $\begin{array}{l}75,0 \\
(50,0)\end{array}$ & $\begin{array}{l}50 \\
(N)\end{array}$ & $\begin{array}{l}.57 \\
(N)\end{array}$ & $\begin{array}{l}57 \\
(N)\end{array}$ \\
\hline $\begin{array}{l}\text { A criança tem história de chiado } \\
\text { referida pela mà ou outro familiar }\end{array}$ & $\begin{array}{l}83,3 \\
(51,3)\end{array}$ & . & $\begin{array}{l}69 \\
(S)\end{array}$ & $\begin{array}{l}69 \\
(S)\end{array}$ \\
\hline $\begin{array}{l}\text { Com que idade este chiado } \\
\text { ocorreu pela primeira vez? }\end{array}$ & $\begin{array}{l}66,6 \\
(45,0)\end{array}$ & $\begin{array}{l}38 \\
(N)\end{array}$ & $\begin{array}{l}58 \\
(N)\end{array}$ & $\begin{array}{l}58 \\
(N)\end{array}$ \\
\hline $\begin{array}{l}\text { A criança tem história dispnéia } \\
\text { junto com o chiado? }\end{array}$ & $\begin{array}{r}100 \\
(n c)\end{array}$ & nc & nc & nc \\
\hline $\begin{array}{l}\text { Esse chiado melhora com o uso de } \\
\text { broncodilatadores (Vo, inalação)? }\end{array}$ & $\begin{array}{l}100 \\
(\text { nc) }\end{array}$ & ne & ne & nc \\
\hline $\begin{array}{l}\text { Esse chiado apareceu durante epi } \\
\text { sódio de infeção resp. aguda? }\end{array}$ & $\begin{array}{l}100 \\
(n C)\end{array}$ & nc & nc & nc \\
\hline $\begin{array}{l}\text { Esse chiado ocorreu fora de epi- } \\
\text { sódio de infeç̧ăo resp. aguda? }\end{array}$ & $\begin{array}{l}84,4 \\
(60,0)\end{array}$ & $\begin{array}{l}57 \\
(N)\end{array}$ & $\begin{array}{l}.63 \\
(N)\end{array}$ & $\begin{array}{l}63 \\
(N)\end{array}$ \\
\hline \multicolumn{5}{|l|}{$\begin{array}{l}\text { Esse chiado pode ser desencadeado por } \\
\text { qualquer dos seguintes fatores: }\end{array}$} \\
\hline RESERIADO/INE.RESP. & $\begin{array}{r}100 \\
(n c)\end{array}$ & ne & nc & nc \\
\hline MUDANÇA TEMPERATURA & $\begin{array}{l}66,7 \\
(60,0)\end{array}$ & $\begin{array}{l}18 \\
(N)\end{array}$ & $\begin{array}{l}18 \\
(N)\end{array}$ & $\begin{array}{l}18 \\
(N)\end{array}$ \\
\hline FUMAÇA DE CIGARRO & $\begin{array}{r}100 \\
(\Omega C)\end{array}$ & nc & nc & nc \\
\hline Pó & $\begin{array}{l}77,8 \\
(64,4)\end{array}$ & $\begin{array}{l}35 \\
(N)\end{array}$ & $\begin{array}{l}35 \\
(N)\end{array}$ & $\begin{array}{l}35 \\
(N)\end{array}$ \\
\hline ODORES, VAPORES, GASES & $\begin{array}{l}100 \\
(77,5)\end{array}$ & $\stackrel{1}{(s)}$ & $\stackrel{1}{(s)}$ & $\stackrel{1}{(s)}$ \\
\hline MOFO & $\begin{array}{l}83,3 \\
(n c)\end{array}$ & ne & nc & nc \\
\hline CORRER/EXERCICIO & $\begin{array}{l}66,7 \\
(n c)\end{array}$ & nc & nc & ne \\
\hline MEDO / PREOCUPACÃO & $\begin{array}{r}100 \\
(n c)\end{array}$ & nc & ne & nc \\
\hline RISO / CHORO & $\begin{array}{l}88,9 \\
(n c)\end{array}$ & nc & ne & ne \\
\hline
\end{tabular}


Contlnuagato

\begin{tabular}{|c|c|c|c|c|}
\hline Perguntas do questionário & $\begin{array}{c}8 \\
\text { concor } \\
\text { dância } \\
\text { medida } \\
\text { (esperada) }\end{array}$ & \multicolumn{3}{|c|}{$\begin{array}{c}\text { indices medidos } \\
\text { (significancia } \\
\text { estatistica } p<, 05 \text { ) }\end{array}$} \\
\hline PRESENÇA DE ANIMAIS & $\begin{array}{r}100 \\
(n c)\end{array}$ & nc & nc & nc \\
\hline INGESTÃO DE ALIMENTOS & $\begin{array}{l}100 \\
(n c)\end{array}$ & nc & nc & nc \\
\hline $\begin{array}{l}\text { Quantas vezes o chiado ocorreu } \\
\text { nos últimos } 12 \text { meses? }\end{array}$ & $\begin{array}{l}11,1 \\
(11,1)\end{array}$ & $\begin{array}{r}-, 02 \\
(N)\end{array}$ & $\begin{array}{l}72 \\
(S)\end{array}$ & $\begin{array}{l}50 \\
(N)\end{array}$ \\
\hline Conclusão do médico entrevistad & & & & \\
\hline $\begin{array}{l}\text { PORTADOR DE DOENÇA CHIADORA } \\
\text { RECORRENTE OU NAO }\end{array}$ & $\begin{array}{l}80,0 \\
(60,6)\end{array}$ & $\begin{array}{l}49 \\
(S)\end{array}$ & $\begin{array}{l}49 \\
(S)\end{array}$ & $\begin{array}{l}49 \\
(S)\end{array}$ \\
\hline Concordancia geral & $\begin{array}{l}76,7 \\
(48,3)\end{array}$ & $\begin{array}{l}.65 \\
(S)\end{array}$ & $\begin{array}{l}.75 \\
(5)\end{array}$ & $\begin{array}{l}71 \\
(S)\end{array}$ \\
\hline
\end{tabular}

nc $=$ nåo calculável $\mathrm{N}=$ năo slgnificante $\mathbf{S}=$ significante

Onze das vinte variáveis não puderam ter indicadores calculados porque a tabela de contingência resultou quer numa única célula, casos em que a concordância foi $100 \%$, ou numa única linha ou coluna, casos em que a concordância foi menor que $100 \%$. Para estes casos o único indicador possivel de concordância foi a frequência de casos com respostas idênticas. Para as 9 variáveis que tiveram seus indicadores calculados, avaliando-se os valores de " $k$ " pode-se concluir que os niveis de concordância foram: fraco em $3(33,3 \%)$ casos, regular em $4(44,4 \%)$ casos e bom em $2(22,2 \%)$ casos.

Vários indicadores não conseguiram significância estatistica ao nivel de 5\%, 0 que pode ser explicado pelo fato de que várias perguntas, em estando condicionadas a perguntas anteriores, aplicavam-se apenas aos pacientes que naquelas apresentassem respostas positivas, podendo resultar em número muito pequeno a despeito da amostra total representar $20 \%$ de todos os pacientes. Assim é que todas as perguntas de caracterização da história de asma ou chiado só se aplicavam aos pacientes com respostas positivas a estas questões e estes somaram apenas $13 \mathrm{com}$ concordância de história positiva entre a primeira e segunda entrevista. Horowitz e $\mathrm{Yu}^{117}$ estudando repitibilidade de informaçōes de pacientes com câncer de mama 
concluiram que haveriam 4 tipos de erros em coleta de dados: dados conflitantes, informação não registrada, informação não disponivel e erro de transcrição. O conflito de dados dada a mudança de "status" do paciente e a indisponibilidade de informação dada a inaplicabilidade de algumas questōes a vários pacientes, constituem os limites da avaliação de repitibilidade do questionário usado neste estudo para investigação da exposição dos pacientes ao fator de risco pesquisado.

O Gráfico XIV mostra as curvas de distribuição das respostas médias dos pacientes na primeira e segunda entrevista, calculadas a partir da redução de cada resposta individual a mesma base unitária na forma de desvios padronizados da média (ZRES). As curvas não se sobrepõem mas mostram tendências semelhantes e comparadas por teste estatistico ( $T$-test) resultam idênticas $(p=1,00)$.

GRÁFICO XIV - CURVAS DE DISTRIBUIÇÃO DE FREQUÉNCIA DAS MÉDIAS DE RESPOSTAS Ȧ INVESTIGAÇĀO DE EXPOSIÇĀO NAS PRIMEIRA E SEGUNDA ENTREVISTAS

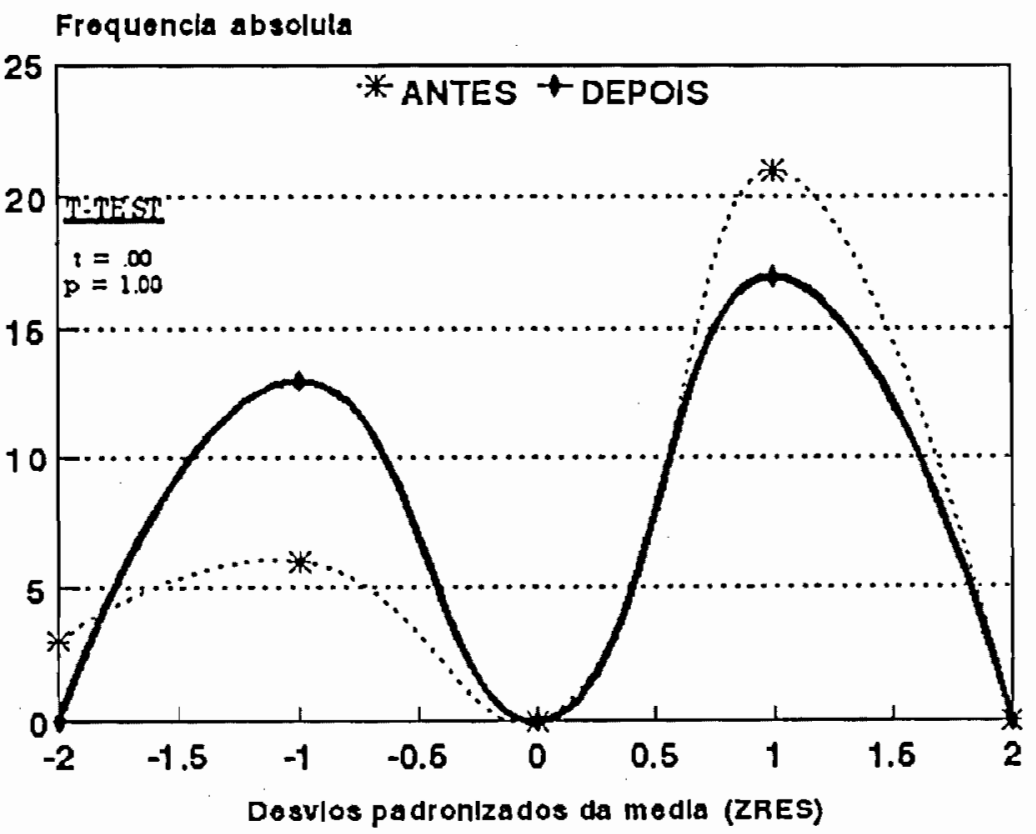




\section{III.6 - INVESTIGAÇÃO DA RELAÇÃO ENTRE DOENÇA CHIADORA RECORRENTE E PNEUMONIA}

Uma tabela de contingência entre as duas variáveis como a apresentada na Tabela XXI, já permite observar uma maior concentração de casos de doença chiadora recorrente entre os pacientes com pneumonia. De fato, o cálculo do odds ratio resulta em 3,83 (intervalo de confiança de $95 \%$ entre 1,80 e 8,11 ), sugerindo que os portadores de doença chiadora recorrente tenham chances até 4 vezes maiores que outras crianças para apresentarem pneumonia. O cálculo do risco atribuivel resulta em 33,33\% (intervalo de confiança de $95 \%$ entre $13,16 \%$ e $48,83 \%$ ), sugerindo que a incidência de pneumonia na população de usuários do Hospital Universitário poderia ter uma redução desta ordem se a ação predisponente da doença chiadora recorrente fosse controlada.

TABELAXXI - CRUZAMENTO SIMPLES DE VARIÁVEIS: PRESENÇA E AUSÊNCIA DE PNEUMONIA E DOENÇA CHIADORA

\begin{tabular}{lccc}
\hline PNEUMONIA & \multicolumn{2}{c}{ DOENÇA CHIADORA } & TOTAL \\
\cline { 2 - 4 } & $\begin{array}{c}\text { PORTADOR DE } \\
\text { DOENÇA CHIADORA }\end{array}$ & $\begin{array}{c}\text { NÂO PORTADOR DE } \\
\text { DOENCCA CHIADORA }\end{array}$ & \\
\hline COM PNEUMONIA & 23 & 28 & 51 \\
& & & $33,3 \%$ \\
SEM PNEUMONIA & 18 & 84 & 102 \\
& & & $66,7 \%$ \\
\hline Total & 41 & 112 & 153 \\
$\%$ & $26,8 \%$ & $73,2 \%$ & $100 \%$ \\
\hline
\end{tabular}

Para se avaliar esta relação sob o controle de variáveis de confusão procedeu-se a análise por regressão logistica que permite o cálculo do efeito de cada variável independente controlado pelo efeito de todas as outras variáveis aceitas para - modelo. Foram consideradas como candidatas a variáveis independentes na funçäo logística todas aquelas que nas análises univariadas que precederam este passo revelaram-se com diferenças significantes entre casos e controles, bem como aquelas predefinidas como potenciais variàveis de confusão, a saber:

SEXO: Tendo sido considerada para o pareamento de casos e controles, foi incluídas no modêlo logistico contrastando sexo masculino contra feminino;

IDADE EM MESES: Também utilizada no pareamento de casos e controles, foi considerada em sua forma original de variável continua; 
EDUCAÇÃO DO PAl: Foi inserida no modelo como variável categórica, tomando o nivel superior completo como referência para contraste com os outros niveis de educação formal;

EDUCAÇĀO DA MĀE: Foi inserida no modelo como variável categórica, tomando o nível superior completo como referência para contraste com os outros niveis de educação formal;

HISTORIA DE LARINGOTRAQUEOBRONQUITE: Foi considerada como variável categórica aceitando-se como história positiva uma referência a episódios anteriores de laringotraqueobronquite com pelo menos um episódio tendo sido registrado nos últimos 12 meses. A história positiva é contrastada com história negativa;

POLUIÇÃO AMBIENTAL: Foi computada como uma variável categórica ordinal representando a soma de fatores ambientais adversos: fogão a lenha, carvão ou querosene dentro de casa; falta de insolação no quarto da criança, presença de umidade com mofo dentro de casa; e residência próxima a fabrica que expele gases, odores ou fumaça. Embora na amostra estudada estas variáveis não tenham expresso diferenças significantes, foram consideradas para estratificação de efeito à vista do conhecimento existente de sua influência sobre doenças respiratórias;

No DE FUMANTES NA CASA: Embora sem significância estatistica na amostra, foi considerada pelas mesmas razões da variável anterior. Sendo uma variável, contínua com valores na amostra entre os limites de 0 e 7 , foi tratada isoladamente ao invés de ser considerada na computação da variável anterior, poluição;

ATOPIA NA FAMÍLIA: Foi computada como uma variável categórica ordinal representando a soma de antecedentes familiares positivos para atopia: pai, mãe e irmãos. Também foi considerada para a análise logística a vista da relação estreita conhecida entre atopia e doenças chiadoras;

ASMA NA FAMILIA: Foi computada como uma variável categórica ordinal representando a soma de antecedentes familiares positivos para asma: pai, mãe e irmãos. Também foi considerada para a análise logística por ter uma relação conhecida, embora disputada na literatura, com a presença de doenças chiadoras;

RENDA FAMILIAR: Foi transformada de variável contínua em categórica ordinal, contrastando-se renda alta com rendas média e baixa. Os cortes para criação das categorias observou os percentis $33,33 \%$ e $66,66 \%$ da distribuição de frequência dos valores originais; 
COMPOSIÇÃO MORADIA: Variável binomial na origem, considerada no modelo logistico por ter registrado diferença significativa entre casos e controles. Contrasta moradia coletiva com moradia individual;

SITUAÇĀO DO BANHEIRO NA CASA: Considerada para análise por ter mostrado distribuição desigual entre casos e controles, podendo ser um indicador indireto de situação socioeconômica. Variável categórica permite contrastar o efeito de ausência de banheiro e banheiro fora de casa com a situação de banheiro dentro de casa;

NN PESSOAS DORMINDO NO QUARTO DA CRIANÇA: Considerada por ter registrado diferenças entre casos e controles. Variável contínua com limites entre $1 \mathrm{e}$ 12;

CONCLUSĀO DO MÉDICO: Categorização binomial do paciente como portador ou não de doença chiadora recorrente. A presença de doença é contrastada com a ausência de modo a medir risco devido à doença.

O método usado foi o de iniciar-se a análise com entrada forçada de todas as variáveis, para em seguida retirar-se em passos sucessivos as de menor significância estatistica até alcançar-se um modelo final reunindo apenas as variáveis que a amostra estudada permita admitir inferências estatisticamente significantes ("backward stepwise method"). O Quadro III apresenta o resultado do primeiro passo de análise onde todas as variáveis participam do modelo, e um resumo dos passos seguintes descrevendo as variáveis que foram sendo sucessivamente desprezadas por falta de significância estatistica. Há que se registrar que numa análise logistica as variáveis descartadas por motivos estatísticos trazem ainda informações não despreziveis a respeito de seus efeitos sobre o fenômeno estudado e, se a nivel da amostra estudada não se pode alcançar conclusāo segura, pode-se, no entanto, conseguir indicaçōes consistentes para investigaçōes posteriores. No Quadro III percebe-se que um modelo com todas as variáveis só teria a situação de portador de doença chiadora recorrente como uma condição de efeito estatisticamente significante sobre a presença de pneumonia, com um risco $(\operatorname{Exp}(B))$ de desenvolvimento da infecção quase 17 vezes maior para crianças portadoras de tal condição. Entretanto, as variáveis educação dos pais, poluição ambiental, atopia da criança, asma na familia, renda familiar e número de pessoas dormindo no quarto da criança mostram efeitos que são consistentes com o conhecimento disponivel sobre a epidemiologia da pneumonia e portanto merecem atenção. 
QUADRO III - RESULTADOS DE REGRESSÃO LOGISTICA: MODELO COM TODAS AS VARIÁVEIS E SEQÜEENCIA DE PASSOS DE EXCLUSÃO DE VARIÁVEIS AQUÉM DA TOLERÂNCIA ESTATISTICA

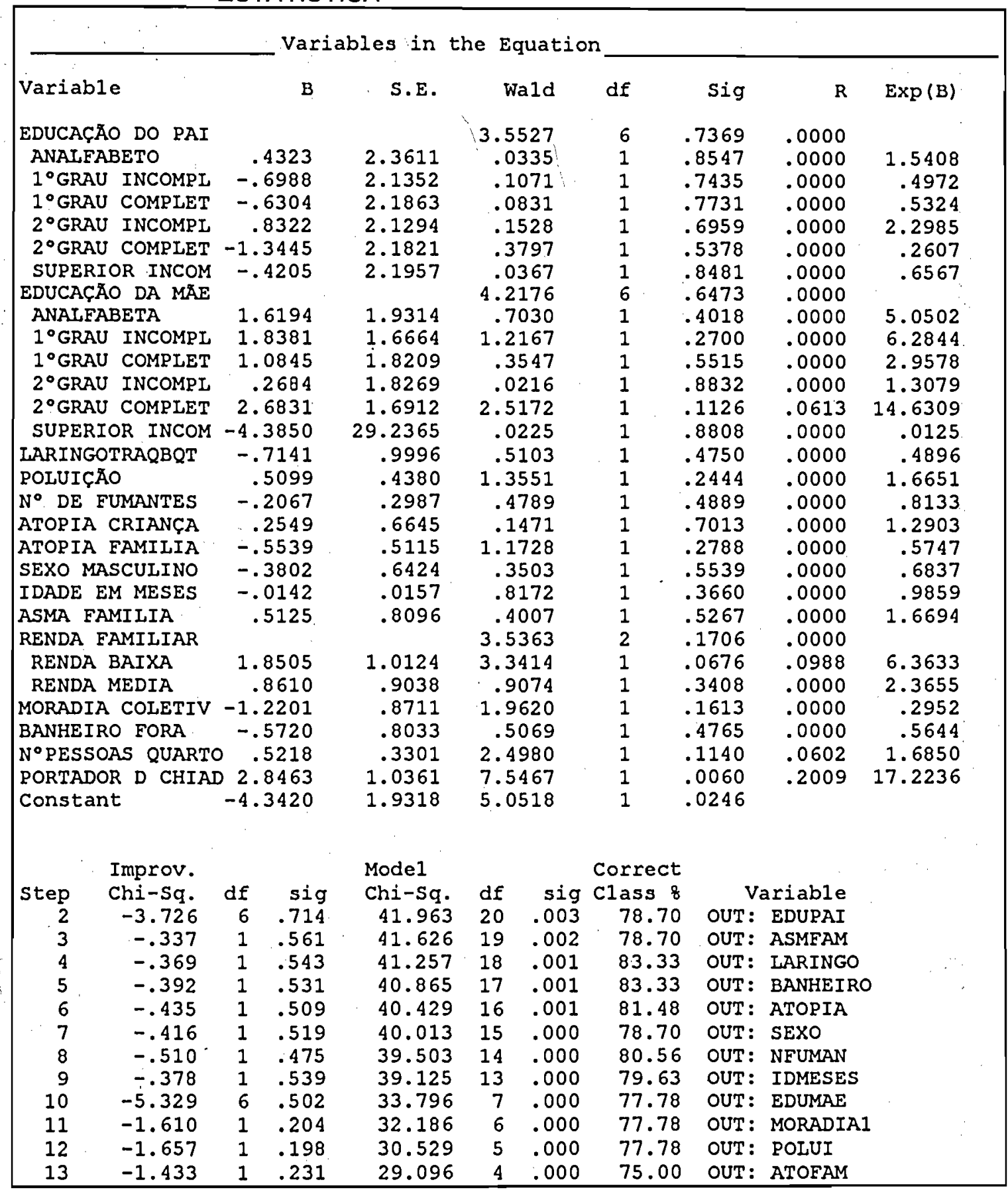

O modelo final da regressão é apresentado no Quadro IV, bem como sua avaliação de consistência, que é elevada à vista dos valores altos das medidas de ajustamento (likelihood e goodness-of-fit). Crianças portadoras de doença chiadora recorrente apresentam um risco de desenvolvimento de pneumonia que é 7 vezes 
maior do que crianças não portadoras desta doença que pertencem a mesma classe de renda familiar e que dormem em quartos com o mesmo número de pessoas. Variaçōes nestas últimas condições, por si mesmas também fortemente predisponentes ao desenvolvimento de pneumonia, têm efeito multiplicativo sobre 0 risco de infecção. Uma criança de familia de baixa renda, que durma em quarto com uma outra pessoa e que seja portadora de doença chiadora recorrente tem 59 (5,59 $\times 1,49 \times 7,07$ ou $e^{(1,72+, 40+1,95)}$ ) vezes mais chances de ter pneumonia do que uma criança de família de renda alta, que durma sozinha e que nāo seja portadora de doença chiadora recorrente. Aplicando-se a fórmula sugerida por Kelsey et al. ${ }^{118}$ para estabelecer relação entre medidas comparadas (odds ratio) e probabilidade de doença, a saber:

Probabilidade

$$
=\frac{1}{1+e^{-\left(A+B_{1} X_{1}+B_{2} x_{2}+\ldots B_{n} X_{n}\right)}}
$$

de doença

poder-se-ia concluir que uma tal criança teria uma probabilidade de apresentar pneumonia da ordem de $62,76 \%$.

QUADRO IV - RESULTADOS DE REGRESSÃO LOGISTICA: MODELO FINAL COM AVALIAÇÃO DE CONSISTÉNCIA

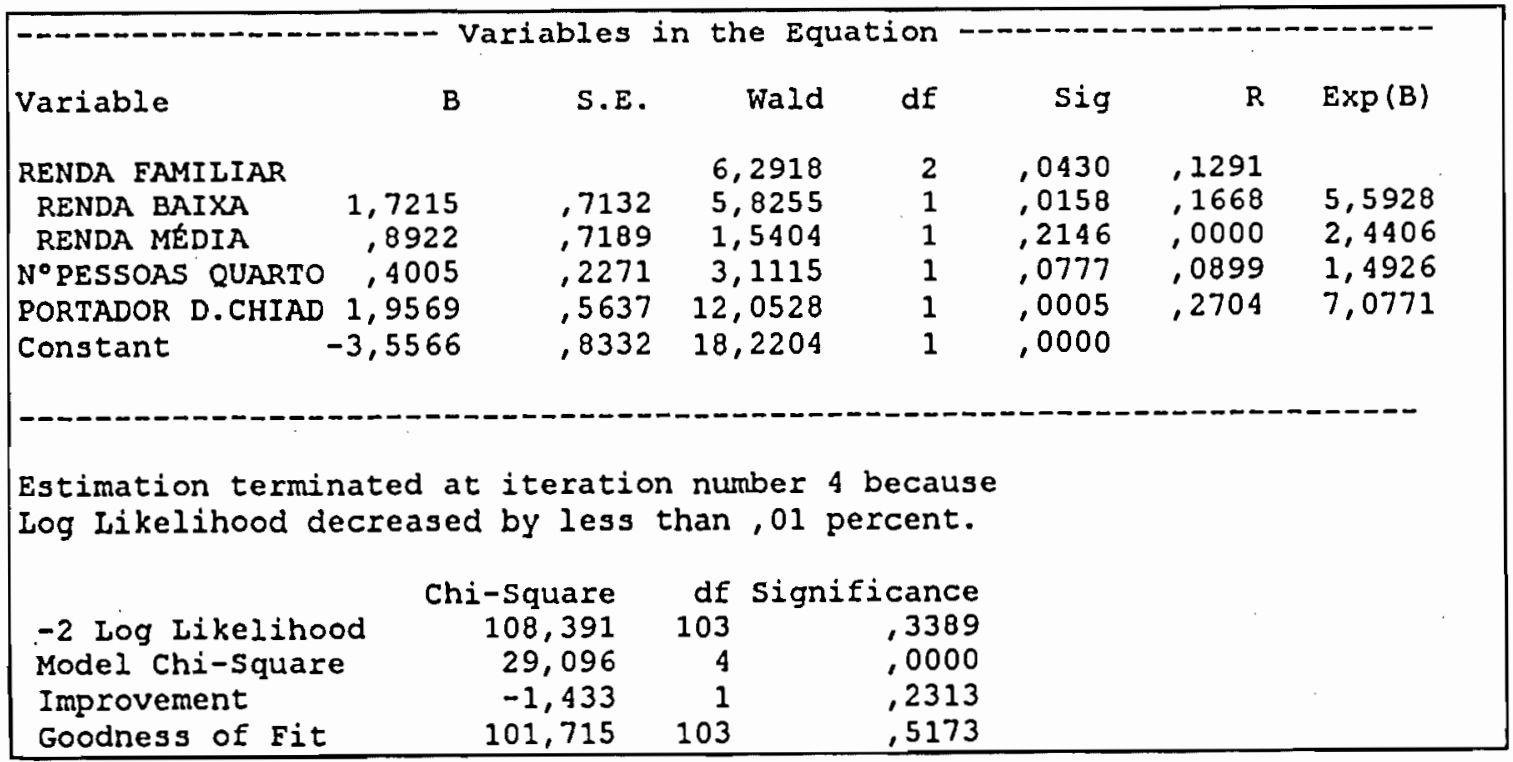

118 Kelsey JL, Thompson WD, Evans AS. Methods in observational epidemiology. New York: Oxlord University Press, 1986: 113 
O cálculo do risco atribuivel à doença chiadora recorrente na incidência de pneumonia a partir do odds ratio identificado na regressão logistica, tomando em conta como possivel frequência do fator de exposição na população de usuários do Hospital Universitário sua frequência entre os controles (18 chiadores em 102 controles), resulta em $51,42 \%$. Ou seja, tendo resultado numa estimativa de risco superior à derivada do simples cruzamento de variáveis (33,33\% identificados acima), - odds ratio agora encontrado sugeriria que um impacto de controle da doença chiadora pudesse ser ainda maior. 
IV - COMENTÁRIOS 


\section{IV.1 - SOBRE A EPIDEMIOLOGIA}

Nas últimas décadas a epidemiologia da asma vem progressivamente recobrando um espaço perdido para as ciências básicas como a bioquimica, a farmacologia e a imunologia no estudo da asma. Peter Barney, epidemiologista dedicado às doenças respiratórias, em Editorial da revista Thorax ${ }^{119}$, destaca que é a epidemiologia que pode hoje fazer avançar o conhecimento da doença porque suas grandes questões como etiopatogenia, relação com fatores ambientais, estratégias de tratamento e etc. já não podem ser respondidas pela abordagem elementar das ciências básicas, requerendo um enfoque mais complexo, próprio da epidemiologia. Ressalva que complexidade neste contexto não significa sofisticação acadêmica (sic) mas método mais abrangente que inclui influências gerais e multivariadas através da observação de fenômenos na natureza e não apenas no ambiente privilegiado do laboratório. Enfatiza os limites do conhecimento experimental dizendo: "To show that a duke in general can be drowned in a butt of Malmsey does not give dukes in general any realistic estimate of the risk they take when entering a cellar. In the same way showing that inhalation of platelet activating factor, or even allergen, increases reactivity in the airway does not show how much risk this poses either to asthmatic or to non-asthmatic individuals in the world at large.".

O trabalho do epidemiologista é testar hipóteses, mas o seu desafio maior é elaborar tais hipóteses. Dai que, embora haja distinção entre os campos das ciências médicas, a interdisciplinariedade da produção do conhecimento é irrecorrivel. Os conhecimentos produzidos por uma área devem indicar caminhos para a investigação em outra, estabelecendo-se complementaridade entre os campos do conhecimento antes de qualquer disputa de hegemonia. Do epidemiologista não se espera uma especialização semelhante à do clínico no campo a que se dedique, mas sem dúvida sua prática não prescinde de uma adequada informação em fisiologia, patologia, propedêutica e terapêutica. As mais importantes contribuições ao conhecimento epidemiológico das doenças respiratórias da infância, particularmente da asma, têm resultado do trabalho em grupo de clínicos e epidemiologistas, como testemunham os 
trabalhos de Anne Woolcock na Austrália, Peter Barney e Anne Tattersfield na Inglaterra, Malcon Sears antes na Nova Zelândia e atualmente no Canadá, Frank Speizer inicialmente na Inglaterra e nos últimos anos nos Estados Unidos, etc..

A epidemiologia da asma talvez tenha sido inaugurada por Henry Salter ${ }^{120}$, médico inglês de meados do século $X I X$, que também foi o primeiro a utilizar metilxantinas no tratamento da doença, pois prescrevia café forte para seus pacientes. Enquanto Trousseau ${ }^{121}$, com o forte empirismo que marca os grandes clínicos, para defender a hipótese de que a asma seria hereditária recorria até a sua experiência pessoal de asmático sugerindo ser ela uma herança materna, Salter fazia as seguintes anotaçōes:

"Is asma hereditary? I think there can be no doubt that it is. Not that I would take this fact for granted, or on the common assertion that it is so; for I think this is a point on which error might be apt to anise. In all diseases a certain number of cases will be found in which, on the mere doctrine of chances, the parents, or other members of the family, have been similanly affected. But I think the number of cases in which there is a family history of asthma is greater than will admit of this explanation. Out of 217 cases in which I have noted this circunstances I find distinct traces of inheritance in 84; in 133 not. It appears, therefore, to be inherited (and my numbers are sufficient to give some evidence) in rather more than two cases out of every five; that is, in the proportion of 2 to $3 "$.

É notável seu raciocínio probabilístico deduzindo que uma associação só se confirmaria demonstrada uma frequência de eventos superior à esperada por simples obra do acaso. Delimitando uma amostra, ele introduz o conceito de denominador, principio básico e hoje bem estabelecido em epidemiologia que rejeita análises de números absolutos. Mais ainda, fazendo cálculos de participação proporcional do fator de exposição, a herança da doença, antecipa o conceito de odds ratio ou risco. Encontrando uma frequência de exposição de dois casos em cada cinco, só the faltou a malicia de ter esta frequência medida entre não doentes como forma de dimensionar objetivamente a ação do acaso para ratificar sua hipótese de que tal frequência fosse mesmo muito elevada. Tivera ele assim procedido, e ter-se-ia tido um estudo digno do título caso-controle.

120. Salter HH. On asthma: its pathology and treatment. London: John Churchill, 1860.

121. Trosseau A. Lectures on clinical medicine delivered at the Hotel-Dieu, Paris. (Translated by PV Bazire). London: Sydenham Society, 1868. 
Antes de Salter, pode-se registrar que John Millar, já em 1769, havia mostrado tino epidemiológico em seu livro dedicado a asma em crianças ao ter demonstrado uma preocupação de delimitação de amostra, pois nas primeiras páginas de seu livro declara $^{122}$ que suas observações haviam sido realizadas no condado de Northumberland e distritos de Roxburgh e Berwick e que, embora julgasse a doença universal, restringia o escopo de seus comentários a estas áreas geográficas. Mais ainda, tendo recorrido a séries históricas de registros para inferir relações de causa e efeito entre variações ambientais e a doença, superou o nivel individual da observação clínica para exercitar-se na abordagem coletiva do processo saúde-doença, tendo registrado ${ }^{123}$ :

"... from a meteorological register, very accurately kept by a clergyman, for almost 14 years, compared with a journal of diseases during that period, it appears, that the asthma was more or less frequent according to the state of the weather, that it prevailed most in spring and autmn, and especially in moist seasons, accompained with east and north-easterly winds, when the weather was variable, when the mercury in the barometer was fluctuating, but generally low, and when sudden changes from frost to thaw were frequent."

Segundo Almeida Filho ${ }^{124}$, a epidemiologia opõe-se à clinica em termos epistemológicos porque aplica um raciocínio indutivo, ou seja com observações particulares infere generalizaçōes, enquanto que a clinica tem raciocínio dedutivo, ou seja à partir de informações gerais deduz o enquadramento da situação particular de um doente. Enquanto a clínica, associando-se as ciências biológicas, cultiva um atavismo metodológico que se referencia no conhecimento empírico de realidades objetivas e mensuráveis, a epidemiologia incorpora a incerteza trocando a afirmação pelo dimensionamento de possibilidades de realidade, sem contudo comprometer-se com declarações definitivas. Ambas lidam com relações de causa e efeito, porém com referenciais teóricos distintos.

122. Millar J. Observations on the asthma, and on the hooping cough. London: T. Cadel, T. Noteman, Johnston \& Payne, 1769: 7.

123. Millar J. Op. clt. (referêncla 122): 14.

124. Almeida Fo. N. A cllnica e a epidemiologia. Salvador: APCE Produtos do Conhecimento, 1992: 62-77. 
As ciências biológicas estão marcadas ainda pelo determinismo Laplaciano de que a natureza pode ser conhecida inteira e detalhadamente. Segundo Laplace ${ }^{125}$, a experimentação empírica acuradamente medida permitiria a indução de leis da natureza que reunidas permitiriam uma perfeita previsibilidade do universo, uma falácia intrínseca ao próprio modelo experimental que só pode afirmar que a replicação de um experimento provavelmente resulte em conclusão semelhante, restando sempre a hipótese de que o experimento ainda não realizado possa negar qualquer evidência experimental acumulada. No século XIX, Claude Bernard ajudava a construir os valores da medicina científica moderna ${ }^{126}$ enfatizando a experimentação e a mensuração de fenômenos e destacando que o conhecimento científico da patologia só poderia derivar de um igual conhecimento da fisiologia. Esta aproximação do processo saúde-doença traz embutida em si um descompromisso com as doenças das pessoas para oferecer uma delimitação de campo que só pode servir à comodidade daqueles que a ele se dedicam como mister de profissão. $O$ que seria do controle do escorbuto se James Lind $^{127}$, em 1747, ao invés de inaugurar os ensaios clínicos controlados oferecendo suco de frutas citricas a um grupo de doentes e reservando outro sem tratamento para comparação, fosse se dedicar a identificação da vitamina $\mathrm{C}$ e de seu papel bioquímico na sintese do colágeno? Tomando ainda exemplo recente no trabalho de Doll e Hill ${ }^{128}$, a demonstração de associação entre tabagismo e câncer de pulmão antecedeu de muito os conhecimentos fisiopatológicos, ainda hoje incompletos, das alterações metaplásicas, displásicas e anaplásicas que se sucedem no epitélio brônquico submetido a agressão repetida.

A epidemiologia é uma disciplina comprometida com a intervenção que, observando o processo saúde-doença numa perspectiva ampla, identifica processos passiveis de ação de controle e os dá a conhecer ainda que não possa sempre explicá-los no campo da fisiopatologia. Se a ciência médica pudesse ser comparada metaforicamente a um microscópio, a epidemiologia seria a lente de menor aumento que no exame de um tecido permite o reconhecimento genérico do processo patológico, enquanto que as ciências biológicas básicas seriam as lentes de exame de imersão que identificam a intimidade deste processo patológico. Observar o particular sem conhecer o geral pode resultar em conhecimento perdulário que veste a toga da

125. Wallace WA. Causality and scientific explanation. Volume 2: Classical and contemporary science. The University of Michigan: Ann Arbor, 1974: 163-8.

126. Canguilhem G. O normal e o patológico. Rio de Janeiro: Forense-Universitária, 1982: 43-85.

127 . Lind J. A treatise of the scurvy. Edinburgh: Sands, Murray, and Cochran, 1793.

128. Doll R. Hill AB. A study of the aetiology of carcinoma of the lung. Br Med J 1952; 1271-86. 
ciência, mas nāo necessariamente se solidariza com a dor da doença. Sir John Floyer $^{129}$, primeiro autor a escrever sobre asma em língua moderna (1698), comprometido com o tratamento da doença por profissão e por ser ele mesmo portador de asma, ironiza os conhecimentos que marcavam o nascimento da medicina como ciência, registrando em seu livro: "though the circulation of the blood be lately discovered, and the circulation of the serum through the lymphatic vessels, yet these discoveries have made but little alterations in the practice of physic. ... The invention of the microscope has much discover'd the sensible mechanism of the solid parts: but what indication can I take from the 'globuli' of the fluid? Tho' they may help me better to explain, yet I fear, I shall not be enabled by their discovery, easily to cure any disease". No particular da Pediatria, Boltanski ${ }^{130}$ demonstrou que as práticas de puericultura podem ter compromissos maiores com a normatização social e a reprodução ideológica do que com a recuperação do bem estar do pequeno paciente. A ciência médica enclausurada nos limites de seus valores e de suas preocupações perde a dimensão da historicidade de sua prática e tem sido a epidemiologia, muitas vezes denominada social, que tem criado a oportunidade de recuperação crítica do componente social do processo saúde-doença. Para além de incorporar categorias sociais entre as variáveis independentes do modelo causal clássico da clínica, a epidemiologia tem sido a disciplina médica que resgata os conhecimentos das ciências sociais para um entendimento mais completo do processo saúde doença ${ }^{131}$.

Susser $^{132}$, como porta-voz da epidemiologia moderna, admite que o objeto de conhecimento em medicina não possa ser recuperado como totalidade e que sua abordagem solicita a definição de quadros de referência para a investigação cientifica que, permitindo o conhecimento de particularidades, ajudem a soma progressiva de conhecimentos que paulatinamente revelem a malha complexa do processo saúdedoença. A epidemiologia abdica da precisão do conhecimento em favor da confiabilidade do conhecimento ${ }^{133}$ e neste sentido se aproxima das ciências exatas que maior progresso registraram nos últimos tempos. A fisica desvendou a intimidade da matéria quando a mecânica quântica propos a incorporação da incerteza ${ }^{134}$ como

129. Floyer J. A treatise of asthma. 3rd edition. London: W Innys and W Parker, 1745.

130. Boltanski L. Prime education et morale de classe. Paris: CSE Mouton, 1969.

131. Breilh J. Reprodução social e investigaçáo em saúde coletiva. In: Costa DC (org.). Epidemiologia: teoria e objeto. Så Paulo: Hucitec-ABRASCO, 1990: 137-65

132. Susser M. Casual thinking in the health sciences. New York: Oxford University Press, 1973.

133. Feinstein AR. Stochastic significance, consistency, apposite data, and some other remedies for the intellectual pollutants of statistical vocabulary. Clin Pharmacol Ther 1977; 22(1):113-23.

134. Hawking SW. A brief history of time. New York: Bantam Books, 1988: 53-61. 
uma característica inerente ao conhecimento, trocando a afirmação pela probabilidade: um elétron não está numa posição, mas deve estar numa zona que corresponde a um intervalo de confiança onde se espera encontrá-lo. Cochrane ${ }^{135}$, em 1972, destacava que a boa prática epidemiológica solicita criatividade na transformação de dados originais principalmente com tradução de variáveis continuas para categóricas, ou quânticas, um artifício de processamento que pode revelar novos conhecimentos sobre velhos objetos.

Esta caracterizaçăo da epidemiologia como uma forma de abordar o conhecimento médico e o ecletismo de seu interesse por todos os campos da ciência médica, deram margem ao surgimento de uma discussão ${ }^{136}$ de que, desprovida de objeto próprio, a epidemiologia não se constituiria em disciplina científica, mas apenas em técnica metodológica. Rothman ${ }^{137}$ já afirma que, embora excelentes estudos epidemiológicos tenham sido conduzidos antes do século $X X$, foi apenas nos últimos 20 anos que a epidemiologia criou identidade própria como disciplina cientifica, o que se deveria ao estabelecimento um cabedal próprio de princípios, métodos e técnicas. Dever ${ }^{138}$, em capitulo de livro dedicado à discussão do papel da epidemiologia em administração de serviços de saúde, enfatiza que a "epidemiologia tem sido mais considerada como um método do que como uma ciência independente". Beneficiandose da intima colaboração que estabelece com a estatística, com a isenção e a familiaridade com o campo médico que podem faltar aos estatisticos ${ }^{139}$, a epidemiologia vem, de fato, progressivamente contribuindo com o estabelecimento de métodos de análise para diferentes especialidades médicas e biológicas. Haynes ${ }^{140}$ destaca também que a incorporação dos recursos de informática nas práticas de análise epidemiológica incluem em seu cabedal um potencial específico que tem resultado em contribuições substantivas ao conhecimento.

Horowitz ${ }^{141}$ amplia esta discussão desafiando a cientificidade dos estudos observacionais, coorte e caso-controle, propondo os estudos experimentais tipo ensaio

135. Cochrane AL. The history of the measurement of ill-health. Int J Epid 1972; 1:89-92.

136. Almeida Fo. N. O problema do objetỏ de conhecimento na epidemiologia. In: Costa DC (org.). Op. cit. (referência 131): 203-20.

137. Rothman KJ. Modern epidemiology. Boston: Little, Brown and Company, 1986: 1-6.

138. Dever GEA. A epidemiologia na administraçăo dos serviços de saúde. Såo Paulo: Pioneira, 1988: 47-70.

139. Feinstein AR. Op. cit. (referência 133).

140. Haynes RB, Ramsden M, McKibbon KA, Walker CJ, Ryan NC. A review of medical education and medical informatics. Acad Med 1989; 64:207-12.

141. Horowitz RI. The experimental paradigm and observational studies of cause-effect relationships in clinical medicine. $J$ Chron Dis 1987; 40(1): $91-9$. 
clínico aleatório como o paradigma científico da produçāo do conhecimento médico. Denomina os estudos observacionais como substitutos do ensaio clinico aleatório (observational surrogates for the randomized clinical trial) e advoga que a seus principios metodológicos deveria submeter-se qualquer investigação de relação causa-. efeito independentemente do objetivo do estudo ser de avaliação terapêutica ou de etiologia de doença. Assim, à disputa da identidade de campo acrescenta-se uma disputa de identidade epistemológica. Feinstein ${ }^{142}$, defendendo uma disciplina que ele chamaria epidemiologia clínica, de forma a contrapor à epidemiologia sem adjetivos para evitar conotações tradicionais do termo (sic), ao mesmo tempo que reconhece na epidemiologia uma estrutura tecnológica própria, desqualifica-a como competente para resolver os problemas de conhecimento da medicina contemporânea, quando afirma: "These problems cannot be adequately investigated merely with statistical or computer theories". Em artigo mais recente ${ }^{143}$, com perspicácia e competência revê estudos epidemiológicos tipo caso-controle e coorte para denunciar suas inconsistências, terminando por apontar a metodologia de ensaios clínicos aleatórios como referência teórica para estudos epidemiológicos.

Há inequivocamente um dominio das ciências biomédicas que corresponde à epidemiologia, seja ela caracterizada por um referencial teórico distinto, ou pela especificidade de um objeto, ou pelo controle de uma tecnologia particular de análise. As divergências e a tentativa de descaracterização são evidências dialéticas de sua presença tanto quanto sua busca de afirmação, pois que ela há que existir para ser negada.

Loose ${ }^{144}$, comentando a obra Thomas S. Kuhn, filósofo contemporâneo da ciência, ensina que paradigmas científicos alternativos só poderiam ser comparados se se dispusesse de uma linguagem independente que registrasse os resultados das observações de cada abordagem. A cada paradigma corresponde uma Gestalt, um universo alternativo de valores, visões e interpretações. Não só são distintos os paradigmas como não são comparáveis ou hierarquizáveis. Como exemplo lembra que da física newtoniana para a relatividade geral, conceitos como tempo, espaço e matéria são inteiramente diversos. Um paradigma só substitui outro quando explica melhor a realidade, quando aumenta a precisão da observação da natureza. Mesmo assim, ainda não necessariamente 0 substituirá definitivamente, mas

142. Feinstein AR. Why clinical epidemiology. Clin Research 1973; XX(5): 821-5.

143. Feinstein AR. Scientific standards in epidemiologic studies of the menace of daily life. Science 1988; 242: 1257-63.

144. Loose J. Introdución histórica a la filosofía de la ciencia. Madrid: Alianza Editorial, 1981: 214-20. 
circunstancialmente segundo a solicitação do conhecimento que se busque: é totalmente dispensável qualquer consjderação sobre curvatura do espaço-tempo para calcular quantas horas se gastará num percurso sobre a superfície terrestre.

John Graunt ${ }^{145}$ não reivindicou o título de epidemiologista para inaugurar os estudos de mortalidade, nem tampouco Edward Jenner ${ }^{146}$ se denominou epidemiologista clinico para demonstrar a eficácia da vacina contra variola, ao realizar - primeiro ensaio clinico da medicina. O presente trabalho não reivindica qualquer vinculação escolástica e pretende-se epidemiológico pela natureza de seu objeto, de seus métodos e do escopo de suas conclusões. Que a incerteza e as disputas não intimidem a produção intelectual e que o trabalho se reconheça por seu produto antes que por qualquer vinculação conceitual.

\section{IV.2 - SOBRE A ASMA E AS DOENÇAS CHIADORAS DA INFÂNCIA}

A controvérsia em asma começa na própria definição da doença. Prof. J.G. Scadding, que presidiu um encontro promovido no Reino Unido pela Fundação Ciba em $1971^{147}$ para buscar uma definição consensual para asma, tem produzido artigos sobre a definição de doenças desde $1959^{148}$, e sobre a asma tece comentários ${ }^{149,150}$ dignos de menção. Ele afirma que a definição de uma doença pode conhecer 3 diferentes niveis: $1^{\circ}$ ) descrição de sinais e sintomas, $2^{\circ}$ ) descrição da anormalidade estrutural ou funcional subjacente e $3^{\circ}$ ) descrição da etiologia. Reconhecendo que a precisão do diagnóstico etiológico é muito maior, ele lembra que esta abordagem não é aplicável a asma com os conhecimentos que se dispõe e propõe que se restrinja a definição da doença às alterações funcionais que a caracterizam: "A disease characterized by wide variations over short periods of time in resistance to flow in

\footnotetext{
145. Graunt J. Natural and political observations mentioned in a following index, and made upon bills of mortality. In: Wilcox WF (ed.). Natural and political observations made upon bills of mortality by John Graunt. Baltimore: Johns Hopkins Press, 1937.
}

146. Jenner E. Vaccination against smallpox. In: Elliot SN (ed.). Scientilic papers. New York: Collier, 1910:153-231.

147. Porter R, Birch J (ed.). Identification of asthma. Ciba Foundation Group N 38. Edinburgh: Churchil Livingstone, 1971.

148. Scadding JG. Principles of definition in Medicine with special reference to chronic bronchitis and enphysema. Lancet 1959; i: 323-25.

149. Scadding JG. Definitions and clinical categories of asthma. In: Clark TJH, Godfrey S (ed.). Asthma. London: Chapman and Hall, 1977.

150. Scadding JG. Asthma and bronchial reactivity [letter]. Br Med J 1987, 294: 1115-6. 
intrapulmonary ainways". Esta é uma definição muito próxima daquela proposta pela American Thoracic Society 151 em 1962: "Asthma is a disease characterized by an increased responsiveness of the trachea and bronchi to various stimuli and manifested by a widespread narrowing of the ainways that changes either spontaneuously or as a result of therapy".

Ambas as definições se apoiam na descrição de alterações funcionais observáveis clinicamente, o que confronta com as proposta do grupo australiano da Profa. Woolcock ${ }^{152}$ que emprega e defende a aplicação de inquérito de sintomas associado a provas de hiperreatividade brônquica, método que envolve inegável dificuldade operacional e razoável infraestrutura tecnológica. Ambas são tarnbém abrangentes o suficiente para incluir sob a denominação de asma todas as doenças chiadoras da infância, embora os clinicos prefiram reservar este diagnóstico aos casos em que algum componente alérgico possa ser identificado. Independentemente da diversidade de mecanismos fisiopatológicos envolvidos, as doenças chiadoras da infância reúnem-se sob o denominador comum da manifestação clínica e da estratégia terapêutica recuperando o antigo conceito de dano em Saúde Pública. Por dano entende-se o conjunto de agravos a saúde susceptiveis a uma estratégia comum de controle e nesta perspectiva é indiferente o nome que se the atribua, não havendo qualquer prejuizo em nomear asma brônquica todas as doenças chiadoras da infância.

O diagnóstico da asma brônquica é do domínio da clínica e qualquer alternativa a esta abordagem delimita outro campo e as comparações ficam prejudicadas. Speight et al. ${ }^{153}$, estudando escolares, encontraram crianças sintomáticas respiratórias que, embora não tivessem asma diagnosticada, beneficiavam-se de tratamento específico e concluiram que a doença estaria sendo subdiagnosticada. Isto pode ser desafiado lembrando que os investigadores tinham o benefício da análise da história posterior dos pacientes e talvez estivessem catalogando como asmáticas crianças portadoras de hiperreatividade que à época em que haviam sido vistas por seus médicos não reuniam características clínicas completas para receberem o diagnóstico de asma. Para uma abordagem epidemiológica é de todo interessante uma aproximação mais ampla do objeto sob a perspectiva das doenças chiadoras da infância, até mesmo porque, enquanto pode haver disputa quanto ao diagnóstico de asma há tendência de

151. American Thoracic Society. Definitions and classification of chronic bronchitis, asthma, and pulmonary enphysema. Am Rev Respir Dis 1962; 85: 762-8.

152. Toelle BG, Peat JK, Salome CM, Mellis CM, Woolcock AJ. Toward a definition of asthma for epidemiology. Am Rev Respir Dis 1992; 146: 633-7.

153. Speight ANP, Lee DA, Hey EN. Underdiagnosis and undertreatment of asthma in childhood. B Med J 1983; 286:1253-6. 
concordância para o reconhecimento das doenças chiadoras, como demonstraram Hill e Tattersfield ${ }^{154}$ comparando diferentes estudos de prevalência de asma e destas doenças. Corhay et al. ${ }^{155}$ lembra que "nem tudo que chia é asma", e oferecendo diagnóstico diferencial aponta as cardiopatias, a bronquite crônica, as embolias pulmonares, as sindromes carcinóides e as estenoses traqueobronquicas, afecções de baixa prevalência em crianças. A estas doenças poder-se-ia ainda acrescentar outras como a fibrose cística, a aspiração de corpo estranho e etc., todas de distinção clínica clara que em nada obstariam o agrupamento das doenças chiadoras com razoável segurança. A principal distinção que se impõe neste grupo etário é com as infecções virais agudas como a bronquite aguda e a bronquiolite, para as quais bastaria acrescentar o adjetivo recorrente à designação de doença chiadora da infância.

$A$ atopia, avaliada por métodos rigorosos como dosagem de imunoglobulina $E$ (IgE) sérica, mostra grande associação com asma ${ }^{156}$. Na verdade, recente trabalho publicado por Sears et al. ${ }^{157}$ caracteriza o paciente asmático como portador de hiperreatividade brônquica $e$ indices elevados de lgE, informação epidemiológica perfeitamente compativel com a fisiopatologia da doença. Como conseqüência, outras doenças atópicas associam-se com frequência à asma $e$, particularmente no caso de rinite alérgica, deve-se dar atenção para o tratamento específico que pode contribuir substancialmente para melhora do problema brônquico ${ }^{158}$. Annesi et al. ${ }^{159}$, estudando adultos masculinos entre 27 e 58 anos, encontraram que mesmo afecções não alérgicas do trato respiratório superior associam-se a asma e hiperreatividade brônquica. A laringite recorrente ${ }^{160}$, ou laringite estridulosa, também associa-se a asma e envolve mecanismos fisiopatológicos semelhantes de atopia e hiperreatividade.

A intimidade entre asma brônquica e atopia é já encontrada na origem do conceito de atopia quando foi pela primeira vez proposto por Coka ${ }^{161}$, em 1922. Em

154. Hill R, Tattersfield AE. Asthma in children: comparison of community surveys in the UK. (Abstract). Thorax 1988; 43:258P.

155. Corhay JL, Bury Th. Cabut C, Rademecker MF. Les pseudo-asthmes: "tout ce qui siffle n'est pas asthme". Revue Medicale de Llege 1993; XLVIII: 137-42.

156. Freidhoff LR, Marsh DG. Relationship among asthma, serum IgE levels and skin test sensitivity to inhaled allergens. Int Arch Allergy Immunol 1993; 100:355-61.

157. Sears MR, Burrows B, Flannery EM et al.. Relation between airway responsiveness and serum IgE in children with asthma and in apparently normal children. N Engl J Med 1991; 325: 1067-71.

158. Carneiro-Sampaio MMS. Asma brónquica. In: Rozov T, Ribeiro de Carvalho CR. Doenças pulmonares em pediatria. Săo Paulo: Harper \& Row do Brasil Lida, 1987: 216.

159. Annesi I. Oryszczyn MP. Neukirch $F$ et al. Relationship of upper airways disorders to FEV1 and bronchial hyperresponsiveness in an epidemiological study. Eur Respir J 1992, 5: 1104-10.

160. Cohen B, Dunt D. Recurrent and non-recurrent croup: an epidemiological study. Aust Paediatr J 1988; 24(6): 339-42.

161. Coka AF, Cooke RA. On the classification of the phenomena of hypersensitiveness. J Immunol 1922; 8(3): $163-82$. 
sua descrição da atopia como uma manifestação idiossincrática da hipersensibilidade anormal, ele apontava a asma e a febre do feno como exemplos. Sibbald, em dois diferentes estudos conduzidos em $1979^{162}$ e $1980^{163}$, concluiu que embora fatores ambientais tivessem algum papel no desenvolvimento da doença, a atopia deveria ser considerada um fator predisponente para o desenvolvimento da asma. Martin et al. ${ }^{164}$, num estudo que acompanhou escolares dos 7 aos 21 anos, não só encontrou associação entre atopia e asma, como também registrou uma relação dose-resposta ao comparar intensidade de sintomas atópicos e severidade da asma. Foncard e Sjoberg $^{165}$, num acompanhamento de crianças por 12 anos, encontraram resultados semelhantes, da mesma forma que Cockcroft et al. $^{166}$, Witt et al. ${ }^{167}$, e outros tantos que podem ser encontrados na literatura. As associações familiares para presença de asma já são conhecidas ${ }^{168}$ e tem sido recentemente confirmadas por grandes estudos com gêmeos ${ }^{169,170}$.

Asma é uma doença inflamatória crônica do trato respiratório inferior. A especificidade desta inflamação em relação a outros processos inflamatórios de superficies epiteliais está, segundo Chapman et al. ${ }^{171}$, na destacada presença de mononucleares e eosinófilos, já há muito descrita na literatura ${ }^{172}$. Holgate ${ }^{173}$, descreve as alteraçōes do trato respiratório afirmando que "The characteristic pathological features of asthma are hypersecretion of mucus with plugging of airways, disruption of the ciliated pseudo-stratified respiratory epithelium, oedema of the airway wall and

162. Sibbald $B$, Turner-Warwick M. Factors influencing the prevalence of asthma among first degree relatives of extrinsic and intrinsic asthmatics. Thorax 1979; 34: 332-7.

163. Sibbald B, Horn MEC, Brain EA, Gregg I. Genetic factor in childhood asthma. Thorax 1980; 35: 671-4.

164. Martin AJ, Landau LI, Phelan PD. Natural history of allergy in asthmatic children followed to adult life. Med J Aust 1981; 2:470-4.

165. Foncard T, Sjoberg O. A prospective 12-year follow-up study of children with wheezy bronchitis. Acta Paediatr Scand $1984 ; 73(5): 577-83$.

166. Cockcroft DW, Murdock KY, Berscheid BA. Relationship between atopy and bronchial responsiveness to histamine in a random population. An Ailergy 1985; 53:26-9.

167. Witt C, Stuckey MS, Woolcock AJ, Dawkins RL. Positive allergy prick tests associated with bronchial histamine responsiveness in an unselected population. J Allergy Clin Immunol 1986; 77(5): 698-702.

168. Gerrad JW, Vickers P, Gerrard CD. The familial incidence of allergic disease. Clin Allergy 1976; 36:10-5.

169. Hopper JL, Hannah MC, Macaskill GT et I.. Twin concordance for a binary trait: III. A bivariate analysis of hay fever and asthma. Genetic Epidemiol 1990; 7:277-89.

170. Duffy DL, Martin NG, Battistutta D et al.. Op. cit. (referência 31): 1351-8.

171. Chapman ID, Foster A, Morley J. The relationship between inflammation and hyperreactivity of the airways in asthma. Clin Exp Allergy 1993; 23: 168-71.

172. Huber HL, Koessler KK. Pathology of asthma. Arch Intern Med 1922; 30: 689-760.

173. Holgate ST, Kay AB. Mast cells, mediators and asthma. Clin Allergy 1985; 15:221-34. 
infiltration of the aimay lumen, mucosa and sub-mucosa with inflammatory cells, particularly eosinophils, neutrophils and monocytes."

A fisiopatologia da doença é complexa envolvendo mecanismos imunológicos e bioquimicos cujos detalhes são revistos e atualizados a grande velocidade pelos pesquisadores do campo ${ }^{174}$. Segundo Lee e Kay ${ }^{175}$, reconhece-se uma fase rápida de resposta brônquica a alérgenos, que è designada espasmogênica e induz modificações na resistência ao fluxo aéreo que duram cerca de 60 minutos. Esta fase parece ser mediada, pelo menos em parte, pela histamina liberada pela degranulação de mastócitos com ação direta sobre a musculatura lisa ou desencadeando reflexos vagais. A liberação por mastócitos de outros mediadores nesta fase é também responsável pela ativação e recrutamento de outras células inflamatórias para as vias respiratórias, as quais vāo responder pela fase denominada tardia da crise asmática. Esta fase, de inicio mais tardio e resolução mais demorada, é caracterizada ainda por broncoespasmo mas também por edema de mucosa e presença de células como neutrófilos, monócitos e eosinófilos. Uma miriade de mediadores quimicos liberados nesta fase renovam a quimiotaxia de células inflamatórias e exercem efeito citotóxico principalmente sobre o epitélio, com conseqüentes alteraçōes estruturais, como descamação e perda de cilios, e funcionais, como hipersecreção e alteração bioquímica do muco. Linfócitos T helpers (OKT4) diminuem no sangue periférico e parecem ser responsáveis pela produção de substâncias estimulantes dos eosinófilos, responsáveis pela maior agressão histológica verificada na asma. Este processo inflamatório se retroalimenta dando condições de perpetuação da doença com forma crônica e grave.

Este processo inflamatório, resultante destas reaçöes alérgicas a nivel do brônquio, é ainda acompanhado, talvez mesmo como conseqüência dele ${ }^{176}$, por uma hiperreatividade a estimulos inespecíficos. Esta hiperreatividade é diagnosticada por testes controlados de laboratório ${ }^{177}$ mas é percebida clinicamente pela dispnéia desencadeada pela exposição do paciente a irritantes inespecificos como $\mathrm{SO}_{2}, \mathrm{O}_{3}$, fumaça de cigarro, mudança de temperatura, gases exalados por combustão a nivel doméstico ou industrial, etc.. Esta fisiopatologia de dupla ascendência dá margem

174. Busse WW, Calhoun WF, Sedgwick JD. Mechanism of ainay inflammation in asthma. Am Rev Respir Dis 1993; 147: $520-4$.

175. Lee TH, Kay AB. Respiratory allergy. In: Lessof MH, Lee TH, Kemeny DM (ed.). Allergy: an international textbook. New York: John Wiley \& Sons, 1989: 499-511

176. Nadel JA. Inflammation and asthma. J Allergy Clin Immunol 1984; 73: 651-3.

177. Eiser NM. Bronchial provocation tests. In: Nadel JA, Pauwels R, Snashall PD (ed.). Bronchial hyperresponsiveness. London: Blackwell Scientific Publications, 1987: 173-254. 
àqueles que buscam uma definição etiológica para doença a explorarem uma distinção de duas doenças. De Vries $^{178}$ propõe designar asma $\circ$ quadro envolvendo mecanismos imunológicos e bronquite o quadro restrito a hiperreatividade brônquica. $\mathrm{Na}$ verdade isto só pode resultar em um exercício acadêmico porque, a nivel do processo patológico, mecanismos especificos e inespecíficos estarão sempre em interação. Manter um segundo diagnóstico para asma interessa mais a fatores psicológicos da relação médico-paciente ${ }^{179}$, de forma evitar um rótulo estigmatizante para a criança e para a família, do que reflete qualquer necessidade de compreensão do processo saúde-doença. O dano de Saúde Pública continua o mesmo.

Laittinen et al. ${ }^{180}$ estudando biopsias brônquicas de asmáticos demonstraram que mesmo pacientes com diagnóstico recente (entre 2 e 12 meses) apresentam infiltração celular da mucosa brônquica que é significativamente diferente de individuos normais. Mesmo pacientes em períodos assintomáticos registram redução da função ventilatória $^{181}$ e seus lavados alveolares mostram a presença de processo inflamatório ${ }^{182}$. A asma é uma condição patológica a qual ainda que silente não abandona o portador, o que Aretaeus, 0 Capadócio ${ }^{183}$ já registrava no século II, como primeiro autor a dedicar um capítulo de livro a asma brônquica: -"...during remissions, although they (the asthmatics) may walk about erect, they bear the traces of the affection".

A British Thoracic Society editou recentemente um suplemento de sua revista Thorax com orientaçōes padronizadas de tratamento para asma brônquica em adultos e crianças ${ }^{184}$. Fazendo distinção entre as situações de crise aguda e tratamento de longo prazo e oferencendo sugestōes de procedimentos de avaliação clínica do doente, dá ênfase ao uso de broncodilatadores para aliviar sintomas e corticóides e cromoglicato para tratamento intercrises. O brometo de ipatrópio e teofilina são apresentados como "áreas de incerteza", recomendando-se que seu uso seja

178. De Vries K. Clinical significance of bronchial hyperresponsiveness. In: Nadel JA, Pauwels R, Snashall PD (ed.). Bronchial hyperresponsiveness. London: Blackwell Scientific Publications, 1987: 359-71.

179. De Montis G, Berman D. Doit-on abandoner le diagnostic de bronchite asthmatiforme? Ann Pediatr (Paris) 1989; 36(9): 603-6.

180. Laitinen LA, Laitinen A, Haahtela T. Airway mucosal inflammation even in patients with newly diagnosed asthma. Am Rev Respir Dis 1993; 147: 697-704.

181. Nakadate T, Kagawa J. Pulmonary function development in children with past history of asthma. J Epidemiol Community Health 1992; 46: 437-42.

182. Boulet LP, Turcotte $H$, Boulet $M$, Montminy $L$, Laviolette $M$. Influence of natural antigenic exposure on expiratory flow, methacholine responsiveness, and airway inflammation in mild allergic asthma. J Allergy Clin Immunol 1993; 91(4): 883-93.

183. Adams $F$ (ed). The extant works of Aretaeus, the Capadocian. London: Sydenhham Society, 1856: 318.

184. British Thoracic Society. Guidelines for the management of asthma. Thorax 1993; 48(Suppl): S1-S24. 
reservado apenas para casos graves que não respondam a outro tratamento, embora se mencione que o brometo de ipatrópio pode ser benéfico em crianças menores de um ano.

O uso regular de beta-adrenérgicos como forma de tratamento da asma tem sido questionado tanto pela falsa confiança que pode prover aos pacientes, conforme constatado em estudos de mortalidade por asma ${ }^{185,186}$, quanto por uma possivel associação a uma deterioração clínica da asma que resultaria de seu uso regular, ao invés de seu uso quando necessário ${ }^{187}$. Esta discussão recoloca em pauta a controvérsia dos anos 60 sobre o uso de adrenérgicos inalados ${ }^{188}$, a qual chegou a prescrever seu uso por algum tempo em alguns paises, além de ter criado um indesejável preconceito contra a via inalatória. Spitzer et al. ${ }^{189}$ lembram que uma associação não demonstra relação causal e que a severidade da asma nos pacientes que evoluem para óbito pode ser uma variável de confusão, já que tal condição se associaria tanto ao risco de óbito quanto ao risco de uso elevado de broncodilatadores. Revisões sobre a matéria ${ }^{190,191}$ mostram que uma possível explicação para este efeito paradoxal do uso prolongado de beta-adrenérgicos seja alterações bioquímicas a nivel dos mastócitos que prejudicando a resposta a alérgenos exporia os pacientes a uma sobrecarga continuada de tais alérgenos. Concluem, no entanto, que o risco se restringe ao uso indevido da droga que pretende prescindir de anti-inflamatórios como os corticóides e cromoglicato. De fato, o Committee on Safety Medicine do Reino Unido informa ${ }^{192}$ que, a despeito do uso de beta-adrenérgicos ter triplicado na década de 80 , a mortalidade por asma permaneceu constante, nada havendo para condenar 0 uso destas drogas.

185. Sears MR, Rea HH. Rothwell RPG et al.. Asthma mortality: comparison between New Zealand and England. Br Med J 1986; 293: 1342-5.

186. Sears MR, Rea HH, Fenwick J et al.. 75 deaths in asthmatics prescribed home nebulizers. Br Med J 1987; $294: 477-80$.

187. Sears MR, Taylor DR, Print CG et al.. Regular inhaled beta-agonist treatment in bronchial asthma. Lancet 1990; $336:$ 1391-6.

188. Speizer FE, Doll R, Heaf $P$, Strang LB. Investigation into use of drugs preceding death from asthma. Br Med J 1968; $1: 339-43$.

189. Spitzer WO, Suissa A, Ernst P et al. The use of beta-agonists and the risk of death from asthma. N Engl J Med 1992; 326: 501-6.

190. Twentyman OP, HigenBottam TW. Controversies in respiratory medicine: regular inhaled beta-agonists - clear clinical benefit or a hazard to health? (1) Beta-agonists can be used safely and benericially in asthma. Respir Med 1992; 86: 471-6.

191. Page C. Cstello J. (2) Why beta-agonists should not be used regularly. Resp Med 1992; 86: 477-79.

192. CSM working party. Beta-agonist use in asthma. Curr Problems 1992; No 33. Apud Twentyman OP, HigenBottam TW, Op. cit. (referência 190): 471 . 
O esquema terapeutico proposto pela British Thoracic Society se restringe a drogas clinica e laboratorialmente bem estabelecidas, mas muitas novas drogas antiasmáticas são estudadas atualmente. Barnes ${ }^{193}$ descreve novos broncodilatadores como a VIP(vasoactive intestinal peptide), inibitores seletivos da fosfodiesterase, anticolinérgicos seletivos de receptores muscarínicos $\mathrm{M}_{2}$, reguladores de canal de $\mathrm{K}^{+}$, antagonistas do cálcio e prostaglandinas $\left(\mathrm{PGE}_{2}\right)$ e novos anti-inflamatórios como antagonistas de leucotrienos e PAF, inibidores de fosfolipase, inibidores de neurotransmissores, imunomoduladores (metotrexate), inibidores de citoquinas e supressores de IgE. A imunoterapia ${ }^{194}$ por técnicas de dessensibilização da alergia, se não chega a ser condenada, não é recomendada sendo apenas tolerada em situações específicas de pacientes com asma leve ou moderada acompanhada de rinoconjuntivite.

Além do tratamento medicamentoso, a British Thoracic Society recomenda também o controle do ambiente para poupar o asmático de contato com alérgenos e poluentes e há registros na literatura que permitem afirmar que programas de apoio afetivo/ emocional ${ }^{195}$ e atividades de condicionamento físico ${ }^{196,197,198}$ podem beneficiar a criança asmática.

A avaliação clínica do asmático e da crise asmática pode ser feita com eficiência através de propedêutica desarmada. Sanchez et al. ${ }^{199}$ concluiram que a avaliação da hiperreatividade brônquica através de simples ausculta do chiado tem uma sensibilidade de $68 \%$ e uma especificidade de $82 \%$. Sinais clinicos como pulso paradoxal $^{200}$ e contração do músculo esternocleidomastoideo ${ }^{201}$ dão indicações seguras da severidade da crise asmática. No entanto, o uso de medidor de fluxo

193. Barnes PJ. New drugs for asthma. Eur Respir J 1992; 5: 1126-36.

194. Rachelefsky GS, Warner JO. International consensus on the management of pediatric asthma: a summary statement. Pediatr Pulmonol 1993; 15:125-7.

195. Vazquez MI, Buceta JM. Effectiveness of self-management programmes and relaxation training in the treatment of bronchial asthma: relationships with trait anxiety and emotional attack triggers. J Psychosomatic Research 1993; 37(1): 71-81.

196. Bar-Or O, Inbar O. Swimming and asthma: benefits and deleterious effects. Sports Med 1992; 14(6): $397-405$.

197. Rocha EM. L'action de la réhabilitation respiratoire sur les altérations fonctionnelles ventilatoires chez l'enfant asthmatique. Allergie et Immunologie 1993; 25(1): 26-34.

198. Fink G, Kaye C, Blau H, Spitzer SA. Assessment of exercise capacity in asthmatic children with various degrees of activity. Pediatr Pulmonol 1993; 15:41-3.

199. Sanchez I, Avital A, Wong I, Tal A, Pasterkamp H. Acoustic vs. spirometric assessment of bronchial responsiveness to methacholine in children. Pediatr Pulmonol 1993; 15:28-35.

200. Rebuck AS, Read J. Assessment and management of severe asthma. Am J Med 1971; 51: 788-98.

201. McFadden ER, Kiser R, Degroot WJ. Acute bronchial asthma. N Engl J Med 1973; 288: 221-5. 
expiratório máximo (peak flow meter) já é sugerido há vários anos ${ }^{202}$ e as últimas recomendações da British Thoracic Society incluiram também o monitoramento da saturação de $\mathrm{O}_{2}$ no sangue através da oximetria de pulso, cuja avaliação de uso ${ }^{203}$ tem mostrado constituir-se em propedêutica não invasiva de alta sensibilidade (100\%) e especificidade (98\%) para identificação de pacientes que requerem terapêutica mais intensiva. A medida transcutânea da pressão parcial de oxigênio no sangue tem também se mostrado como uma técnica propedêutica não invasiva de boa relação tanto com a gasometria arterial quanto com as provas ventilatórias ${ }^{204,205}$.

Finalmente, há uma tendência de desviar-se o enfoque individual da assistência ao asmático para organização de programas com padronização e supervisão de atividades. Desde 1969, há em Edimburgo, Escócia, um programa de auto-admissão hospitalar para asmáticos ${ }^{206}$ que tem demonstrado sucesso através da diminuição de atendimentos de casos graves com risco de vida. Em Glasgow, também na Escócia, um programa ${ }^{207}$ de padronização de condutas e fornecimento de material didático para pacientes, avaliado através da comparação com controles, mostrou capacidade de promover aumento da prescrição de corticosteróides, tanto inalados quanto orais, e uma redução no uso de antibióticos. Nos Estados Unidos tem se incentivado programas de auto-controle da asma infantil ${ }^{208,209}$ que envolvem a educação de pais e crianças para aderência a tratamento, reconhecimento de sinais de gravidade, e segurança na adoção autônoma de medidas terapêuticas ou de busca de socorro médico. Na Austrália ${ }^{210}$, um programa de educação para o controle da asma infantil abordando médicos, farmacêuticos e familias de pacientes mostrou-se efetivo para redução de número de consultas médicas e melhoria de função respiratória avaliada por resposta brônquica à histamina. Estas iniciativas mostram que a asma, a exemplo

202. Anonimous. Increasing deaths from asthma [Editorial]. Br Med J 1968; 1: 329-30.

203. Connett GJ, Lenney W. Use of pulse oximetry in the hospital management of acute asthma in childhood. Pediatr Pulmonol 1993; 15: 345-9.

204. Holmgren D, Sixt R. Transcutaneous and arterial blood gas monitoring during acute asthmatic symptoms in older children. Pediatr Pulmonol 1992; 14: 80-4.

205. Holmgren D, Engstrom I, Bjure J, Sixt R, Aberg N. Respiratory resistance and transcutaneous $P_{2} \mathrm{O}_{2}$ during histamine provocation in children with bronchial asthma. Pediatr Pulmonol 1993; 15: 168-74.

206. Crompton Gk, Grant IWB, Bloomfield P. Edinburgh emergency asthma admissions services: report on 10 years' experience. Br Med J 1979; 2: 1199-201.

207. Bucknall CE. Assessment of an asthma management programme for general practitioners (abstract). Thorax 1988; 43: 253P.

208. Feldman CH. Asthma education: general aspects of childhood programs. J Allergy Clin Immunol 1987; 80(3Pt2): $494-7$.

209. Creer TL. Self-management in the treatment of childhood asthma. J Allergy Clin Immunol 1987; 80(3Pt2): 500-5..

210. Toelle BG, Peat JK, Salome CM, Mellis CM, Bauman AE, Woolcock AJ. Evaluation of a community-based management program in a population sample of schoolchildren. Med J Aust 1993; 158: 742-6. 
das infecçōes respiratórias, está reclamando uma abordagem coletiva que convoca a Saúde Pública para uma ação no campo.

\section{IV.3 - SOBRE O PRESENTE ESTUDO}

\section{IV.3.1 - DOS MÉTODOS E DA IDENTIFICAÇĀO DE CASOS E CONTROLES}

Tradicionalmente há uma grande ênfase a estudos epidemiológicos do tipo coorte. Samet ${ }^{211}$, conhecido epidemiologista de doenças respiratórias, em estudo com colaboradores acerca da relação entre infecçōes respiratórias na infância e doença obstrutiva crônica em adultos, chegou a apontar que não se poderia afirmar que a relaçăo entre os dois eventos fosse definitiva enquanto a questão năo fosse perfeitamente esclarecida através de estudos de coorte que acompanhassem pessoas do nascimento à vida adulta.

De fato, estudos de coorte deste tipo poderiam contribuir na elucidação não só deste, mas de muitos outros aspectos da infecção respiratória na infância, sua relação com a doença chiadora, ou a asma, incluída. A fisiopatologia da asma é ainda nebulosa. Sabe-se que uma variedade de fatores hereditários, ambientais, alérgicos e de hiperreatividade brônquica estão envolvidos, mas os mecanismos patogênicos continuam incompletos ${ }^{212}$ e as investigações epidemiológicas tem sido enfaticamente chamadas a contribuir para a elucidação da história natural da doença, como testemunham as recomendações da Força Tarefa sobre Mortalidade por Asma patrocinada pela Academia Americana de Alergia e Imunologia e Sociedade Americana de Torax ${ }^{213}$. No entanto, além de um custo elevado, estudos de coorte envolvem dificuldades operacionais não despreziveis. Gregg ${ }^{214}$ lembra que estudos prospectivos serão necessários para elucidação da história natural da asma, mas recomenda que "Rather than carrying out large population surveys, epidemiologists should direct their efforts to the study of smaller groups of subjects, deliberately

211. Samet JM, Tager IB, Speizer FE. The relationship between respiratory illness in childhood and chronic air-flow obstruction in adulthood. Am Rev Respir Dis 1983; 127: 508-23

212 Phelan PD et al, Op. cit. (referência 82): 110.

213. Anonimous. Recommendations of the asthma mortality task force. J Allergy Clin Immunol 1987; 80(3Pt2): 364-6.

214. Gregg I. Epidemiology. In: Clarck TJH \& Godfrey S [Editors]. Asthma. London: Chapman and Hall, 1977. Pg.240. 
selected because they exhibit constrasting features in one or more respects, in an effort to determine whether these differences are reflected in different prevalence rates".

Numa linha semelhante, uma oficina de trabalho realizada em junho de 1985 em Bethesda, nos Estados Unidos, com a participação de renomados epidemiologistas de asma ${ }^{215}$, recomendou o desenho caso-controle para investigações da doença: "There are now a number of interesting and diverse hypotheses and these might be more efficiently tested in case-control studies. Case-control studies based on prevalence surveys would have the added advantages of obviating some of the major problems of sampling in case-control studies, and would, in addition, provide information on attributable as well as relative risks".

Cole ${ }^{216}$, discutindo o papel dos estudos caso-controle na investigação de cancer, lembra importantes qualidades deste tipo de estudo: "The major strength of the case-control design compared with other types of epidemiological research is its 'informativeness'. A case-control study can simultaneously evaluate many causal hypothesis whether they have been previously evaluated or are new. These sudies permit the evaluation of interaction - the extent and manner in which two (or more) causes of the disease modify the strength of one another. This design also permits the evaluation and control of confounding, that is, of an association resulting because the factor under study is associated with a known or suspected cause of the cancer." Prosseguindo em sua análise ele aponta quatro vantagens dos estudos caso-controle: possibilidade de descrição epidemiológica dos doentes envolvendo as caracteristicas de interesse; eficiência, porque são estudos rápidos e de baixo custo; aplicabilidade tanto a doenças raras como a doenças de maior prevalência; permite a avaliação da significância causal de exposições raras porque se relevantes elas tendem a comparecer entre os casos.

O desenho caso-controle tem hoje larga aplicação em estudos epidemiológicos, comparando através da medida do odds ratio a frequência de exposição a um dado fator, que é investigado como possivel predisponente ao surgimento de doença, entre portadores e não portadores desta doença. Até que Miettinen ${ }^{217}$, em 1976, tivesse provido uma revisão dos principios teóricos deste método, sua aplicação era

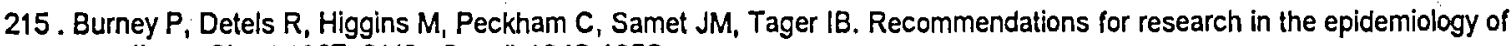
asthma. Chest 1987; 91 (6 - Suppl):194S-195S.

216. Cole P. Introduction. In: Breslow NE \& Day NE. Statistical methods in cancer research. Volume 1 - The analysis of casecontrol studies. Lyon: International Agency for Research on Cancer. IARC Scientific Publications $n^{\circ} 32,1980 . \mathrm{Pg} .20$ 1.

217. Mieltinen O. Estimability and estimation in case-referent studies. Am J Epidemiol 1976; 103: 226-35. 
interpretada como restrita ao estudo de doenças raras. Em seu estudo, Miettinen oferece demonstração matemática de que na comparação de incidências de exposição a fatores de risco, o cálculo do odds ratio é uma boa aproximação da medida de risco de doença a que estão sujeitos indivíduos expostos ao fator estudado. Rodrigues e Kirkwood ${ }^{218}$, numa revisão recente, sugerem que o odds ratio será uma boa aproximação de diferentes medidas de risco segundo carateristicas de desenho do estudo. $O$ presente estudo se enquadra no que eles designam de caso-controle concorrente, onde os controles são selecionados concorrentemente com a identificação de casos, entre pessoas ainda sob risco de contraírem a doença. Neste tipo de desenho, segundo Rodrigues e Kirkwood, o odds ratio é uma medida aproximada da razão de densidade de incidencia que se obteria num estudo prospectivo.

Qualquer inferência a respeito da influência do fator de risco investigado sobre a doença depende da representatividade da amostra estudada em termos de frequência de eventos de doença e exposição na população em geral. Numa amostra de usuários de um hospital como é o caso do presente estudo, argúi-se se seus resultados possam ser extrapolados para a comunidade em geral. Segundo Rothman $^{219}$, um estudo caso-controle pode ser realizado ate para a demanda de um consultório médico especifico desde que a seleção de controles seja feita de modo a representar aquele ambiente particular. Controles devem representar pessoas que poderiam ter sido casos com as mesmas chances daqueles que tenham sido tomados como casos e, mais ainda, na situação de virem a tornar-se casos, teriam procurado 0 mesmo recurso assistencial. Vieses de seleção na escolha de casos e controles podem comprometer os resultados de um estudo.

No presente estudo, durante o periodo de observação qualquer controle poderia ter vindo a se tornar caso, situação que não ocorreu mas que levaria tal paciente a contribuir na amostra tanto como caso quanto como controle. Durante o periodo de observação todo paciente que preencheu os requisitos de entrada no estudo como caso foi incluído na investigação de forma a evitar-se um viés de seleção. No entanto, como as observações só foram realizadas no periodo diurno, não se pode excluir que tenha havido alguma margem de erro. $O$ que permitiu tolerância para este possivel erro foi a avaliação de que eventuais casos que se apresentassem no periodo

218. Rodrigues L, Kirkwood BR. Case-control designs in the study of common diseases: updates on the demise of the rare disease assumption and the choice of sampling scheme for controls. In J Epidemiol 1990; 19:205-13.

219. Rothman K J. Op. cit. (referéncia 137): 64. 
noturno provavelmente o fariam pela gravidade do quadro clinico, que não permitiria adiamento para busca de assistência, e assim provavelmente ficariam retidos para tratamento hospitalar podendo ser recuperados na manhã do dia seguinte. Esta situação de fato ocorreu, tendo-se recuperado casos internados durante o periodo noturno, mas, no entanto, se casos de pneumonia com condições de entrada no estudo foram atendidos e dispensados à noite, tais casos foram perdidos com prejuizo de precisão para o estudo.

Quanto às oportunidades de utilização dos mesmos serviços médicos, os resultados apresentados nas tabelas $I X$ e $X$ sugerem que os padrões de utilização dos serviços do Hospital pelos individuos estudados não apresentem diferenças estatisticamente significantes.

O Hospital Universitário da Universidade de São Paulo atende a uma comunidade adstrita a de um sistema local organizado hierarquicamente com rotinas de referência e contra-referência, além de atender a própria comunidade universitária. É um hospital geral que desempenha papel tanto de porta de entrada como de unidade de referência dentro deste sistema assistencial e atende a um conjunto de pessoas que compreende um largo espectro de caraterísticas sociais e econômicas. A renda familiar, que variou desde zero até $\mathrm{R} \$ 5$ mil por mês, bem como a escolaridade que variou desde analfabetos até universitários, dão indicações de que a amostra cobriu um largo espectro de carateristicas socio-econômicas no estudo realizado.

A adequada seleção de controles poderia ainda ser prejudicada se fatores ligados à exposição pudessem influenciar quer a busca ou a captação de pacientes pelo hospital, supondo-se que por alguma razão individuos mais expostos a doença chiadora preferissem ou fossem preferidos para o atendimento no Hospital. Para diminuir uma interferência deste tipo foi que escolheu-se o pareamento duplo incluindo-se controles sadios, que não estavam procurando assistência médica. Desta forma, os casos puderam ser comparados a controles que reunindo estes dois grupos distintos deveriam conter estes eventuais fatores condicionadores de busca ou captação dentro de um maior espectro de possiveis ocorrências. Também por isto é que, embora tenha-se obtido dois grupos controles, os casos são comparados ao conjunto de controles obtidos.

Quanto à seleção de casos, ponderou-se que a identificação da exposição pudesse influenciar a decisão clínica do diagnóstico de pneumonia. Com vistas a minimizar esta interferência foi que estabeleceu-se que as investigações de doença e exposição seriam feitas de forma independente, cada uma por uma pediatra distinta. Não há como se garantir que o raciocinio clínico da pediatra que selecionou os casos 
para entrada no estudo nāo tenha sido influenciado por uma história clinica que incluisse a exposição ao fator investigado. No entanto, possiveis vieses de detecção tanto de doença quanto de exposição foram circunscritos pelas avaliações de validação das conclusões clínicas. Além da exigência de confirmação radiológica para classificação de qualquer paciente como caso, a análise discriminante múltipla (Quadro II) sugere que os sinais clinicos registrados para os individuos estudados teriam separado casos e controles da mesma forma com que foram classificados pela decisão clinica em pelo menos $75 \%$ da amostra.

No que tange a possiveis vieses de detecção ou informação para a exposição, ou presença de doença chiadora recorrente, a variabilidade devida ao observador foi controlada pelo fato de um único observador, a médica designada para a tarefa de avaliar a exposição, ter realizado todas as observações. A repitibilidade das informações coletadas alcançou um nivel geral de concordância de $76,7 \%$ que pode parecer modesto a primeira vista, mas é um indice que supera bastante a expectativa de concordância ao acaso $(48,3 \%$, Kappa de, 65$)$ e que não difere de outros registrados pela literatura. Venables et al. ${ }^{220}$, que testaram recentemente um questionário de sintomas respiratórios para asma aplicado a adultos, conseguiram uma repitibilidade que variou para os diferentes itens de informação entre $72 \%$ e $88 \%$, 0 que consideram bom principalmente porque apuraram que na literatura a repitibilidade apenas para o item tosse produtiva tem variado entre $38 \%$ e $71 \%$. Desde os primeiros estudos da década de 50 sabe-se que a repitibilidade cai proporcionalmente ao tempo decorrido entre a primeira e segunda coleta de informaçöes ${ }^{221}$, e no presente estudo há que se considerar tanto o fato de que o informante fala de sintomas em terceiros ( $a$ criança que não informa autonomamente), quanto o fato que o tempo médio decorrido entre a primeira e segunda entrevista foi de 45 dias.

Ainda em relação ao diagnóstico de exposição a doença chiadora recorrente, deve-se destacar que além da confiabilidade da informação registrou-se coerência entre a história clinica colhida e a conclusão da médica examinadora. Entre os 41 casos identificados, apenas um nāo correspondia perfeitamente às definições prévias de caracterização da exposição fixadas na seção de métodos deste estudo. Mesmo assim tratava-se de caso com vários episódios de chiado nos últimos 12 meses, com susceptibilidade declarada a variações ambientais de temperatura e que só não

220. Venables KM, Farrer N, Sharp L, Graneek BJ, Newman Taylor AJ. Respiratory symptoms questionnaire for asthma epidemiology: validity and reproducibility. Thorax 1993; 48: $214-9$.

221 . Fletcher $\mathrm{CM}$, Elmes PC, Fairbairn AS. Wood CH. The significance of respiratory symptoms and the diagnosis of chronic bronchitis in a working population. Br Med J 1959; ii: 257-66. 
correspondia perfeitamente às premissas anteriores porque não informava resposta dos sintomas a broncodilatadores.

A detecção da exposição à doença chiadora é desafiadora pelas próprias caraterísticas do fenômeno. As considerações apresentadas sob o título "A asma e as doenças chiadoras da infância" sugerem que há um grupo nosológico cujas carateristicas sintomáticas e fisiopatológicas se assemelham ao quadro clínico da asma brônquica e que talvez até pudesse ser designado sob este mesmo nome. No entanto, considerando que o diagnóstico de asma é reservado pelos clinicos a situações particulares de apresentação deste grupo de doenças, no presente trabalho optou-se pela designação doenças chiadoras da infáncia ou doenças chiadoras recorrentes da infáncia. Não se trata de uma opção isenta de falhas até porque o sintoma (chiado) pertence ao paciente e não à doença mas, no entanto, entendeu-se que fosse esta a melhor designaçăo para o evento que se buscou investigar como fator de exposição. O adjetivo "chiadora" deve ser entendido como "que provoca chiado", num paralelo ao que já acontece com outras adjetivações em medicina, eg. doença hipertensiva, doença que provoca hipertensão. Com esta designação clinica pretende-se reunir todas com alterações brônquicas funcionais que se apresentam clinicamente como episódios recorrentes de dispnéia com sibilos que melhoram espontaneamente ou por resposta a medicação.

As normas de padronização das observações na forma descrita pelos roteiros de observação anexos a este estudo, constituíram-se num esforço de restrição a possiveis vieses de seleção e detecção. O treinamento dos observadores bem como a permanente supervisão e análise de consistência das informações recolhidas foram também medidas adotadas no mesmo sentido. Vieses de confusão, que poderiam derivar da presença de fatores associados tanto à doença quanto à exposição foram controlados pelo método de análise, a regressão logística, que permitiu avaliar o efeito simultâneo do conjunto de variáveis selecionadas para avaliação.

A regressão logística é um instrumento poderoso de análise multivariada para o estudo de variáveis dependentes binomiais ${ }^{222}$; sendo considerada robusta o bastante para lidar com dados que apresentem variações quanto a suas premissas matemáticas $^{223}$. Envolve procedimentos matemáticos complexos e só teve sua aplicação popularizada nas últimas décadas graças ao desenvolvimento da tecnologia de computação eletrônica tanto em termos de "soff" quanto de "hardware", vindo a

222. Finney DJ. Probit analysis. Cambridge: University Press, 1971.

223. Cox DR. The analysis of binary data. London: Melthuen \& Co., 1970. 
substituir com vantagem as técnicas de estratificação. Estas, que na descrição de MacMahon e Pugh ${ }^{224}$ incluem desde simples comparaçōes de proporçōes dentro de cada categoria estratificada até a técnica de Mantel-Haenszel ${ }^{225}$ que deriva medidas gerais de risco tomando em conta a contribuição de cada categoria, têm restrições que dizem respeito não só à computação, que requer uma frequência minima para cada categoria considerada, como também interessam a análise e interpretação dos dados já que, como lembra Rothman ${ }^{226}$, seriam dificilmente aplicáveis quando um grande número de fatores de confusão devessem ser considerados para estratificação: eg. 10 variáveis binárias independentes resultariam em $2^{10}=1024$ estratos. A regressão logística identifica fatores associados à condição estudada e os expressa como odds ratios, os quais são ajustados para cada variável que entre na equação ${ }^{227}$, ou seja podem ser interpretados valores de odds ratios com controle de efeito para as outras variáveis da equação.

No modelo logístico, a avaliação estatística da significància dos coeficientes é dada pela estatistica de $\mathrm{Wald}^{228}$, que representa a razão entre o coeficiente e seu erro padrão, a qual tem uma distribuição de probabilidades segundo o número de graus de liberdade que permite aferir a hipótese nula de ser o coeficiente igual a zero. A contribuição de cada variável ao modelo logístico construído pode ser avaliada pelo valor de "R", que é um coeficiente de correlação que para fins de interpretação pode ser tomado como semelhante ao $r$ de Pearson, embora seja calculado à partir da estatística de Wald. A consistência do modelo é avaliada pelo ajustamento da função derivada em relação uma função ideal com probabilidade de acerto de $100 \%{ }^{229}$ (-2 log likelihood e goodness of fit cujas significâncias devem ser superiores a 0,10 ).

Como uma forma adicional de exploração da relação estudada, além do cálculo do odds ratio, calculou-se também o risco atribuivel. Almeida e Rouquayrol ${ }^{230}$ ensinam que 0 risco atribuivel pode ser calculado a partir do odds ratio em estudos casocontrole, desde que se disponha de informação sobre a frequência da exposição na população, utilizando-se a fórmula:

224. MacMahon B, Pugh TF. Principios y métodos de epidemiologia. Mexico: La Prensa Médica Mexicana, 1975: $258-61$.

225. Mantel N, Haenszel W. Statistical aspects of the analysis of data from retrospective studies of disease. J Nat Cancer Inst 1959; 22: 719-48.

226. Rothman KJ. Op. cit. (referencia 137): 291.

227 . Kelsey JL; Thompson WD, Evans AS. Op. cit. (referência 157): 113-21.

228. Hauck WW, Donner A. Wald's test as applied to hypothesis in logit analysis. J Am Stat Assoc 1977; $72: 851-3$.

229 . Armitage P, Berry G. Op. cit. (referencia 17): 393-9.

230. Almeida Fo. N, Rouquayrol MZ. Op. cit. (referéncia 114): 106-109 


$$
\text { Risco Atribuivel }=\frac{F(O R-1)}{F(O R-1)+1}
$$

onde

$$
\begin{aligned}
& \text { F = Frequência do fator de exposição na } \\
& \text { população. Quando desconhecida pode ser } \\
& \text { estimada como frequência entre controles } \\
& \text { desde que a exposição seja rara } \\
& \text { OR= Odds ratio }
\end{aligned}
$$

Já Armitage e Berry ${ }^{231}$ ensinam como calcular o risco atribuível em estudos caso-controle sem cálculo prévio do odds ratio utilizando-se uma tabela de contingência do tipo:

\begin{tabular}{cccc} 
& & \multicolumn{2}{c}{ DOENÇA } \\
& Presente & Ausente \\
EXPOSIÇÃo & Ausente & b & $c$ \\
& & & $d$
\end{tabular}

onde

$$
\text { Risco Atribuivel }=\frac{a d-b c}{d(a+b)}
$$

Mais ainda, oferecem fórmula para o cálculo indireto da variância do risco atribuivel, na seguinte forma:

Variância $\ln (1-$ RiscoAtrib $)=\frac{a}{b(a+b)}+\frac{c}{d(c+d)}$

Com esta abordagem há o ganho de poder-se medir o intervalo de confiança para o risco atribuivel mas há, no entanto, a perda de utilização do odds ratio que, quando derivado de um procedimento que controla variáveis de confusão como a 
regressão logistica, pode ser mais consistente do que a simples análise isolada da interação entre o fator de exposição e a doença investigada.

Ambas as alternativas de cálculo foram consideradas no âmbito deste trabalho, mas há que se considerar que a avaliação do possivel impacto de um controle do fator de exposição (doença chiadora recorrente) deve levar em conta não só os limites de inferência permitido por uma amostra de usuários de hospital, mas também o fato de que a complexidade de tal ação de controle dificilmente permitiria conhecer sua contribuição especifica a uma eventual redução de incidência de doença (pneumonia). De fato, o controle da exposição demandaria algo como um programa de assistência à criança com doença chiadora recorrente que redundaria numa reorganização dos serviços médicos a qual por si só poderia explicar eventuais reduções de incidência de pneumonia, quer devido a medidas de prevenção primária que poderiam ganhar maior abrangência, quer devido a prevenção de complicaçōes de doenças mais simples que poderiam ganhar melhor assistência. Por isso, embora se tenha procedido ao cálculo do risco atribuivel pelas duas técnicas descritas acima, não se pretende oferecer uma medida precisa do eventual impacto do controle da exposição sobre a incidência da doença. Busca-se com isto apenas produzir-se um indicador objetivo da eventual importância deste controle.

Concluindo, o presente estudo selecionou uma amostra e aplicou um desenho de investigação e uma técnica de análise que devem ser adequadas à exploração da hipótese proposta de que doença chiadora recorrente seja um fator predisponente a infecção respitatória. Cabe ainda, no entanto, alguns comentários sobre os métodos estatisticos utilizados para identificar diferenças entre casos e controles e para validar as observações clinicas.

Para comparar as medidas das diferentes variáveis entre os grupos de caso e controles utilizou-se a análise de variança (ANOVA), que examina a variança de uma variável entre vários grupos de classificação constituindo-se numa extensão do teste $t$ de Student para situação particular onde mais de dois grupos são comparados. Testase a hipótese de que as médias de todos os grupos sejam iguais através do cálculo da razão das variâncias entre os grupos e dentro dos grupos, resultado normalmente designado de $F$ e que tem uma distribuição normal que, classificada segundo os graus de liberdade dados pelo número de individuos e grupos observados, corresponde a uma probabilidade $p$. Valores de $F$ superiores à unidade já sugerem distinção entre os grupos. Valores de $p$ inferiores a 0,05 são com frequência utilizados para rejeição da hipótese nula de igualdade entre os grupos. Sempre que isto aconteça deve-se explorar as diferenças entre os grupos dois a dois para identificação das categorias 
que se destacam, o que pode ser feito pela comparação das médias e erros padrões de cada grupo, que permite o cálculo dos intervalos de confiança para cada categoria. O teste de Kruskal-Wallis, que é chamado de análise univariada de variância por hierarquia (oneway analysis of variance by ranks) e que foi utilizado para as variáveis categóricas, segue a mesma racionalidade da ANOVA aplicanda a variáveis categóricas: cada registro original é substituído por um número de ordem (rank) que depois é processado da mesma forma que na ANOVA, pelo que resulta em conclusões idênticas quando aplicado a variáveis continuas.

Para validação do diagnóstico de pneumonia, aplicou-se a técnica de análise discriminante multivariada (ADM), que é uma técnica estatística para derivar combinações lineares de duas ou mais variáveis independentes que possam discriminar a priori as categorias de uma variável dependente categórica. Estas combinações lineares são funções matemáticas idênticas a uma equação de regressão linear múltipla, dela se diferenciando apenas pelo fato da variável dependente ser originalmente categórica quando na regressão linear ela é, por principio, contínua e de distribuição normal. Nas funçōes discriminantes derivadas do processamento das variáveis independentes, esta variável dependente passa a ser medida em "scores" que representam a soma dos valores de cada variável independente transformados pela sua estrutura de variância: são os coeficientes da equação, que aqui são denominados pesos. Apesar desta denominação, a contribuição de cada variável dependente é melhor avaliada pela estrutura de correlação com a função derivada, onde se medem as contribuições individuais ("loadings") de cada variável ao modelo em valores que variam de -1 a +1 , que podem ser analisados à semelhança da correlação medida pelo $r$ de Pearson (veja a seguir), devendo-se, no entanto, tomar o valor absoluto, abstraindo-se o sinal. A análise discriminante multivariada é normalmente usada para fins preditivos mas, no presente estudo, foi usada para verificar se os sinais clínicos anotados para casos e controles levavam a conclusões semelhantes às da médica examinadora, de forma a validar-lhe o diagnóstico que classificou casos, controles não respiratórios e controles sadios.

$\mathrm{Na}$ ADM, analisando-se os "scores" médios de cada categoria da variável dependente, denominados de centróides do grupo, em cada função discriminante pode-se avaliar quanto aparte estão os grupos, tendo-se em mente que a unidade medida é um resíduo padronizado: qualquer diferença maior do que 3 sugere distinção praticamente perfeita, já que 3 desvios padrão de um ponto central corresponde numa distribuição de probabilidades a praticamente $100 \%$. Para validar o modelo derivado da análise discriminante compara-se $o$ enquadramento de grupo predito com o observado 
e mede-se a concordância. Desde que Hills ${ }^{232}$, em 1966, demonstrou a superestimação desta concordância quando os mesmos dados são usados tanto para derivar funções discriminantes como para testar sua concordância, recomenda-se o que foi realizado neste estudo: a divisão aleatória da amostra estudada em um grupo de análise (analysis sample) e um grupo de teste (hold out sample), avaliando-se as proporções de concordância nas duas populações.

Para validação do diagnóstico de exposição a doença chiadora recorrente, cotejou-se a conclusão da médica examinadora com as informações recolhidas pelo questionário cuja cópia segue em anexo. Os questionários são largamente empregados na investigação da asma e de sintomas respiratórios mas, a despeito dos esforços da Sociedade Americana de $\operatorname{Tórax}^{233}$, não existe até hoje nenhum questionário padrão de consenso internacional.

A variabilidade de informações coletadas é conhecida no campo das doenças respiratórias, com registros na literatura já de longa data ${ }^{234}$. Barker e Rose ${ }^{235}$ discutem que esta variabilidade é devida a instabilidade tanto do objeto quanto do observador e recomendam que qualquer estudo contemple uma medida desta variabilidade através do dimensionamento da repitibilidade das informações, definindo esta repitibilidade como o nivel de concordância entre medidas replicadas de um mesmo fenômeno. Kramer e Feinstein ${ }^{236}$ recomendam que a proporção de concordância observada seja comparada com a proporção de concordância esperada por simples obra do acaso, e sugerem o indice Kappa para medir concordância porque este indice inclui uma correção para concordâncias ao acaso. Comentam que avaliações de correlação para variáveis contínuas e mesmo categóricas, respectivamente " $r$ " de Pearson e " $r$ " de Spearman, podem ser indicadoras indiretas de concordância desde que não haja sobre ou subestimação sistemática numa das medidas realizadas. As três medidas foram realizadas para avaliar a repetibilidades das informações coletadas no presente estudo.

O indice Kappa de concordncia aplica-se a variáveis categóricas e expressa a razão entre a proporção de concordância observada reduzida da ação do acaso e a

232. Hills M. Allocation rules and their error rates. J R Stat Soc 1966; B28: 1-20.

233. Ferris BG. Epidemiology standardization project. Am Rev Respir Dis 1978; 118(6-Part 2): 1-120.

234. Cochrane AL, Chapman PJ, Oldham PD. Observer's errors in taking medical histories. Lancet 1951; i:1007-9.

235 . Barker DJP, Rose G. Epidemiology in medical practice. London: Churchill Livingstone, 1976.

236. Kramer MS, Feinstein AR. Clinical biostatistics: LIV. The biostatistics of concordance. Clin Pharmacol Ther 1981; $29(1): 111-23$ 
proporção máxima de concordância possivel igualmente reduzida da ação do acaso, podendo ser expresso pela seguinte fórmula:

$$
k=\frac{P(O)-P(E)}{1-P(E)}
$$

onde $P(O)$ é a proporção de concordância observada, $P(E)$ são as proporçōes esperadas por ação do acaso e 1 (ou 100\%), o máximo possível de concordância. Desde as análises apresentadas por Cohen ${ }^{237}$, em 1960, aceita-se que "k" obedece uma distribuição normal com média 0 (zero), podendo-se calcular o resłduo padronizado de uma leitura qualquer de " $k$ " (normalmente notado como " $z$ " $e$ correspondendo a uma probabilidade de ocorrência freqüentemente referida como "p"238). Assim pode-se testar a significância estatistica de um " $k$ " verificando-se a hipótese nula de que " $k$ " seja igual a zero.

0 indice Kappa de concordância pode variar entre $-1 \mathrm{e}+1$, os valores negativos significando concordância inferior ... esperada pelo acaso e os valores positivos indicando concordância de diferentes niveis. A classificação qualitativa desta concordância já foi objeto de diferentes autores ${ }^{239}, 240$ e Beard et al. ${ }^{241}$, em um trabalho recente de avaliação de confiabilidade de informações epidemiológicas da asma brônquica, propõem que a concordância seja pobre, regular, boa ou excelente conforme o indice Kappa seja menor/igual a 0,4, entre 0,41 e 0,59, entre 0,60 e 0,74 ou igual/maior a 0,75 , respectivamente. $O$ indice Kappa de concordância pode ser calculado em matrizes não quadráticas, mas o registro em que uma das observações esteja ausente é inteiramente desprezado (painwise deletion). Não pode, no entanto, ser calculado em tabelas de contingência de uma única célula, uma única linha ou coluna, dada a impossibilidade de cálculo da proporção esperada. Estas restrições explicam as eventuais divergências que possam ser observadas entre nivel de

237 . Cohen J. A coefficient of agreement for nominal scales. Educ Psychol Meas 1960; 20:37-46.

238. Armilage P, Berry G. Op. cit. (referéncia 17): 67-72.

239. Landis RJ, Koch GG. The measurement of observer agreement for categorical data. Biometrics 1977; 33:159-74.

240. Fleiss JL. Statistical methods for rates and proportions. New York: John Wiley \& Sons; 1981:218.

241 . Beard CM, Yunginger JW, Reed CE, O'Connell EJ, Silverstein MD. Interobserver variability in medical record review: an epidemiological study of asthma. J Clin Epidemiol 1992; 45(9):1013-20. 
concordância alto e valor de Kappa baixo ${ }^{242}$ e não descartam 0 uso deste índice em favor de qualquer outro ${ }^{243}$.

O coeficiente de correlação de Pearson, a razão entre a covariância das medidas analisadas e o produto de seus desvios padrão, e pode ser calculado através da fórmula:

$$
r=\frac{S_{X Y}}{\left(S_{X X} S_{Y Y}\right)^{3 / 2}}
$$

onde

Sxy = covariância de $x$ e $y$, ou seja a somatória do produto das diferenças entre cada registro de $x$ e y e suas correspondentes $m$, dias;

Sxx e Syy = variâncias de $x$ e $y$, ou seja a somatória do quadrado das diferenças entre cada registro ( $x$ ou $y$ ) e sua correspondente média ( $x$ ou $y$ ).

O coeficiente de correlação de Pearson não poderá ser calculado quando a variância de qualquer medida for nula, ou seja quando a tabela de contingência das medidas resultar em uma única célula, uma única linha ou coluna. Seus valores variam entre -1 e +1 , com os extremos significando perfeita proporcionalidade inversa ou direta, respectivamente, entre as duas medidas estudadas. $O$ valor nulo significa nenhuma correlação entre as medidas e pode constituir-se em hipótese nula para teste de significância estatística, que se procede através do cálculo do valor do $t$ de Student, - qual para cada número de graus de liberdade tem correspondência com uma probabilidade de ocorrência, tamb,m normalmente designada " $p$ ". O valor de $t^{244} \dot{e}$ calculado como o produto de " $r$ " pela raiz quadrada da razão entre o número de graus de liberdade e o complemento de " $r$ " para a unidade.

O coeficiente de Spearman segue a mesma lógica de cálculo que o coeficiente de Pearson, com a diferença de que os valores originais das medidas são substituídos

242. Feinstein AR, Clcchettl DV. High agreement but low kappa: I. The problems of two paradoxes. J Clin Epidemiol 1990; 43(6):543-49.

243. CicchettI DV, Feinstein AR. High agreement but low kappa: II. Resolving the paradoxes. J Clin Epidemiol 1990; 43(6):551-58.

244 . Armilage $P$, Berry G. Op. cit. (refere̊ncia 17): 155. 
por números de ordem, a menor medida correspondendo à unidade e a maior medida correspondendo ao ordinal mais alto encontrado no intervalo de valores registrado para a medida. O cálculo de sua significância estatística segue também a mesma racionalidade do coeficiente de Pearson, com o qual concordará sempre que a ordenação das medidas não resulte em empates, situação em que o cálculo do coeficiente de Spearman sofre correções e pode resultar significativamente diferente do coeficiente de Pearson.

\section{IV.3.2 - DOS RESULTADOS}

A pesquisa resultou numa larga quantidade de informaçōes para cujo processamento haveriam várias alternativas de abordagem e exploração. Obedeceuse, no entanto, as definições pré-estabelecidas na seção de métodos, apresentandose uma descrição de frequências de todas as variáveis e escolhendo-se para análise da relação entre doença chiadora e pneumonia aquelas cujas medidas diferissem entre casos e controles ou cujas informações de literatura sugerissem importância.

A caracterização da amostra mostrou uniformidade de carateristicas pessoais entre casos e controles. Entre os diagnósticos presente nos controles não respiratórios, o diagnóstico de otite poderia ser disputadó como um diagnóstico de infecção respiratória alta mas, no entanto, conforme anotado referiam-se a diagnósticos de otite sem presença de infecção de vias aéreas sugerindo tratar-se de doença independente de afeç̧ão respiratória.

A caracterização socio-econômica dos indivíduos estudados permitiu a seleção das variáveis composição da moradia, localização do banheiro, renda familiar e nivel de escolaridade do pai e da mãe para consideração na análise das relações doença chiadora e pneumonia.

$\mathrm{Na}$ descrição da situação atual de saúde dos indivíduos estudados já se destaca uma maior referência a doenças chiadoras entre os portadores de pneumonia. A situação nutricional que potencialmente afetaria as chances do diagnóstico de pneumonia, foi encontrada sem diferenças entre casos e controles.

Nos antecedentes clínicos dos pacientes, história de pneumonia anterior não diferiu entre casos e controles, embora a literatura registre este antecedente como 
fator de risco para a doença ${ }^{245}$. Se história de pneumonia fosse tomada como variável dependente, encontrar-se-ia na amostra que uma frequencia de doença chiadora 3,11 vezes (intervalo de confiança de $95 \%$ entre 1,47 a 6,57 ) maior entre individuos com história positiva comparados a individuos com história negativa.

$\mathrm{Na}$ caracterização da presença de doença, chama a atenção o fato de que entre os casos considerados $78.4 \%$ foram de pneumonia com tratamento hospitalar (Tabela XVIII), o que poderia sugerir uma seleção de casos mais graves. No entanto, os sinais e sintomas registrados para caracterização do caso clínico não dão suporte a esta hipótese: apenas $15,7 \%$ dos casos tinham derrame pleural, nenhum caso foi registrado com comprometimento grave do estado geral (nenhuma toxemia grave $(++++)$ ) e apenas $15,7 \%$ tinham toxemia importante $(+++)$, nenhum caso de cianose e apenas $9,8 \%$ dos casos tinham dispnéia importante ou grave (+++ ou ++++). Tampouco as condições socioeconômicas dos casos explicam melhor do que a gravidade da doença as razões de tratamento hospitalar porque, embora os casos tenham formado o grupo de menor renda familiar mensal $(R \$ 269,15$ contra $R \$ 341,52$ para doentes não respiratórios e $R \$ 543,01$ para controles sadios), as médias de renda familiar entre pacientes internados $(R \$ 274,73)$, tratados ambulatorialmente $(R \$ 189,00)$ ou com alta $(R \$ 347,50)$ não mostraram diferenças estatisticamente significantes.

$\mathrm{Na}$ caracterização da exposição à doença chiadora, chama a atenção o fato de que, a despeito de 20 controles sadios apresentarem história de chiado com frequência média de 4,45 episódios nos últimos 12 meses, apenas 8 foram considerados portadores de doença chiadora recorrente. Para esclarecer a conclusão clínica deve-se considerar que a média de 4,45 episódios de chiados para estas crianças foi derivada de uma medida de larga variabilidade: 3 crianças não haviam tido qualquer episódio de chiado nos últimos 12 meses, 9 tinham tido apenas 1 episódio neste periodo, 1 tinha tido 4 episódios, 1 tinha tido 5 episódios, 1 tinha tido 7 episódios, 4 tinham tido 10 episódios e 1 tinha tido 24 episódios. As 12 crianças que relataram um único ou nenhum episódio nos últimos doze meses foram classificadas pela pediatra responsável pela observação como não expostas a doença chiadora. De acordo com as premissas adotadas, as 3 crianças sem história de chiado nos últimos 12 meses não seriam elegiveis para classificação como expostas e as 9 crianças com um único episódio no período só o seriam se referissem um diagnóstico médico de asma brônquica. Destas 9,3 excluiriam-se por não referirem este diagnóstico. Das 6 
restantes, 5 relataram que o episódio a que se referiam estava ligado a um evento de infeç̧ão respiratória, que por si só poderia explicar o chiado, e negaram que o chiado pudesse ser provocado por qualquer dos outros fatores desencadeantes investigados (alérgenos, irritantes, climáticos, exercício, stress). Para a última criança entre as excluidas, a mãe não soube informar com certeza se o episódio de chiado havia estado associado a uma infecção respiratória ou não, como tampouco soube informar a reação da criança à exposição a outros potenciais fatores desencadeantes, mas tratava-se de uma criança de apenas 14,5 meses, cuja história de chiado e suposto diagnóstico médico de asma referiam-se ambos a este episódio de chiado que constituia-se no único evento de chiado da vida da criança.

Entre os casos, das 25 crianças com história anterior de chiado apenas 2 foram excluidas da classificação de portadoras de doença chiadora, mas a exclusão obedeceu o mesmo critério. Uma delas era uma criança de 12,8 meses para a qual se relatava um diagnóstico médico de asma e 2 episódios de chiado nos últimos 12 meses mas, no entanto, ambos os episódios estavam ligados a infecção respiratória e negava-se susceptibilidade a outros fatores desencadeantes. A outra criança tinha 24,9 meses, história de diagnóstico médico de asma e 2 episódios de chiado nos últimos 12 meses mas, igualmente, associava estes episódios a infecções respiratórias e negava susceptibilidade a outros fatores desencadeantes.

$\mathrm{Na}$ avaliação de repitibilidade das informações que permitiram classificar os individuos como expostos e não expostos, a concordância no julgamento do médico examinador quanto à condição do paciente como portador ou não de doença chiadora recorrente teve uma proporção de concordância de $80 \%$ que, embora boa, suscita interesse sobre os $20 \%$ de discordância. Revendo-se os dados dos 6 pacientes em que houve discordância na opinião do médico entre a primeira e a segunda entrevista constatou-se que 4 poderiam ser devidas a variações do objeto e não do observador, já que a mudança de situação era de negativa para positiva, o que poderia ter ocorrido no intervalo entre as entrevistas. Isto se confirmou para duas destas crianças: a primeira era um caso de pneumonia que havia sido examinado pela primeira vez aos 4 meses e na segunda entrevista, já com 6 meses, tinha tido 3 episódios de chiado e havia sido diagnosticada como asmática por médico; a segunda criança era um controle não respiratório que, com diagnóstico de diarréia, havia sido examinada pela primeira vez aos 3 meses e ao ser revista aos 5 meses havia apresentado 3 episódios de chiado com dispnéia. Para as outras duas crianças constatou-se que havia desacordo também em outras informaçōes permanecendo a dúvida sobre desacordo do próprio observador. Se a mudança de status da criança pudesse ser considerada 
para explicação da diferença de conclusão entre a primeira e segunda entrevista, pelo menos mais dois casos poderiam ser acrescentados como concordantes, e desta forma o nivel de concordância na conclusão do médico poderia subir dos $80 \%$ medidos para $86,6 \%$.

A avaliação da associação entre pneumonia e doença chiadora resultou em figuras diferentes conforme o odds ratio foi calculado pelo cruzamento simples das variáveis $(3,83$, IC $95 \%=1,80$ a 8,11$)$ ou pela regressão logística $(7,07$, IC $95 \%=2,34$ a 21,36 ). Ambos os resultados têm intervalos de confiança que se sobrepõem, e a diferença de odds ratio se explica pelo fato de que na regressão logística só foram processados para análise os registros com anotaçōes válidas para todas as variáveis consideradas, tendo sido por isso desprezados 45 registros (15 casos, 21 controles não-respiratórios, 9 controles sadios) por falta de informação numa das seguintes variáveis: educação do pai, educação da mãe, história de laringotraqueobronquite e renda familiar. Se estas variáveis fossem retiradas da análise, ter-se-ia os 153 registros processados e obter-se-ia um resultado com odds ratio de 3,654 (IC 95\% = 1,702 a 7,846 ) para a condição de portador de doença chiadora (valor muito próximo dos 3,83 do cruzamento simples de variáveis) e de 1,279 (IC $95 \%=1,008$ a 1,625) para cada pessoa a mais dormindo no quarto da criança. No entanto, as variáveis de registros incompletos já haviam demonstrado diferenças estatisticamente significantes entre casos e controles não poderiam ser desprezadas sob pena de violação das premissas de análise definidas no capitulo de métodos.

Os 45 registros desprezados na regressão logistica por falta de informação tiveram distribuição aleatória entre casos e controles e, embora a frequência entre controles não respiratórios seja significativamente (a nivel de $p<0,05$ ) superior a controles sadios, a frequência entre casos não tem diferença estatisticamente significante quer em relação a controles sadios ou a controles não respiratórios. $O$ odds ratio para pneumonia entre portadores e não portadores de doença chiadora, calculado pelo cruzamento simples das variáveis entre os 108 registros processados na regressāo logística resulta em 4,96 (IC $95 \%=1,94$ a 12,66) e entre os 45 desprezados resulta em 2,40 (IC $95 \%=0,65$ a 8,80 ). 


\section{IV.3.3 - DAS CONCLUSÕES E INFERÊNCIAS}

"Life is short, science is long; opportunity is elusive, experiment is dangerous, judgement is difficult" - Hippocrates ${ }^{246}$

Já Hipócrates, no século V A.C., percebia que a construção do saber médico incluia uma laboriosa coleta de informações para um julgamento dificil, uma ciência extensiva para uma vida curta.

Um estudo caso-controle não provê informações definitivas para o estabelecimento de um conhecimento especifico, mas a medicina tem construido seu saber a partir de múltiplos estudos isolados que quando congruentes vão progressivamente reduzindo a margem de dúvida sobre o assunto tratado. Estudos do tipo caso-controle podem prover evidências de uma associação, medir sua intensidade e ainda controlar a influência de variáveis de confusão. Schlesselman ${ }^{247}$, em seu livro inteiramente dedicado ao estudo dos procedimentos epidemiológicos de investigações caso-controle, provê inúmeros exemplos da riqueza deste tipo de metodologia e dedica o epílogo de seu livro a um balanço da contribuição deste tipo de estudo na elucidação da associação entre o uso de dietilestibestrol e mal formações congênitas. Através de todo o livro as pesquisas sobre esta associação são lembradas e o epilogo constitui-se num arrazoado de como os estudos caso-controle de natureza observacional se repetem para constituir um conhecimento básico e como os estudos caso-controle de natureza experimental os sucedem para confirmar e definitivamente estabelecer 0 conhecimento.

Graham $^{248}$, lembra que as inevitáveis imperfeições de quaisquer estudos científicos não podem obstar a produção do conhecimento: "Flaws can be found in any study. The findings of particular studies need to be considered in the context of relevant findings from other inquiries, which undoubtedly are also flawed, but in different ways. When enough congruent findings have accrued from a large number and variety of studies, credence may be given to the findings in spite of flaws".

O presente estudo tem, para além das limitaçōes do método, a limitação de interessar-se por um objeto amplo, a relação entre doença chiadora recorrente da

246. Chadwick J, Mann WN. The medical works of Hippocrates. Aphorisms. Oxford: Blackwell Scientific Publications, 1950: 148.

247. Schlesselman JJ. Op. cit. (referéncia 95) Pg. 291-2.

248. Graham S. Enhancing creativity in epidemiology. J Epidemiol 1988; 128(2): 249-53. 
infância e pneumonia, mas abordá-lo no ambiente restrito da clientela de um hospital. As medidas de associação, na forma de odds ratio e risco atribuivel, que se realizam não extrapolam este ambiente e poder-se-ia mesmo argüir a propriedade do último indicador para um estudo sem base populacional. No entanto, estas medidas são realizadas para provocar a especulação: seria a associação encontrada neste estudo aplicável para a população em geral? O estudo se propôs a verificar se e quanto dos dois fenômenos estariam associados $e$, ainda que por restriçōes de desenho suas medidas não tenham valor universal, há que se prover medidas que sugiram objeto $e$ dimensão para a especulação.

Rothman ${ }^{249}$, discutindo os limites da inferência causal em epidemiologia, aponta para o fato que este exercicio é de natureza mais filosófica que científica e conclui que talvez a assunção da generalidade de uma relação causal pertença ao domínio das políticas públicas e não da ciência. $O$ presente estudo provê evidência de que no ambiente estudado a doença chiadora recorrente da infância seja um fator de risco importante para o desenvolvimento de pneumonia e que seu controle pode ter impacto não desprezivel sobre a frequência de doença neste ambiente. Embora os limites do método científico não permitam afirmar que isto aconteça na população em geral, há motivos para se crer que este ambiente difira do universo?

Não é preciso qualquer generosidade para reconhecer que 0 ambiente estudado tenha carateristicas semelhantes ao universo se este for considerado como a cidade de São Paulo. Ai se encontra a diversidade de uma comunidade de bairro da capital que inclui desde áreas urbanizadas até favelas associada a uma comunidade universitária representando estamentos mais privilegiados da urbe. Detecta-se ainda ai, e a amostra estudada revela, um largo espectro de condiçōes socioeconômicas representadas por condições de moradia e renda familiar. Com estas caracteristicas a comunidade usuária do Hospital Universitário avança para além da delimitação geográfica de definição de comunidade para incluir uma diversidade cultural, social, econômica e de padrão de saúde muito sugestiva daquela que se espera encontrar na cidade. Ora, se esta conjectura for verdade, então as frequência de eventos de saúdedoença desta comunidade deverão ser semelhantes às da população da capital e a adoção de decisões políticas para ações no campo poderão ter suas medidas como parâmetros de referência.

Encontrou-se na amostra estudada que a presença de doença chiadora recorrente deva implicar em risco 7 vezes maior para 0 desenvolvimento de 
pneumonia, controlados outros dois fatores de risco, igualmente identificados: renda familiar e número de pessoas dormindo no mesmo quarto da criança. Um recente estudo de Infante-Rivard ${ }^{250}$, aplicando regressão logística em 457 casos de asma e igual número de controles pareados por idade e área de residência encontrou que a história de pneumonia, supostamente bacteriana, era 3,12 (intervalo de confiança de $95 \%$ entre 1,92 e 5,09) vezes maior entre asmáticos do que entre não asmáticos. Minor et al. ${ }^{251}$, que num estudo prospectivo acompanharam crianças asmáticas e não asmáticas por 6 meses, já haviam encontrado que asmáticos tinham uma maior incidência de infecções virais, particularmente por rinovirus. Mais recentemente, Porro et al. $^{252}$, na Itália, aplicando regressão logística num estudo tipo corte transversal, estudaram fatores de risco para infecções respiratórias altas em 2304 escolares e encontraram que doenças chiadoras, que eles dividiram em asma e bronquite recorrente, constituiam-se nos maiores predisponentes a infecção com "odds ratios" medidos de 2,20 (intervalo de confiança de 95\% entre 1,44 e 3,35) e 2,24 (intervalo de confiança de $95 \%$ entre 1,44 e 3,49 ) respectivamente, riscos muito superiores aos calculados para fatores socioeconômicos (1,36 para baixo nivel socioeconômico) e ambientais (tabagismo na familia: não significante; umidade na casa: não significante; número elevado de pessoas por cômodo: 1,40). Neste trabalho, entretanto, a infecção respiratória alta foi caracterizada por questionário como obstrução nasal ou secreção nasal (blocked or runny nose), e por isso pode ter sido confundida com rinite alérgica, cuja alta associação com doença chiadora seria esperada.

Em Campinas, em 1987, Ribeiro ${ }^{253}$ demonstrou que a frequência de pneumonia aumentava com o aumento da gravidade da asma diagnosticada, com diferenças estatisticamente significantes: $52,4 \%$ dos pacientes com asma em grau IV tinham história de 3 ou mais pneumonias, contra 40,6\% para asma de grau $111,31,8 \%$ para asma de grau II e 12,1\% para asma de grau I. Tal efeito dose-resposta permite supor que a relação se estenda também para um nivel inferior onde ausência de asma corresponda à menor frequência de antecedentes de pneumonia.

No presente trabalho, nos limites da criatividade do epidemiologista, buscou-se argüir a relação da asma em crianças, ou das doenças chiadoras recorrentes, com as

250. Infante-Rivard C. Childhood asthma and indoor environmental risk factors. Am J Epidemiol 1993; 137: 834-44.

251. Minor TE, Baker JW, Dick EC, et al. Greater frequency of viral respiratory infections in asthmatics children as compared with their non-asthmatic siblings. J Pediatr 1974; 85: 472-77.

252. Porro E, Calamita P, Rana I, Montini L, Criscione S. Alopy and environmental factors in upper respiratory infections: an epidemiological survey on 2304 school children. Int J Ped Otorhinolryngol 1992; 24:111-20.

253. Ribeiro JD. Asma brônquica na infância: associaçâo entre comportamento cllnico-laboratorial e severidade. Departamento de Pediatria da Faculdade de Ciencias Médicas da Universidade de Campinas, 1987: 86. 
infecções respiratórias, fugindo-se do enfoque tradicional que investiga como as últimas influenciam as primeiras para propor a hipótese que as doenças chiadoras recorrentes, independentemente de deverem ou não às infecçōes seu desencadeamento clínico, podem constituir-se em fator de risco para as infecções respiratórias. A associação dos dois eventos nesta direção tem consistência enquanto hipótese na própria fisiopatologia conhecida da doença: a inflamação crônica dos brônquios deve implicar em diminuição dos mecanismos locais de defesa e ainda prover meio propício ao crescimento bacteriano.

Jakab $^{254}$ descrevendo os mecanismos da superinfeç̧ão bacteriana em infecçōes virais destaca que no processo inflamatório desencadeado pelo vírus alterase o clearance mucociliar, diminui a função fagocitária das células de defesa, aumenta a descamação epitelial e há uma exsudação que cria meio próprio para o crescimento bacteriano. Não é diferente o processo inflamatório que se encontra na asma, com desnudamento epitelial, aumento das secreções e diminuição do clearance por prejuizo da estrutura ciliar do epitélio. Recentemente Lundgren ${ }^{255}$ demonstrou que a secreção excessiva de muco pode por si conduzir à infecção respiratória.

Seddon et al. $^{256}$ estudaram a colonização do retrofaringe por Branhamella catarrhalis em crianças normais, crianças asmáticas estáveis e crianças asmáticas em crise e encontraram um efeito tipo dose-resposta para a presença da bactéria: $33 \%$ das crianças normais, $70 \%$ em asmáticos estáveis e $75 \%$ em asmáticos sintomáticos. O risco elevado de infecção bacteriana em bronquite crônica é reconhecido já há décadas $^{257}$, e o mesmo se pode dizer da bronquiectasia ${ }^{258}$. Um recente estudo de Nayyar et al. ${ }^{259}$ com adultos portadores de DPOC (doença pulmonar obstrutiva crônica) mostra que, de fato, o diagnóstico de bronquite crônica em relação a outros deste grupo de doenças, representa um risco mais elevado para infecção (odds ratio de 3,80 ), embora fossem igualmente fatores de risco o tempo de exacerbação dos sintomas (odds ratio de 13,46 para mais de 3 dias), a história de corticoterapia (odds de 16,27) e a história de infeç̧ão anterior (odds de 37,11).

254. Jakab GJ. Mechanisms of virus-Induced bacterial superinfectlons of the lung. Clin Chest Med 1981; 2(1): 59-66.

255 . Lundgren JD. Pathogenesis of airway mucus hypersecretion. J Allergy Clin Immunol 1990; 85: 399-416.

256. Seddon PC, Sunderland D, O'Halloran SM, Hart CA, Heaf DP. Branhamella catarnhalis colonization in preschool asthmatics. Pediatr Pulmonol 1992; 13:133-5.

257. Lee AW, McNaught W. Bacteriology of lower respiratory tract secretions, sputum, and upper respiratory tract secretions in normals and chronic bronchitis. Lancet 1959; ii: 1112-5.

258. Murray JF. Prevencion de las infecciones respiratorias. Bol Union Inter Tuberculosis 1983; 58(1): 56-9.

259. Nayyar $V$, Antonisamy $B$, John $G$. Factors associated with isolation of pathogenic bacteria from sputum of patients with acute bronchospasm. Indian J Chest Dis Allied Sci 1992; 34(4): 197-204. 
Como a relação entre infecção e asma tem sido sempre investigada sob o prisma da primeira causando a segunda, mesmo informações relevantes sobre o sentido inverso não recebem atenção. Hudgel et al. ${ }^{260}$, num estudo com adultos, encontraram que alguns pacientes asmáticos tinham o trato respiratório cronicamente colonizado por bactérias potencialmente patogênicas, mas como não encontraram associação entre a presença destas bactérias e um aumento de frequência de crises asmáticas, enfatizaram mais a associação com infeç̧ões virais porque estas sim tinham correlação com exacerbação da asma. Graham et al. ${ }^{261}$, tendo realizado um ensaio clínico com pacientes em crise de asma separando grupos com e sem amoxacilina, demonstraram que a antibioticoterapia não influenciava a recuperação da crise, informação que embora auxilie a exclusão de antibioticoterapia sistemática no tratamento da asma, não nega que o tratamento adequado da asma possa prevenir a infecção: apenas este sentido da relação não é explorado.

Estudos de lavados broncoalveolares de asmáticos leves e moderados revelam a presença excessiva de células epiteliais descamadas, mastócitos, eosinófilos e linfócitos $T^{262}$. Marcadores de mucina examinados em expectoração de asmáticos ${ }^{263}$ informam que há secreção exagerada de muco. Lavados broncoalveolares de asmáticos tratados demonstram redução significativa do processo inflamatório ${ }^{264}$. A soma destas informações é inegavelmente sugestiva que no asmático existem condiçōes pré-patológicas de diminuição de defesa e meio de cultura para o desenvolvimento de infecção e que o tratamento da asma pode reverter tais condiçōes. Stenius-Aarniala ${ }^{265}$, numa revisão sempre preocupada com quanto a infecção pode ser responsável pela asma, registra que "bacterial infections of nasal sinuses and bronchi are probably secondary to mucosal edema, hypersecretion, bronchospasm and mucocilliary dysfunction. There is no evidence that they are the primary cause of an exacerbation of asthma. It is possible that some bacterial infections

260. Hudgel DW. Langston L, Selner JC, Mclntosh K. Viral and bacterial infections in adults with chronic asthma. Am Rev Resplr Dis 1979; 120: 393-7.

261. Graham VAL, Knowles GK, Milton AF, Davies RJ. Routine antibiotics in hospital management of acute asthma. Lancet 1982; i: 418-20.

262. Beasley R, Burgess C, Crane J, Pearce N, Roche W. Pathology of asthma and its clinical implications. J Allergy Clin Immunol 1993; 92: 148-54.

263. Fahy JV, Steiger DJ, Liu J, Basbaum CB, Finkbeiner WE, Boushey HA. Markers of mucus secretion and DNA level in Induced sputum from asthmatic and from health subjects. Am Rev Respir Dis 1993; 147: 1132-7.

264. Duddridge $M$, Ward $C$, Hendrick DJ, Walter $E H$. Changes in bronchoalveolar lavage inflammatory cells in asthmatic patients treated with high dose inhaled beclomethasone dipropionate. Eur Respir J 1993; 489-97.

265. Stenius-Aarniala B. The role of infection in asthma. Chest 1987; 91 (6): 157S-60S. 
will limit themselves, if the pathologic state of the mucosa is reversed and its normal function restored by the antiasthmatic medication".

Em epidemiologia se entende que uma associação causal se confirme demonstrada a sucessão temporal conseqüente entre causa e efeito, a resposta proporcional do efeito a variaçōes da causa e a compatibilidade da relação causa e efeito à luz do conhecimento vigente. Na amostra estudada, o presente estudo foi bem sucedido em demonstrar que crianças previamente expostas a doença chiadora recorrente têm maior probabilidade de posteriormente apresentarem pneumonia e esta informação não parece conflitar com os conhecimentos existentes sobre a fisiopatologia da doença, como mostram os comentários acima. 


\section{V - CONCLUSÕES}


A análise de uma amostra de usuários do Hospital Universitário da Universidade de São Paulo incluindo 51 casos de pneumonia comparados a 102 controles pareados por sexo e idade divididos entre 51 crianças com outras doenças não respiratórias e 51 crianças sadias, permitiu detectar-se que havia distinção entre casos e um ou outro tipo de controle para as seguintes situaçōes:

- condições de moradia: casos de pneumonia habitavam em moradias coletivas numa proporção $(15,7 \%)$ maior que controles sadios $(2,0 \%)$, embora não significativamente diferente da observada para controles não respiratórios $(17,6 \%)$ e da mesma forma habitavam em residências com banheiro fora de casa numa proporção $(19,6 \%)$ superior a controles sadios $(2,0 \%)$, embora não diferente de controles não respiratórios $(25,5 \%)$;

- renda familiar: casos apresentaram diferenças significativas quanto comparados a controles sadios (médias mensais de $R \$ 269,15$ e $R \$ 952,30$, respectivamente), embora não tenham diferido de controles não respiratórios $(R \$ 341,52)$;

- escolaridade dos pais: casos apresentaram uma frequência de pais e mães analfabetos ou com apenas primeiro grau incompleto $(78,2 \%$ e $80,4 \%$, respectivamente) superior à observada para controles sadios $(29,1 \%$ e $31,4 \% \%$, na mesma ordem), embora não tenham diferido de controles não respiratórios $(71,1 \% \%$ e $70,0 \%$, respectivamente para pai e mãe);

- história pregressa de laringotraqueobronquite: $45,1 \%$ casos referiam história positiva, frequência significativamente diversa da de controles sadios e não respiratórios (23,5\% e $14,3 \%$, respectivamente);

- número de pessoas dormindo no quarto da criança: a média para casos $(4,02$ pessoas) era estatisticamente superior à de controles sadios (2,92 pessoas), embora não diferisse de controles não respiratórios ( 3,80 pessoas);

- presença de doença chiadora recorrente: casos tinham uma frequência $(45,1 \%)$ estatisticamente superior tanto a controles sadios quanto a controles não respiratórios (15,7\% e 19,6\%, respectivamente).

A relação de frequências de doença chiadora recorrente entre casos e controles tomados em conjunto analisada em tabela de contingência simples resulta num odds ratio de 3,83 (intervalo de confiança de $95 \%$ entre $1,8038,11$ ). 
Uma análise por regressão logistica para avaliar a importância desta relação com controle para outras variàveis potencialmente geradoras de confusão, identifica um odds ratio de 7,07 para presença de doença chiadora controlados os efeitos de renda familiar e número de pessoas dormindo no quarto da criança, dois fatores que são igualmente revelados como associados ao diagnóstico de pneumonia. $O$ odds ratio para rendas familiares baixa e média resulta em respectivamente 5,59 e 2,44 se contrastados com renda familiar alta. $O$ odds ratio para número de pessoas no mesmo quarto resulta em 1,49 para cada aumento de uma pessoa.

O risco de pneumonia atribuivel à presença de doença chiadora recorrente é calculado para a associação encontrada nas duas abordagens realizadas e que resultaram nas duas figuras de odds ratio $(3,83$ e 7,07$)$, encontrando-se respectivamente os valores de $33,33 \%$ e $51,42 \%$.

Concluiu-se que a amostra estudada revela uma associação entre doença chiadora recorrente da infância e pneumonia. Crianças portadoras de doença chiadora têm chances para pneumonia que são de 3 a 7 vezes maiores que as chances de crianças não portadoras desta doença, fixadas as mesmas condições para renda familiar e para número de pessoas no quarto de dormir. Segundo o modelo logístico, se além da presença de doença chiadora, a criança apresentar também situação adversa para estas condiçōes (renda familiar mais baixa ou maior número de pessoas no quarto de dormir) suas chances para pneumonia resultam multiplicadas: uma criança com doença chiadora, pertencente a uma familia de renda familiar baixa e dormindo num quarto com um acompanhante, tem $59(7,07 \times 5,59 \times 1,49)$ vezes mais chances de pneumonia do que uma criança sem doença chiadora, pertencente a uma familia de renda familiar alta e que durma sozinha num quarto.

Os cálculos de risco atribuivel sugerem que, se de fato a amostra representar bem a comunidade de usuários do Hospital Universitário no que tange a frequência dos fenômenos estudados, um controle médico da doença chiadora que impeça sua ação predisponente à pneumonia pode resultar numa redução de frequência desta infecção respiratória nesta comunidade que deverá ser da ordem de pelo menos $33 \%$. 


\section{VI - COMENTÁRIOS FINAIS}


As evidência providas por este trabalho sobre o efeito das doenças chiadoras sobre a pneumonia, principal preocupação da Saúde Pública para a promoção da saúde da criança, deve convidar os atores da Saúde Pública a novas reflexões para as definições politicas de controle da morbimortalidade por doenças respiratórias na infância. $O$ enfoque exclusivo que se tem dado ao tratamento clínico dos casos agudos de infecções respiratórias tem excluído de antemão a assistência regular a doenças de base, cujo esquecimento deve se constituir no limite da capacidade de intervenção desta estratégia. Em áreas miseráveis do globo, onde as taxas de mortalidade são muito altas, garantir o acesso à antibioticoterapia pode resultar numa redução de óbitos como igualmente poderia ser bem sucedida qualquer outra intervenção que controlasse fatores de risco como desnutrição, falta de aleitamento materno, ausência de cobertura vacinal, etc.. Já se comentou aqui o trabalho de Jerzy Leowski ${ }^{206}$ que identificou alta correlação entre óbitos por doenças respiratórias e produto nacional bruto $(r=-, 89)$, o que sugere que se de forma inespecífica as condições gerais de vida puderem melhorar, a taxa de mortalidade por doença respiratória também tenderá a decrescer.

No entanto, superada a miséria, a conseqüente redução absoluta dos óbitos por doença respiratória não reduz sua participação proporcional nas causas de morte. Dar à curva de mortalidade por estas doenças inflexão distinta daquela observada nos óbitos em geral requer uma ação específica no campo, a exemplo do que parece acontecer nos paises desenvolvidos. O que o presente trabalho pode sugerir é que esta ação especifica deva ser uma garantia não de tratamento de infeç̧ões, mas de tratamento de moléstias de base responsáveis por alterações físiopatológicas que predispõem ao desenvolvimento da infecção. As doenças chiadoras recorrentes requerem uma estrutura de serviços hierarquizada para garantir tratamento continuado, orientação adequada e prontidão de intervenção quando quer que necessário.

Com esta conclusão não se trata de condenar a estratégia patrocinada pela Organização Mundial da Saúde, mas de apontar-Ihe os limites. O Estado de São Paulo é um exemplo destes limites, pois a despeito de uma inegável cobertura vacinal e amplo acesso a tratamento médico, os óbitos por pneumonia seguem sendo a principal causa evitável de óbito em crianças. As crianças que aqui morrem, estão internadas em hospitais recebendo antibioticoterapia, quando não mesmo assistidas por cuidados 
intensivos de alta tecnologia. $O$ que tem faltado a estas crianças é uma assistência médica continuada e não o socorro para o episódio agudo de infecção.

O estudo da mortalidade de crianças apresentado na introdução deste trabalho a guisa de identificação do problema aqui investigado, sugere que 0 impacto do controle de óbitos de asma sobre os óbitos de pneumonia poderia ser da ordem de apenas algumas dezenas num universo de alguns milhares de óbitos. No entanto, esta conclusão deriva de um modelo teórico de análise que supõe fixo $\circ$ padrão de causa de óbito e se restringe à análise interna da relação entre doença chiadora recorrente e pneumonia no universo dos óbitos registrados, ou seja compara as probabilidades de óbito com pneumonia entre óbitos com e sem asma, dada uma probabilidade de óbito na população. Certamente poder-se-ia ser mais otimista levando-se em conta que uma intervenção a nivel dos eventos que precedem a morte deva diminuir o risco de óbito. Entre os atendimentos hospitalares da capital, também analisados na introdução deste trabalho, das 25545 internações por doença respiratória, 16318 (63,87\%) foram devidas a pneumonia. Se o risco atribuivel encontrado para a comunidade do Hospital Universitário (30 a 50\%) fosse aplicado a este universo, esperar-se-ia que 5 a 8 mil internações pudessem ser evitadas a cada ano na capital, o que sugeriria uma conseqüente redução de óbitos.

Madel T. Luz, em obra ${ }^{207}$ que nos fins dos anos setenta analisou as instituições médicas no Brasil, identificou entre quatro formas de discurso médico, uma que designou discurso sanitarista campanhista. Tal discurso, que teria sido hegemônico no Brasil na primeira metade do século para paulatinamente ser desafiado por diferentes discursos com ênfase na assistência médica, privada ou estatal, talvez não se restrinja a uma organização ideológica da prática médica, mas se constitua em referencial teórico substantivamente arraigado no pensamento dos profissionais de Saúde Pública. O enunciado do programa oficial da OMS/OPS para o controle de doenças respiratórias testemunha esta expectativa quando aponta como horizonte da estratégia de controle das IRA uma ação que possa ser semelhante a do controle da diarréia. Indaga-se explicitamente qual seria nas IRA o equivalente ao soro de reidratação das diarréias, o qual pudesse ser objeto de uma ampla campanha que pusesse fim às IRA. O presente trabalho, ao sugerir que è o controle de doenças crônicas, as quais demandam uma assistência continuada, que pode contribuir para o controle das IRA, sugere que não haverá soro de reidratação para as IRA, não haverá campanha de controle das IRA. No âmbito da instituição médica, porque a nivel do social poder-se-ia

207 . Luz MT. As instituiçoes médicas no Brasil: Instituiçăo e estratégia de poder. Rlo de Janeiro: Ediçðes Graal, 1979. 
considerar ainda outras alternativas, só resta a solução assistencial que para moléstias desta complexidade solicitará respostas igualmente complexas de organização estrutural e funcional de serviços médicos.

Thomas S. Kuhn ${ }^{208}$, filósofo contemporâneo da ciência, ao questionar a visão tradicional de que a ciência acumula conhecimentos somando produçōes precedentes a conseqüentes, entende que a evolução das ciências se faça por processos de ruptura, que denomina revolução cientifica. Estas revoluçōes são evidentes nas grandes transformaçōes a que se associam nomes como Newton ou Einstein, mas são também uma realidade quotidiana da comunidade cientifica onde fatos novos que sejam fruto de uma abordagem alternativa tendem a ser relegados porque ameaçam de ruptura a ordem vigente. Ou seja, seu conceito de revoluçăo cientifica pode tanto auxiliar a compreensão da dinâmica da produção científica quanto explicar as grandes transformaçōes da história das ciências, embora sejam estas que validem tal proposição teórica. Kuhn propōe ainda o conceito de paradigma como o universo de valores que condiciona a produção científica, valores de ordem tanto lógica e epistemológica quanto de ordem gnóstica e axiológica interessando a sociologia ou a psicologia social. O pensamento campanhista na Saúde Pública parece constituir-se num paradigma do campo através do qual se busca apreender a realidade e definir estratégias de intervenção. Fatos que o desafiem não podem ser facilmente aceitos.

A informação produzida foi resultado de uma abordagem alternativa da relação entre os dois eventos estudados e leva a conclusōes que implicam em propostas de intervenção distintas das correntemente adotadas. Sua eventual influência em práticas individuais ou coletivas da medicina dependerá menos de sua própria consistência do que da receptividade do campo ao novo.

208. Kuhn TS. A estrutura das revoluçoes cientlificas. Såo Paulo: Editora Perspecliva S.A., 1994. 


\section{BIBLIOGRAFIA}




\section{- LITERATURA CONSULTADA EM ORDEM ALFABÉTICA -}

Abbey DE, Petersen F, Mills PK, Beeson WL. Long-term ambient concentrations of total suspended particulates, ozone, and sulfur dioxide and respiratory symptoms in a nonsmoking population. Arch Environ Health 1993; 48(1); 33-46.

Adams $F$ (ed). The extant works of Aretaeus, the Capadocian. London: Sydenhham Society, 1856.

Ahlbom A, Norell S. Introduction to modern epidemiology. Chestnut Hill,MA: Epidemiology Resources Inc, 1990.

Almeida Fo. N, Rouquayrol MZ. Introdução à epidemiologia moderna. Rio de Janeiro: COOPMED Editora, 1992.

Almeida Fo. N. A clínica e a epidemiologia. Salvador: APCE Produtos do Conhecimento, 1992.

American Thoracic Society. Definitions and classification of chronic bronchitis, asthma, and pulmonary enphysema. Am Rev Respir Dis 1962; 85: 762-8.

Anderson RH. The epidemiological and allergic features of asthma in the New Guinea Highlands. Clin Allergy 1974; 4: 171-6.

Andrae $S$, Axelson $O$, Bjorkstén B, Fredriksson $M$, Kjellman $N-I M$. Symptons of bronchial hyperreactivity and asthma in relation to environmental factors. Arch. Dis Child 1988, 63: 473-8.

Annesi I, Oryszczyn MP, Neukirch F et al.. Relationship of upper airways disorders to FEV1 and bronchial hyperresponsiveness in an epidemiological study. Eur Respir J 1992, 5: 1104-10.

Anonimous. Childhood pneumonia: strategies to meet the challenge. London: AHRTAG, 1992.

Anonimous. Increasing deaths from asthma [Editorial]. Br Med J 1968; 1: 329-30. 
Anonimous. Recommendations of the asthma mortality task force. J Allergy Clin Immunol 1987; 80(3Pt2): 364-6.

Arias SJ, Benguigui $Y$, Bossio JC. Infecciones respiratorias agudas en las Américas: magnitud, tendencia y avances en el control. Washington: OPS, Série PALTEX, 1992.

Armitage P, Berry G. Statistical methods in medical research. London: Blackwell Scientific Publications; 1987.

Ayres J, Tunnicliffe W, Miles J. Rate of asthmatic attacks [Letter]. Br Med J 1993; 306: 1069.

Baltazar JC. El potencial del método de casos y controles para las evaluaciones epidemiológicas rápidas. Boletín de la Oficina Sanitaria Panamericana 1994; 117(1): 44-52.

Bar-Or O, Inbar O. Swimming and asthma: benefits and deleterious effects. Sports Med 1992; 14(6): 397-405.

Barker DJP, Rose G. Epidemiology in medical practice. London: Churchill Livingstone, 1976.

Barnes PJ. New drugs for asthma. Eur Respir J 1992; 5: 1126-36.

Barney P. Why study epidemiology of asthma? [Editorial]. Thorax 1988; 43: 425-8.

Beard CM, Yunginger JW, Reed CE, O'Connell EJ, Silverstein MD. Interobserver variability in medical record review: an epidemiological study of asthma. J Clin Epidemiol 1992; 45(9):1013-20.

Beasley R, Burgess C, Crane J, Pearce N, Roche W. Pathology of asthma and its clinical implications. J Allergy Clin Immunol 1993; 92: 148-54.

Behrhorst C. El proyecto de desarrollo de Chimaltenango (Guatemala). In: Newell KW. Op. cit.: 33-57. 
Berend N, Peters MJ, Armour CL. Effect of inhaled formyl-methionyl-leucylphenyllalanine on airway function. Thorax 1987; 42:36-40.

Boltanski L. Prime education et morale de classe. Paris: CSE Mouton, 1969.

Boulet LP, Turcotte $H$, Boulet $M$, Montminy $L$, Laviolette $M$. Influence of natural antigenic exposure on expiratory flow, methacholine responsiveness, and airway inflammation in mild allergic asthma. J Allergy Clin Immunol 1993; 91(4): 883-93.

Bousquet T, Hatton F, Godard P, Michel FB. Asthma mortality in France. J Allergy Clin Immunol 1987; 80(3Pt2): 389-94.

Breilh J. Reprodução social e investigação em saúde coletiva. In: Costa DC (org.). Epidemiologia: teoria e objeto. Sã Paulo: Hucitec-ABRASCO, 1990.

British Thoracic Society. Guidelines for the management of asthma. Thorax 1993; 48(Suppl): S1-S24.

Britton J, Tattersfield A. Does measurement of bronchial hyperresponsiveness help in clinical diagnosis of asthma? Eur J Respir Dis 1986; 68:233-8.

Brunekreef B. Associations between questionnaire reports of home dampness and childhood respiratory symptoms. Science Total Environ 1992; 127: 79-89.

Bucknall CE. Assessment of an asthma management programme for general practitioners (abstract). Thorax 1988; 43: 253P.

Bulla A, Hitze KL. Acute respiratory infections: a review. Bull World Health Org 1978; 56(3): 481-98.

Burchfiel CM, Higgins MW, Keller JB et al..Passive smoking in childhood: respiratatory conditions and pulmonary function in Tecunseh, Michigan. Am Rev Respir Dis 1986; 133: 966-73.

Burney $P$, Detels $R$, Higgins $M$, Peckham $C$, Samet JM, Tager IB. Recommendations for research in the epidemiology of asthma. Chest 1987; 91(6 - Suppl):194S-195S. 
Burney PGJ. Asthma mortality in England and Wales - evidence for a further increase. Lancet 1986; II: 323-6.

Busse WW, Calhoun WF, Sedgwick JD. Mechanism of airway inflammation in asthma. Am Rev Respir Dis 1993; 147: 520-4.

Canguilhem G. O normal e o patológico. Rio de Janeiro: Forense-Universitária, 1982.

Carneiro-Sampaio MMS. Asma brônquica. In: Rozov T, Ribeiro de Carvalho CR. Doenças pulmonares em pediatria. São Paulo: Harper \& Row do Brasil Ltda, 1987.

Chadwick J, Mann WN. The medical works of Hippocrates. Aphorisms. Oxford: Blackwell Scientific Publications, 1950.

Chapman ID, Foster A, Morley J. The relationship between inflammation and hyperreactivity of the airways in asthma. Clin Exp Allergy 1993; 23: 168-71.

Charpin D, Vervloet D. 2000 morts par asthme en France chaque année: qui sont-ils? Rev Mal Resp 1993; 10: 277-8.

Chilmonczyk BA, Salmun LM, Megathlin $\mathrm{KN}$ et al.. Association between exposure to environmental tobbaco smoke and exacerbations of asthma in children. $\mathrm{N}$ Engl $\mathrm{J}$ Med 1993; 328: 1665-9.

Cicchetti DV, Feinstein AR. High agreement but low kappa: II. Resolving the paradoxes. J Clin Epidemiol 1990; 43(6):551-58.

Clifford RD, Howell JB, Radford M, Holgate ST. Associations between respiratory symptoms, bronchial rsponse to methacholine, and atopy in two age groups of schoolchildren. Arch Dis Child 1989; 64(8): 1133-9.

Clough JB, Dow L. Epidemiological approach to bronchial responsiveness. [Editorial]. Clin Allergy 1987; 17: 265-9.

Cochrane AL, Chapman PJ, Oldham PD. Observer's errors in taking medical histories. Lancet 1951 ; i:1007-9.

Cochrane AL. The history of the measurement of ill-health. Int J Epid 1972; 1:89-92. 
Cockcroft DW, Murdock KY, Berscheid BA. Relationship between atopy and bronchial responsiveness to histamine in a random population. An Allergy 1985; 53:26-9.

Cohen $B$, Dunt $D$. Recurrent and non-recurrent croup: an epidemiological study. Aust Paediatr J 1988; 24(6): 339-42.

Cohen J. A coefficient of agreement for nominal scales. Educ Psychol Meas 1960; 20:37-46.

Coka AF, Cooke RA. On the classification of the phenomena of hypersensitiveness. J Immunol 1922; 8(3): 163-82.

Cole P. Introduction. In: Breslow NE \& Day NE. Statistical methods in cancer research. Volume 1 - The analysis of case-control studies. Lyon: International Agency for Research on Cancer. IARC Scientific Publications $n^{\circ} 32,1980$.

Connett GJ, Lenney W. Use of pulse oximetry in the hospital management of acute asthma in childhood. Pediatr Pulmonol 1993; 15: 345-9.

Cooreman J, Segala C, Henry C, Neukirch F. Mortalité rapportée à l'asthme: tendances pour la France de 1970 à 1987. Rev Mal Resp 1992; 9:495-501.

Corhay JL, Bury Th. Cabut C, Rademecker MF. Les pseudo-asthmes: tout ce qui siffle n'est pas asthme. Revue Medicale de Liege 1993; XLVIII: 137-42.

Cox DR. The analysis of binary data. London: Melthuen \& Co., 1970.

Creer TL. Self-management in the treatment of childhood asthma. J Allergy Clin Immunol 1987; 80(3Pt2): 500-5..

Crompton GK, Grant IWB, Bloomfield P. Edinburgh emergency asthma admissions services: report on 10 years' experience. Br Med J 1979; 2: 1199-201.

Curry JJ. Comparative action of acetyl-beta-methyl-choline and histamine on the respiratory tract in normal, patients with hay fever, and subjects with bronchial asthma. J Clin Invest 1947; 26:43-8. 
Curwitz $D$, Mindorff $C$. Levison $\mathrm{H}$. Increased incidence of bronchial reactivity in children with a history of bronchitis. J Paediatr 1981; 98: 551-5.

De Montis G, Berman D. Doit-on abandoner le diagnostic de bronchite asthmatiforme? Ann Pediatr (Paris) 1989; 36(9): 603-6.

De Vries $K$. Clinical significance of bronchial hyperresponsiveness. In: Nadel JA, Pauwels R, Snashall PD (ed.). Bronchial hyperresponsiveness. London: Blackwell Scientific Publications, 1987.

Denson-Lino JM, Willies-Jacobo JW, Rosas A, O'Connor RD, Wilson NW. Effect of economic status on the use of house dust mite avoidance measures in asthmatic children. Ann Allergy 1993; 71(2): 130-2.

Dever GEA. A epidemiologia na administração dos serviços de saúde. São Paulo: Pioneira, 1988.

Dodge RR, Burrows $B$. The prevalence and incidence of asthma and asthma-like symptoms in a general population sample. Am Rev. Respir Dis 1980; 122:567-75.

Doll $R$, Hill AB. A study of the aetiology of carcinoma of the lung. Br Med J 1952; 127186.

Douglas RM, Kumar V, Miller DL et al.. A programme for controlling acute respiratory infections in children: Memorandum from a WHO Meeting. Bull World Health Org 1984; 62(1): 47-58.

Duddridge $\mathrm{M}$, Ward $\mathrm{C}$, Hendrick DJ, Walter $\mathrm{EH}$. Changes in bronchoalveolar lavage inflammatory cells in asthmatic patients treated with high dose inhaled beclomethasone dipropionate. Eur Respir J 1993; 489-97.

Duffy DL, Martin NG, Battistutta D, Hopper JL, Mathews JD. Genetics of asthma and hay fever in Australian twins. Am Rev Respir Dis 1990; 142: 1351-8.

Editorial. Asthma deaths: a social or medical problem? JAMA 1993: 269(15); 1994-5.

Eiser NM. Bronchial provocation tests. In: Nadel JA, Pauwels $R$, Snashall PD (ed.). Bronchial hyperresponsiveness. London: Blackwell Scientific Publications, 1987. 
Empey DW, Laitinen LA, Jacobs L, Gold WM, Nadel JA. Mechanisms of bronchial hyperreactivity in normal subjects after upper respiratory tract infection. Am Rev Respir Dis 1976; 113: 131-9.

Fahy JV, Steiger DJ, Liu J, Basbaum CB, Finkbeiner WE, Boushey HA. Markers of mucus secretion and DNA level in induced sputum from asthmatic and from health subjects. Am Rev Respir Dis 1993, 147: 1132-7.

Feinstein AR, Cicchetti DV. High agreement but low kappa: I. The problems of two paradoxes. J Clin Epidemiol 1990; 43(6):543-49.

Feinstein AR. Scientific standards in epidemiologic studies of the menace of daily life. Science $1988 ; 242$ : 1257-63.

Feinstein AR. Stochastic significance, consistency, apposite data, and some other remedies for the intellectual pollutants of statistical vocabulary. Clin Pharmacol Ther 1977; 22(1):113-23.

Feinstein AR. Why clinical epidemiology. Clin Research 1973; XX(5): 821-5.

Feldman $\mathrm{CH}$. Asthma education: general aspects of childhood programs. J Allergy Clin Immunol 1987; 80(3Pt2): 494-7.

Ferris BG. Epidemiology standardization project. Am Rev Respir Dis 1978; 118(6-Part 2): $1-120$.

Fink $G$, Kaye $C$, Blau $H$, Spitzer SA. Assessment of exercise capacity in asthmatic children with various degrees of activity. Pediatr Pulmonol 1993; 15:41-3.

Finney DJ. Probit analysis. Cambridge: University Press, 1971.

Fleiss JL. Statistical methods for rates and proportions. New York: John Wiley \& Sons; 1981.

Fletcher CM, Elmes PC, Fairbairn AS. Wood CH. The significance of respiratory symptoms and the diagnosis of chronic bronchitis in a working population. $\mathrm{Br}$ Med J 1959; ii: 257-66. 
Floyer J. A treatise of asthma. 3rd edition. London: W Innys and W Parker, 1745.

Foncard T, Sjoberg O. A prospective 12-year follow-up study of children with wheezy bronchitis. Acta Paediatr Scand 1984; 73(5): 577-83.

Freidhoff LR, Marsh DG. Relationship among asthma, serum IgE levels and skin test sensitivity to inhaled allergens. Int Arch Allergy Immunol 1993; 100:355-61.

Gerrad JW, Vickers P, Gerrard CD. The familial incidence of allergic disease. Clin Allergy $1976 ; 36: 10-5$.

Gerstman BB, Bosco LA, Tomita DK. Trends in the prevalence of asthma hospitalization in the 5 to 14-year-old Michigan Medicaid population, 1980 to 1986 . J Allergy Clin Immunol 1993; 91: 838-43.

Graham S. Enhancing creativity in epidemiology. J Epidemiol 1988; 128(2): 249-53.

Graham VAL, Knowles GK, Milton AF, Davies RJ. Routine antibiotics in hospital management of acute asthma. Lancet 1982; i: 418-20.

Graunt J. Natural and political observations mentioned in a following index, and made upon bills of mortality. In: Wilcox WF (ed.). Natural and political observations made upon bills of mortality by John Graunt. Baltimore: Johns Hopkins Press, 1937.

Gregg I. Epidemiology. In: Clarck TJH \& Godfrey S [Editors]. Asthma. London: Chapman and Hall, 1977.

Hair JF Jr, Anderson RE, Tatham RL. Multivariate data analysis. New York: Macmillan Publishing Co., 1987.

Halfon N, Newacheck PW. Childhood asthma and poverty: differential impacts an utilization of health services. Pediatrics 1993; 91(1): 56-61.

Harving $H$, Korsgaard J, Dahl R. House-dust mites and associated environmental conditions in Danish homes. Allergy 1993; 48: 106-109.

Hasse M, Berdal BP, Straume B et al.. Pneumonia - a clinical or radiographic diagnosis? Scand J Infect Dis 1992; 647-55. 
Hauck WW, Donner A. Wald's test as applied to hypothesis in logit analysis. J Am Stat Assoc 1977; 72: 851-3.

Hawking SW. A brief history of time. New York: Bantam Books, 1988.

Haynes RB, Ramsden M, McKibbon KA, Walker CJ, Ryan NC. A review of medical education and medical informatics. Acad Med 1989; 64:207-12.

Herxheimer $H_{1}$ Schaefer O. Asthma in Canadian eskimos. New Engl J Med 1974; 291: 1419-24.

Hill $R$, Tattersfield AE. Asthma in children: comparison of community surveys in the UK. (Abstract). Thorax 1988; 43:258P.

Hills M. Allocation rules and their error rates. J R Stat Soc 1966; B28: 1-20.

Holgate ST, Kay AB. Mast cells, mediators and asthma. Clin Allergy 1985; 15:221-34.

Holmgren D, Engstrom I, Bjure J, Sixt R, Aberg N. Respiratory resistance and transcutaneous PO2 during histamine provocation in children with bronchial asthma. Pediatr Pulmonol 1993; 15: 168-74.

Holmgren D, Sixt R. Transcutaneous and arterial blood gas monitoring during acute asthmatic symptoms in older children. Pediatr Puimonol 1992; 14: 80-4.

Hopper JL, Hannah MC, Macaskill GT et I.. Twin concordance for a binary trait: III. A bivariate analysis of hay fever and asthma. Genetic Epidemiol 1990; 7:277-89.

Horowitz RI, Yu EC. Assessing the reliability of epidemiologic data obtained from medical records. J Chron Dis 1984; 37: 825-31.

Horowitz RI. The experimental paradigm and observational studies of cause-effect relationships in clinical medicine. J Chron Dis 1987; 40(1): 91-9.

Huber HL, Koessler KK. Pathology of asthma. Arch Intern Med 1922; 30: 689-760.

Hudgel DW, Langston L, Selner JC, McIntosh K. Viral and bacterial infections in adults with chronic asthma. Am Rev Respir Dis 1979; 120: 393-7. 
Hutchinson AA, Hinson JM, Brigham KL, Snapper JR. Effect of endotoxin on airway responsiveness to aerosol histamine in sheep. J Appl Physiol: Respirat Environ Exercise Physiol 1983; 54: 1463-8.

Infante-Rivard C. Childhood asthma and indoor environmental risk factors. Am J Epidemiol 1993; 137: 834-44.

Jackson RT, Beaglehole R, Rea HH, Sutherland DC. Mortality from asthma: a new epidemic in New Zealand. Br Med J 1982; 285: 771-4.

Jakab GJ. Mechanisms of virus-induced bacterial superinfections of the lung. Clin Chest Med 1981; 2(1): 59-66.

Jenner E. Vaccination against smallpox. In: Elliot SN (ed.). Scientific papers. New York: Collier, 1910:153-231.

Johnston DA, Bland JM, Ingram D, Anderson HR, Warner JO. Effect of whooping cough in infancy, a subsequent lung function and bronchial reactivity. Am Rev Respir Dis 1986; 134: 270-5.

Kaplan KM. Epidemiology of deaths from astma in Pennsylvania, 1978-87. Public Health Reports 1993; 108(1): 66-9.

Kelsey JL, Thompson WD, Evans AS. Methods in observational epidemiology. New York: Oxford University Press, 1986.

Kendrick AH, Higgs CMB, Whitfield MJ, Laszlo G. Accuracy of perception of severity of asthma: patients treated in general practice. Br Med J 1993; 307: 422-4

Kramer MS, Feinstein AR. Clinical biostatistics: LIV. The biostatistics of concordance. Clin Pharmacol Ther 1981; 29(1):111-23

Krasnowska M, Malolepszy J, Liebhart $E$, Inglot AD. Inhaled natural human interferon alpha induces bronchoespastic reactions in asthmatics. Archivum Immunologiae Therapiae Experimentalis 1992; 40:75-78.

Kuhn TS. A estrutura das revoluções científicas. São Paulo: Editora Perspectiva S.A., 1994. 
Kun HY, Oates RK, Mellis CM. Hospital admissions and attendances for asthma - a true increase? Med J Aust 1993; 159: 312-3.

Laitinen LA, Laitinen A, Haahtela T. Airway mucosal inflammation even in patients with newly diagnosed asthma. Am Rev Respir Dis 1993; 147: 697-704.

Landis RJ, Koch GG. The measurement of observer agreement for categorical data. Biometrics 1977; 33:159-74.

Lee AW, McNaught W. Bacteriology of lower respiratory tract secretions, sputum, and upper respiratory tract secretions in normals and chronic bronchitis. Lancet 1959; ii: 1112-5.

Lee DA, Winslow NR, Speight ANP, Hey EN. Prevalence and spectrum of asthma in childhood. Br Med J 1983; 286: 1256-8.

Lee TH, Kay AB. Respiratory allergy. In: Lessof MH, Lee TH, Kemeny DM (ed.). Allergy: an international textbook. New York: John Wiley \& Sons, 1989: 499-511

Leowski J. Mortality from ARI in children under 5 years of age: global estimates. Rapp Trimest Statist Sanit Mon 1986; 39: 138-44.

Levitt RC. Understanding biological variability in susceptibility to respiratory disease. Pharmacogenetics 1991; 1: 94-7.

Lind J. A treatise of the scurvy. Edinburgh: Sands, Murray, and Cochran, 1793.

Littlejohns P, MacDonald LD. The relationship between severe asthma and social class. Respir Med 1993; 87: 139-43.

Loose J. Introdución histórica a la filosofia de la ciencia. Madrid: Alianza Editorial, 1981.

Lundgren JD. Pathogenesis of ainway mucus hypersecretion. J Allergy Clin Immunol 1990; 85: 399-416.

Luz MT. As instituições médicas no Brasil: instituição e estratégia de poder. Rio de Janeiro: Edições Graal, 1979. 
MacMahon B, Pugh TF. Principios y métodos de epidemiologia. Mexico: La Prensa Médica Mexicana, 1975.

Manfreda J, Becker AB, Wang P-Z, Roos LL, Anthonisen NR. Trends in physiciandiagnosed asthma prevalence in Manitoba between 1980 and 1990. Chest 1993; 103(1): $151-57$.

Mantel N, Haenszel W. Statistical aspects of the analysis of data from retrospective studies of disease. J Nat Cancer Inst 1959; 22: 719-48.

Mantle J, Pepys J. Asthma among Tristan da Cunha islanders. Clin Allergy 1974; 4: 161-5.

Mao Y, Semenciw R, Morrison H, MacWilliam L, Davies J, Wigle D. increased rates of illness and deaths from asthma in Canada. Can Med Assoc J 1987; 137(7): 620-4.

Mao $\mathrm{Y}$, Wilkins $\mathrm{K}$. Trends in rates of admission to hospital an death from asthma among children and young adults in Canada during the 1980s. Can Med Assoc J 1993; 148(2): 185-90.

Martin AJ, Landau LI, Phelan PD. Natural history of allergy in asthmatic children followed to adult life. Med J Aust 1981; 2:470-4.

McFadden ER, Kiser R, Degroot WJ. Acute bronchial asthma. N Engl J Med 1973; 288 : 221-5.

McNichol KN, Williams HE, Allan J, McAndrew I. Spectrum of asthma in children. III, psychological and social components. Br Med J 1973; 4: 16-20.

Millar J. Observations on the asthma, and on the hooping cough. London: T. Cadel, T. Noteman, Johnston \& Payne, 1769.

Minor TE, Baker JW, Dick EC, et al. Greater frequency of viral respiratory infections in asthmatics children as compared with their non-asthmatic siblings. J Pediatr 1974; 85: 472-77. 
Minor TE, Dick EC, Baker JW, Oullette JJ, Cohen M, Reed CE. Rhinovirus and influenza type A infections as preciptants of asthma. Am Rev Respir Dis 1976; 113: 149-53.

Mok JYQ, Simpson $H$. Outcome for acute bronchitis, bronchiolitis and pneumonia in infancy. Arch Dis Child 1984; 59:306-9.

Mortagy AK, Howell JBL, Waters WE. Respiratory symptoms and bronchial reactivity: identification of a syndrome and its relation to asthma. B Med J 1986; 293: 525-9.

Murray JF. Prevencion de las infecciones respiratorias. Bol Union Inter Tuberculosis 1983; 58(1): 56-9.

Murray M, Webb MSC, O'Callaghan C, Swarbrick AS, Milner AD. Respiratory status and allergy after bronchiolitis. Arch Dis Child 1992; 67: 482-7.

Nadel JA. Inflammation and asthma. J Allergy Clin Immunol 1984; 73: 651-3.

Nakadate T, Kagawa J. Pulmonary function development in children with past history of asthma. J Epidemiol Community Health 1992; 46: 437-42.

Nayyar V, Antonisamy B, John G. Factors associated with isolation of pathogenic bacteria from sputum of patients with acute bronchospasm. Indian J Chest Dis Allied Sci 1992; 34(4): 197-204.

Neville RG, Clark RC, Hoskins G, Smith B. National asthma attack audit 1991-2. Br Med J 1993; 306: 559-62.

Newell KW. La salud por el pueblo. Ginebra: Organizacion Mundial de la Salud, 1975.

Norn $S$, Stahl Skov $P$, Jensen $C$, Jarlov JO, Espersen F. Histamine release induced by bacteria. A new mechanism in asthma? Agents Actions 1987; 20(1/2):29-34.

Organización Mundial de la Salud. Medición del cambio del estado nutricional. Ginebra: OMS, 1983.

Page $C$, Cstello J. (2) Why beta-agonists should not be used regularly. Resp Med 1992; 86: 477-79. 
Park ES, Golding J, Carswell F, Stewart-Brown S. Preschool wheezing and prognosis at 10. Arch Dis Child 1986; 61:642-6.

Pattemore PK, Johnston SL, Bardin PG. Viruses as precipitants of asthma symptoms. I. Epidemiology. Clin Exp Allergy 1992; 22: 325-36.

Peat JK, Britton WJ, Salome CM, Woolcock AJ. Bronchial hyperresponsiviness in two populations of Australian schoolchildren. II. Relative importance of associated factors. Clin Allergy 1987; 17:283-90.

Pereira JCR, Carswell F, Hughes AO. Assessment and prediction of asthma and its severity in the pediatric community. Rev Saúde públ, S. Paulo, 1990; 24(6): 437-44.

Pereira JCR, Miranda Ribeiro TV, Pripas S. Newsletter from Brazil. J Trop Ped 1988; 34: $199-200$.

Pereira JCR, Stuginski LA, Miranda Ribeiro TV. Assessment of a strategy for the control of respiratory diseases in children. Rev Saúde públ, S.Paulo, 1992; 26(6): 414-23.

Phelan PD, Landau LI, Olinsky A. Respiratory illness in children. Oxford: Balckwell Scientific Publications, 1990.

Pilling D. The child with asthma: social, emotional, educational adjustment. An annoted bibliography. Slough: NFER Publishing Company Ltd, 1975.

Pio A. Acute respiratory infections in children in developing countries: an international point of view. Ped Infec Dis 1986, 5(2): 179-83.

Pio AJ, Leowski J, Ten Dam HG. The magnitude of the problem of acute respiratory infections. Proceedings of an International Workshop on Acute Respiratory Infections in Children. Sydney: University of Adelaide, 1985.

Porro E, Calamita P, Rana I, Montini L, Criscione S. Atopy and environmental factors in upper respiratory infections: an epidemiological survey on 2304 school children. Int J Ped Otorhinolryngol 1992; 24:111-20. 
Porter R, Birch J (ed.). Identification of asthma. Ciba Foundation Group No 38 . Edinburgh: Churchil Livingstone, 1971.

Pullan CR, Hey EN. Wheezing, asthma and pulmonary dysfunction 10 years after infection with respiratory syncitial virus in infancy. Br Med J 1982; 284:1665-9.

Rachelefsky GS, Warner JO. International consensus on the management of pediatric asthma: a summary statement. Pediatr Pulmonol 1993; 15:125-7.

Rebuck AS, Read J. Assessment and management of severe asthma. Am J Med 1971; 51: 788-98.

Ribeiro JD. Asma brônquica na infância: associação entre comportamento clínicolaboratorial e severidade. Departamento de Pediatria da Faculdade de Ciências Médicas da Universidade de Campinas, 1987.

Rocha EM. L'action de la réhabilitation respiratoire sur les altérations fonctionnelles ventilatoires chez l'enfant asthmatique. Allergie et Immunologie 1993; 25(1): 26-34.

Rossi OVJ, Kinnula VL, Tienari J, Huhti E. Association of severe asthma attacks with weather, pollen, and air pollutants. Thorax 1993; 48: 244-8.

Rothman KJ. Modern epidemiology. Boston: Little, Brown and Company, 1986.

Ryan M. Observations on the history and cure of asthma, in which the property of using the cold bath in that disorder is fully considered. London: C.A.J. \& J. Robinson, 1793.

Saldiva PHN, Lichtenfels AJFC, Paiva PSO et al.. Association between air pollution and mortality due to respiratory diseases in children in São Paulo, Brazil: a preliminary report. Environ Res 1994; 65: 218-25.

Salome CM, Peat JK, Britton WJ, Woolcock AJ. Bronchial hyperresponsiveness in 2 populations of australian children. I. Relation to respiratory symptoms and diagnosed asthma. Clin Allergy 1987; 17: 271-81.

Salter HH. On asthma: its pathology and treatment. London: John Churchill, 1860. 
Samet JM, Tager IB, Speizer FE. The relationship between respiratory illness in childhood and chronic air-flow obstruction in adulthood. Am Rev Respir Dis 1983; 127: $508-23$

Sanchez I, Avital A, Wong I, Tal A, Pasterkamp H. Acoustic vs. spirometric assessment of bronchial responsiveness to methacholine in children. Pediatr Pulmonol 1993; 15:28-35.

Scadding JG. Asthma and bronchial reactivity [letter]. Br Med J 1987, 294: 1115-6.

Scadding JG. Definitions and clinical categories of asthma. In: Clark TJH, Godfrey S (ed.). Asthma. London: Chapman and Hall, 1977.

Scadding JG. Principles of definition in Medicine with special reference to chronic bronchitis and enphysema. Lancet 1959; i: 323-25.

Schlesselman JJ. Case-control studies. Design, conduct, analysis. New York: Oxford University Press, 1982.

Schmitzberger $R$, Rhomberg $K$, Buchele $H$ et al. Effects of air pollution on the respiratory tract of children. Pediatr Pulmonol 1993; 15: 68-74.

Scislicki A, Rudnik J, Gawel J, Pryjma J. The risk of bronchial asthma in children with a history of obstructive bronchitis in the first two years of life. Arch Immunol Ther Exp 1978; 26:723-9.

Sears MR, Burrows B, Flannery EM et al.. Relation between airway responsiveness and serum IgE in children with asthma and in apparently normal children. $\mathrm{N}$ Engl $\mathrm{J}$ Med 1991; 325: 1067-71.

Sears MR, Jones DT, Holdaway MA et al..Prevalence of bronchial reactivity to inhaled methacholine in New Zealand children. Thorax 1986; 41: 283-9.

Sears MR, Rea HH, Fenwick $J$ et al.. 75 deaths in asthmatics prescribed home nebulizers. Br Med J 1987; 294: 477-80.

Sears MR, Rea HH. Rothwell RPG et al.. Asthma mortality: comparison between New Zealand and England. Br Med J 1986; 293: 1342-5. 
Sears MR, Taylor DR, Print CG et al.. Regular inhaled beta-agonist treatment in bronchial asthma. Lancet 1990; 336: 1391-6.

Seddon PC, Sunderland D, O'Halloran SM, Hart CA, Heaf DP. Branhamella catarrhalis colonization in preschool asthmatics. Pediatr Pulmonol 1992; 13:133-5.

Sibbald B, Hom MEC, Brain EA, Gregg I. Genetic factor in childhood asthma. Thorax 1980; 35: 671-4.

Sibbald $B$, Turner-Warwick $M$. Factors influencing the prevalence of asthma among first degree relatives of extrinsic and intrinsic asthmatics. Thorax 1979; 34: 332-7.

Siegel S, Castellan Jr NJ. Nonparametric statistics for the behavioral sciences. New York: McGraw-Hill; 1988.

Siegel SC. History of asthma deaths from antiquity. J Allergy Clin Immunol 1987; 80(3Pt2): 458-62.

Simpson $H$, Mok JYQ. Outcome of respiratory disease in childhood. In: Milner $A D$, Martin RJ [Editors]. Neonatal and Pediatric Respiratory Medicine. London: Butterworths, 1985.

Skobeloff EM, Spivey WH, St.Clair SS, Scholfstall JM. The influence of age and sex on asthma admissions. JAMA 1992; 268(24): 3437-40.

Sly PD, Hibbert ME. Childhood asthma following hospitalization with acute viral bronchiolitis in infancy. Pediatr Pulmonol 1989; 7: 153-8.

Sly RM. Increases in deaths from asthma. Am Allergy 1984; 53: 20-5.

Smith D. Patterns of ARI morbidity/mortality and health services utilization in the Azaro Valley, Papua New Guinea, 1980-81. Proc 18th Ann Symp Med Soc Papua New Guinea, Port Morsby, 1982.

Speight ANP, Lee DA, Hey EN. Underdiagnosis and undertreatment of asthma in childhood. B Med J 1983; 286:1253-6. 
Speizer FE, Doll R, Heaf $P$, Strang LB. Investigation into use of drugs preceding death from asthma. Br Med J 1968; 1:339-43.

Speizer FE, Doll R. A century of asthma deaths in young people. Br Med J 1968; 3: 245-6

Spiropoulos $K$, Stevens J, Eigen $H$, Spiropoulos A. Specificity and sensitivity of methacholine challenge test in children with normal and hyperreactive airways. Acta Paediatr Scand 1986; 75(5): 737-43.

Spitzer WO, Suissa A, Ernst $P$ et al. The use of beta-agonists and the risk of death from asthma. N Engl J Med 1992; 326: 501-6.

Stanescu DC, Frans A. Bronchial asthma without increased airway reactivity. Eur J Respir Dis 1982; 63:5-12.

Stenius-Aarniala B. The role of infection in asthma. Chest 1987; $91(6)$ : 157S-60S.

Sterk PJ. Virus-induced airway hyperresponsiveness in man. Eur Respir J 1993; 6:894902.

Strunk RC, Mrazek DA, Fuhramann GSW, LaBrecque JF. Physiologic and psychological characteristics associated with death due to asthma in childhodd. JAMA 195; 254: 1193-8.

Susser M. Casual thinking in the health sciences. New York: Oxford University Press, 1973.

Tiffeneau R. Hypersensibilité cholinergico-histaminique pulmonaire de l'asthmatique. Acta Allerg 1958; 12(Suppl 5): 187-221.

Toelle BG, Peat JK, Salome CM, Mellis CM, Bauman AE, Woolcock AJ. Evaluation of a community-based management program in a population sample of schoolchildren: Med J Aust 1993; 158: 742-6.

Toelle BG, Peat JK, Salome CM, Mellis CM, Woolcock AJ. Toward a definition of asthma for epidemiology. Am Rev Respir Dis 1992; 146: 633-7. 
Trigg CJ, Bennett JB, Tooley M, D'Souza MF, Davies RJ. Do patients with bronchial hyperreactivity attend more frequently with respiratory complaints in general practice? Proceedings of the British Thoracic Society Winter Meeting, London 89/12/87: Abstract S4, pg. 9.

Trosseau A. Lectures on clinical medicine delivered at the Hotel-Dieu, Paris. (Translated by PV Bazire). London: Sydenham Society, 1868.

Twentyman OP, HigenBottam TW. Controversies in respiratory medicine: regular inhaled beta-agonists - clear clinical benefit or a hazard to health? (1) Beta-agonists can be used safely and beneficially in asthma. Respir Med 1992; 86: 471-6.

Unit of Research Promotion and Coordination, Division of Human Resources and Research. Acute respiratory infections in children. Washington: Pan American Health Organization, 1983.

Vazquez MI, Buceta JM. Effectiveness of self-management programmes and relaxation training in the treatment of bronchial asthma: relationships with trait anxiety and emotional attack triggers. J Psychosomatic Research 1993; 37(1): 71-81.

Venables KM, Farrer N, Sharp L, Graneek BJ, Newman Taylor AJ. Respiratory symptoms questionnaire for asthma epidemiology: validity and reproducibility. Thorax 1993; 48: 214-9.

Victora CG, Fuchs SC, Flores JA, Fonseca W, Kirkwood B. Risk factors for pneumonia among children in a Brazilian metropolitan area. Pediatrics 1994; 93(6 Pt 1): 977-85

Vollmer WM, Buist AS, Osbrone ML. Twenty year trends in hospital discharges for asthma among members of a health maintenance organization. $J$ Clin Epidemiol 1992; 45(9): 999-1006.

Waite DA, Eyles EF, Tonkin SL, O'Donnell TV. Asthma prevalence in Tokelaun children in two environments. Clin Allergy 1980; 10: 71-5.

Wallace WA. Causality and scientific explanation. Volume 2: Classical and contemporary science. The University of Michigan: Ann Arbor, 1974. 
Wandalsen NF. Aspectos epidemiológicos das crises de asma brônquica na populaçăo infantil do municipio de Santo André, no periodo de 1975 a 1984. Escola Paulista de Medicina: Tese de Mestrado, 1988.

Wardlaw AJ. The role of air pollution in asthma. Clin Experim Allergy 1993; 23: 81-96.

Ware JH, Dockery DW, Spiro A et al.. Passive smoking, gas cooking and respiratory health of children living in six cities. Am Rev Respir Dis 1984; 129: 366-74.

Weiss $\mathrm{Kb}$, Wagener $\mathrm{Dk}$. Changing patterns of asthma mortality: identifying target populations at high risk. JAMA 1990; 264: 1683-1687.

Weitzman M, Gortmaker SL, Sobol AM, Perrin JM. Recent trends in the prevalence and severity of childhood asthma. JAMA 1992: 268: 2673-7.

Whallett EJ, Ayres JG. Labelling shift from acute bronchitis may be contributing to the recent rise in asthma mortality in the 5-34 age group. Respir Med 1993; 87: 183-6.

Willers S, Svenonius E, Skarping G. Passive smoking and childhood asthma: urinary cotinine levels in children with asthma and in referents. Allergy 1991; 46: 330-4.

Witt C, Stuckey MS, Woolcock AJ, Dawkins RL. Positive allergy prick tests associated with bronchial histamine responsiveness in an unselected population. $\mathrm{J}$ Allergy Clin Immunol 1986; 77(5): 698-702.

Wittig HJ, Cranford NJ, Glaser J. The relationship between bronchiolitis and childhood asthma: a follow-up study of 100 cases of broncholitis in infancy. J Allergy 1959; 30:19-23.

Wood PR, Hidalgo HA, Prihoda TJ, Kromer ME. Hispanic children with asthma: morbidity. Pediatrics 1993; 91(1): 62-9.

Woodward M, Francis LMA. Statistics for health management and research. London: Edward Arnold 1988.

World Health Organization. Programme for the control of acute respiratory infections. Programme Report WHO/ARI/90.7. Geneva: WHO, 1990. 
ANEXO I

PROTOCOLOS DE COLETA DE DADOS $E$

ROTEIROS DE PADRONIZAÇÃO DO PREENCHIMENTO 
I. CLASS
DATA

REGISTRO TIPO:

1. CASO

2. CONTROLE NÃo PNEUMONIA

3. CONTROLE SADIO

一II. IDENTIFICAÇÃO

NOME DO PACIENTE
SEXO 1. MASC I-
2. FEM I_l
DATA DO NASCIMENTO
RAÇA 1. BRANCA |
2. NEGRA |
3. AMARELA I_l
4. mulato |_l
9. NÃO IDENTIFICADA |

NOME DO ENTREVISTADO

PARENTESCO

ENDEREÇO

BAIRRO

-III. CARACTERIZAÇÃo SOCIO-ECONÔMICA DA FAMÍLIAMORADIA:

1. INDIVIDUAL (só a família)

2. COLETIVA (várias familias)

9. NS/NR

-

1. PRÓPRIA

2. ALUGADA

3. CEDIDA

9. NS/NR 
DOENÇA CHIADORA/PNEUMONIA: PROTOCOLO DE COLETA DE DADOS

* caracterização do paciente e da pResença de doença *

III. CARACTERIZAÇĀO SOCIO-ECONÔMICA DA FAMÍLIA

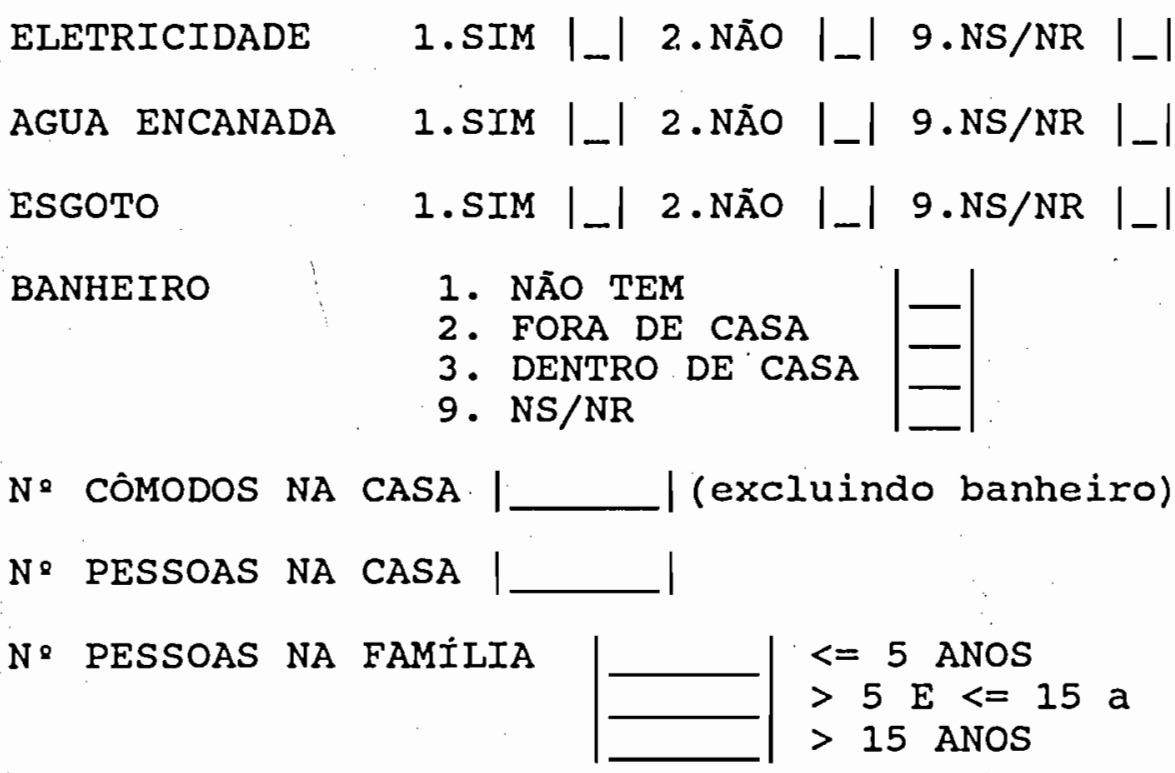

RENDA :

N 9 PESSOAS QUE TRABALHAM

SOMA DOS SALÁRIOS NO MÊS PASSADO

EDUCAÇÃO: $\quad$ PAI OU ARRIMO

1. ANALFABETO

2. 1ः GRAU INCOMPLETO

3. 1 . GRAU COMPLETO

4. 2: GRAU INCOMPLETO

5. 2. GRAU COMPLETO

6. SUPERIOR INCOMPLETO

7. SUPERIOR COMPLETO

9. NS/NR

MÃE OU TUTORA

1. ANALFABETO

2. 1 \& GRAU INCOMPLETO

3. I\& GRAU COMPLETO

4. 2 GRAU INCOMPLETO

5. $2^{\circ}$ GRAU COMPLETO

6. SUPERIOR INCOMPLETO

7. SUPERIOR COMPLETO

9. NS/NR

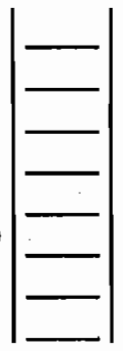

Quando a criança adoece que recursos procura?

\begin{tabular}{|c|c|c|}
\hline \multirow{2}{*}{$\begin{array}{l}\text { ACESSO A } \\
\text { SERVIÇOS }\end{array}$} & 1 A OPÇÃO & 1. SERV. MEEDICOS OSEC \\
\hline & & 2. REDE PÚBLICA / CONVENIADA \\
\hline DE SAÚDE: & 2 ^ OPÇÃO & $\begin{array}{l}\text { 3. CONVĖNIOS PRÓPRIOS/EMPRESA } \\
\text { 4. SERVICOS PRIVADOS }\end{array}$ \\
\hline & 3: OPÇÃO & 5. OUTROS: \\
\hline
\end{tabular}

ACESSO A

SERVIÇOS

OPÇÃO

5. OUTROS: 
CIV - CONTROLE dE VARIÁVEIS DE CONFUSĀO

ANTECEDENTES PESSOAIS - Assinale se a criança tem história das seguintes doenças e em caso posi tivo, assinale o número de episódios nos liltimos 12 meses, quando aplicável:

DOENÇA HISTÓRIA POSITIVA?

$\mathrm{N}$ - DE EPISÓDIOS ÚLTIMOS 12 MESES

LARINGOTRAQUEOBRONQUITE

$$
\text { 1.SIM|_| 2.NÃO|_| 9. NS/NR }\left.\right|_{-} \mid
$$

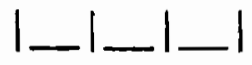

LARINGITE

ESTRIDULOSA

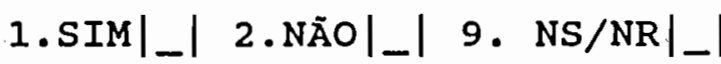

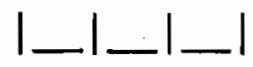

ECZEMA /DERMATITE ATÓPICA

RINITE ALÉRGICA

1.SIM|_| 2.NÃO|_!

9. NS/NR

SINUSITE

1.SIM $\left.\right|_{-} \mid$2.NÃO|_| 9. NS/NR $\left.\right|_{-} \mid$

OTITE

1.SIM $\left.\right|_{-} \mid$2.NÃO _ $\mid$9. NS/NR $\left.\right|_{-} \mid$

SARAMPO 1.SIM|_l, há|_|_l_ |meses

2. NÃO|_I

9.NS/NRI_1

COQUELUCHE 1.SIM|_|, há|_l_l_|meses

2.NÃO|_I

9.NS/NR $\left.\right|_{-} \mid$

TUBERCULOSE 1.SIM __l, há|_l_l_|meses

2. NÃO|_l

$9 . \mathrm{NS} /\left.\mathrm{NR}\right|_{-} \mid$

BRONQUIOLITE 1.SIM|_|, há|_l_l_|meses

2. NÃOl_l $9 . \mathrm{NS} /\left.\mathrm{NR}\right|_{-} \mid$

PNEUMONIA

1.SIM|_l

2. NĂO|_|

9. NS/NR $\left.\right|_{-} \mid$

Quantas vezes? |_l_l das quais

|_ _ l tratadas em casa nas idades de

|_ _ | tratadas em hospital nas idades

Anote se a criança é portadora de alguma doença crônica e se está recebendo alguma medicação regularmente:

DOENÇA :

TRATAMENTO: 
-IV - CONTROLE DE VARIÁVEIS DE CONFUSÃO

ANTECEDENTES FAMILIARES - Assinale se há história das seguintes doenças:

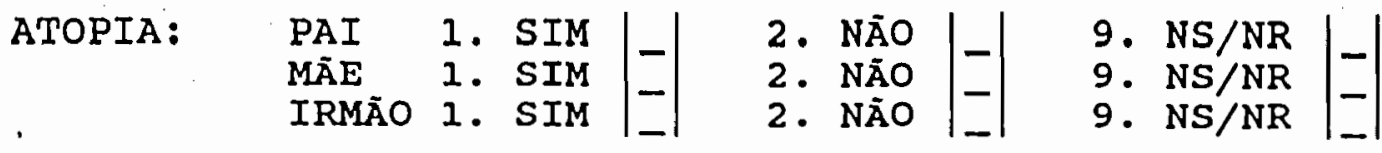

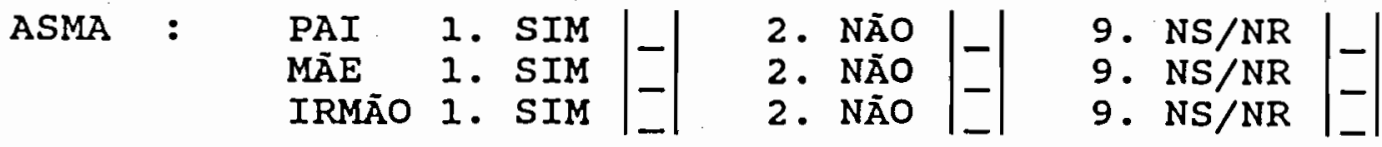

FATORES AMBIENTAIS - Assinale se a criança está exposta aos seguintes fatores ambientais:

$\mathrm{N}^{\circ}$ PESSOAS DORMINDO NO MESMO QUARTO QUE O PACIENTE I_l_l

TABAGISMO: $\mathrm{N}^{\circ}$ FUMANTES NA CASA __ _

FOGÃO A LENHA/CARVÃO/QUEROSENE 1.SIM|_| 2.NÃO|_| 9.NS/NR |_l DENTRO DE CASA

FALTA DE INSOLAÇÃO NO QUARTO DA 1.SIM|_| 2.NÃO|_| 9.NS/NR |_l CRIANÇA (FACE SUL?)

UMIDADE DENTRO DE CASA (MOFO)

1.SIM $\left.\right|_{-} \mid$2.NÃO $\mid$| $9 . \mathrm{NS} /\left.\mathrm{NR}\right|_{-} \mid$

RESIDÊNCIA JUNTO A FÁBRICA QUE EXPELE GASES, ODORES, FUMAÇA

1.SIM $\left.\right|_{-}|2 . \mathrm{NÃO}|_{-}|9 \cdot \mathrm{NS} / \mathrm{NR}|_{-} \mid$

V - CARACTERIZAÇÃO DO DIAGNÓSTICO DE PNEUMONIA-

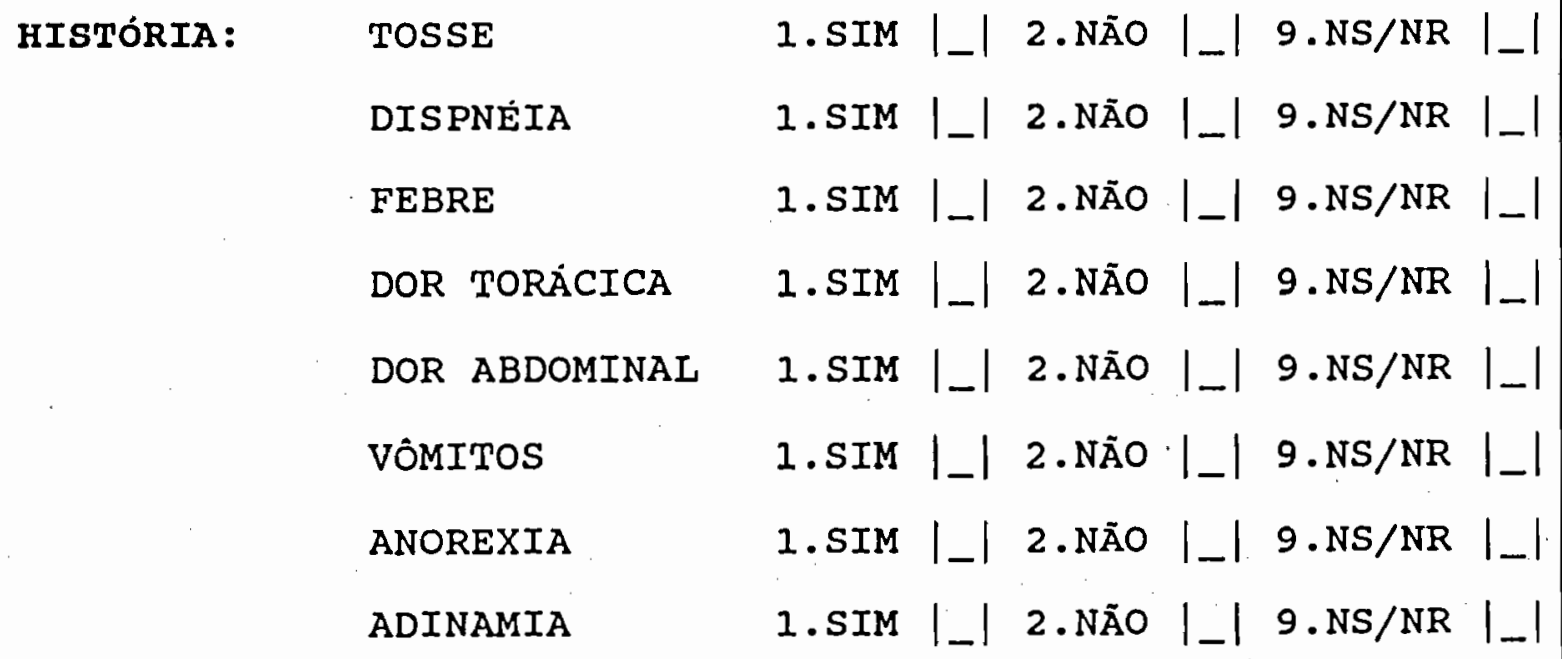




\section{[ V - CARACTERIZAÇÃO DO DIAGNÓSTICO DE PNEUMONIA- EXAME FÍSICO: TEMPERATURA ESTATURA \\ FC | \\ FR I PESO}

Anote a avaliação do estado nutricional da criança:

1. EUTRÓFICA I_l 2. DESNUTRIDA I_I DO I__ GRAU

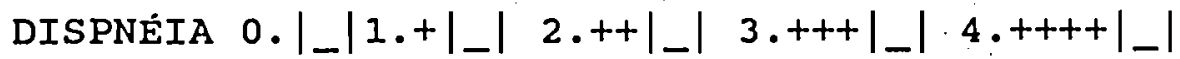

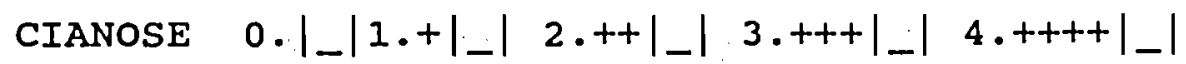

$$
\begin{aligned}
& \text { TOXEMIA } 0 .\left.\right|_{-}|1 .+|_{-}|2 .++|_{-}|3 .+++|{ }_{-}\left|4_{.+++}+\right|_{-} \mid
\end{aligned}
$$

ESTERTORES

$$
\text { SUBCREPITANTES SIM I_l 2. NÃO I_L }
$$

ES̀TERTORES

$\begin{array}{lll}\text { CREPITANTES } & \text { 1. SIM I_l NÃO I_l } \\ \text { SOPRO BRONQ. } & \text { 1. SIM I_ NÃO I_L }\end{array}$

EXAME RADIOLÓGICO:
CONDENSAÇÃo 1. SIM LOBAR/SEGMENTAR

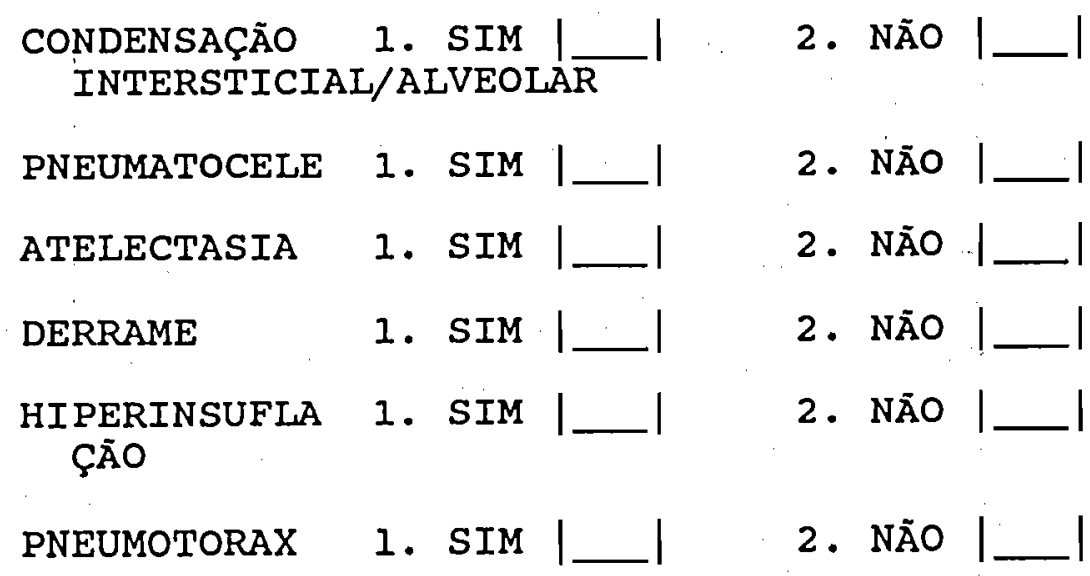

2. NÃO |

. NÃO 
V - CARACTERIZAÇÃO DO DIAGNÓSTICO DE PNEUMONIA

\section{EXAMES}

LABORATORIAIS

CONCLUSÃO

DIAGNÓSTICA:

ETIOLOGIA

SUPOSTA
1. SIM

2. NÃO |

1. BACTERIANA |

2. VIRAL | $\mid$

3. SEM HIPÓTESE ETIOLÓGICA

OUTROS DIAGNÓSTICOS

CONDUTA :
1. TRATAMENTO AMBULATORIAL
2. TRATAMENTO HOSPITALAR
3. ALTA

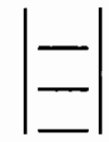




\section{CAMPO I - CLASSIFICAÇÃO}

Anotar a data do exame com algarismos e com um " $x$ " a classificação do paciente entrevistado, lembrando:

1. Caso $=$ paciente com diagnóstico de pneumonia de qualquer natureza etiológica e qualquer gravidade, desde que a infecção tenha sido adquirida na comunidade. Qualquer história de tratamento anterior dos sintomas, com ou sem hospitalização, pode dar margem a dúvida quanto a natureza da infecção e o caso deve ser desprezado.

2. Controle não pneumonia: paciente atendido no PS sem queixa respiratória e com diagnóstico que exclua doença respiratoria. Deve ser examinado para o estabelecimento do diagnóstico de ausência de pneumonia.

3. Controle sadio: acompanhante de paciente ou cliente de puericultura do centro de saúde.

OS CONTROLES SÃO ESCOLHIDOS AO ACASO, COM PAREAMENTO DE SEXO E IDADE. EM RELAÇÃO Ȧ ÚLTIMA A DIFERENÇA DE IDADE NÃO DEVE SER MAIOR DO QUE 6 MESES PARA MAIORES DE 2 . ANOS NEM MAIOR DO QUE 3 MESES PARA CASOS DE 2 ANOS OU MENOS.

\section{CAMPO II - IDENTIFICAÇÃO}

1. Nome: anotar por extenso, sem abreviação

2. Sexo: Um ' $\mathrm{X}$ ' na alternativa correspondente.

3. Data do nascimento: anotar com algarismos. Quando o informante nāo souber, levantar no prontuário: nunca deixar a informação ausente.

4. Raça: Um ' $x$ ' na alternativa correspondente. Inclua na alternativa 'não identificada' qualquer eventual alternativa diferente das previstas, eg. indio.

5. Nome do entrevistado: anote por extenso.

6. Parentesco: anote por extenso.

7. Endereço: anote por extenso, registrando pontos de referência.

8. Bairro: anote por extenso, registrando referência de identificação da área onde se situe o bairro, eg. Jardim das Imbuias, na Capela do Socorro. 


\section{CAMPO III - CARACTERIZAÇÃO SOCIO-ECONOMICA DA FAMILIA}

1. Tipo de ocupação da moradia: Um ' $x$ ' na alternativa correspondente.

2. Tipo de propriedade da moradia: Um ' $x$ ' na alternativa correspondente.

3. Presença de eletricidade na moradia: Um ' $x$ ' na alternativa correspondente.

4. Presença de rede de esgoto na moradia: Um ' $x$ ' na alternativa correspondente.

5. Presença de banheiro na moradia: Um ' $x$ ' na alternativa correspondente.

6. Situação do banheiro na moradia: Um ' $x$ ' na alternativa correspondente.

7. $\mathrm{N}^{2}$ de cômodos na casa: anote com algarismos. Na ausência de informação, registre o código '99'. Em caso de habitações coletivas, lembrar que a informação se refere a planta fisica toda e não apenas a área ocupada pela familia.

8. $\mathrm{N}^{\circ}$ de pessoas na casa: anote com algarismos. $\mathrm{Na}$ ausência de informação, registre o código '99': Nas habitações coletivas, lembrar que a informaçăo se refere a todos que moram no endereço do paciente.

9. $\mathrm{N}^{2}$ de pessoas na familia: anote com algarismos, segundo a faixa etária. Na ausência de informação, registre o código '99'. O conceito de familia é de familia estendida, não nuclear, ou seja, todos que por laço de consangüinidade ou afinidade vivam juntos numa unidade social e econômica, incluindo-se parentes de qualquer grau e agregados.

10. $\mathrm{N}^{2}$ de pessoas que trabalham: anotar $\circ \mathrm{n}^{\circ}$ de pessoas que contribuem para renda; trabalho doméstico ou diletante deve ser desconsiderado.

11. Soma dos salários do mês passado: anotar em cruzeiros reais a soma dos salários nominais das pessoas que trabalham. Conte apenas salário em dinheiro e despreze qualquer remuneração em espécie (moradia, vale refeição, etc), aceite aproximaçōes ("deve ganhar mais ou menos 'x' ") desde que sejam arbitradas autonomamente pelo entrevistado.

12. Educação do pai ou do arrimo da familia: Um ' $x$ ' na alternativa correspondente. 
13. Educação da mãe ou tutora: Um ' $x$ ' na alternativa correspondente. Só considere como tutora uma pessoa que substitua integralmente a mãe, como nos casos de madrasta ou parente que seja responsável pela criação da criança na ausência permanente da mãe. Quando houver mãe que conviva com a criança, anote sua educação, mesmo que haja uma outra pessoa que se encarregue da criança na maior parte do tempo por ausểncia eventual da mãe, ainda que esta ausência seja sistemática.

14, 15, 16. 14, 24 e 34 opções de acesso a serviços de saúde: Usando os códigos indicados, anote as 3 primeiras opçōes que a mãe ou responsável faz para buscar recursos quando a criança adoece. Se não houverem $2^{\text {s }}$ e $3^{\text {s }}$ opções, anote o código '99' para assinalar que a pergunta não se aplica.

\section{CAMPO IV - CONTROLE DE VARIÁVEIS DE CONFUSÃO}

1. Antecedente de laringotraqueobronquite: Um ' $x$ ' na alternativa correspondente e em caso positivo registre $\circ \mathrm{n}^{\circ}$ de episódios nos últimos 12 meses. Caracterize como um quadro de infeç̧ão respiratória acompanhado de sintomas de cornagem e/ou ruidos no tórax (chiado, ronco, peito cheio).

2. Antecedente de laringite estridulosa: Um ' $x$ ' na alternativa correspondente e em caso positivo registre $\circ \mathrm{n}^{\circ}$ de episódios nos últimos 12 meses. Caracterize como episódios de cornagem com dispnéia e angústia, autolimitados $e$ de remissão espontânea, desencadeados por infeç̧ão respiratória alta, por alérgeno ou por causa desconhecida.

3. Antecedente de eczema/dermatite atópica: Um ' $x$ ' na alternativa correspondente e em caso positivo registre $\circ \mathrm{n}^{2}$ de episódios nos últimos 12 meses. Caracterize o quadro como lesão erimato-descamativa ou eritemato-infiltrativa, pruriginosa ou não, exudativa ou não, recorrente em áreas conhecidas, com remissão espontânea ou que responde a tratamento com corticosteróides.

4. Antecedente de rinite alérgica: Um ' $x$ ' na alternativa correspondente e em caso positivo registre $\circ \mathrm{n}^{\circ}$ de episódios nos últimos 12 meses. Caracterize o quadro pela inspeç̧ão atual do fascies e mucosa nasal, mais história de rinorréia recorrente acompanhada de espirros, que piora com exposição a algum alérgeno ou com infecção respiratória alta, e que melhora com tratamento especifico ou foi diagnosticada por médico. 
* DOENÇA CHIADORA E PNEUMONIA *

ROTEIRO PARA PREENCHIMENTO DO PROTOCOLO DE

CARACTERIZAÇÃO DA PRESENÇA DE DOENÇA

\section{CAMPO IV - CONTROLE DE VARIÃVEIS DE CONFUSĀO}

5. Antecedente de sinusite: Um ' $x$ ' na alternativa correspondente e em caso positivo registre o $n^{\circ}$ de episodios nos ultimos 12 meses. Caracterize o quadro como rinorréia purulenta que sucede ou acompanha infecção respiratória alta, que melhora com antibiótico ou que foi diagnosticada por médico.

6. Antecedente de otite: Um ' $x$ ' na alternativa correspondente e em caso positivo registre o $\mathrm{n}^{\circ}$ de episódios nos últimos 12 meses. Caracterize o quadro como otalgia que sucede ou acompanha infecção respiratória alta, que melhora com antibiótico ou que foi diagnosticada por médico.

7. Antecedente de sarampo: Um ' $x$ ' na alternativa correspondente e em caso positivo registre em meses o tempo transcorrido entre o episódio e a data atual. Caracterize o quadro como infeç̧ão respiratória baixa acompanhada de exantema, diagnosticada por médico.

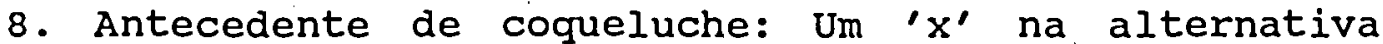
correspondente e em caso positivo registre em meses o tempo transcorrido entre o episódio e a data atual. Caracterize o quadro como infeç̧ão respiratória baixa acompanhada de tosse quintosa, diagnosticada por médico.

9. Antecedente de tuberculose: Um ' $x$ ' na alternativa correspondente e em caso positivo registre em meses o tempo transcorrido entre a data da alta e a data atual. Caracterize o quadro como infecção respiratória baixa que respondeu a tratamento especifico conduzido por médico.

10. Antecedente de bronquiolite: Um ' $x$ ' na alternativa correspondente e em caso positivo registre em meses o tempo transcorrido entre o episódio e a data atual. Caracterize o quadro como infeç̧ão respiratória baixa com dispnéia em menor de 2 anos, diagnosticada por médico.

11. Antecedente de pneumonia: Um ' $\mathrm{x}$ ' na alternativa correspondente. Caracterize o quadro como infecção respiratória baixa que respondeu a tratamento especifico conduzido por médico. Em caso positivo registre quantas vezes teve pneumonia, quantas foram tratadas ambulatorialmente e quantas necessitaram tratamento hospitalar, bem como a idade em que ocorreram.

12. História de doença crônica: registre se a criança é portadora de qualquer patologia crônica diagnosticada por médico e, em caso positivo, se faz uso de qualquer tratamento regular. 


\section{CAMPO IV - CONTROLE DE VARIÁVEIS DE CONFUSÃO}

20. Residència localizada junto a fábrica que expila poluentes: Um ' $x$ ' na alternativa correspondente. A simples presença de uma fábrica não deve ser interpretada como história positiva. Pergunte sobre o que se fabrica, se tem chaminés, se na casa percebe-se fuligem, odores desagradàveis, fumaça, se as pessoas se queixam de irritação das mucosas nasais e conjuntivais. Conclua por resposta positiva apenas se puder recolher elementos sugestivos de poluição ambiental.

—CAMPO V - CARACTERIZAÇĀO DO DIAGNÓSTICO DE PNEUMONIA-

1. História de tosse: $U m$ ' $x$ ' na alternativa correspondente. Considere positiva uma história de tosse com qualquer caracteristica, desde que relacionada à queixa atual.

2. História de dispnéia: Um ' $x$ ' na alternativa correspondente. Considere história positiva qualquer referência a faltar de ar ou desconforto para respirar relacionados à queixa atual.

3. Historia de febre: $U m$ ' $x$ ' na alternativa correspondente. Considere positiva a impressão subjetiva da mãe ou informante, desde que relacionada com a queixa atual.

4. História de dor torácica : Um ' $\mathrm{x}$ ' na alternativa correspondente. Considere positiva a impressão subjetiva da mãe ou informante, desde que relacionada com a queixa atual.

5. História de dor abdominal: Um ' $x$ ' na alternativa correspondente, desde que relacionada com a queixa atual.

6. História de vômitos : Um ' $x$ ' na alternativa correspondente, desde que relacionada com a queixa atual.

7. História de anorexia : $U m$ ' $x$ ' na alternativa correspondente, desde que relacionada com a queixa atual.

8. História de adinamia : $U m$ ' $x$ ' na alternativa correspondente, desde que relacionada com a queixa atual.

9. Temperatura: Anote com até 2 digitos, mais uma casa decimal.

10. Frequência cardiaca (FC): Anote com até 3 digitos o número de batimentos por minuto. Conte pulso ou ausculte coração por 30 segundos. 


\section{CAMPO V - CARACTERIZAÇÃO DO DIAGNÓSTICO DE PNEUMONIA}

11. Frequência respiratória (FR): Anote com até 3 digitos o número de movimentos respiratórios por minuto. observe movimentos do tórax ou ausculte a passagem de ar pela fúrcula por 1 minuto. Repita a operação e anote a maior medida.

12. Estatura: Anote em centímetros, com até 3 digitos e despreze fraçōes decimais.

13. Peso: Anote em gramas, com até 3 dígitos e sem fração decimal.

14. Estado nutricional: Um ' $x$ ' na alternativa correspondente.

15. Em caso positivo de desnutrição, anote o grau $\left(1{ }^{\circ}\right.$, $2^{2}$ ou $3^{2}$ ) conforme aplicável.

16. Presença de dispnéia: Um ' $x$ ' na alternativa correspondente. Observe para fins de padronização que:

$0 \quad=$ dispnéia ausente

$+\quad=$ taquipnéia isolada e/ou tiragem intercostal

subcostal

$++=$ taquipnéia + tiragem intercostal + tiragem

$+++=$ taquipneia + tiragem intercostal e subcostal, com retração de fúrcula e/ou protusão de apêndice xifóide e/ou batimento moderado de asa de nariz. Eventualmente com agitação psicomotora.

++++ = taquipnéia + tiragem intercostal e subcostal, com retração de fúrcula e/ou protusão de apêndice xifóide e/ou retração abdominal (abaixamento paradoxal do abdome na inspiração) e/ou batimento marcado de asa de nariz, com repercussões sistêmicas evidentes como palidez, prostração, cianose e diminuição da perfusão periférica.

17. Presença de cianose: Um ' $x$ ' na alternativa correspondente. Observe que:

$$
\begin{array}{ll}
0 & =\text { ausência de cianose } \\
+ & =\text { cianose labial e/ou de leito ungueal } \\
++ & =\text { cianose labial }+ \text { lingua cianotica } \\
+++ & =\text { cianose de pele e mucosas } \\
++++ & =\text { cianose generalizada com comprometimento do }
\end{array}
$$
estado geral e sinais de alteraçōes hemodinâmicas (frequência cardiaca elevada, má perfusão periférica) 


\section{CAMPO V - CARACTERIZAÇÃO DO DIAGNÓSTICO DE PNEUMONIA}

26. Atelectasia: Um ' $x$ ' na alternativa correspondente. Entenda como atelectasia imagens radiopacas Iineares ou geométricas de sentido centrífugo em relação ao hilo brônquico, eventualmente com desvio de mediastino.

27. Derrame: Um ' $x$ ' na alternativa correspondente. Entenda como derrame a presença de nivel liquido na cavidade pleural.

28. Hiperinsuflação: Um ' $x$ ' na alternativa correspondente. Entenda hiperinsuflação como imagem pulmonar de transparência aumentada com aumento dos espaços intercostais, retificação de arcos costais e abaixamento e retificação da linha diafragmática. A imagem cardiaca pode parecer diminuida e o perfil dos espaços intercostais pode estar abaulado.

29. Pneumotórax: Um ' $x$ ' na alternativa correspondente. Entenda como pneumotórax a presença de ar na cavidade pleural.

\section{EXAMES LABORATORIAIS}

Registre os resultados de quaisquer exames que por ventura venha a solicitar.

\section{CONCLUSÃO DIAGNÓSTICA}

30. Pneumonia: Um ' $x$ ' na alternativa correspondente. Apenas considere 'sim' se tiver concluido pelo diagnóstico de pneumonia ao fim do exame realizado no paciente. Considere 'não' se tiver concluido que precisará ainda aguardar resultados de exames ou evolução clínica. Em outras palavras, a conclusão diagnóstica se refere ao exame realizado e não a uma hipótese sobre o curso da doença/queixa apresentada pelo paciente.

31. Etiologia suposta: Um ' $x$ ' na alternativa correspondente. Anote por extenso a identificação do agente etiológico especifico, se por ventura tiver chegado a alguma hipotese neste sentido.

32. Outros diagnósticos: Registre qualquer outro diagnóstico que tenha estabelecido no exame do paciente.

33. Conduta: Um ' $x$ ' na alternativa correspondente. Registre tratamento ambulatorial para o paciente que tenha recebido recomendação para reapresentação para reavaliação clinica, laboratorial ou radiológica. 
I. IDENTIFICAÇĀO

NOME DO PACIENTE

一II. CARACTERIZAÇÃO DA EXPOSIÇÃO

A criança já foi anteriormente diagnosticada como asmática?

$\begin{array}{ll}\text { 1. } & \text { SIM } \\ \text { 2. } & \text { NÃO } \\ \text { 9. } & \text { NS/NR }\end{array}|-|$

Com que idade este diagnóstico foi feito pela primeira vez?

$|-|$ anos

A criança tem história de chiado

referida pela mãe ou outro familiar?

1. SIM

2. NÃO

9. $\mathrm{NS} / \mathrm{NR}$

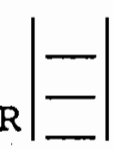

EM CASO POSITIVO:

Com que idade este chiado apareceu pela primeira vez?

$1-1$ anos

A criança tem história de dispnéia junto com o chiado?

Esse chiado melhora com o uso de broncodilatores (Vo, inalação)?

Esse chiado apareceu durante um episódio de infecção respiratória aguda?

Esse chiado ocorreu fora de um episódio

de infecção respiratória aguda?

\begin{tabular}{ll|} 
1. & $\operatorname{SIM}$ \\
2. & $\mathrm{NA} O$ \\
9. & $\mathrm{NS} / \mathrm{NR}$
\end{tabular} \mid-

1. SIM

2. NÃO

9. NS/NR

二|

1. SIM

2. NÃO

9. NS/NR

二

1. SIM

2. NÃO

9. $\mathrm{NS} / \mathrm{NR}$

Esse chiado pode ser desencadeado por qualquer dos seguintes fatores:

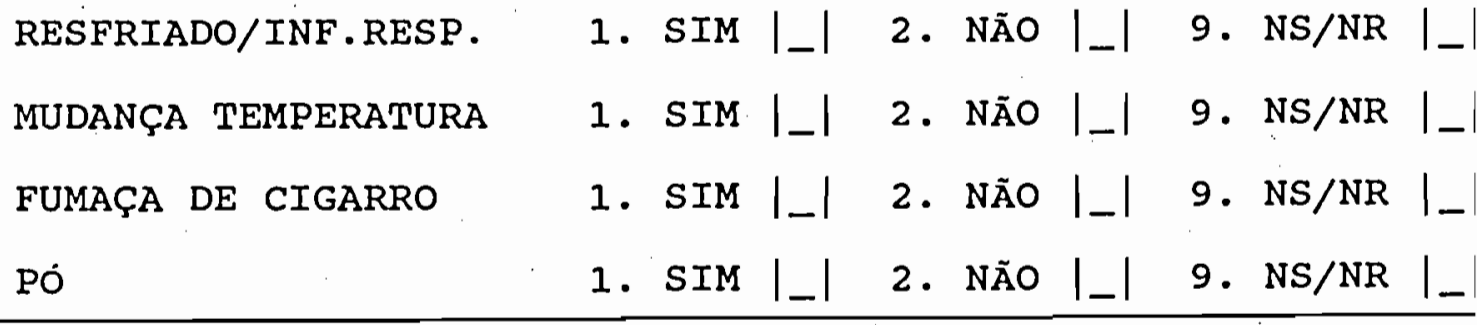


一II. CARACTERIZAÇÃO DA EXPOSIÇÃO

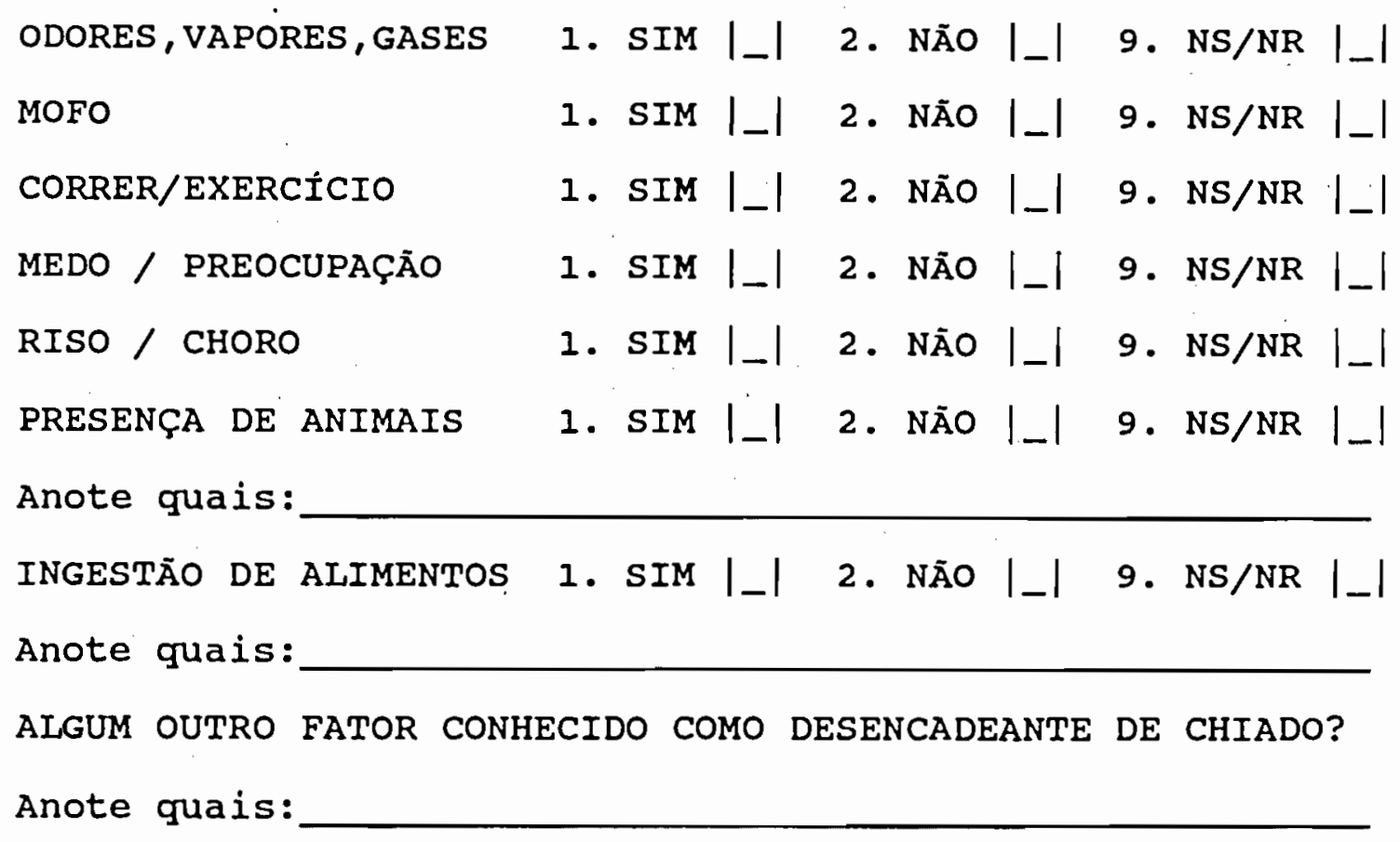

Quantas vezes este chiado ocorreu nos ultimos 12 meses?

Conclusão do médico entrevistador:

1. PORTADOR DE DOENÇA CHIADORA RECORRENTE |_l

2. NÃO PORTADOR DE DOENÇA CHIADORA RECORR I_l 
* doEnça chiadora e pNEUMONia *

ROTEIRO PARA PREENCHIMENTO DO PROTOCOLO DE

INVESTIGAÇÃO DA EXPOSIÇÃO

CAMPO I - IDENTIFICAÇÃO

NOME DO PACIENTE: Anote por extenso o nome completo.

\section{CAMPO II - CARACTERIZAÇÃO DA EXPOSIÇÃO}

1. A criança já foi anteriormente diagnosticada como asmática?

Um ' $x$ ' na alternativa correspondente. Considere positivo apenas casos que refiram diagnóstico feito por médico.

2. Com que idade foi feito este diagnóstico?

Anote com algarismos. Registre o código "99" para os casos em que a pergunta não se aplique.

3. A criança tem história de chiado referida pela mãe ou outro familiar?

Um ' $x$ ' na alternativa correspondente. Considere informação positiva qualquer referência feita por pessoa adulta que conviva com a criança ou que se incumba de cuidar dela de forma sistemática (babás, professoras, amas).

4. Com que idade este chiado apareceu pela primeira vez?

Anote com algarismos a idade completa da época em que se tenha registrado um episódio de chiado pela primeira vez. Registre zero "0o" quando isto tenha ocorrido antes da criança completar 1 ano e registre "99" quando esta pergunta não se aplicar.

5. A criança tem história de dispnéia junto com o chiado? Um ' $x$ ' na alternativa correspondente.

6. Esse chiado melhora com o uso de broncodilatores? Um ' $x$ ' na alternativa correspondente.

7. Este chiado apareceu durante um episódio de infecção respiratória aguda?

Um ' $x$ ' na alternativa correspondente.

8. Este chiado ocorreu fora de um episódio de infecçāo respiratória aguda?

Um ' $x$ ' na alternativa correspondente.

9. O chiado pode ser desencadeado por resfriado / infecçāo respiratória?

$U m$ ' $x$ ' na alternativa correspondente.

10. O chiado pode ser desencadeado por mudança de temperatura?

Um ' $x$ ' na alternativa correspondente. 


\section{CAMPO II - CARACTERIZAÇÃO DA EXPOSIÇÃO}

11. O chiado pode ser desencadeado por fumaça de cigarro?

Um ' $x$ ' na alternativa correspondente. Considere positiva qualquer história de chiado provocado por fumaça de tabaco.

12. O chiado pode ser desencadeado por pó?

Um ' $x$ ' na alternativa correspondente. Considere positiva a referência a qualquer tipo de pó ou poeira doméstica ou não.

13. O chiado pode ser desencadeado por odores, vapores ou gases?

Um ' $x$ ' na alternativa correspondente. Considere positiva uma história de intolerância a perfumes ou talco.

14. 0 chiado pode ser desencadeado por correr ou executar exercicios?

$\mathrm{Um}$ ' $\mathrm{x}$ ' na alternativa correspondente.

15. O chiado pode ser desencadeado por medo ou preocupação? Um ' $\mathrm{x}$ ' na alternativa correspondente.

16. O chiado pode ser desencadeado por riso ou choro? $U$ U ' $x$ ' na alternativa correspondente.

17. O chiado pode ser desencadeado pela presença de animais? Um ' $x$ ' na alternativa correspondente $e$ anote $o(s)$ animal(ais) cuja presença é julgada danosa à criança.

18. 0 chiado pode ser desencadeado pela ingestão de alimentos?

Um ' $x$ ' na alternativa correspondente $e$ anote quais alimentos são suspeitos de desencadear chiado.

19. Algum outro fator conhecido como desencadeante de chiado? Anote qualquer referência pertinente da mãe a fator que não tenha sido mencionado anteriormente.

20. Quantas vezes este chiado ocorreu nos últimos 12 meses? Anote com algarismos, registrando o código "99" no caso da mãe não saber informar.

21. Conclusão do médico entrevistador:

Um ' $x$ ' na alternativa correspondente, segundo seu julgamento pessoal. 
ANEXO II

RELAÇÃO DOS PACIENTES

QUE COMPUSERAM A AMOSTRA ESTUDADA 
RELAÇÃO DAS CRIANÇAS EXAMINADAS

\begin{tabular}{|c|c|c|c|c|c|}
\hline $\mathrm{N}$ & TIPO REGISTRO & $\begin{array}{c}\text { NOME } \\
\text { (iniciais) }\end{array}$ & $\begin{array}{l}\text { IDADE } \\
\text { (meses) }\end{array}$ & SEXO & $\begin{array}{c}\text { PORTADOR } \\
\text { D. CHIADORA? }\end{array}$ \\
\hline \multirow[t]{3}{*}{1} & CASO & VIC & 10 & M & $s$ \\
\hline & CONTR NAO RESPIR & MAO & 12 & M & $\mathrm{N}$ \\
\hline & CONTROLE SADIO & AASE & 12 & M & $\mathrm{N}$ \\
\hline \multirow[t]{3}{*}{2} & CASO & LPR & 25 & E & $\mathrm{N}$ \\
\hline & CONTR NAO RESPIR & ILLB & 25 & $\dot{E}$ & $\mathrm{~N}$ \\
\hline & CONTROLE SADIO & LGES & 27 & E & $\mathrm{N}$ \\
\hline \multirow[t]{3}{*}{3} & CASO & ALA & 45 & F & $s$ \\
\hline & CONTR NAO RESPIR & RJR & 39 & F & $\mathrm{s}$ \\
\hline & CONTROLE SADIO & CVB & 44 & $E$ & $s$ \\
\hline \multirow[t]{3}{*}{4} & CASO & ASA & 12 & F & $\mathrm{N}$ \\
\hline & CONTR NAO RESPIR & TRS & 15 & F & $\mathrm{N}$ \\
\hline & CONTROLE SADIO & PC & 11 & $\mathbf{F}$ & $\mathrm{s}$ \\
\hline \multirow[t]{3}{*}{5} & CASO & BES & 37 & F & s \\
\hline & CONTR NAO RESPIR & SCS & 43 & $\mathrm{~F}$ & $\mathrm{~N}$ \\
\hline & CONTROLE SADIO & $\cos$ & 45 & $\mathrm{~F}$ & $\mathrm{~N}$ \\
\hline \multirow[t]{3}{*}{6} & CASO & SIS & 82 & F & $\mathrm{N}$ \\
\hline & CONTR NAO RESPIR & PMA & 85 & $\mathbf{E}$ & $\mathrm{N}$ \\
\hline & CONTROLE SADIO & JAM & 78 & $\mathbf{F}$ & $\mathrm{N}$ \\
\hline \multirow[t]{3}{*}{7} & CASO & AAS & 36 & $F$ & $\mathrm{~N}$ \\
\hline & CONTR NAO RESPIR & CMB & 35 & $\mathbf{E}$ & $\mathrm{N}$ \\
\hline & CONTROLE SADIO & MEPA & 31 & $\mathrm{~F}$ & $\mathrm{~N}$ \\
\hline \multirow[t]{3}{*}{8} & CASO & EDT & 51 & M & $\mathrm{N}$ \\
\hline & CONTR NAO RESPIR & RSJ & 56 & M & $\mathrm{N}$ \\
\hline & CONTROLE SADIO & TFB & 45 & M & $\mathrm{N}$ \\
\hline \multirow[t]{3}{*}{9} & CASO & $\operatorname{COA}$ & 12 & M & $s$ \\
\hline & CONTR NAO RESPIR & GSS & 13 & M & $\mathrm{N}$ \\
\hline & CONTROLE SADIO & EOB & 8 & M & $\mathrm{N}$ \\
\hline \multirow[t]{3}{*}{10} & CASO & RLR & 62 & M & s \\
\hline & CONTR NAO RESPIR & PSGV & 60 & $\mathrm{M}$ & $\mathrm{N}$ \\
\hline & CONTROLE SADIO & DSR & 60 & M & $\mathbf{s}$ \\
\hline \multirow[t]{3}{*}{11} & CASO & WIS & 25 & M & s \\
\hline & CONTR NAO RESPIR & WBO & 30 & M & s \\
\hline & CONTROLE SADIO & MGPM & 21 & M & $\mathrm{N}$ \\
\hline \multirow[t]{3}{*}{12} & CASO & Jso & 8 & F & $\mathrm{N}$ \\
\hline & CONTR NAO RESPIR & NBS & 7 & F & N \\
\hline & CONTROLE SADIO & $\operatorname{csJ}$ & 11 & $\mathbf{E}$ & $\mathrm{s}$ \\
\hline \multirow[t]{3}{*}{13} & CASO & Aso & 5 & F & $\mathrm{N}$ \\
\hline & CONTR NAO RESPIR & JASM & 7 & $\mathbf{E}$ & s \\
\hline & CONTROLE SADIO & RMOCP & 8 & $\mathrm{~F}$ & $\mathrm{~N}$ \\
\hline
\end{tabular}


RELAÇÃO DAS CRIANÇAS EXAMINADAS

\begin{tabular}{|c|c|c|c|c|c|}
\hline $\mathbf{N}$ & TIPO REGISTRO & $\begin{array}{c}\text { NOME } \\
\text { (iniciais) }\end{array}$ & $\begin{array}{l}\text { IDADE } \\
\text { (meses) }\end{array}$ & SEXO & $\begin{array}{c}\text { PORTADOR } \\
\text { D. CHIADORA? }\end{array}$ \\
\hline \multirow[t]{3}{*}{14} & CASO & TSB & 7 & $F$ & $\mathrm{~N}$ \\
\hline & CONTR NAO RESPIR & AAM & 10 & $\mathbf{F}$ & $\mathrm{N}$ \\
\hline & CONTROLE SADIO. & IRC & 7 & E & $\mathrm{N}$ \\
\hline \multirow[t]{3}{*}{15} & CASO & AAA & 51 & $\mathbf{F}$ & $s$ \\
\hline & CONTR NAO RESPIR & NSA & 55 & $\mathbf{F}$ & $\mathrm{N}$ \\
\hline & CONTROLE SADIO & FWMD & 55 & $\mathbf{F}$ & $\mathrm{N}$ \\
\hline \multirow[t]{3}{*}{16} & CASO & CAS & 17 & $\mathbf{F}$ & $\mathrm{s}$ \\
\hline & CONTR NAO RESPIR & NBO & 18 & $\mathrm{~F}$ & $\mathrm{~s}$ \\
\hline & CONTROLE SADIO & DAS & 18 & F & $\mathrm{s}$ \\
\hline \multirow[t]{3}{*}{17} & CASO & $\mathrm{CS}$ & 13 & $E$ & $\mathrm{~S}$ \\
\hline & CONTR NAO RESPIR & PEL & 12 & $\mathrm{~F}$ & $\mathrm{~s}$ \\
\hline & CONTROLE SADIO & THM & 10 & $\mathrm{E}$ & $\mathrm{N}$ \\
\hline \multirow[t]{3}{*}{18} & CASO & ABN & 11 & M & $\mathrm{N}$ \\
\hline & CONTR NAO RESPIR & JAS & 15 & M & $\mathrm{s}$ \\
\hline & CONTROLE SADIO & $\mathrm{CNCN}$ & 11 & $\mathrm{M}$ & $\mathrm{N}$ \\
\hline \multirow[t]{3}{*}{19} & CASO & RSR & 24 & $\mathbf{F}$ & $\mathrm{N}$ \\
\hline & CONTR NAO RESPIR & $\mathrm{BAB}$ & 26 & $\mathbf{F}$ & $\mathrm{N}$ \\
\hline & CONTROLE SADIO & LMLS & 14 & $\mathbf{F}$ & $\mathrm{N}$ \\
\hline \multirow[t]{3}{*}{20} & CASO & TSO & 12 & $\mathbf{E}$ & $\mathrm{N}$ \\
\hline & CONTR NAO RESPIR & AER & 10 & $\mathbf{F}$ & $\mathrm{N}$ \\
\hline & CONTROLE SADIO & GAB & 8 & E & $\mathrm{N}$ \\
\hline \multirow[t]{3}{*}{21} & CASO & EVMS & 3 & M & $\mathrm{N}$ \\
\hline & CONTR NAO RESPIR & ASS & 4 & $\mathrm{M}$ & $\mathrm{N}$ \\
\hline & CONTROLE SADIO & CAP & 4 & M & $\mathrm{N}$ \\
\hline \multirow[t]{3}{*}{22} & CASO & SAC & 25 & $\mathbf{F}$ & $s$ \\
\hline & CONTR NAO RESPIR & LCJS & 28 & $\mathrm{~F}$ & $\mathrm{~N}$ \\
\hline & CONTROLE SADIO & MSS & 23 & $\mathbf{E}$ & $\mathrm{N}$ \\
\hline \multirow[t]{3}{*}{23} & CASO & CHS & 8 & M & $\mathrm{s}$ \\
\hline & CONTR NAO RESPIR & JARS & 12 & M & $\mathrm{s}$ \\
\hline & CONTROLE SADIO & KSA & 11 & M & $\mathrm{N}$ \\
\hline \multirow[t]{3}{*}{24} & CASO & LSS & 27 & $\mathbf{F}$ & $\mathrm{s}$ \\
\hline & CONTR NAO RESPIR & VSR & 22 & F & $\mathrm{N}$ \\
\hline & CONTROLE SADIO & BSM & 24 & $\mathbf{F}$ & N \\
\hline \multirow[t]{3}{*}{25} & CASO & LES & 7 & M & N \\
\hline & CONTR NAO RESPIR & DRAV & 8 & M & $\mathrm{N}$ \\
\hline & CONTROLE SADIO & FBS & 7 & M & $\mathrm{N}$ \\
\hline \multirow[t]{3}{*}{26} & CASO & CVMS & 2 & M & $\mathrm{N}$ \\
\hline & CONTR NAO RESPIR & ADV & 1 & M & $\mathrm{N}$ \\
\hline & CONTROLE SADIO & LRSA & 1 & $\mathrm{M}$ & $\mathrm{N}$ \\
\hline
\end{tabular}


RELAÇÃO DAS CRIANÇAS EXAMINADAS

\begin{tabular}{|c|c|c|c|c|c|}
\hline $\mathrm{N}$ & TIPO REGISTRO & $\begin{array}{c}\text { NOME } \\
\text { (iniciais) }\end{array}$ & $\begin{array}{l}\text { IDADE } \\
\text { (meses) }\end{array}$ & SEXo & $\begin{array}{c}\text { PORTADOR } \\
\text { D. CHIADORA? }\end{array}$ \\
\hline \multirow[t]{3}{*}{27} & CASO & $A M$ & 14 & $\mathrm{~F}$ & $s$ \\
\hline & CONTR NAO RESPIR & PMS & 10 & F & $\mathrm{N}$ \\
\hline & CONTROLE SADIO & LTA & 13 & $\mathrm{~F}$ & $\mathrm{~N}$ \\
\hline \multirow[t]{3}{*}{28} & CASO & RFS & 32 & $M$ & $s$ \\
\hline & CONTR NAO RESPIR & AHNB & 29 & $M$ & $\mathrm{~N}$ \\
\hline & CONTROLE SADIO & OAS & 35 & M & $\mathrm{N}$ \\
\hline \multirow[t]{3}{*}{29} & CA.SO & RFS & 15 & M & $\mathrm{N}$ \\
\hline & CONTR NAO RESPIR & JMS & 12 & $\mathrm{M}$ & $\mathrm{N}$ \\
\hline & CONTROLE SADIO & RMP & 15 & M & $\mathrm{N}$ \\
\hline \multirow[t]{3}{*}{30} & CASO & NSO & 35 & $\mathrm{~F}$ & $\mathrm{~N}$ \\
\hline & CONTR NAO RESPIR & JBO & 30 & $\mathrm{~F}$ & $\mathrm{~N}$ \\
\hline & CONTROLE SADIO & RMS & 38 & $\mathrm{~F}$ & $\mathrm{~N}$ \\
\hline \multirow[t]{3}{*}{31} & CASO & MSM & 13 & M & $\mathbf{s}$ \\
\hline & CONTR NAO RESPIR & DLC & 13 & M & $\mathrm{N}$ \\
\hline & CONTROLE SADIO & LA & 13 & M & $\mathbf{s}$ \\
\hline \multirow[t]{3}{*}{32} & CASO & LSG & 7 & M & $\mathbf{s}$ \\
\hline & CONTR NAO RESPIR & GPA & 9 & M & $\mathrm{N}$ \\
\hline & CONTROLE SADIO & BSH & 5 & M & $\mathrm{N}$ \\
\hline \multirow[t]{3}{*}{33} & CASO & wso & 6 & M & $\mathbf{s}$ \\
\hline & CONTR NAO RESPIR & HES & 8 & M & $\mathrm{N}$ \\
\hline & CONTROLE SADIO & DSM & 5 & M & $s$ \\
\hline \multirow[t]{3}{*}{34} & CASO & LFP & 56 & M & $\mathrm{N}$ \\
\hline & CONTR NAO RESPIR & ACS & 52 & M & $s$ \\
\hline & CONTROLE SADIO & ICCM & 56 & M & $\mathrm{N}$ \\
\hline \multirow[t]{3}{*}{35} & CASO & MBS & 41 & $\mathbf{E}$ & $s$ \\
\hline & CONTR NAO RESPIR & MSR & 37 & $\mathbf{F}$ & $\mathrm{N}$ \\
\hline & CONTROLE SADIO & SRO & 39 & $\mathrm{~F}$ & $\mathrm{~N}$ \\
\hline \multirow[t]{3}{*}{36} & CASO & KRP & 40 & F & N \\
\hline & CONTR NAO RESPIR & TGE & 46 & F & $\mathbf{s}$ \\
\hline & CONTROLE SADIO & $\mathrm{BMR}$ & 45 & $\mathrm{~F}$ & $\mathrm{~N}$ \\
\hline \multirow[t]{3}{*}{37} & CASO & RSR & 25 & F & $s$ \\
\hline & CONTR NAO RESPIR & MMS & 17 & $F$ & $\mathbf{N}$ \\
\hline & CONTROLE SADIO & NTAT & 17 & $F$ & $\mathrm{~N}$ \\
\hline \multirow[t]{3}{*}{38} & CASO & CTE & 42 & $\mathrm{~F}$ & $\mathrm{~N}$ \\
\hline & CONTR NAO RESPIR & NPS & 49 & $\mathrm{~F}$ & $\mathrm{~N}$ \\
\hline & CONTROLE SADIO & IBS & 45 & $\mathrm{~F}$ & $\mathrm{~N}$ \\
\hline \multirow[t]{3}{*}{39} & CASO & ILAHL & 28 & M & $\mathrm{S}$ \\
\hline & CONTR NAO RESPIR & LHES & 29 & M & N \\
\hline & CONTROLE SADIO & TSC & 27 & M & $N$ \\
\hline
\end{tabular}


RELAÇÃO DAS CRIANÇAS EXAMINADAS

\begin{tabular}{|c|c|c|c|c|c|}
\hline $\mathrm{N}$ & TIPO REGISTRO & $\begin{array}{c}\text { NOME } \\
\text { (iniciais) }\end{array}$ & $\begin{array}{c}\text { IDADE } \\
\text { (meses) }\end{array}$ & SEXO & $\begin{array}{c}\text { PORTADOR } \\
\text { D. CHIADORA? }\end{array}$ \\
\hline \multirow[t]{3}{*}{40} & CASO & KSS & 15 & F & s \\
\hline & CONTR NAO RESPIR & TMA & 18 & $E$ & $\mathrm{~N}$ \\
\hline & CONTROLE SADIO & PCOP & 12 & $\mathbf{F}$ & $\mathrm{N}$ \\
\hline \multirow[t]{3}{*}{41} & CASO & PEAG & 10 & $M$ & S \\
\hline & CONTR NAO RESPIR & JNBC & 12 & M & $\mathrm{N}$ \\
\hline & CONTROLE SADIO & LECC & 12 & M & $\mathrm{N}$ \\
\hline \multirow[t]{3}{*}{42} & CASO & DS & 15 & $\mathbf{F}$ & $\mathrm{N}$ \\
\hline & CONTR NAO RESPIR & MLG & 12 & $\mathbf{F}$ & $\mathrm{s}$ \\
\hline & CONTROLE SADIO & LSS & 15 & $\mathrm{~F}$ & $\mathrm{~N}$ \\
\hline \multirow[t]{3}{*}{43} & CASO & FDRS & 63 & F & s \\
\hline & CONTR NAO RESPIR & KCSA & 66 & $\mathbf{F}$ & $\mathrm{N}$ \\
\hline & CONTROLE SADIO & PS & 60 & $\mathbf{F}$ & $\mathrm{N}$ \\
\hline \multirow[t]{3}{*}{44} & CASO & CES & 2 & $\mathbf{F}$ & $\mathrm{N}$ \\
\hline & CONTR NAO RESPIR & MSISS & 5 & $\mathbf{F}$ & $\mathrm{N}$ \\
\hline & CONTROLE SADIO & LSS & 2 & $\mathbf{F}$ & $\mathrm{N}$ \\
\hline \multirow[t]{3}{*}{45} & CASO & MFH & 17 & M & $\mathrm{N}$ \\
\hline & CONTR NAO RESPIR & GFL & 15 & M & $\mathrm{N}$ \\
\hline & CONTROLE SADIO & EMSX & 6 & M & $\mathrm{N}$ \\
\hline \multirow[t]{3}{*}{46} & CASO & DHCP & 7 & M & $\mathrm{N}$ \\
\hline & CONTR NAO RESPIR & FSP & 8 & $\mathbf{M}$ & $\mathrm{N}$ \\
\hline & CONTROLE SADIO & CGT & 10 & M & $\mathrm{N}$ \\
\hline \multirow[t]{3}{*}{47} & CASO & DPS & 12 & M & $\mathrm{N}$ \\
\hline & CONTR NAO RESPIR & TPS & 13 & $M$ & $\mathrm{~N}$ \\
\hline & CONTROLE SADIO & CHSS & 16 & $\mathrm{M}$ & $s$ \\
\hline \multirow[t]{3}{*}{48} & CASO & WAO & 7 & M & $\mathrm{N}$ \\
\hline & CONTR NAO RESPIR & $\mathrm{COB}$ & 7 & $\mathrm{M}$ & $\mathrm{N}$ \\
\hline & CONTROLE SADIO & DES & 12 & $\mathrm{M}$ & $\mathrm{N}$ \\
\hline \multirow[t]{3}{*}{49} & CASO & JNS & 34 & $\mathbf{F}$ & $\mathrm{N}$ \\
\hline & CONTR NAO RESPIR & ASS & 37 & $E$ & $\mathrm{~N}$ \\
\hline & CONTROLE SADIO & IFCO & 30 & $F$ & N \\
\hline \multirow[t]{3}{*}{50} & CASO & JNS & 6 & M & $\mathrm{N}$ \\
\hline & CONTR NAO RESPIR & JLOS & 9 & M & $\mathrm{N}$ \\
\hline & CONTROLE SADIO & JPCC & 7 & $M$ & $\mathrm{~N}$ \\
\hline \multirow[t]{3}{*}{51} & CASO & MJS & 7 & $M$ & $\mathrm{~N}$ \\
\hline & CONTR NAO RESPIR & RS & 6 & M & $\mathrm{N}$ \\
\hline & CONTROLE SADIO & SSL & 4 & $\mathrm{M}$ & $\mathrm{N}$ \\
\hline
\end{tabular}

